


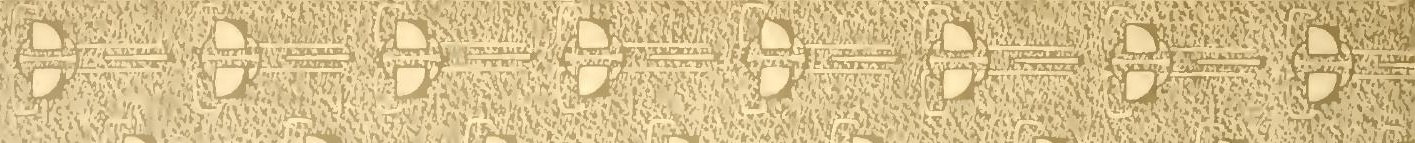

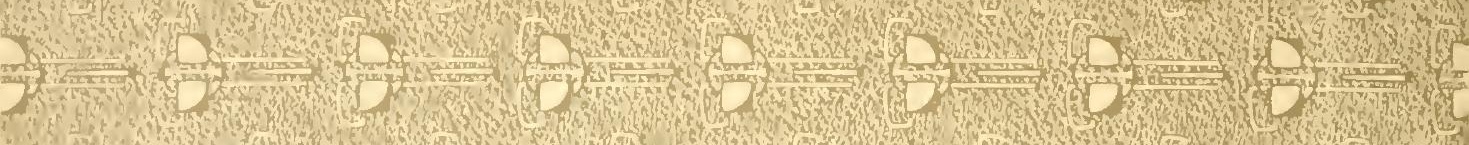

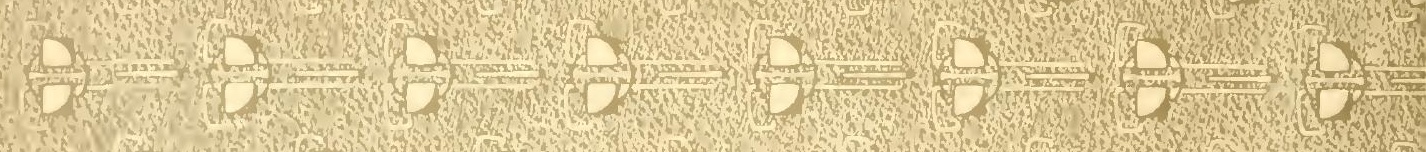
$3.7-8-y-y=8=8$

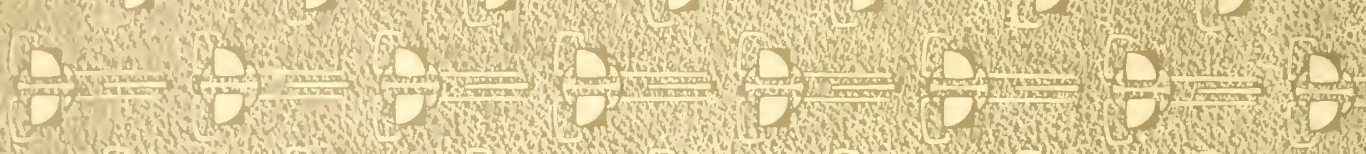
$y-3=\frac{y}{2}=y=\frac{y}{2}=\frac{3}{2}$

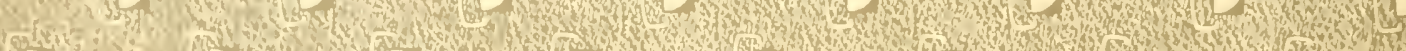

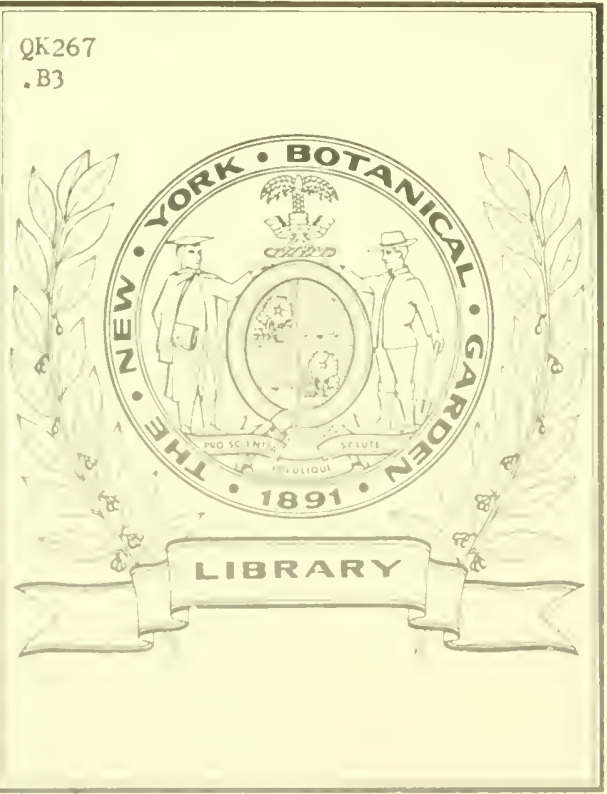
$3=1$
$y-3$ $\frac{3}{2}+\frac{9}{2}=$ $y^{2}$
$y^{2}$

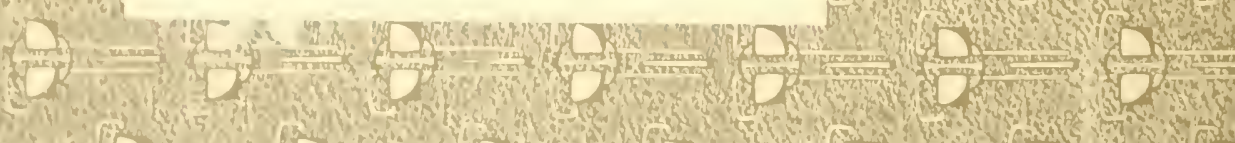
$y=0-y=3-3,0,0=8$ $8-8=8-3=3-y-3$ $y=y-y=y-z$

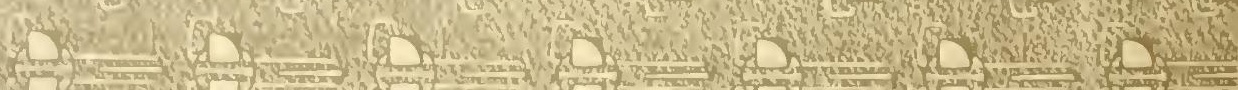





\section{PLANTAE MATTCGROSSEESSESS}

\section{OU \\ RELACÃO DE PLANTAS NOVAS}

Colhidas, classificadas e desenhadas

POR

J. BARBOSA RODRIGUES

Director do Jardim Botanico do Rio de Janeiro,

Cavalheiro das Ordens de $\mathrm{S}$ Thiago e da Corôa de Italia, Laureado com a Grande

medalha de Galileu e nuembro de varias associaçōes scientificas

nacionaes e estrangeiras.

RIO de JANEIRO

Typographia I, Fi: ZING Fi

$15+4-9$

1898 

PLANTAE MATTOGROSSENSES 



\title{
PLANTAE MATTCGROSSENSESS
}

\author{
$\mathrm{OU}$ \\ RELACÃO DE PLANTAS NOVAS
}

Colhidas, classificadas e desenhadas

POR

J. BARBOSA RODRIGUES

Director do Jardim Botanico do Rio de Janciro,

Cavalheiro das Ordens de S. Thiago e da Corôa de Italia, Laureado com a Grande medalha de Gatileu e nembro de varias associaçōes scientificas

nacionaes e estrangeiras.

$$
\begin{aligned}
& \text { LIKKAHY } \\
& \text { NEW YUS } \\
& \text { BUTGAREL } \\
& \text { OARDEN }
\end{aligned}
$$

Rio de Janeiro

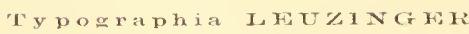

$4514-9$

1898 
B 3 


$$
\begin{aligned}
& \text { Lises } \\
& \text { Ni:n Yes } \\
& \text { BC: A AKAL } \\
& \text { OAKUER }
\end{aligned}
$$

\title{
AO LEITOR
}

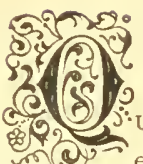

Uando voltei da expedição que fiz ao Rio Paraguay e ao Estado de Matto-Grosso, pretendia publicar em um só volume o resultado botanico que obtive, nos F poucos mezes de colheita e em época impropria, mas, dependendo isso de meios pecuniarios, dividi o trabalho em tres partes. Publiquei as Palma Mattogrossenses nove com os recursos que o Governo então poude me dispensar, e agora apresento esta nova contribuição, auxiliado ainda pelo mesmo Governo, para mais tarde publicar a relaçāo de viagem.

E' praxe em trabalhos semelhantes, relacionar todas as plantas colhidas, pelo interesse geographico que apresenta, mas alongando assim muito esta publicação, apresento aqui sómente as que me parecem ser novas ( ${ }^{1}$ ), deixando as outras para a referida relação de viagen.

Deixo tambem de consignar aqui algumas Bignoniaceas, que presumo serem novas, esperando a conclusão da monographia d'essa familia, na Flora Brasiliensis para, se o forem, fazer uma publicação especial.

Costume tem sido entre nós, salvo honrosas excepções, ser remettido para o estrangeiro o resultado botanico das expedições mandadas fazer pelo governo, ou mesmo as collecções feitas officialmente; mas, como nảo concorde com esse habito, que julgo menos honroso para a nossa patria, por depôr contra nosso saber, arrisco-me sempre a apresentar o resultado dos meus estudos, bons ou máos, a pedir a outrem que os faça,
\end{abstract}

(') Prodromus Flora Granatensis, 1862, pag. 8. 
como procede tambem o Dr. Philippi, botanico chileno, e eis porque apparece mais esta insignificante contribuição, preferindo errar a passar por desidioso.

Desse atrevimento, resultado satisfactorio parece ter colhido o paiz, pois centenas de especies e alguns generos novos de plantas, já figuram no mundo scientifico com nome brasileiro. Nos Gencras, nas Floras e em diversas publicações estrangeiras têm sido ellas citadas, referidas e representadas. porque as que tenho como novas apresentado, como tal têm sido reconhecidas e aceitas pelas insuspeitas autoridades do velho mundo scientifico. Entretanto devo sempre dizer como Triana e Planchon "nous réclamons d'avance l'indulgence pour les cas où notre irnorance trahirait notre désir d'éviter les doubles emplois ».

Como, pois, não pertença á escola d'aquelles que só determinam plantas comparando-as com outras devidamente etiquetadas, nos herbarios europeus, ainda uma vez oftereço ao publico este ramalhete, que se não é grande, comtudo é assás sufficiente para mostrar que, com patriotismo e com trabalho, as pequenas pedras tambem servem para auxiliar a construcçåo de grandes monumentos. O templo da Flora brasileira está quasi concluido, foi se erguendo com a esplendida Flora de Martius, á custa de obreiros estrangeiros que vivem longe da nossa patria, mas para que não tenham meus filhos, como brasileiros, de córar para o futuro, elles encontraråo tambem n'esse monumento o suor de seu pai, servindo para argamassar o material das columnas que o sustentam. O nome brasileiro ahi já está gravado e, mercê de Deus, com algum brilho.

Assim fallo, não por enfatuada vaidade ou desmedido orgulho, mas sim porque no meu passado houve um tempo em que a sciencia official do paiz procurou duvidar dos meus estudos, não só dos feitos por conta propria, sem o favonio do poder, como dos que apresentei mais tarde, quando o governo, depois de maduro exame, entendeu confiarme commissóes. Como, porém. esses mesmos trabalhos menoscabados, depois de passar pelo cadinho das celebridades européas. fossem 
sanccionados, creio estar autorizado a não calar-me, devendo com franqueza me exprimir, afim de que o meu exemplo seja seguido por aquelles que se occupam da sciencia de Linneo, e, para que a mocidade estudiosa se anime a percorrer nossos campos e florestas, onde tanto ainda ha por fazer. Que ella apanhe ahi novas folhas, flores e fructos, e mesmo com os espinhos que forçosamente ha de encontrar, entreteça coroas, grinaldas e festões e adorne o templo, para que ao menos, como remate, possa n'elle ser entoado o hymno do trabalho nacional.

VALE.

Jaridm Botanico do Rio de Janeiro, aos 3 de Março de 1898 . 



\title{
PLANTAE MITTOGROSSENSES
}

\author{
Ordo ANONACE E Juss.
}

Gen. Anona Linn.

Sect. Guanabani Mart.

1. ANONA MACROCARPA Barb. Rodr. Trunco crasso mediocri tortuoso; foliis oblongo-ellipticis v. obovalibus acutis coriaceis, novissimis in petiolo nervo venisque subtus sub. tiliter ferrugineo-pubescentis; pedunculis solitariis; fructu lato ovato vel cordato maximo, areolis numerosis umbone in muricem acutum producto, seminibus fulvis.

Tab. $I$.

A. bor trunco $3^{\mathrm{m}}-4^{\mathrm{m}} \times \mathrm{O}^{\mathrm{m}}, 20 \mathrm{lg}$. diviso in ramos validos, tortuosis, cortice corrugato cinereo fusco. Ramuli cinereo-ferruginei, leviter ferrugineo-pubescenti, corrugati, glandulosi. Folir petiolis $\mathrm{o}^{\mathrm{m}}, 008 \mathrm{lg}$., subteretibus $\mathrm{supra}$ canaliculatis, $\mathrm{O}^{\mathrm{m}}, \mathrm{I} 1-\mathrm{O}^{\mathrm{m}}, \mathrm{I} 5 \times \mathrm{O}^{\mathrm{m}}, 06-\mathrm{O}^{\mathrm{m}}, 08 \mathrm{lg}$., oblonga, elliptica vel obovalia, acutiuscula v. acuta, supra nitida. Flores non vidi. Bacca magna, $\mathrm{O}^{\mathrm{m}}, 1 \mathrm{1} 3 \times \mathrm{O}^{\mathrm{m}}, 14 \mathrm{lg}$. Corte $x$ areolas exhibet subtetragonas umbonatas, umbone, acuti. Pulpa alba. Semina fulva, oblonga, $\mathrm{O}^{\mathrm{m}}$, or $8 \times \mathrm{O}^{\mathrm{m}} .0 \mathrm{Or} \mathrm{lg}$.

Haг, in campis generalibus editis, ad Serra da Chapada, Prov. Natto Grosso. Fructibus siccis observati arborem mense julio. In Cuyaba dicitur Araticum grande da serra.

Atravessando a serra chamada Manoel Antonio, quando percorria as immensas planicies da Chapada, ou planalto de Matto Grosso, a 800 metros acima do mar, em época em que a 
plantas estavam sem flores, e os campos completamente seccos, diariamente devorados pelas queimadas que consumiam muitas leguas c'e v'egetação,encontrei esta expecie, que me fez recordar - Mancllo, dos campos de Minas Geraes, descripto no IV fasciculo das Plantas noras cultioadas no jardim Botanico to Rio dé Funtino, á pags. I e seguintes. sob o nome de Anona Rodrisuesii. Infelizmente só achei um unico fructo, já secco, porèm $\mathrm{em}$ perfeito istado de conservação. Examinando-o, estudando o porte da arvore, vi que tendo muita affinidade é, comtudo. differcnte da especie de Minas Geraes, e que supponho não estar descripta.

( I)r. Patricio da Silva Manso, autor da Enumeragene das planlas que podem fromerer a catarse, um clos mais antigos colleccionadores das plantas de Matto-Grosso e que por muitos annos residiu em Cuyabá, si a tivesse encontrado forçosamente estaria descripta na monographia de Martius, visto como o seu herbario, está reunido aos do celebre botanico bavaro.

As mesmas razões, pois, que me levaram a considerar novo o Marolle, de Minas, me levam tambem a assim considerar - Araticum grande dia serra.

Pelo tamanho parecem-se, porém pela fórma, disposição e consistencia das protuberancias. afastam-se inteiramente, assim como pelo facies da planta. Não conhecendo monographia moderna, que desta familia se occupe. não receio dal-a como nora. Entrctanto. ¿ natural que esta especie nestes ultimos annos fossc colhida, principalmente pelo Dr. Jindman, mas como este. que me conste, nada ainda publicou, apresso-me em entregal a á sciencia para que maiores autoridades decidam.

Crein. como disse. não existir trabalho algum, visto como Lindman, que tenho a honra de contar no numero dos meus amigos, ainda nåome enviou nenhum trabalho. quando Malme. seu companteiro ját n tem feite. pelo que se prova nào haver aincta publicado o resultado de seus traballios botanicos.

o) Index Riarnsis, publicalo em $1 \$ 9 \hat{3}$, si menciona as antigas resperedes e it de presumir que nao a omittisse. 
2. A. CUYABAENSIS Barb. Rod. Trunco humili caspitosi erecti; foliis magnis obovatis, vel ellipticis, oblusissime acutis, subsessilis, supra atroviridis asperis subtus vellutinis; pedunculis solitariis infra foliis erupentibus velutinis, sepalis petalisque velutinis, sepalis connatis triangularibus acuminatis, petalis exterioribus ovatis carnosis obtusissimis, interioribus minoribus valvulatis concavis obtusis, bacca non vidi.

Tab. II.

Arbuscula $1-2^{\mathrm{m}} \lg$.. Truncus etrami erecti, caspitosi. Folia $\mathrm{O}^{\mathrm{m}}, \mathrm{I}_{3}-\mathrm{O}^{\mathrm{m}}, 20 \times \mathrm{O}^{\mathrm{m}}, 09-\mathrm{O}^{\mathrm{m}}, \mathrm{I}_{4} \mathrm{lg}$., obovata aut elliptica subsessilia, basi rotundata aut cordata. Pedunculus $\mathrm{O}^{\mathrm{m}}, \mathrm{O} 5 \mathrm{lg}$., cernuus. Sepala velutina, acuminata, $\mathrm{O}^{\mathrm{m}}$, o $15 \times \mathrm{O}^{\mathrm{m}}$. Oro $\mathrm{lg}$. Petala exteriora crassa, $\mathrm{O}^{\mathrm{m}}, \mathrm{O} 4 \times \mathrm{O}^{\mathrm{m}}, 027 \mathrm{lg}$., interiora duplo minora, concava, obtusa. ochroleuca. Stamina numerosissima. Bacca magna. Caro alba. Semina nigra.

Hab. in campis prope Cuyabá. Araticum Graxde nuncupatur. Floret. Funio.

Nos campos, que circumdam a cidade de Cuyabá, encontram-se facilmente esta especie, formando pequenas soqueiras de hastes finas e erectas, semelhantes a varas de marmeleiro. Penso que a planta toma este aspecto devido ás queimadas annuaes. Não vi um só pé com tronco, todos se apresentain emittindo do solo um numero variado de hastes. Nāo encontrei nenhum specimen com fructos, porque começavam a florescer na occasião, porém affirmaram-me os naturaes que os fructos são grandes, escamosos e quando maduros com a casca amarello-esverdeada, com a polpa branca e as sementes pretas. Como o Murollo de Minas Geraes são tambem muito aromaticas. Tive occasião de tomar um licôr feito do fructo dessa especie, muito agradavel não só ao paladar como ao olfacto.

A' primeira vista, esta especie, parece ser a Anona coriacea Mart., mas affasta-se não só no porte, como no tamanho das 
folhas, fórma e côr das sepalas e das petalas. Spencer Moore encontrou em Santa Cruz (') uma variedade da coriasea. Elle notou differenças, tenclo-a entretauto como sendo a mesma de Martius e estabeleceu por isso então uma variedade a que deu o nome de ampicxicaulis.

Esta especie assim como a que se secrue me obrigam a fazer algumas observações.

As Anonas segundo Baillon $\left({ }^{2}\right)$ têm sempre as petalas muito espessas e quando em botão a prefloração valáulada. J)essa opinião são tambem Bentham e Hooker $\left({ }^{3}\right)$ e todos dão a prefloração imbricada, para as Duguetias ou Aberemous. En. tretanto este caracter nåo é fixo, porquanto a Anona muricata se tem as petalas exteriores perfeitamente valvuladas apresenta, ccmtudo, as tres interiores, não só em botão como mesmo depois de abertas, as tres externas completamente imbricadas. I: o facto que se dá tanto nesta especie, como na minha $A$. liodrigucsii e na que se segue.

Istas especies apresentam uma transição para as Duguetias, da secçio que comprehende a Anona lonsifolia de Aublet a Pinaiua. Aublet encontrou na Guyana Franceza, com o nome de Pináun e I'ináiona, duas especies que denominou Anona functata e longifolia, nome vulgar este que se estende até ao Sul do Brazil, sempre dado a Anonaceas.

() Pináu e P'ináioua ć a I'inda u on una e Pindá y.b. dos Laranys, que a pronuncia franceza modificou na escripta, do $u$ indigena fez ou. E' notavel como esse nome seja só empregado em anonaceas, assim é que, a Duguctia Bracteosa de Martius é a - I'indi una de Santa Catharina e a -Viropia finctescens L. è a I'indiylur de Minas.

l'indi una. quer dizer anzol preto e pintí ybu caniço depescar, dos indigenas.

(1) The Jthanerog Iix of the Matto (irose Lyp, in The Trans of the lin. a loco

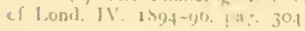

(2) Ilus des lliant. I. p. 229

(2) Gen 1\%, 1. 1. 23. 
O professor Baillon (*) observando o facto na muricata e na involucrata, diz: "Les anona ordinairement valvaires, peuvent avoir les pétales très-manifestement imbriqués \#, que é o caso das minhas especies, que sāo outras tantas que se unem ás duas conhecidas, podendo por isso formarem uma seção.

3. A. AURANTiACA Barb. Rodr. Trunco humili cxspitosi erecti pubescenti; foliis oblongis emarginatis sessillibus erectis glaucis a basi cordatis; ramulis novellis, pedunculis solitariis calycis triangularibus brunneo-pubescentibus: petalis extus brunneo-tomentosis; bacca aurantiaca minima globoso-ovata, areolis rhombeis, umbone acutissimo.

Tub. III.

A buscula $1^{\mathrm{m}}-2^{\mathrm{m}} \lg$., Folia $\mathrm{O}^{\mathrm{m}}, 07-0^{\mathrm{m}}, 09 \times 0^{\mathrm{m}}, 045-0^{\mathrm{m}}, 055 \mathrm{lig}$. , sessilia, ylauca, erecta, emarginata, basi cordata. Pedunculus $0^{\mathrm{m}}, 03$ lg. erectus, bracteola semi amplexicauli, lanceolata, acuminata. Flores non vidi. Bacca $0^{m}, 06 \times 0^{m}, 055$ lg. aurantiaca, areolis subtetragonis, umbone accutissini. Caro alba.

Haв, in camtis frope Rio do Peixe et Coxipó, ad Cuyabá. Finct. Funio.

Nos campos de Cuyabá, proximo aos rios do Peixe e do Crxipó, encontrei esta especie com flores em botão e com um fructo maduro, porém, internamente, todo comido pelos pas. saros ou insectos. Distingue-se e separa-se de todas as congeneres pela disposição das folhas e pelo seu aspecto. As follhas são pruinosas, de um verde azulado, isto é, de um glauco especial, parecendo de cêra e que na apparencia não denota uma anonacea. E' tambem um arbusto pequeno. Os fructos são de um amarello de ouro ou côr de laranja brilhante, com a polpa branca e as sementes pretas. Tem o nome de Araticum do cumpo. Com as especies conhecidas procurei

(4) Ilist. des Piant. I. p. 259. 
achar identidade, mas o resultado foi negativo: não a encontrei descripta e por isso aqui apresento como nova.

A Anona phacoclados de Martius, que cresce tambem em Cuyabá, approxima-se da especie em questão. mas presumo não ser a mesma. A época da florescencia tambem é differente, a minha especie Horesce em Junho e a de Martius em Novembro e Dezembro. 


\section{7}

Gen. Aberemoa Aubl.

(DUguetia S* Hil.

1. ABEREMIOA FURFURACEA, var. Junasiana Barb. Rod. Trunco mediocri caespitosi, ramulis novellis fulvo-lepidotis; folliis coriaceis lanceolatis utrinque acutis, supra nitentibus, subtus furfuraceis rufo-argenteis: pedunculis solitariis; calyce trisepalo sepalis liberis lato-ovatis acutis recurvis, utrinque furfuraceis, petalis exterioribus oblongis subacutis, interioribus majoribus oblongis acutis aut sub emarginatis, concavis, ad basin rugoso-callosis, subtus furfuraceis, supra tomentosis. Bacca oblonga, areolis tetragonis aut pentagonis laviter acutis.

Tab. IV:

Frutex $1^{\mathrm{m}}-2^{\mathrm{m}} \lg$., ramosus, ramis adscendentibus, furfuraceis lepidotis. Folia $\mathrm{O}^{\mathrm{m}}, 07-0,12 \times \mathrm{O}^{\mathrm{m}}, 020-0^{\mathrm{m}}, 035 \mathrm{lg}$., peticli brevi. lepidoti, $0^{m} .005 \mathrm{lg}$. Pedunculus sub oppositifolius solitariis, $0^{m}, 10 \mathrm{lg}$. cernuus. Calyx trisepalus pubescentis, sepala $\mathrm{O}^{\mathrm{m}}, 015 \times \mathrm{O}^{\mathrm{m}}, 012 \mathrm{lg}$., recurva, subacuta. Petala exteriora glandulosa, flava, ad basin rosea, interiora basi purpurascentia calloso-sulcata, exteriora majore. $\mathrm{o}^{\mathrm{m}}$, o $5 \times \mathrm{O}^{\mathrm{m}}$, o I $1 \mathrm{lg}$. Bacca $\mathrm{O}^{\mathrm{m}}, 07 \times \mathrm{0}^{\mathrm{m}}, 055 \mathrm{lg}$., oblonga, flava, semina in carne flava nidulant obovato-compressa; testa alutacea, albumen ruminatum, radiis parallelis, corneum.

Har. in campis prope Rios Coxipó et do Peixe. Araticum nuncupatur. Floret. et finct. Funio.

Esta planta cresce, formando pequenos capões, nos campos de Cuyabá, onde a encontrei com flores e com fructos. ainda não bem maduros, no mez de Maio.

A principio a tomei pela Anona furfuracea de St. Hilaire, antes Duguetia furfuracer, segundo Bentham e Hooker ('), 
mas, comparando a com a descripção do notavel botanico francez (') e com a estampa que a representa, assim como com exemplares collidos por mim em Minas Geraes, districto de Alfenas, vejo nio ser a nesma especie e sim uma variedacle, pois se affasta nảo só pelas flores como pelos fructos. () 1)r. Spencer Noore, entretanto, diz ter encontrado a verdadacleira Dusuctia furfuracca $\left(^{2}\right)$ em Santa Cruz, no mesmo Estado de Mlatto Grosso. Comparando a com a especie de St. Hilaire, vê-se á primeira vista que as flores desta sĩo maiores, as petalas roseas, assim como que o fructo tem a polpa de ı11 amarello côr de abobora, com as divisões do epicarpo rose:ıs, emqquanto que a de que me occupo tem as petalas pequenas. branco-rosadas ou esverdeadas, com os fructos com a polpa branco-amarellacia e com o epicarpo amarello esverdeado. Consiclero-a uma variedacle bem distincta.

Levo a para o genero Abercmoa, escudado no sabio professor Bailion (3), posto que contra a sua opinião sejam Eindlicher, De Candolle, Hooker e Benthan, Martius, etc.

Baseado, porém, nas decisões do Congresso Internacional Ibotanico de l'aris, como Baillon, reivindico o genero para Fusè d'Aublet. Este, em 1775, creou o genero Abcrmoa (4) para uma especie da Guyana Franceza, conhecida por Abercmu, denominando 21. Guyancnsis, mas conservou para a sua Pinaïua, o de Anona longifoir, especie que pertence tambem ao mesmo senero. sergundo Baillon. Cincoenta annos depois, em 1825, St. Hilaire, para uma especie do genero de Aublet, encontrada no Sumidouro. perto da antiga Villa do Principe, hoje cidade do Serro, estabeleceu o seu zenero Duguetia, que, não sei purque, foi aceito, sendo levade á synonymia a de seu compatriota Aublet. Entretanto o Ibermoa tem o direito de priori-

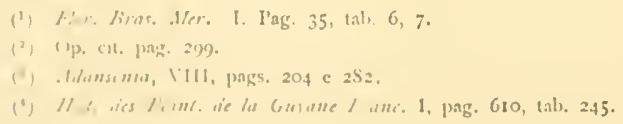


dade. O Dr. Otto Kuntze, na sua Revisio Generum Piantarum, deste genero não se occupou, o que me admira.

A planta de que me occupo é da secção da $A$. longifolia de Aublet.

As Aberemous ou Duguetias são Anonas, mas que têm sempre a prefloração embricada e não valvuladas, sendo as petalas menos carnudas.

Considerando bem distincta esta variedade, como disse, dedico-a ao meu companheiro de excursões. a quem, em parte, devo o bon resultado dá minha expedição, o Sr. I)r. Fonas Corrêa da Costa, medico distincto. Aqui deixo perpetuada a minha gratidāo ao amigo da sciencia, que tanto me auxiliou. 
Ordo ANACARDIACE E R. Br.

Trib. MANGIFERA L. March.

Gen. Anacardium Rottb.

ANACARDIUMI CORYMBOSUM Barb. Rod. Trunco subterraneo, ramulis caespitosis adscendentibus pilosis, demum lavibus, dense foliosis; foliis decrescentis, coriaceis. erectis, supra strigosis, subtus dense pilosis, sessilis, oblongis, emarginatis basin versus cuneatim attenuatis, costa crassa nervisque lateralibus cum venis numerosis reticulatis pilosis, subtus prominentibus. Ramis floriferis axillaribus pilosis teretibus corymboso-capitatis foliis subrequantibus, erectis; ramulis brevissimis densissimé muitifloris, bracteis lanceolatis acutis pubescentis, pedicellis quadruplo floribus minores, sepalis lineari-lanceolatis, acutis; pubescentibus, petalorum duplo minoribus; petalis lineari-lanceolatis acutis contortis, extus pubescentibus, intus ad apicem tomentosis et ad basin papillosis; staminibus inclusis; ovario ovoideo; stylo tenui continuo ovarium multo superante.

Tab. $V$.

Frutcx $\mathrm{I}^{\mathrm{m}}-\mathrm{I}^{\mathrm{m}}, 50$ alt., Folice $\mathrm{O}^{\mathrm{m}}, \mathrm{I}_{3}-\mathrm{O}^{\mathrm{m}}, \mathrm{O} 5 \times \mathrm{O}^{\mathrm{m}}, 75-\mathrm{O}^{\mathrm{m}}, \mathrm{O} 3 \mathrm{lg}$, petiolo nullo. Inflorescencic axillario-corymbosæ usque $0^{\mathrm{m}} \cdot 3 \mathrm{lg}$., ramis pilosis, primariis erectis. apice sub clavatis. dense corymboso-capitatis, $\mathrm{O}^{\mathrm{m}}, 1-\mathrm{O}^{\mathrm{m}}, 05 \mathrm{lg}$; ; extimis trichotomis corymbosis bracteatis, bractere $\mathrm{O}^{\mathrm{m}}, 015-0^{\mathrm{m}}, 005 \mathrm{lg}$., linearilanceolate, acutae, extus pilose, ramulis minoræ. Calyces lacinite $0^{\mathrm{m}}, 005 \mathrm{lg}$. Pctala $\mathrm{o}^{\mathrm{m}}$,oro $\mathrm{lg}$., intus albido-rosea ad apicem tomentosa, basi purpureo-papilosa, tri-striata. Sta$m \mathrm{cn}$ fertile $\mathrm{O}^{\mathrm{m}}, \mathrm{OO} 2 \mathrm{lg}$., intra petala inclusum; cetera aequantia; anthere flavicanti-albidx.

Hab. in campis prov. Matto-Grosso, ad Serra da Chapada, prope Rio da Casca. Caju do cauro incolorum. Ful. floret.

Quando, em Julho, percorria os vastos campos da Serra da Chapada, encontrava commummente o Cajuciro do campo, 
mas, tomando-o pelo Anacardium humile de Saint Hilaire, que já o conhecia muito dos campos geraes da provincia de Minas, não lhe dei a principio importancia. Entretanto, sempre que com elle me encontrava, alguma cousa se me passava no espirito, que me attrahia a attenção, comquanto tivesse a convicção de que me enfrentava com planta conhecida.

Tanto isso se deu, que resolvi colher exemplares, então no começo da florescencia, porque vi que alguma differença se apresentava, que a memoria me não dizia.

Com effeito, mais tarde, essa impressão que me produzia, se avivou quando tratei de estudal-a. Quando de visu se conhece bem uma planta, qualquer modificação nos seus caracteres chama a attenção, sem que possamos, logo, dizer porque assim ella nos impressiona.

$\mathrm{O}$ que me confundia era a inflorescencia, mas d'isso então não cogitava. A planta que eu conhecia, mas não a via desde I876, tinha paniculas terminaes e esta tinha corymbos axillares, sendo um terminal. Essa differença me passava pelo espirito, sem me avivar a memoria.

O Cajuciro do campo, foi encontrado por St. Hilaire, assim como por WVarming, em Minas-Geraes. Foram os exemplares ahi colhidos que serviram de typo para a classificação, entretanto Riedel tambem o encontrou em Matto-Grosso, na mesma Serra da Chapada, d'onde é o exemplar de que me occupo.

O Dr. Engler, escrevendo a monographia das Anacardiaceas, comparando os especimens dos herbarios, identificou os Mineiros com o Mattogrossense, pelo que parece que os Cajus do campo se identificam nas duas provincias, o que não duvido. Apezar, porém, d'isso creio que mais uma especie existe nos campos de Matto-Grosso, que é esta que me occupa agora, e que não é a de Riedel. Encontrei tambem, muito, o $A$. pumilum St. Hilaire, Caju rasteiro, que não me impressionou, e que depois o estudando identifiquei perfeitamente com o de Minas-Geraes, onde foi elle encontrado pelos mesmos botanicos. 
O Dr. Spencer Moore, tratando do A. occidentale, apenas - referiu da secruinte maneira: Ad Serra da Chapada et alibi sacpe widi hujus seneris speciem nanam, floriferam, rarius jimcificantcm e'visimiliter ad. A pumilum St. Hil., relc. s'(2)dam.

By some oacrsaght I omitted to dry specimons of this curions lillle Cashor') (')

O aspecto geral, o habitus, o logar em que cresce tudo è o do A. humilc, entretanto se examinarmos attentamente. vîrse-ha que a especie de Matto-Grosso tem as follas sesseis e sĩo pubescentes em ambas as faces, posto que menos na superior; que a intlorescencia é axillar e não terminal; que as flores são en corymbos e não em paniculas; que as petalas sảo retorcidas e não simplesmente recurvadas, que são pubescentes exteriornente, mas com a parte interior tamben avelludada, na porçĩo que se dobra e se retorce, que é na altura das sepalas, e, que além disso tem a base do lado interior como que pappilosa. Os estames são inclusos como o é tambem o estylo e nào são vitra pelala cxsertum, como são os do pumizm.

Estudando os meus exemplares pela descripção do Dr. Linyler, na Flora Brasiliensis, $\left({ }^{2}\right)$ por não conhecer a de St. Hilaire, feita nos Annacs de Scienizis Naluracs de Paris encontro as differenças acima apontadas assim como outras. como sejam: wrandes bracteas de 6 a + centimetros de comprimento, que ornam a pruncula que é maior do que as follas e que cara. cterisa o liumile. Nåo posso admittir qque Engler denominasse panicula a intlorescencia da especie cm questio, porque na mesma IFlora, o mesmo autor, tratanclo do pumilum diz que

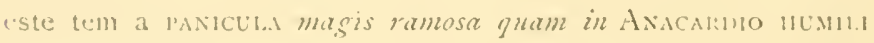
e na estampaia ( ) que representa aquelle da uma verdadeira pit-

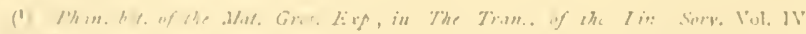
$\Delta \mathrm{C}=\mathrm{SCT}, \mathrm{I} \quad 242$

(") Vil XII, p. II, " +11.

(1) I/6r. firn. This. as. 
nicula. Compare-se a panicula de Engler com a inflorescencia que represento aqui na Est. IV e ver-se-ha, que se o humle tem panicula, esta especie não a tem.

A proposito do $A$. humile devo referir aqui um facto no. tavel. Pedindo ao correspondente deste jardim, o pharmaceutico Joaquinı Candido de Abreu. que é natural de Minas Geracs, e tem percorricio quasi toda a provincia, que me mandasse fructos do Cajueiro to campo, para ser cultivado neste jardim, mandou-me alģuns, que plantados, żerminaram e hoje já sào soberbos exemplares (') que acabam de florescer. Pois bem, se nåo fosse ter recebido de um homem consciencioso e conhecedor pratico da flora de Minas, diria ter sido enganado, porquanto os exemplares que tenho nada têm do $A$. humile, approximanclose mais do Occidentale Lin. As follhas e tlores se iclentificau, só se afastam nos ramos da panicula que no occidenta'e terminam quasi en coymbo e neste os ramos são simples, com inflorescencia indefinida. Comparando os meus exemplares de Matto-Grosso, com os nascidos de sementes do humile nada têm de commum.

Seria en enganado? As sementes que recebi de Minas seriam do occillentale? Nảo o creio e a forma da panicula me autoriza a isso.

Deı-se portanto uma grande modificação no habitus; de arvoreta rusteira, quando muito de $\mathrm{I} \mathrm{m}$. de altura, passou a ser arwore erecta de mais de $3 \mathrm{~m}$. Essa transformação é devida naturalmente ao facto não só climaterico, como á natureza do terreno e a circumstancia de nảo poder crescer nos campos, devido ao fogo que annualmente clevora toda a vegetação. Resiste a este e quando brota e quer se desenvolver, vem nova queimada que o atrophia e assim em vez de se desenvolver para o ar, o tronco rasteja sobre a terra. Transplantado para local, cuja terra the seja mais favoravel, e livre do fogo, náo por atavismo, mas naturalmente, toma outro porte.

(1) Hortus Fiuminunis, pag. 98 , n. 1987 . 
O Accidenlale, que é uma grande arvore nos bons terrenos, nas restingas do littoral torna-se rasteiro, posto que não perca o seu grande porte.

Comparando pois estes exemplares cultivados com a especie em questão, affasta-se inteiramente, mas lembram bem - Cajú do campo de Minas-Geraes. Dou aqui a especie como nova, as autoridacles que decidam.

Comparando tambem o meu specimem com as descripções dos A. Curatellafolium St. Hil., nanum St. Hil., que Walpers, quer no Repertorio, quer nos Amnaes Botanicos apresenta como especies distinctas e que o Hortus Kewensis, tambem aceita, com nenhum se identifica. O Dr. Engler, não sei porque, nem na synonymia apresenta estas especies brasileiras. que entretanto. estão confirmadas no Hortus Kewensis (') como está tambem o meu Anacardinm Brasitiense, que publiquei em $18 s_{3}$, na Revistu de Engenharia, tendo sido achado no rio Urubú, na provincia de Amazonas, como se vê do meu Relatorio dirigido ao Sr. Ministro da Agricultura (').

A sua monographia é de 1876 , quando todas estas especies, exceptuando a minha, todas são muito mais antigas. Nem - A. Mediterraneum de Velloso (') apresenta. Quando mesmo essas especies sejam synonymas, deveriam ser mencionadas. Creio que se deu o facto por não ter sido examinado o herbario de St. Hilaire, que o Museu de Paris não permittiu fosse remettido para a Allemanha, por competir á França, estudar as collecções feitas por seus filhos, como disse o proprio St. Iilaire.

Entretanto, nós remettemos as plantas brasileiras, colleccionadas por brasileiros, para serem estudadas por estrangeiros !...

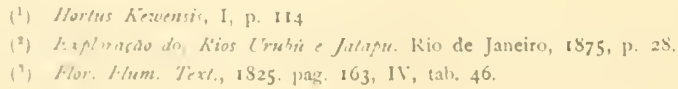


Ordo LEGUMINOSÆ Endl.

Sub ordo PAPILIONACEA Bth. et Hook.

Tribu PHASEOLE $£$ Bth, et Hook.

Gen. Mucuna Adans

Sect. Stizolobium D. C.

1. MUCUNA MATTOGROSSENSIS Barb. Rod. Foliis ut rinque argentio villosis mediocris apiculatis; pedunculo erecto elongato apice racemoso; vexillo latissimo alis æquilongo. Legumine lineari curvato, compresso, longitudinaliter costato, badio-hirsuto-velutino.

Tab. VI.

Caulis alte volubiles ramulis argenteo-velutinis. Stipulo minuta, setacer, caduca. Stipelo minutissima, setacere. Petiol $\mathrm{O}^{\mathrm{m}}, \mathrm{O}_{3}-\mathrm{O}^{\mathrm{m}}, \mathrm{O}_{4} \mathrm{lg}$., antice sulcati, velutini. Foliolu $\mathrm{O}^{\mathrm{m}}, \mathrm{O}_{5}-$ $-\mathrm{O}^{\mathrm{m}}, \mathrm{OS} \times \mathrm{O}^{\mathrm{m}}, \mathrm{O} 3 \mathrm{O}-\mathrm{O}^{\mathrm{m}}, \mathrm{O} 45 \mathrm{lg}$., terminale oblongo-cuneata, obtusa, lateralia oblonga, basi sub cordata, apiculata, paulo minoria, omnia apiculata, membranacea, utrinque argenteovillosa. Pedunculi $\mathrm{O}^{\mathrm{m}}, \mathrm{O} 2-\mathrm{O}^{\mathrm{m}}, 15 \mathrm{lg}$., erecti, argenteo-villosi, apice racemosi. Flores albo-violacei, brevissime pedicullati. Calyx magnus, campanulatus, sericeo argenteo-villosus, lacinia superiore latissima, bidentata, lateralibus multo minoribus, acuminatis, infima longiore angusta. Vexillım ovatum, emarginatum, recurvum, $\mathrm{O}^{\mathrm{m}}, \mathrm{O} 35 \times \mathrm{O}^{\mathrm{m}}, \mathrm{O} 2 \mathrm{O} \mathrm{lg}$., auriculis baseos parvis inflexis, ungue minuto. Aloe $\mathrm{O}^{\mathrm{m}}, \mathrm{O}_{3} 8 \times \mathrm{O}^{\mathrm{m}}, \mathrm{OO} 4$ lg., longe falcatæ, apice subrotundæ, auricula brevi, ungue $0.005 \mathrm{lg}$.. Carina alis latior, longior, apice incurva, breviter cartilagineo-rostrata. Anthere oblongo-linearis. Ovarium sessile, hirsutum. Stylus longus, filiformis, lævis, stigmato parvo, terminali, sub globosi. Legumen breviter pedicellatum, $\mathrm{O}^{\mathrm{m}}, 11-\mathrm{O}^{\mathrm{m}}, \mathrm{I} 2 \times \mathrm{O}^{\mathrm{m}}, \mathrm{O} 2-\mathrm{O}^{\mathrm{m}}, \mathrm{O} 23 \mathrm{lg}$., densissime badiohirsuto villosissimum, prope basin recurvatum, versus apicem incurvum utrinque longitudinaliter 1 -costatum, costis multo proeminentibus, marginibus costatis. Semina matura non vidi. 
Iab. in memibns hmmitis ad Rio S. Lourenço el Rio Coxipó, prope Cuyabi, in l'roe. Matto Grosso. Mucena incolemem. Fun. et full. fioret.

Muitas são as especies d'este genero até hoje descriptas, mas, muito poucas são americanas e apenas quatro foram cncontradas no Brasil, segundo G. Bentham, na Monograplia das Leguminosas da Filora Brasiliensis. De Candolle nos dá apenas tres, porém uma, a macroceratides, que benthan nĩo renciona, o Index kewensis affirma tambem ser brasileira, pelo que podemos dizer que cinco especies såo indigenas. Quando o Brasil apresentava tão pequeno numero a Africa e a Asia nos forneciam quarenta e uma especies.

A planta em questio foi por mim encontrada com flores. pela primeira vez, nas terras das barrancas do Rio S. Lourenço, no Ençenho S. João, em velhas capoeiras, porém mais tarde, tamben encontrei proximo ás margens do Rio Coxipó, aftuente do Rio Cuyabá. Como no norte do Brasil, os naturaes dão, tambem, á esta especie o nome de Mucuni, d’onde se originou o generico Mucuna. O nome indigena deriva-se de $M b u r u$. grande, $n \bar{\varphi}$ por $n / h \cdot i$, listrado, riscaclo longitudinal. mente, referencia á casca dos fructos. Cresce formando um zrande cipoal que se cobre em grande extensio por entre os arbustos e as arıores dos logares humidos. Nảo encontrei bagens seccas, pelo que não sei qual a côr clas sementes, a sua forma e tamanho.

Nas plantas mencionadas por Spencer Moore, collhidas em Matto Grosso, não vem esta mencionada. 
Gen. Pterocarpus Linn.

Tribu. DALBERGIE E Bronn.

Sect. Santalaria DC.

PTEROCARPUS PARAGUAYENSIS Barb. Rod. Foliolis 4-9. oblongis utrinque acutis apiculatis, subtus ramulisque villosulis; racemis plurimis simplicibus tomentosis, pedicellis calyce tomentoso duplo longioribus : vexillo lato emarginato vittelino rubro lineato; staminibus diadelphis; ovario subsessili contorti tomentoso; legumine reniformi-oblongo, compresso, circumcirca coriaceo attenuato-alato, ala corrugata in extremis revoluta, medio reticulato.

Tab. VII. Fig. B.

Arbor. ramulis novillis petiolulis racemisque brevi pubescentibus. Petioli communes $\mathrm{O}^{\mathrm{m}}, \mathrm{O} 6-\mathrm{O}^{\mathrm{m}}, 10 \mathrm{lg}$., Foliola suboppo. sita, $0^{m}, 017-0^{m}, 030 \times 0^{m}, 006-0^{m} .010$ Ig., acuta, brevi-apiculata, basi acuta, subtus pube tecta. Racemi pluri, in axillis superioribus simplices, $\mathrm{O}^{\mathrm{m}}, 10-\mathrm{O}^{\mathrm{m}}, 20 \mathrm{lg}$, erecti. Pedicelli $\mathrm{O}^{\mathrm{m}}$,oro $\mathrm{lg}$.. erecti, uti calyces pube tenuime rufescentes. Caly'x $0^{\mathrm{m}}, 005 \mathrm{lg}$., dentibus brevibus latis acutis sub æqualibus, 2 summis paucius coalitis. T'exillum $\mathrm{O}^{\mathrm{m}}, \mathrm{O} 9 \times \mathrm{O}^{\mathrm{m}}$.015 $\mathrm{lg}$. , calyce triplo longius, late orbiculatum, emarginatum, ambitu vitellinum, medio supra unguem carmineo lineatum, ungue calycem æquante. Alc falcatoobovatæ, medio contortæ, lateraliter squamosæ. Carina brevior, petalis dorso apice breviter connatis. Stamina diadelpha. Ovarium subessile, contortum, villosum. Legumen sessile, reniformi-oblongum, nitidum, reticulatum, $\mathrm{O}^{\mathrm{m}}, \mathrm{O}_{2} \times \mathrm{O}^{\mathrm{m}}, 015 \mathrm{lg}$, circumcirca corrugato-alatum, medio utrinque convexum, reticulato-venosum, monospermum, stylo supra medium lateris superioris tortum. Semina reniformia, rubela.

$\mathrm{HAb}_{\mathrm{A}}$ ad ripas Rio Paraguay, prope Assumpção. April. floret. 
Logo após a minha chegada á Assumpção, do P’araguay. começando as minhas herborisaçōes, fui no dia 25 de Abril, en companhia do Professor Daniel Anizitz, rio abaixo, a uma lagoa das proximidades da cidade a ver a Victoria régia. As aguas baixavam e algumas margens estavam ainda alagadas, porém, a lagroa estava quasi secca e a rainla dos lagos havia desapparecido, achando-a posteriormente, em Maio, em plena florescencia, acima de Corumbá. Ahi colhi, em flôr, uma nymphea, bastante rara.

No percurso tive occasião de fazer uma boa colheita, e, entre outras plantas, consegui apanhar uma leguminosa, então florida que embellezava as margens, n'um ou n'ontro ponto, e que de longe se me assemelhava uma Sesbania pelo porte, inflorescencia e côr das flôres. Com difficuldade pude alcançal-a e, então, pelos fructos que apresentava conheci ser um Plerocarpus.

As plantas d'este genero, pela diversidade da fórma dos fructos, têm sido levadas ora para um, ora para outro genero, que para ellas têm sido creados, e hoje por esse motivo estão reunidos diversos generos, que formam o seu cortejo synonymico e divide-se em seç̧ões. Este grenero creado em $176_{3}$ por Linneo, é por sua vez synonymo do Lingoum, creado em $17+2$ por Rumpf, mas que não foi adoptado, pelo que o Dr. Otto Kuntze ( ${ }^{1}$ ) o reivindica. Quinze a vinte especies são hoje conhecidas, umas da Asia, outras da Africa e algumas da America Meridional. O lirazil tem como representantes da sua natureza quatro especies ( $\left.{ }^{2}\right)$, mas nenluma é a de que trato. Uma d'ellas, entretanto, que colhi no Amazonas, o 1. Rohrii, Vohl. fui encontral-a em Matto Grosso e tambem no l'araguay.

A fórma dos fructos. cliamou logo a misha attenção, pelo que procurei ver que especie seria, visto como, era natural

(') Rirt: Iluml. I. p. 193 el 202.

(s) Hor. liras. XV p. 1, pag. 266 
estar classificada, por vegetar em loşar proximo á capital. lialansa que tanto herborison no Paraguay, Morong ( ${ }^{x}$, que explorou as circumvizinhanças de Assumpção, Graham ( $\left.{ }^{2}\right)$, que percorreu o Rio Pilcomayo, não a mencionam. Griseluach d’ella tambem não se occupa, nem nas Piante Lorentziana, nem nos Symbole ad Floram argentinan. O Dr. Spencer Moore, tambem nào o viu. Não sendo nenhuma das especies antigas e conlecidas, animo-me a consideral-a nova. Por alguns caracteres, deve ser incluida na secção Sintalaria de 1)e Candolle $\left({ }^{3}\right)$, onde está incluido o gigante $P$. Indicus, que lá o Sangue de Drago, da Asia. A recente monographia das leguminosas. publicada pelo Dr. Tauberg (4), nas suas duas secçōes, Stipitati e Sessiles, não apresenta especie alguma moderna, assim como o Index Kezensis, o que me faz confirmar a opinião supra.

Cresce como disse. esta especie, nas margens alagadiças (lo Rio Pararguay, proxinıo á Assumpção. perto do arraial dos indios Payaguás, e formam grandes arbusto; ou arroretas, que têm mais ou menos o habitus das Sesbanias, com as folhas muito parecidas com as destas. Em geral os Pterocurpus são arvores. sendo algumas excelsas, como o Indirus, que dá grandes sapopenbas, fazendo com que o tronco tenha um diametro de muitos metros.

As foòres desta especie apresentam de notarel a carina que têm cntre as nervuras una serie de bursiculas scalariformes. Os fructos reniformes, acliatados. rugrosos, com as margens parecendo unduladas pela structura do tecido fibroso, nos chama a attenção e dá á planta um aspecto agradavel á rista. Encontrei-a não só con flôres, como tambem com grande quantidade de fructos, alguns já maduros, porém nāo

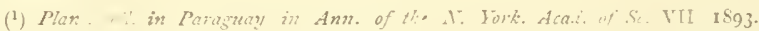

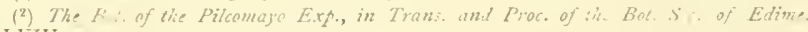
Sess, LIIII. 44 .

(3) Prod"erens I. p. II. pag. 4 Io

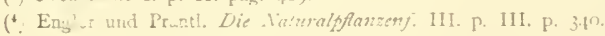


seccos. Devo notar que Morong encontrou no Chaco, em frente a Assumpção, uma outra especie que para Balansa e para Michelli ( $\left.{ }^{2}\right)$ é o P. Rohrii, mas que Britton considerou especie distincta e the deu o nome de $P$. Michollii ( $\left.{ }^{2}\right)$. Esta, porém, é uma arvore que floresce em outra época, e cujo habitus, folhas e fructos são muito differentes. O P. Rohrii, tem os estames monadelphos e esta especie os tem didelphos, o que o leva para outra seç̧ão. Não sei se Parodi d'ella se occupa porque não me foi possivel obter os trabalhos do mesmo autor e nem tão pouco saber o nome indigena da planta.

(') Of. cit. pag. 86.

(2) Contrib, a la fore du Paraguay. Lesuminerses. Genive. 1983. 
Sub-ordo C ESALPINIEAE Bth. et Hook.

Tribu ANHERSTIE E Bth. et Hook.

Gen. Hymenaea Linn.

Foliolis glabris

1. HYMENAA CORREANA B. Rod. Foliolis maximis. oblique oblongis in ${ }^{2}$ uilateris subacutis glabris basi incequalibus; supra nitidis, legumine crasse compressiusculo triplo longiore quam lato verruculoso nitido.

Tab. VIII.

Arbor $3^{\mathrm{m}}-6^{\mathrm{m}}$ alt., coma patula, ramulis foliisque glabris. Ramuli turtuosi. Foliola subsessilia, oblonga. subacuta, basi valde inxquilatera, $0,{ }^{\mathrm{m}} 2+\times \times 0,{ }^{\mathrm{m}} 13 \mathrm{lg}$., coriacea, supra nitida, subtus opaca, pennivenia, pellucido-punctata. Petiolus communis $0,{ }^{\mathrm{m}} 035 \mathrm{lg}$. Legumen brevissime stipitatum, plus minus inclinatum, $0,{ }^{\mathrm{m}} 15 \times 0,{ }^{\mathrm{m}} \mathrm{O} 7 \mathrm{lg}$., lignosum, crassum, compresso-subteres, verruculoso-nitidum, 10-1 2 spermum, suturis subacutis prominentibus. Semina oblonga, compressa, lateraliter subconcava, $0,{ }^{\mathrm{m}} \mathrm{O} 32 \times 0,025 \mathrm{lg}$., testa ossea, brunnea.

HAB. in campis ad Serra da Chapada prope Corrego Secco. JATOBÁ DA SERRA incolorum. Fun. fruct.

Percorrendo em Junho os vastos campos da Serra da Chapada, em Matto-Grosso, encontrei alguns exemplares d'esta especie, infelizmente sem flores e no fim da fructificação. Apenas alguns fructos pude colher que me foram sufficientes para o estudo.

Incompleto, como é o exemplar que possuo, comtudo serve-me para diagnostical-o por ter visto e examinado as plantas vivas. 
Até hoje. que me conste, alem das seis especies descriptas na Flora Brasiliensis ainda ha mais oito, umas descriptas por Humboldt e outras por Heyne. A não ser as de llumboldt, as outras só conheço por curtas diagnoses, que, felizmente, caracterisam os mesmos orgãos que possuem os meus specimens, pelo que póde-se bem comparal-os.

Entre os traballıos modernos, em que poderiam figurar estas especies, está o Beilräge zur Kenntniss der Flora des centralbrasilianischen Staates Goyaz do infortunado amigo Dr. Taubert, em que descreve as plantas collhidas pelo Sr. E. Ule. quando no desempenho da commissão de que o encarregara o Governo Brasileiro no planalto de Goyaz.

Entre as suas leguninosas, novas, não ha uma só hymeneae. Entretanto as chapadas de Goyaz se ligam ás de Matto Grosso e penso que a vegetação será identica, pelo menos vejo que. muitas plantas por min encontrados são as mesmas que estão indicadas na parte geographica feita pelo Sr. Ule e que faz parte do mesmo trabalho do fallecido Taubert.

Tendo. como nova a especie acima lhe impuz o nome do governador de Matto-Grosso, o Exm. Sr. Dr. Antonio Corrêa da Costa como testemunho de gratidão, pelo muito que se esforçou para que a minha expediçăo scientifica fosse coroada de resultados, apezar da má época para herborisações.

Cresce nos campos dos grandes taboleiros da serra da Chapada,onde tem o nome vulgar de Futobí-grande ou ąu. E' uma arvore de mediana altura, esgalhada, de gallos e ramos torcidos, de tronco pequeno cujo diametro não vi exceder de 0.30 , dando grandes fructos, os maiores que tenho visto n'este renero, chegando a ter o, Io de compr. sobre 0,07 de largo.

Os fructos, posto que muito maiores, têm muita seme. thança com os do Futahy asu do Amazonas, o IIym. Courhixril, [prén affasta-se pelo porte e pelas follhas. Esta especie existe cultivada n'este Jardim ha mais de trinta annos, e fructifica todos os annos en Dezembro, emquanto que a especie de que 
me occupo estava com fructos ainda em Junho, o que nos mostra ıma época de florescencia differente.

Comparando a especie em questão, com as conhecidas, com nenhuma se identifica, pelo que a considero nova. E' natural que algum dos ultimos botanicos, que têm percorrido o estado de Matto-Grosso, a tenha encontrado, mas como não conheço trabalho algum d'elles, publicado, animo-me apresental-a aqui.

\section{Foliolis ailloso-tomentosis}

2. H. CHAPADENSIS Barb. Rod. Foliolis oblongis incequilater subacutis coriaceis supra pubescenti-hirtis subtus vellutinis, pellucido punctatis, basi valde inxqualibus; legumine crasse compresso demidio longiore quam lato-verrucoso nitido.

\section{Tab. HII. Fis. 1 .}

Arbor $\mathrm{S}^{\mathrm{m}}-1 \mathrm{O}^{\mathrm{m}}$ alt. coma patula, ramis tortuosis, ramulis foliisque pubescentibus, Foliola sessilia, oblonga, subacuta, base valde inxquilatera, $\mathrm{O}^{\mathrm{m}}, 10-\mathrm{O}^{\mathrm{m}} . \mathrm{r} 2 \times \mathrm{O}^{\mathrm{m}}, 07-\mathrm{O}^{\mathrm{m}}, \mathrm{O} \mathrm{O} \mathrm{lg}$., coriacea, supra pubescenti-hirta, subtus vellutina, pellucido-punctata. Le-. gumen $0^{m}, 08-0^{m}, 09 \times 0^{m}, 03-0^{m}, 035 \mathrm{lg}$. Semina $0^{m}, 022 \times$ $\times \mathrm{o}^{\mathrm{m}}, 016 \mathrm{lg} .$, Testa bruanea.

Hab. in campis prope Cuyaba, prov. Matto-Grosso. JaToBá Do Caspo incolorum. Jun. Fruct.

Esta especie é vulgar nos campos de Cuyabá, que se es. tendem até á base da serra de Chapada, encontrando-a tambem ás vezes no alto da serra. Em alguns logares é uma arvore pequena, mas en outros attinge a uma altura de mais de 20 metros, sempre de galhos e ramos tortuosos. Encontrei com fructos em Junho. Ten vulgarmente o nome de Fatobí do campo, e dá uma excellente resina branca que se forma dentro dos fructos, junto do pedunculo, tomando o logar e quasi que a forma das sementes. 
Com as especies de folhas pubescentes, que o professor Bentham descreve. náo se identifica, pelo que, pelos motivos jí dados em relação á outra especie, presumo não estar esta classificada e aqui a apresento como nova.

Depois da monographia deste notavel professor. não conheço trabalho aloum que mencione novas hymenxas. O Index Kécensis que nos dá o que é conhecido até 1895. só menciona as antigas especies, e devo aqui notar que já em 1830 . St. Hilaire () idisse: "le savant M. Martius rapporte le jatobà à l'hymenaea courbaril, L., mais je serai tenté de soupçonner que le jatoba du Sertão n'est pas celui des bois vierges".

l'enso que o autor da Flora do Brasilic Meridionalis, tinha razão quando assim suspeitava, pelo menos as duas especies que aqui consigno e que são dos campos do Sertão, não é a especie de Linneo. No Valle do Amazonas os naturaes distinguem tres especies florestaes pelos nomes de Fatahy açu. Fatahy mirim, Fatahy pororoka, pelas differenças que encontram na côr do lenho, no tamanho das folhas e dos fructos.

O nome jatoba do sul, ou y'utahy', jutahy', jutaicig, ou jatahy' do Norte, é applicado a varias hymenzas pelos nossos indigenas. A sua etymologia é $Y$, elle, $u \dot{a}$, fructo, alá, duro, $y \dot{b}$, arvore, arvore de fructo duro e, tambem, de $y$, agua, at $i$, dura e j'b arvore, ou arvore de agua dura ou de rezina. No Amazonas não dizem senão ýataycica, quando se referem, propriamente, á resina.

Jatobí ou jatobá, diz a mesma cousa, y'atá-uá elle fructo duro. Com effeito as hymenaas têm todas o fructo muito duro.

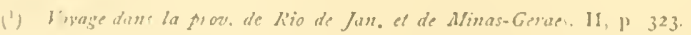


Fan. PASSIFLORAE Endl.

Gen. Passiflora Linn.

Sub. gen. Astrophaca D. C.

Sect. Cirratit:

1. PASSIFLORA CAMIPESTRIS Barb. Rod. Frutex ramis caspitosis erectis velutinis cirratis; foliis coriaceis latissime ovalis obtusis $v$. acutis, supra nitidis brevissime sparse velutinis, subtus opacis velutinis, petiolis apice in utroque latere granduliferis; thoribus $1-2$ contemporaneis axillaribus campanulatis; sepalis oblongis dorsaliter mucronatis tubo majoribus; coronx triseriatx, filamentose; faucialis filis falcatis crassis aurantiaceis; baccis longo-obovalis longitudinaliter trisulcatis coriaceis sparse arguté velutinis.

Tab. IX.

Fratex erectus, cespitosus, $\mathrm{I}^{\mathrm{m}}-\mathrm{I}^{\mathrm{m}}, 50$ alt. Rami teretes, viridi, velutini. Petioli $\mathrm{o}^{\mathrm{m}}$, ro $\lg$., velutini, prope basin laminxe in utroque latere glandulis duabus sessilibus instructi. Folia $\mathrm{O}^{\mathrm{m}}, \mathrm{O9}-\mathrm{O}^{\mathrm{m}}, \mathrm{I} \mathrm{O} \times \mathrm{O}^{\mathrm{m}}, \mathrm{OS}-\mathrm{O}^{\mathrm{m}}, \mathrm{OS} 2 \mathrm{lg}$., coriacea, latissime ovata, obtusa v. acuta, v. emarginata, supra nitida laxé velutina, subtus opaca, velutina. Stipula minutæ, deciduæ. Cirri axillari elongati. erecti, velutini. Pedunculi $0^{\mathrm{m}}, 006-\mathrm{o}^{\mathrm{m}}, 008 \mathrm{lg}$., teretes, velutini, petiolos minores. Alabastra oblonga, obtusa. Flos $\mathrm{O}^{\mathrm{m}}, 06 \mathrm{lg}$., expansas $\mathrm{O}^{\mathrm{m}}, 054$ diam., extus velutinus. Floris tubus campanulatus, sepalis brevior. Sepala linearioblonga, obtusa, subtus ad epicen dorsaliter mucronata, $\mathrm{O}^{\mathrm{m}}, 025 \times \mathrm{O}^{\mathrm{m}}, 006 \mathrm{lg}$., viridia. Petala sepalis conformia, alba. Corome triseriata filamentosa. Seriei exterioris radii numerosissime erecto-patentes, petalis demidio breviores, complanati versus apicem falcati, aurantiacei; seriei secunda 
radii externis minutis falcatis viriclis; radiz inimi tubo paulo minores. tereti, incurvi, viridi. Gynandrofhorm glabrum, inclusum, ad apicem attenuatum. Orarium oblongum. puberulum. S/yli compressi, puberuli. Stigmata capitata. Fructus elongato-obovatus, trisulcatus, coriaceus, flavus. Scmina compressa, oblonga, arillo pulposo ad apicem bicornuto induta, testa arguté granulata.

HAB. in campis Serra da Chapada, proz. Matto-Grosso. Brasiliensibus vocahur maracuji DE safo. Fum. floret.

Entre as plantas colhidas pelo Dr. Patricio da Silva Manso, em Cuyahá, figura a Passiflora Mansoi, que perpetua o seu nome, sendo esta homenagem prestada pelo sabio Dr. Martius aos serviços prestados pelo mesmo medico. Esta especie, que não encontrei, mas que ouvi nomear, é o Maracujá da Chapada, nome que vulgarmente lhe dão, por crescer nos campos da Serra da Chapada. Entretanto nessa mesma Chapada encontrei uma outra especie muito proxima á P. Mansoi, com o nome vulgar de Maracujá de rato. A primeira pertence á secção das Eciralae, está bem descripta e representada na Flora Brazilicnsis, a segunda é da secção das Cirratac, onde só existem seis especies, mencionadas na mesma flora. Se bem que a monographia do professor Masters seja de 1872, comtudo, não conheço outra mais moderna. Como nas obras em que poderia estar descripta não a encontro, por conseguinte aqui a dou, como nova, baseado nos elementos de que posso dispor $\left(^{x}\right)$.

Encontrei-a em Junho, em plena Horescencia, nos altos campos da Serra da Chapacta, formando pequenas soqueiras de hastes escralhadas e erectas, não attingindo a mais de um e meio metro de altura. Se bem que não fosse tempo de fructos, comtudo encontrei alguns perfeitamente maduros, que me ser-

1', ") professor 11. Ilarms que escreveu a ultima monograplia, nan cita tralialho algum moderno, sem augmenta o numero de especies, entrelanto e de 1593 e ji cita e accita (1) meu novo genero Tetrastylis, desta familia. 
viram para o estudo. E' uma bella especie de flores inteiramente brancas. com a coròa côr de ouro, que se destacam do verde negro da folhagem.

Os fructos que são de um amarello de ouro, quando seccos têm o epicarpo muito tenue e quebradiço. Caracterisa-se bem esta especie pelas sementes que são involvidas por um arillo transparente que forma uma especie de bolsa que termina em duas pontas incurvadas.

\section{Sect. Granadilla}

2. PASSIFL.ORA CURUMB.AENSIS Barb. Rod. Fruticosa; foliis nembranaceis, superne, glabris nitidis, subtus arguté villosis, quinquelobatis, lobis oblongis acutis mucronatis serratis; petiolis prope basin biglandulosis; pedunculis petiolos subrquantibus; fructu pyriformi raro subrotundo.

Tab. X.

Fruticosa scandens. Rami striati. Folia $\mathrm{O}^{\mathrm{m}} \cdot 1 \mathrm{I} \times \mathrm{O}^{\mathrm{m}}, \mathrm{I} 35 \mathrm{lg}$., basi cordata, apice profunde 5-lobata, quinquenervia. Petioli $\mathrm{o}^{\mathrm{m}}, \mathrm{0} 6 \mathrm{lg}$. Flores non vidi. Pedunculi 0,06 lg., axillares. Fructus pendulus, pyriformis raro oblongis, roseo-flavus.

НАв. ad ripas Rio Paraguay, in sitio Tamarindeiro prope Corumbá. Minakuri-m vulgariter. Mai. flor.

Na margem do Rio Paraguay. abaixo do Puerlo Suarez, na Bolivia, proximo á Pedra Branca, no sitio Tamarindeiro, encontrei esta especie, sómente com fructos. E' notavel pela fórma e côt dos mesmos. O epicarpo é amarello de um lado e roseo de outro, parecendo pela fórma e pela côr uma verdadeira pêra.

Entre as especies de folhas quinquelobadas não se encontra a de que trato que, vulgarnente, tem o nome de $M a$ rakuyá mi, nome que tambem é dado á $P$. edulis e outras. 
Torna-se notavel tambem pelo comprimento do pedunculo. As razões que militam para consideral-a nova são as mesmas que apresentei para a especie anterior. No Rio S. Lourenço encontrei tambem uma outra passiflora, que a tinha como nova, porém depois verifiquei ser a que ultimamente $N$. E. Brown descreveu com o nome de I'. Gibcrti. achada por Graham Ker, na expedição ao Pilcomayo, em IS91. Foram as unicas passifloras que encontrei na minha expedição. 


\section{Ordo CACTEA Endl.}

Gen. Malacocarpus Salm Dick.

MALACOCARPUS HEPTACANTHUS Barb. Rod. Caule depresso-globoso, concavitate lanugine alba densa longiore et aculeis intermixtis farta, basi aplanato, costis 10-1 I verticalibus sulcis altis transversis in tubercula angulosoconica supra areolaria divisis; areolis suborbicularibus tomento densiore obductis mox denudatis, aculeis albescentis 7 inæqualibus retrorsis teretibus subcorneis acutissimis rigidis marginalibus, appicalibus (1) minoribus suberectis, mediis (2) paulo majoribus, subretrorsis, infimis (3) multo majoribus. Flores non vidi.

\section{Tab. XI.}

Caulis cum cephalio $\mathrm{O}^{\mathrm{m}}, \mathrm{OS}-\mathrm{O}^{\mathrm{m}}, \mathrm{O} 9 \times \mathrm{O}^{\mathrm{m}}, 1 \mathrm{lg}$., Costae basi $\mathrm{O}^{\mathrm{m}}, \mathrm{O} 2$ lat., tubercula $\mathrm{O}^{\mathrm{m}}, \mathrm{O} 2$ alt., obscure virides. Cephalizm album aculeis erectis v. sub incurvis copiosis pertusum $\mathrm{O}^{\mathrm{m}}, \mathrm{O}_{3}-\mathrm{O}^{\mathrm{m}}, \mathrm{O} 5 \mathrm{lg}$. Arcolae $\mathrm{O}^{\mathrm{m}}, \mathrm{O}_{3}-\mathrm{O}^{\mathrm{m}}, \mathrm{O} 4$ diam.. superiores lanugine alba obductie. inferiores demum nudx. Aculei 7 . superiores $0^{\mathrm{m}}, \mathrm{O}$ I $\lg$., laterales $\mathrm{O}^{\mathrm{m}}, 02 \mathrm{lg}$., inferiores $\mathrm{O}^{\mathrm{m}}, 35 \mathrm{lg}$..

HAB. in arenosis cumpis Serra da Chapada et prope Cuyabá, Prov. Matto-Grosso.

Nos terrenos areientos ou pedregosos dos campos proximos á cidade de Cuyabá, e mesmo nos campos da Chapada, da Serra de S. Jeronymo, por varias vezes encontrei esta especie em differentes gráos de crescimento. Infelizmente nunca a vi em flor. Transportando, para este jardim, mais de uma vintena de exemplares vivos, alguns morreram, escapando comtudo alguns que estão em plena vegetação, mas que ainda não floresceram. Transplantei-os no mez de Junho e até esta data ainda não floresceram, quando em geral o mez de Janeiro e de Fevereiro é o das flores das cactaceas. Não conheço as 
flores, mas pelo estudo do caule, creio que não estou em erro levando a especie para o genero Malacocarpus de Salm Dyck ('), considerando-o distincto do Ecluinocactus de link e Otto, se bem que Bentham, Hooker $\left({ }^{2}\right)$, e Baillon $\left(^{3}\right)$ considerem aquelle symonymo deste. O Dr. C. Schumann (4) o separa e apresenta como caracter distinctivo o seguinte: "Caulis apice tomento areolarum confluente longissimo cephalium convexum exhibens aculeis intermixtum n.

Comparando o Echinocactus com o Melanocarpus diz tambem: "In illis caput plantæ praesertim nomine ceplali salutatur, sed etiamsi in Malacocarpo cephalium aculeis intermixtum est. tamen differentia essentialis inter ambo vix existat ". Com effeito este caracter apresenta e se assim não fôra o levaria para a seç̧ão Discocacłus, que Schumann estabeleceu para o genero de Link e Otto.

Melanocarpus ou Echinocactus constitue todavia, uma especie não descripta, porque, já não me referindo ás especies que De Candolle $\left(^{5}\right)$ e 1 Valpers $\left(^{6}\right)$ citam, mas procurando determinal-a com as especies de ambos os generos, que Schumann apresenta, como conhecidas até 1890 , na sua Monographia com nenhuma dellas se identifica.

No genero Melanocarpus apenas apresenta oito especies e no Echinocactus dezoito, sendo que deste genero a seç̧ão Discocactus, só contém duas especies.

Ainda me confirma ser um Malacocarpus o facto das especies conhecidas serem, quasi todas, do Uruguay, isto é, do Sul do Brasil ou Brasil austra1.

Caracteriza bem esta especic os espinhos dos mamelóes, sempre en numero de sete, dos quaes os tres inferiores

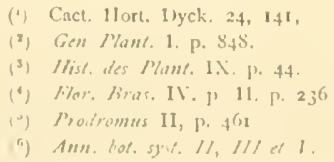


são sempre grandes, com a apparencia cornea, durissimos, recurvados, arredondados, com as extremidades mais escuras e agudissinas. Os quatros superiores são muito menores e erectos, sc ndo que destes os dois internos ou mais superiores são ainda menores. Estes espinhos sahem de uma areola que quando nova é um pouco cotonosa. Os espinhos da cabeca são erectos, finos e curvos e sahem de pequenos cochins muito lanuginosos que unidos formam um só corpo, o cephalizm. O numero de quinas (costæ) que são formadas de mamelões tambem a caracterisa. Invariavelmente os mamelões são dispostos a $m$ lo series, raras vezes I l de 3 a 4 em cada serie, que da base para o apice decrescem.

O Dr. Spencer Moore não encontrou esta planta, na sua expedição, e creio mesmo que pouca importancia ligou ás Cactaceas, porque apenas menciona a Pereskia Bleo DC. e nem fala nos gigantes Cereus Peruzimus que cobrem os terrenos calcareos das margens do Paraguay. O Dr. Morong, tambem entre as especies desta familia ( ${ }^{\mathrm{I}}$ ), que encontrou, nem uma só apresenta deste genero, pelo que como nova aqui a apresento.

Occupando-me aqui de uma cactacea, devo observar que na recente monographia da Flora Brasiliensis, o Dr. Schumann não menciona o Melocactus communis de Link e Otto o Cactus Melccactus de Linneo, bem representado por Pyramo De Candolle $\left({ }^{2}\right)$ que o dá como sendo da America Meridional e das Antilhas, tendo sido introduzido na Europa em r601. Esta especie entretanto é tambem brasileira e se encontra em Pernambuco e no Ceará com o nome de Corôa de Frade. Este jardin possue um soberbo exemplar da variedade macrocephalus, proveniente d'este ultimo Estado. Floresce quasi todo o anno.

1) An. Fnum. of the Flant. esl. by Dr. T. Merens in Faraguay 1888-1890. Ann. of the Nezw. Bitk Acaul of Sc. Vol. VII. 1893.

$\left({ }^{2}\right)$ Flankes grasses, t. 112. 
Orlo GENTIANACEA Lindl.

Gen. Deianira Cham, et Schl.

1. DEIANIRA ERUBESCENS Cham. et Schl. in Linnaa 1, 95. Griseb. Gent. 114, id. in D. C. Prodr. 1X. 48. Mart. Fl. Bras. VI, p. 1, pag. 201. - Callopisma perfolzahum Mlart. Nov. Gen. II. 107, tab. $1 \$_{3}$.

I wr. Al.BA Barb. Rod. major, altior; foliis perfoliatis, lato-ovatis, actitis, internodliis majoribus; floribus albo-lacteis.

Encontrei na serra cla Chapada a especie typica. onde a encontrou tambem o Dr. Silva Manso, exactamente como a descreveu e representou Martius sob o nome de Callopisma perfoliatum, e posteriormente a variedade em questão, que se affasta da erubescens em ter a haste muito longa, de $\mathrm{I}^{\mathrm{m}}: 70$. com os intrenós muito espaçados, distando as folhas na base umas das outras 1 decimetro e no apice $7-S$ centimetros. O que a distingue immediatamente são os grandes cy̆mos de flores de um branco de leite, que entre as folhas glauco pruinosas se ostentam. Quiz identifical-n com a variedade pallescens Schlchtd, mas encontrando tambem esta, que é de um roseo côr de carne, collocando-as ao lado uma da outra, se destacaram extraordinariamente, pelo que apresento esta nova variedade.

2. D. CYATHIFOLIA Barb. Rad. Caule simplice; foliis subrotundis basi attenuatis alté connatis perfoliatis concavis, cyma trichotoma foliis subaquantia, corolla lobis oblongis obtusis.

Tab. XII Fig. $A$.

Caulis erectus, strictus, $\mathrm{O}^{\mathrm{m}}, 40-\mathrm{O}^{\mathrm{m}}, 50 \mathrm{lg} .$, teres, pallide viridis, pruinnsis. Folic omnia ad tertiam circiter altitudinis partem connata et perfoliata, internodiis majora, $0^{m} ; 045 \times 0^{m}, 0.40 \mathrm{lg}$.. subrotunda, obtusa, concava, pruinosa, nervis 11 evanidis 
percursa, margine lateraliter sub recurva. Flores in cymis axillaribus trichotomis corymboso-coartactis, numerosi, alborosei. Pedunculus communis $\mathrm{O}^{\mathrm{m}}, \mathrm{O} \mathrm{I} \mathrm{lg}$., pedunculi partialis minori. Bractea et bractcola oblongx, obtusx, $\mathrm{O}^{\mathrm{m}}$, or $4 \mathrm{lg}$., sursum minores, pruinosx. Calyx $\mathrm{o}^{\mathrm{m}}, 007-\mathrm{o}^{\mathrm{m}}, 008$ alt., quadripartitus, laciniis lanceolatis dorso sub carinato, acutis. Corolla albo-rosea, tubus cylindricus, rectus $0^{\mathrm{m}}, 006 \mathrm{lg}$, limbus in lacinias xquales horisontaliter patentes, oblongas, obtusas, $\mathrm{O}^{\mathrm{m}}, \mathrm{OI} \times \mathrm{O}^{\mathrm{m}}, 006 \mathrm{lg}$. Stamina aequalia, flamenta supra medium tubum inserta, basi dilatata, antherac filamentis majorare, laciniis dupla minoræ, erectæ, sagittatæ, flavæ, $\mathrm{O}^{\mathrm{m}} . \mathrm{OO} 4 \mathrm{lg}$., ovarium oblongum, trigonum, stylus filiformis, stigma bilobum, lobrs oblongis, intus glandulosus.

Hab. in campis Serra da Chapada, prope Capão Secco, ad Prov. Matto-Grosso. Fun. floret.

Entre as diversas plantas que no mez de Junho colhi nos campos da Serra da Chapada, perto do rio da Casca, distingue-se esta bella Dejanira, de flores tambem brancas, porém lavadas de um roseo-pallido.

Duas especies com quatro variedades, segundo o Dr. Progel, ou tres especies segundo o Index Kervensis. apresenta até hoje este genero, sendo que todas têm as flores côr de rosa vivo ou pallido. Todas apresentam os cimos muito maiores do que as folhas e mesmo peniculados e não com cymos menores, ou pouco maiores do que ellas, e por assim dizer occultos na sua concavidade. A especie em questão tem as folhas não tão perfoliadas como a erubescens, mas muito mais largas e concavas, dando á primeira vista a forma de um vaso cheio cle flores.

Além disso a especie de Chamisso têm os cimos todos quasi que terminaes, isto é, posto que axillares, só no apice da haste se apresentam 2 a 4 , emquanto que a especie ẹm questão apresenta os seus cymos axillares, quasi desde a base da haste, até ao apice onde termina por um maior e corymboso. Se bem que as folhas sejam tambem glaucas, estas são 
do comprimento dos entrenós. a ponto de ficarem estes occultos pelos cymos lateraes, cujas thores os circundam. Ainda mais, os caules que na crubcsccns são fistulosos, n'esta especie não o são.

lispecie bem distincta não só pelo porte. como pela côr clas Hores e disposição dos cymos. l'osto que Martius seja de opinião que segundo o solo e a idade a Deianira crubesccns varie, não acredito que produzisse uma variedade. com caracteres de nova especie. Variedade é a minha alba, como são as pallescens e cordifolia. Poder-se-ha ver bem as differenças comparando-se a minha estampa com as que Martius apresenta coloridas no seu Nova Gencra, vol. I. pags. $1 \delta_{j}$ e $1 \delta_{4}$, sob o genero Callopisma. Este genero passou á synonymo do Dcianir a, porque quando já cstavam impressas as estampas da sua obra, mas não expostas ao publico, Schlechtendal publicou, na Limnaca, o seu genero Dcianira, sahindo portanto antes da publicação de Martius, que não podia mais inutilisar as estampas, e sú pela demora da impressão deu-se o facto de Martius perder a prioridade do seu Callopisma. 


\section{Ordo ORCHIDACEÆ Lindl.}

Gen. Maxillaria R, et Pav.

\section{(.Yylobium Linall.)}

1. MAXILLARIA CHAPADENSIS Barb, Rod. Pseudobulbis conicis angulosis diphyllis, foliis lanceolatis triplicatis acutis basi angustatis, scapo racemoso multifloro pseudobulbis triplo longiore, sepalis lanceolatis acutis, petalis minoribus subconniventibus, labello postico trilobo, lobo intermedio reniforme, intus calloso callo quinquelineato, extus ad apicem tuberculoso.

\section{Tab. NII. Fig. B.}

Pseudobulbis $\mathrm{O}^{\mathrm{m}}, 06-\mathrm{O}^{\mathrm{m}}, 07 \times \mathrm{O}^{\mathrm{m}}, 30-\mathrm{O}^{\mathrm{m}}, 55 \mathrm{lg}$. Folia super laete viridia, subtus tri-nervata, nervis prominentibus, basi attenuata, acuta, $\mathrm{O}^{\mathrm{m}}, 20 \times \mathrm{O}^{\mathrm{m}}, \mathrm{OS} \mathrm{lg}$. Scapo erecto, $\mathrm{O}^{\mathrm{m}}, 12-\mathrm{O}^{\mathrm{m}}, 15 \mathrm{lg}$., laxifloro. Bratere linearix, pedunculo paulo minoræ. Flores 10-12-contemporanei, albi, patenti. Ojarium incurvum, $\mathrm{O}^{\mathrm{m}}, 010-\mathrm{O}^{\mathrm{m}}, 012 \mathrm{lg}$. Sepala superiora minora, inferiora subrecurva. $0^{\mathrm{m}}, 015 \times 0^{\mathrm{m}}, 004-0^{\mathrm{m}} .005 \mathrm{lg}$., dorso carinata. Petalu $\mathrm{O}^{\mathrm{m}}, \mathrm{O} 13 \times \mathrm{O}^{\mathrm{m}}, 003 \mathrm{lg}$., plana. Labellum $\mathrm{O}^{\mathrm{m}}, 015 \mathrm{lg}$., album; Columna alba, incurva, laviter claviformis, inferne longe producta, antice plana, $0^{m}, 007 \mathrm{lg}$. Anthera unilocularis, galeata. Pollinia 4, per paria, in glandulam lunatam sessilia. HaB. in arboribus sylvis umbrosis loco dicto Capão secco, ad Serra da Chapada, in Matto-Grosso. Floret. Mirt.

Explorando as florestas do grande Capão, no logar denominado Capão Secco, encontrei ahi algumas orchidaceas, chamando-me para ellas a attenção a bella e perfumosa Catleya Princeps, que encontrei e descrevi em 1868, nos rochedos da serra de Caldas, em Minas-Geraes. Crescia esta, então, sobre os galhos das arvores que davam para o campo e eram batidas pelo sol. Apresentava-se coberta de flores. 
N'este capâo tive eu occasiáo de vêr esta familia repre. sentada por especies do Rio de Janeiro. de Mlinas e do Amazonas. No sombrio da floresta encontrei muitos exemplares do meu Cycuoches Hargï, do Amazonas, e a C. Princeps, de Ninas, Entre outras especies, como Plcurothallis apanhei varios exemplares tormando grandes e bellas soqueiras de uma Maxillaria que, então, tomei pela M. squalens, apenas pelo porte, pois que não estava em flor. Transportada e cultivada n'este Jardim, em Março, deste anıo, floresceu.

Na apparencia é uma squalins branca, mas nos detallies afasta-se inteiramente. Tive occasião de comparar as llores de ambas as espigas porque fioresciam, conjunctamente. e pude vêr que são bem distinctas, não só na côr como nas fórmas.

Todas as divisões da flôr são de um branco-marfim. Considerando-a nova denominei-a $M$. Chapadensis, por ser encontrada no planalto de Cuyabá, que tem o nome de Serra da Chapada.

Depois dos desgostos por que passei, com a minha malograda Iconographic des Orchidées du Brésil, abandonei completamente o estudo d'esta familia, a ponto de muitas especies novas me haverem passado pelas mãos sem que eu as descrevesse. As orchidaceas que foram sempre as minhas flôres predilectas. ellas que sempre me pagram com usura o amor que thes tributava, foram desprezadas! Para que d'ellas me occupar, se o meu trabalho. o meu sacrificio, o que com ellas gastava, tudo era perdido?

Perto de oitocentas especies novas descrevi; com ellas gastei os melhores dias de minha vida; por ellas expuz minha existencia, com cllas distribui todo o pão que ganhei e quando suppunha que ellas apparecessem no campo scientifico. ostentando as suas galas, conquistando gloria para seu paiz, fui desilludido, tinham de morrer na obscuridade, porque assim exigria o furrionsmo hrasileiro. Para que tamanho traballo se não perdesse, eu que recusara a collaboração com Reichembach filho, com Kraeslin e outros; que desprezei grande offerta pecuniaria. 
entreguei graciosamente o fructo de muitos annos de trabalho ao sabio professor Alfredo Cogniaux que, já em cinco grandes fasciculos da Flora de Martius, as tem publicado e representado $\left(^{\mathrm{x}}\right)$. O que o governo do meu paiz negou-me, gentilmente me offereceu o estrangeiro. Salvas as minhas especies novas e já figurando no mundo da sciencia, posso agora reanimar-me e d'ellas outra vez achegando-me, dizer : on revient toujours à ses premiers amours.

(1) Com raras excepçoes todas as estampas da monograpbia da Flora de Mutrius, são minbas, fielmente copiadas da minha Iconographiza. 
Gen. Lycaste. lindt

LYCASTE ROSSIANA var. MATTO-GROSSENSIS Barb. Rod. ['seudobulbis ovatis complanatis anguloso-rugatis bitrifoliatis, quum aphyllis ad apicem bi-aculeatis, foliis late lanceolatis acutis ad basin attenuatis, scapo erecto unifloro pseudobulbis paulo majore, tribracteato, bratea envaginatre cuculate acutx, internodiis minorx, sepalis patentibus ad apicem recurvis late lanceolatis acutis lateralibus majoribus. petalis sepalisque paulo minoribus erectis oblongo lanceolatis acutis, labello petalis minore, trilobo, lobis lateralibus erectis ad apicem emaryinatis, lobo medio lanceolato acutissimo recurvo ad apicem sub plicato brunueo leviter maculato, calloso callo longo concavo, columna dorsaliter angulosa antice plana basi producta.

Tab. XIII.

Pseudobulbis $0^{\mathrm{m}}, 07 \times \mathrm{O}^{\mathrm{m}}, 05 \mathrm{lg}$., vernicosis; Scapo erecto, albo viridi, $\mathrm{O}^{\mathrm{m}}, 10 \mathrm{lg} \cdot \mathrm{g}$, Bractece invaginatæe, ad apicem cuculiata acuta, on or 5 lg.. brunnex. Flores aurantiaceis. Sspala superiora recurva, plana, $0^{m}, 030 \times 0^{m}, 019 \mathrm{lg}$. inferiora majora, $0^{m}: 035 \times 0^{m} .017 \mathrm{lg}$. Petala $0^{\mathrm{m}} .030 \times 0^{\mathrm{m}}, 016 \mathrm{lg}$. Labellum $\mathrm{O}^{\mathrm{m}}, 025 \mathrm{lg}$. Columua $\mathrm{O}^{\mathrm{m}}, 015 \mathrm{lg}$, antice laviter velutina, alba. Anthera unilocularis, granulosa. Pollinia + per paria, caudicula longa, glanclula lanceolata.

$\mathrm{H}_{\mathrm{AB}}$. In arboribus sylizs umbrosis loco dicto. Capão secco, ad serra da Chapada. proo'. Matto.Grosso. Flor. Ful.

Attrahido pelo aroma da minha Caltleya Princeps (') que á borda da matta do Capio secco, no alto da Serra da Chapada, se: ostentava com um bello pendåo de flores, que se balouçava pela aragem gelada que açoutava os campos. n'uma

(1) licscolurta en 1868 , em companhia do hotanico suecu salomon 1lenschen. em Minas licrues, c muito postcriormente descripts pelo profesor kechambach, com a nome de Ciallicial dolosit. 
temperatura de 4 gráos, penetrei na referida matta e ahi encontrei, sem flores, mas representada por muitos exemplares a especie que me occupa.

Transportados para este Jardim, despiram-se das follhas e em Julho floresceram, dando cada pseudobulbo cinco a seis magnificas flores de um bello amarello de curo.

Procurando determinal-a vi que se approxima muito do Lycaste liossiana que o professor Rolfe descreveu em 1893 , desconhecendo a patria. Tendo sido remettida de Florença para a collecção do Sr. Warocqué, em Mariemont, ahi floresceu.

Posto que muito proximas sejam as especies, comtudo, se afastam não só no colorido como no tamanho e fórmas. O Lycastc Ressiana tem as sepalas amarello-esverdeadas, com pellos na base e têm $0^{\mathrm{m}} \cdot 035-0,04 \times \mathrm{O}^{\mathrm{m}}, 20$ de comprimento emquanto que a presente tem as petalas de um amarello de ouro. sem pellos e com $0,30 \times \mathrm{O}^{\mathrm{m}}, 015$ de comprimento. As petalas são esverdeadas com manchas pardas e pelludas na base, emquanto que as da minha são amarello de ouro sem pellos. O lobulo tem a base muito concava. listrado transversalmente de pardo, com os lobulos redondos e com o disco munido de grandes pellos, quando o da minha especie nada disso apresenta. Outras differenças ainda apresenta que facilmente serão vistas pelos detalhes que apresento.

Não descrevo aqui as folhas porque são semelhantes ás das outras especies, chamando apenas a attenção para um caracter dos pseudobulbos. Estes depois da queda das folhas, apresentam no apice dois espinhos em fórma de unha de gato, excessivamente duros e pungentes, que mostraram a sua utilidade dando-me dois profundos golpes na mão, quando arranquei o primeiro exemplar que achei. Cresce sobre o musgo das arvores nos logares humidos. 



\section{EXPLICACAAO IDAS ESTAMPAS}

Tab. I. - Anona Macrocarpa Barb. Rod.

1. Galho com folhas, de tamanho natural.

2. Fructo inteiro, idem.

3. Semente, vista de lado, idem.

7ab. II. - Anona Cuvabaensis Barb. Rod.

$A$. Uma folha vista pelo dorso e destituida de pellos, de tamanho natural.

B. Galho con uma fôr, idem.

I. Calyce, visto pela parte externa, idem.

2. Uma petala exterior, vista pelo interior, idem.

3. Tres petalas interiores, idem.

4. Uma petala interior, vista de lado, idem.

5. Estames, idem.

Tab. HII.-Anona aurantiaca Barb. Rod.

$A$. Um galho com fructo pequeno, de tamanho natural.

$B$. Um fructo maduro, idem.

Tab. IV.-Aberemoa Jonasiana Barb. Rod.

$A$. Um galho com flôr e fructo, de tamanho natural.

B. Fructo maduro, cortado verticalmente, idem.

I. Sepala de tamanho natural.

2-3-4. Petalas exteriores, idem.

$5^{-6-7}$. Petalas interiores, vistas de frente, de tamanho natural.

8. Uma petala interior, vista do lado externo, idem.

9. Estames e estylo, idem.

10. O mesmo, duas vezes augmentado.

11. O mesmo, cortado verticalmente, idem.

12. O mesmo visto pelo lado superior, idem.

Tab. V.-Anacardun corymbosum Barb. Rod.

A. Um galho com flôres, de tamanho natural.

$B$. Uma folha, vista pelo lado posterior, idem.

1. Uma flôr esteril, idem.

2. Uma dita, tres vezes augmentada.

3. Una flôr fertil, cinco vezes augmentada.

4. Calyce, idem. 
5. Una pctala, vista do lado intericr, idem.

6. LTma dita, na sua posiçio natural, idem.

7. Estylo, idem.

8. Parte superior do mesmo, idem.

9. Estame esteril, muito augmentado.

ro. Dito furtil, idem.

Tab. I\%.-Mucuna Matrogrossensis Barb. Rod.

I. Galho com follas e flôres, de tamanho natural.

2. Calyce, do lado exterior, idem.

3. Aza, idem.

4. Carina, idem.

5. Estandarte, idem.

6. Estames, idem.

7. Ovario e estylo, idem.

8. Fructo não maduro, idèm.

9. Parte interna do mesmo, fragmento mostrando a semente, idem.

ro. Córte transversal do mesmo, idem.

Tah. VIl.-Hymeniza Chapadensis Barb. Rod.

A. Uma folha, do lado inferior, de tamanho, natural.

I-2. Semente inteira, e cortada verticalmente, idem.

Tal. B.- Prerocarpus Parafuayensis Barb. Rod.

I. Foliolo, de tamanho natural.

2. Aza, idem.

3. Carina, idem.

4. Estandarte, idem.

5. Calyce e estames, idem.

6. Uvario e estylo, idem.

Tab. HIIT. - Hymen.e Corkean. Barb. Rod.

A. Uma folla, vista pelo dorso, de tamanho natural.

b. Un fructo maduro, idem.

1. Sentente inteira, idem.

2. Dita partida verticalmente, idem.

Tab. IX. - Passiflora cimpestris Barb. Rod.

A. Galho com follua, gavinha e fructo, de tamanho natural.

f. Lma for partida verticalmente, duas vezs augmentada.

1. Sepala, tamanho natural.

2. Petala, idem.

3. Corte transversal do fructo, idem.

4. Semente, rom o arillo bicoruudo, idem.

5. Semente, idem. 
Tab. X.-Passifloka Curumbaensis Barb. Rod.

$A$. Galho com folha, gavinha e fructo, de tamanho natural.

$B$. Fructo, como raras vezes se apresenta, idem.

Tab. XI.-Malacocarpus heptacanthus Barb. Rod.

$B$. Planta, de tamanho natural.

r. Espunhos, idem.

Tab. NII. - Dejanira Cyathlfolia Barb. Rod.

$A$. Purção média da haste, com flôres, de tamanho natural.

1. Botão, de tamanho natural.

2. Calyce, duas vezes augmentado.

3. Corolla, idem.

4. Anthera, vista de frente, tres vezes augmentada.

5. A mesma, pelo dorso, idem.

6. Apice da anthera, muito augmentado.

7. Ovario e estigma, duas vezes augmentado.

8. Estigma, muito augmentado.

Tab. B.- Maxillaria Chapadensis Barb. Rod.

Pseudobulbos, folha e forres, de tamanho natural.

I. Sepala superior, idem.

2. Sepala lateral, idem.

3. Petala, idem.

4. Lobullo, visto de lado, idem.

5. Dito, visto pelo dorso, idem.

s.. Dito, visto pela frente.

7. Columna, de lado, duas vezes augmentada.

8. Pollinias, muito augmentadas.

Tab. Xill. - Lycaste Mattogrossensis Barb. Rod.

$A$. Planta de tamanho natural.

1-2. Sepalas superior e lateral, idem.

3. Petala, idem.

4. Labello; de lado idem.

5. O mesmo de face, idem.

6. Columna, de lado idem.

7-8. Antheras de frente e de costas, muito augmentadas.

9-ro. Pollinias vistas de frente e pelo dorso, idem. 



\section{Indice das plantas contidas n'este volume}

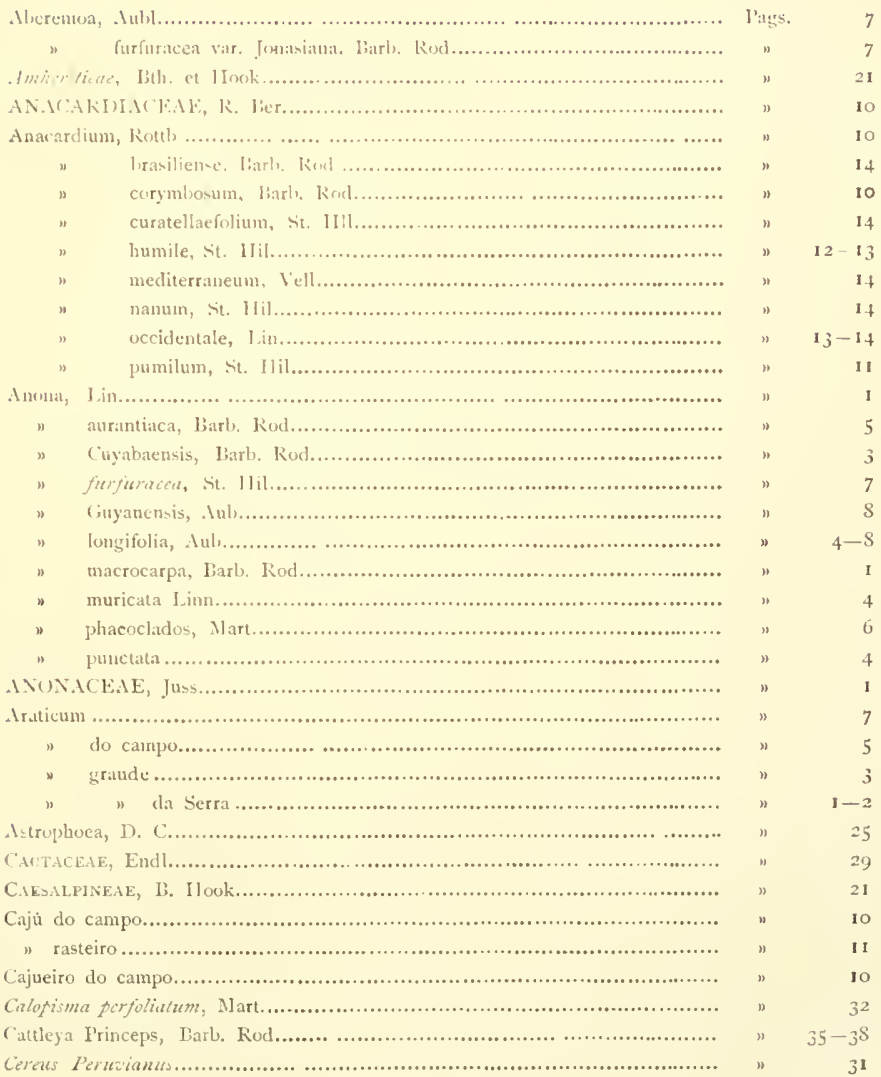




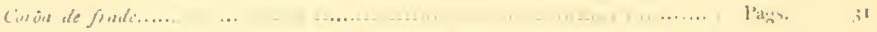

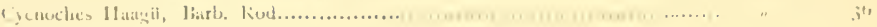

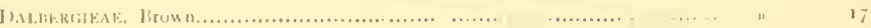

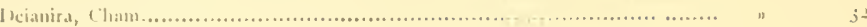

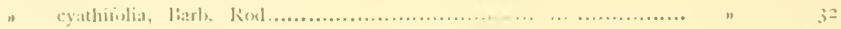

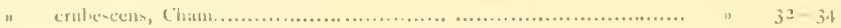

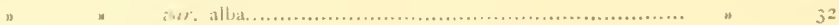

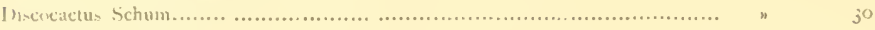

1)

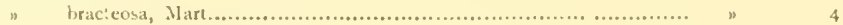

" furfuraceat, Bent. e lloukcr...................................... n $\quad 7-8$

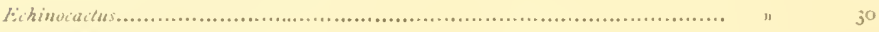

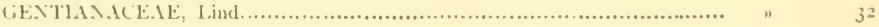

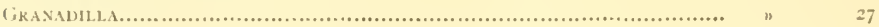

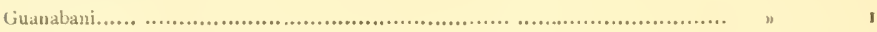

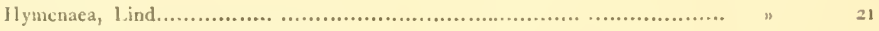

" Chapadensis, larb. Rud...................................... "

" Correana, Barb. Rod............................................. n

" courlaril ..................................................... " $22-24$

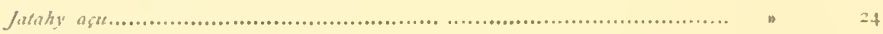

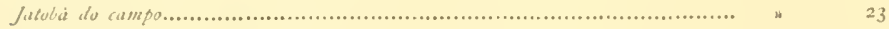

n grande ................................................................ n $\quad 22$

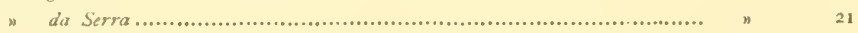

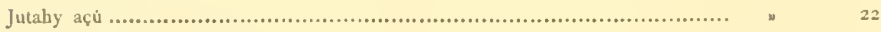

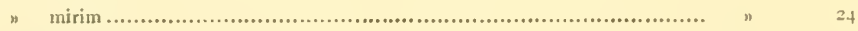

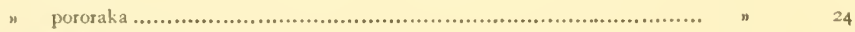

LEGUMIXOSEAF, Endl................................................ "

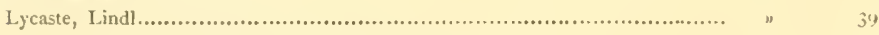

" Kossiana, Rolfe ................................................ n $\quad 39$

" $\quad$ var. Mattogrossensis, Barb. Kod ............................. " 39

Mangifrera, Marcb..................................................... n

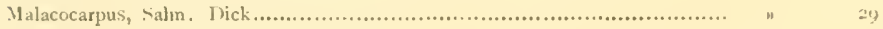

Malacocarpus heptacianthus, Barb. Kod..................................... n $\quad$ (i)

Maracuja da clapada................................................................... w 20

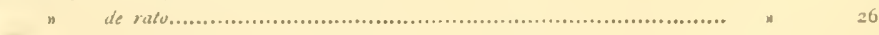

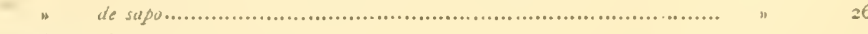

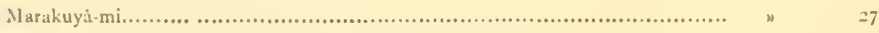

Mlaxillaria, K. Pav......................................................... n $\quad$ "

w Chapadensis, Barb. Kod....................................... " $\quad 35$

" squalens..............................................................

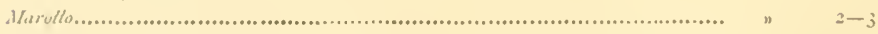

Mclocactus communis, Link ................................................. "

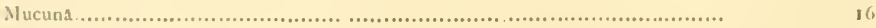

Mucuna, $\lambda$ dauk................................................................... 15

w macruccratides.........................................................

1) Mattogrossensis, liarl. Kurl...................................... " 15

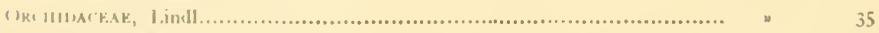

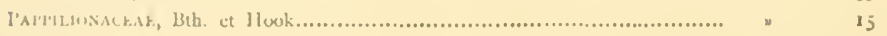




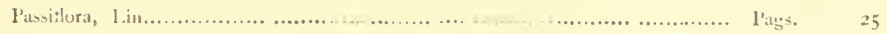

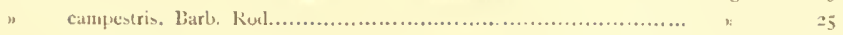

" Cormubaensis, liarb. kod...................................... " $\quad 27$

" Giluertii. (irah...............................................

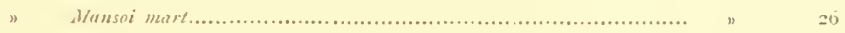

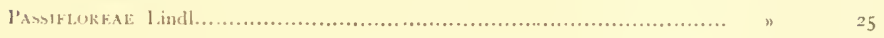

Pireskir Bled, D. C....................................................... n

l'HASEOLEA., Bth. et llouk................................................. "

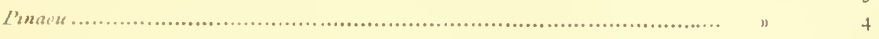

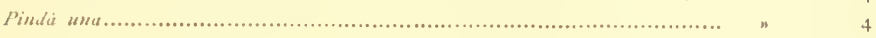

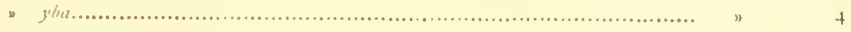

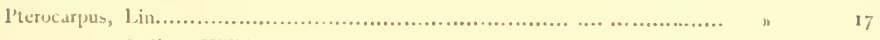

Indicus willdn............................................. " 19

" Michelü Brittun................................................. " 20

" Paraguayensis, barb. kod..................................... n 17

" Kohrii, Volıl................................................. n

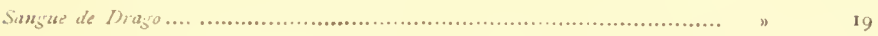

Sintaliria, I). C....................................................... " $\quad 17$

Stizolobium, 1). C........................................................... "

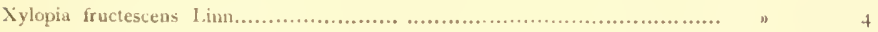

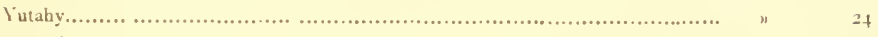

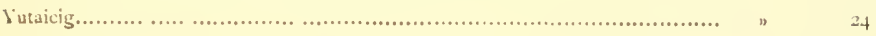





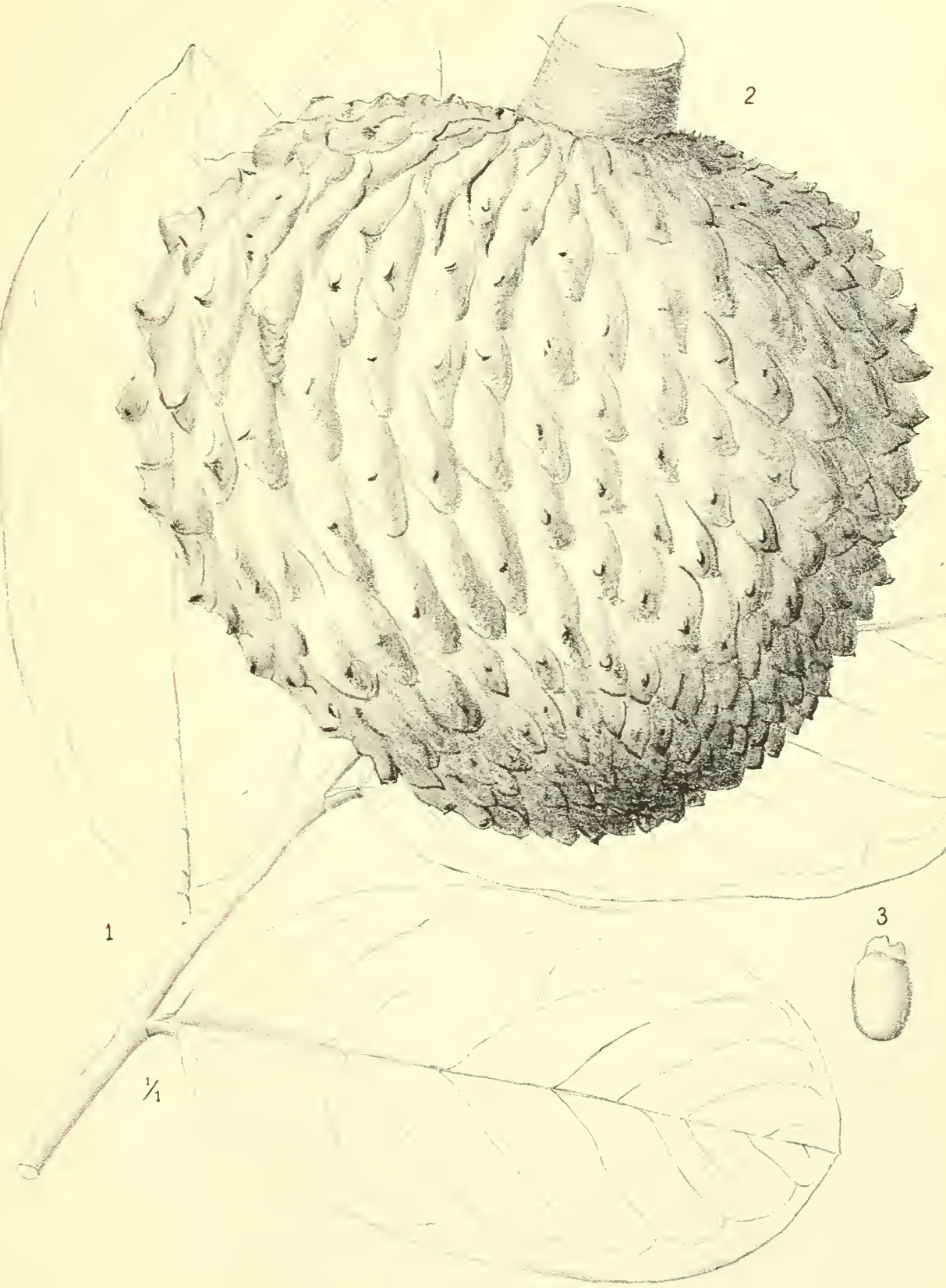

Barb. Rod des. dap nat.

ANONA MACROCARPA Barb. Rod. 

Tab.II.

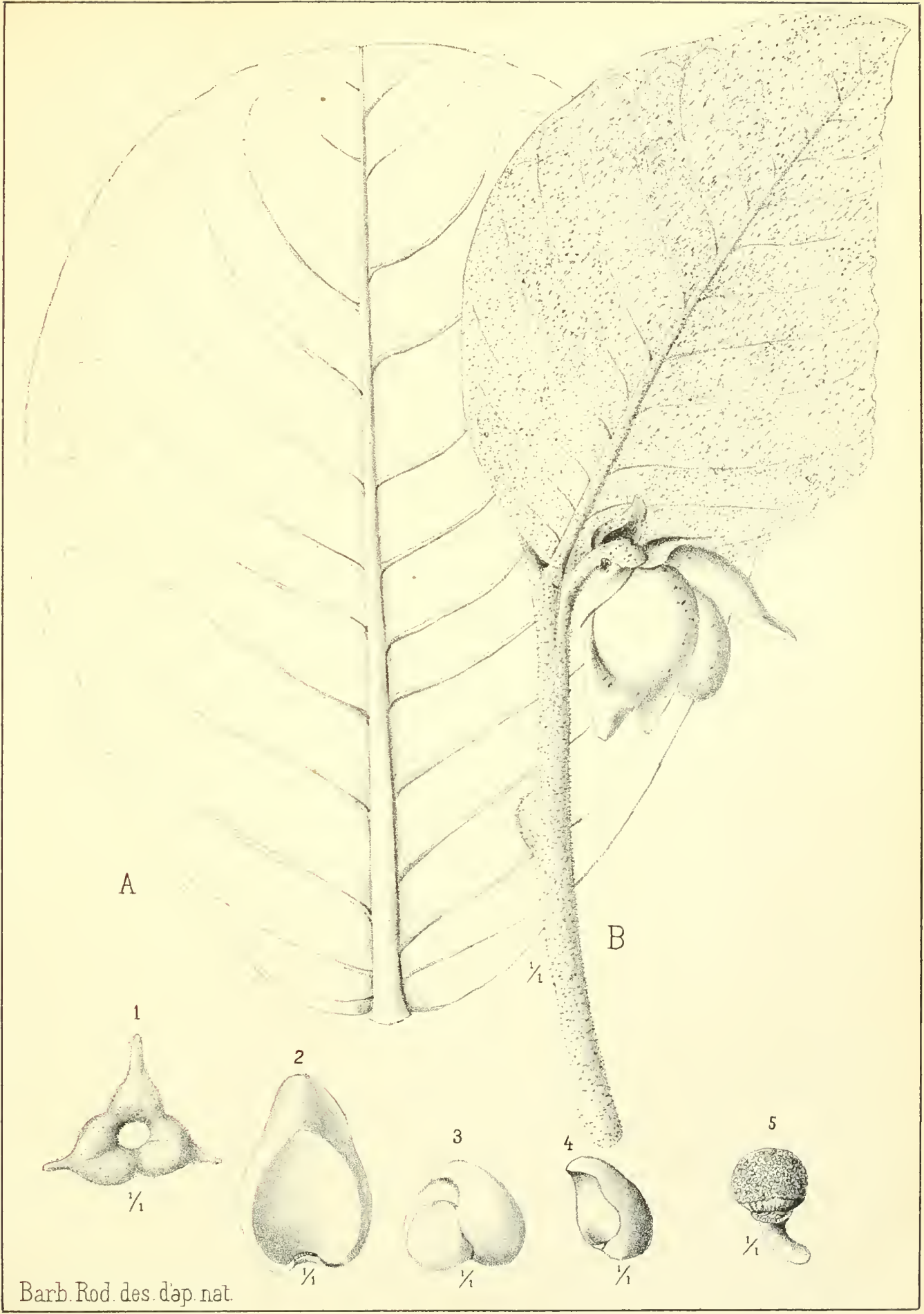

ANONA CUYABAENSIS Barb.Rod. 



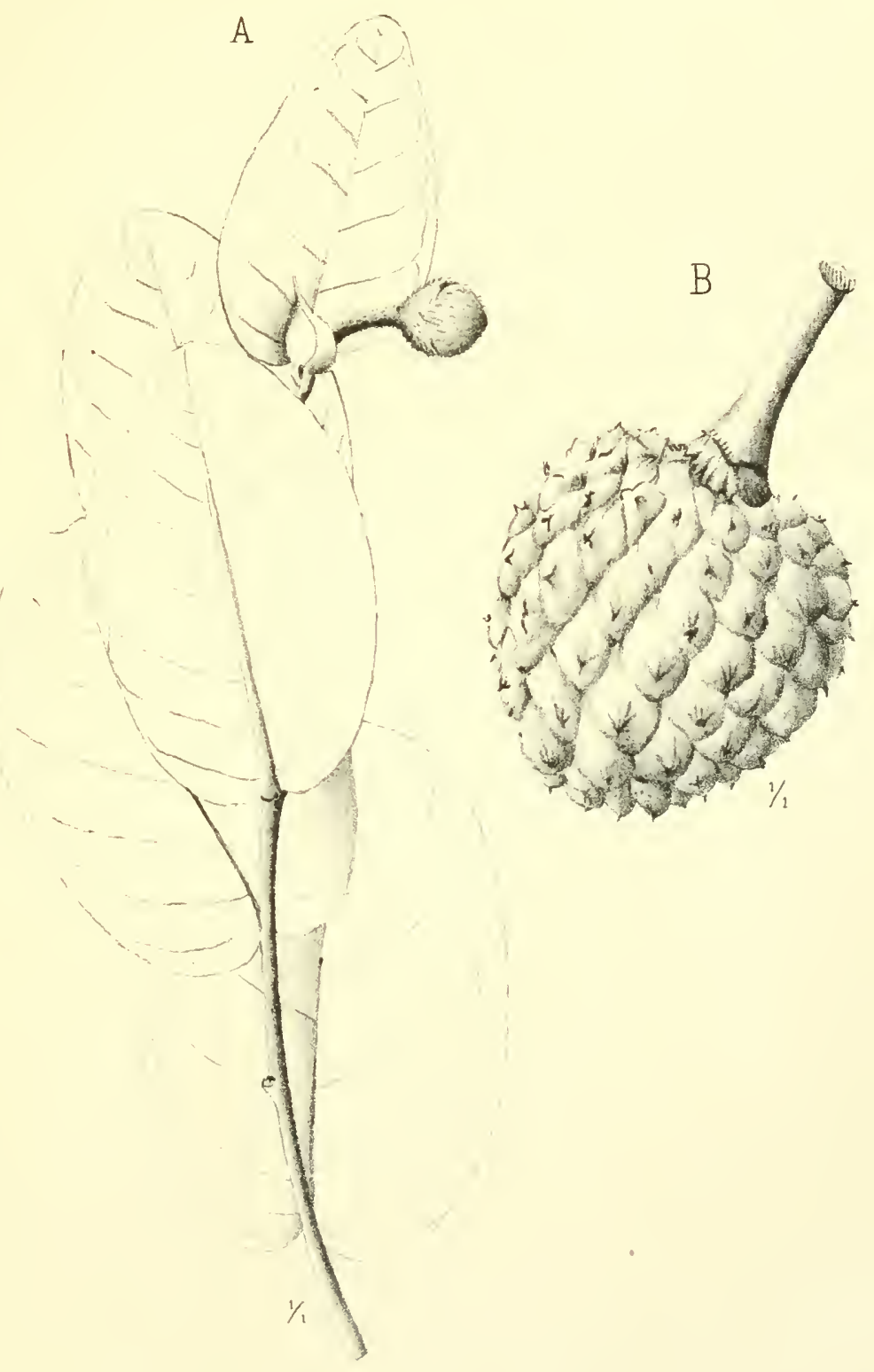

Barb. Rod des. dap. nat.

ANONA AURANTIACA Barb.Rod. 

Tab. IV.

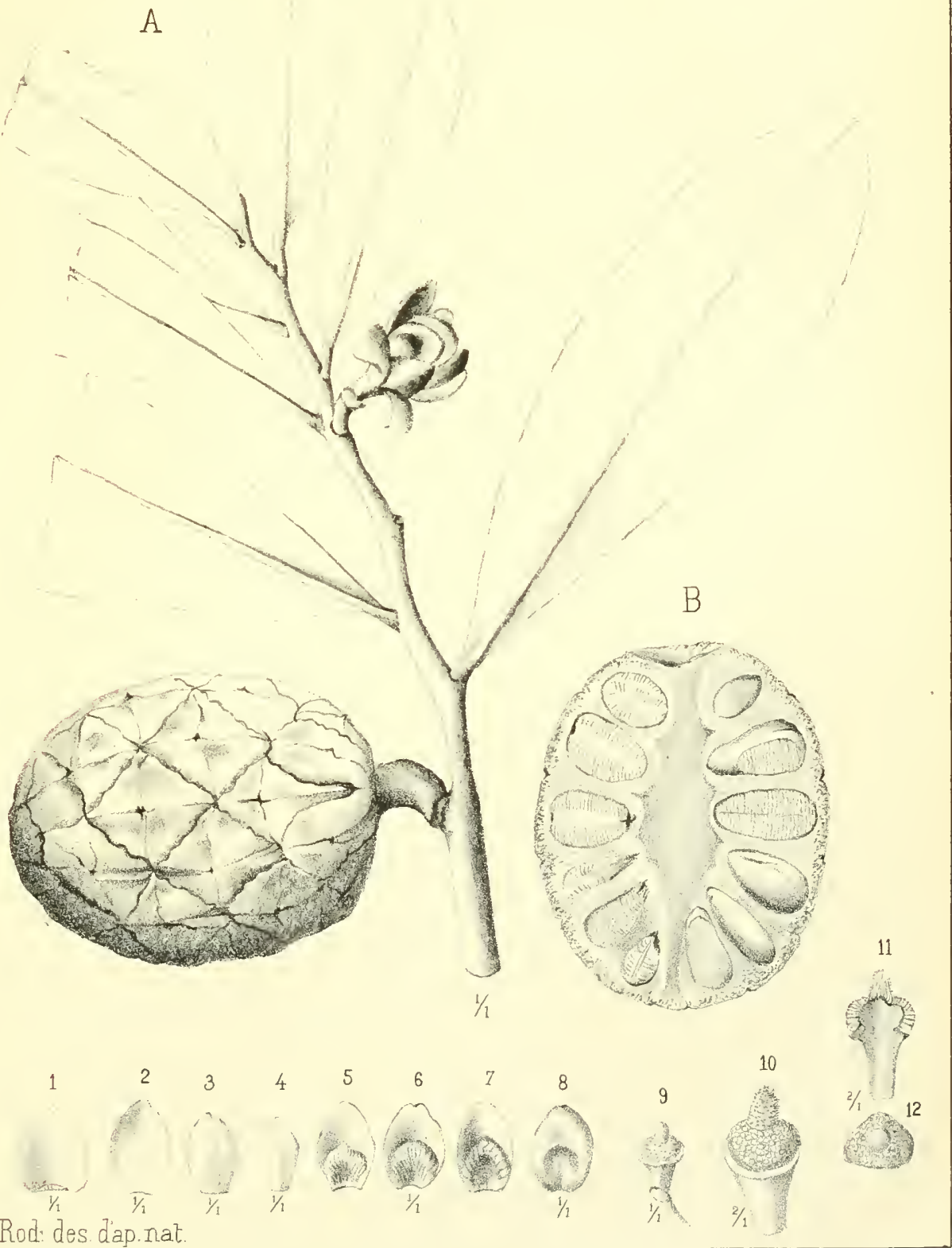

Barb. Rod: des d'ap.nat. 



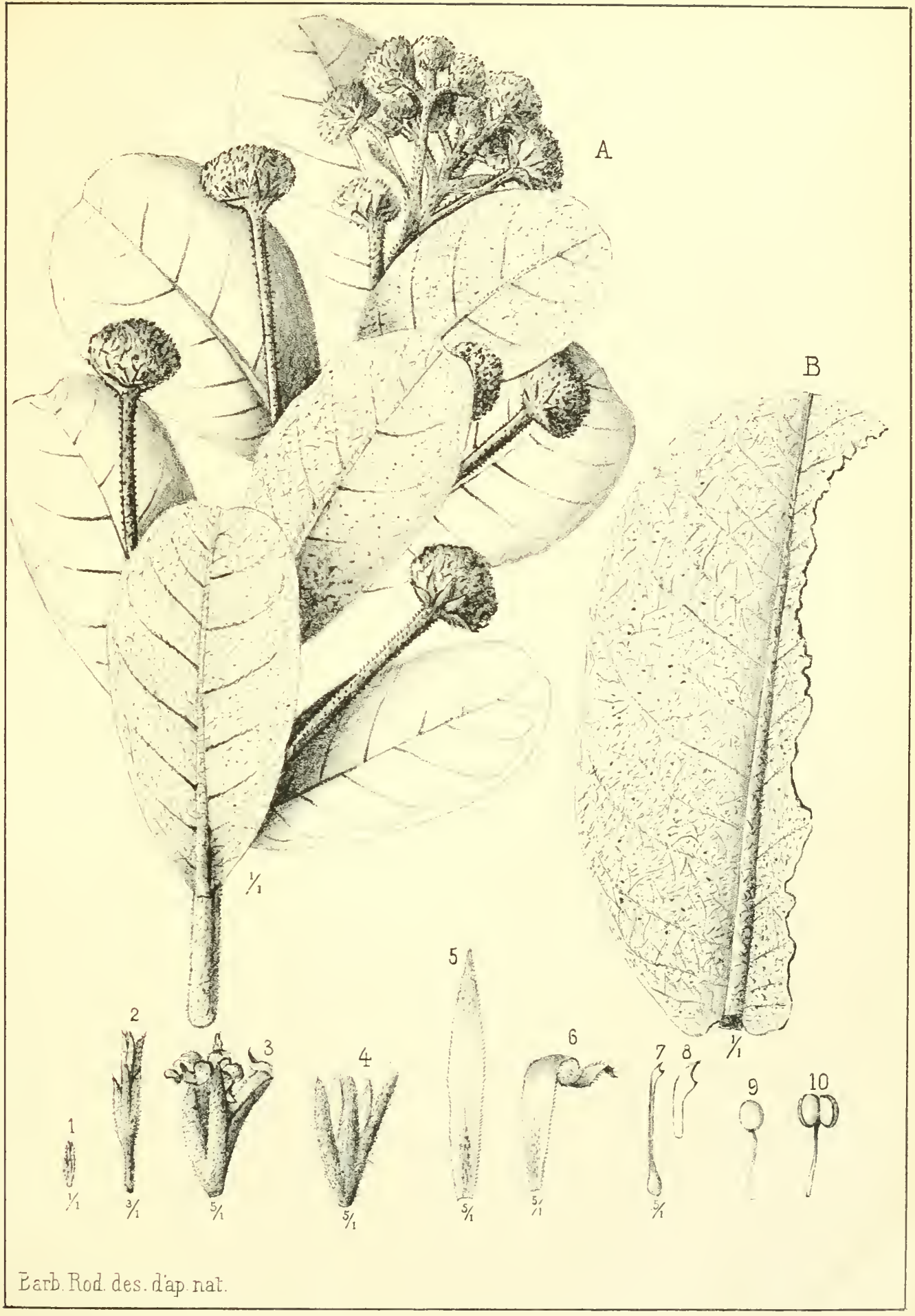

ANACARDIUM CORYMBOSUM Barb.Rod. 



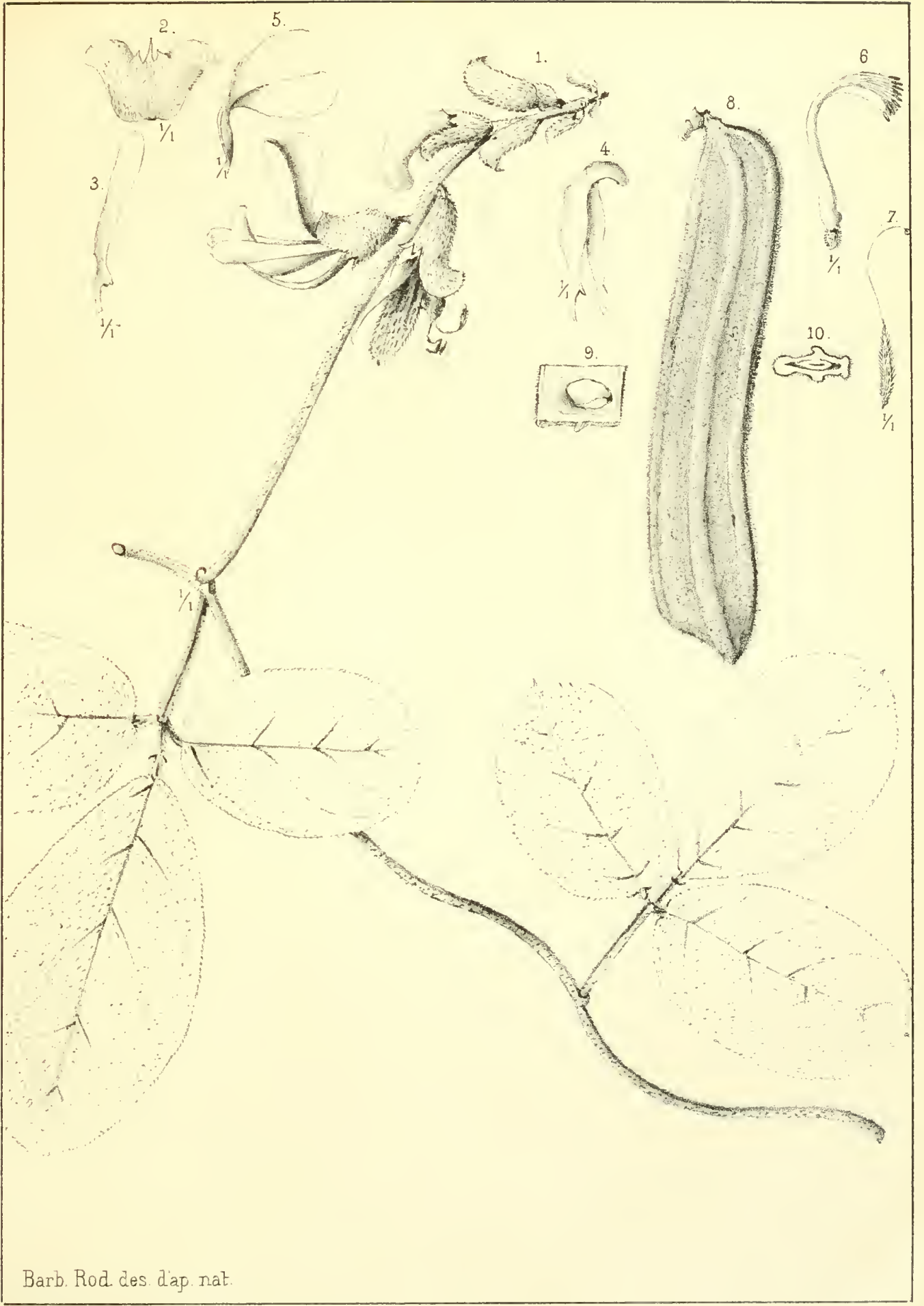

MUCUNA MATTO GROSSENSSIS Barb.Rod. 



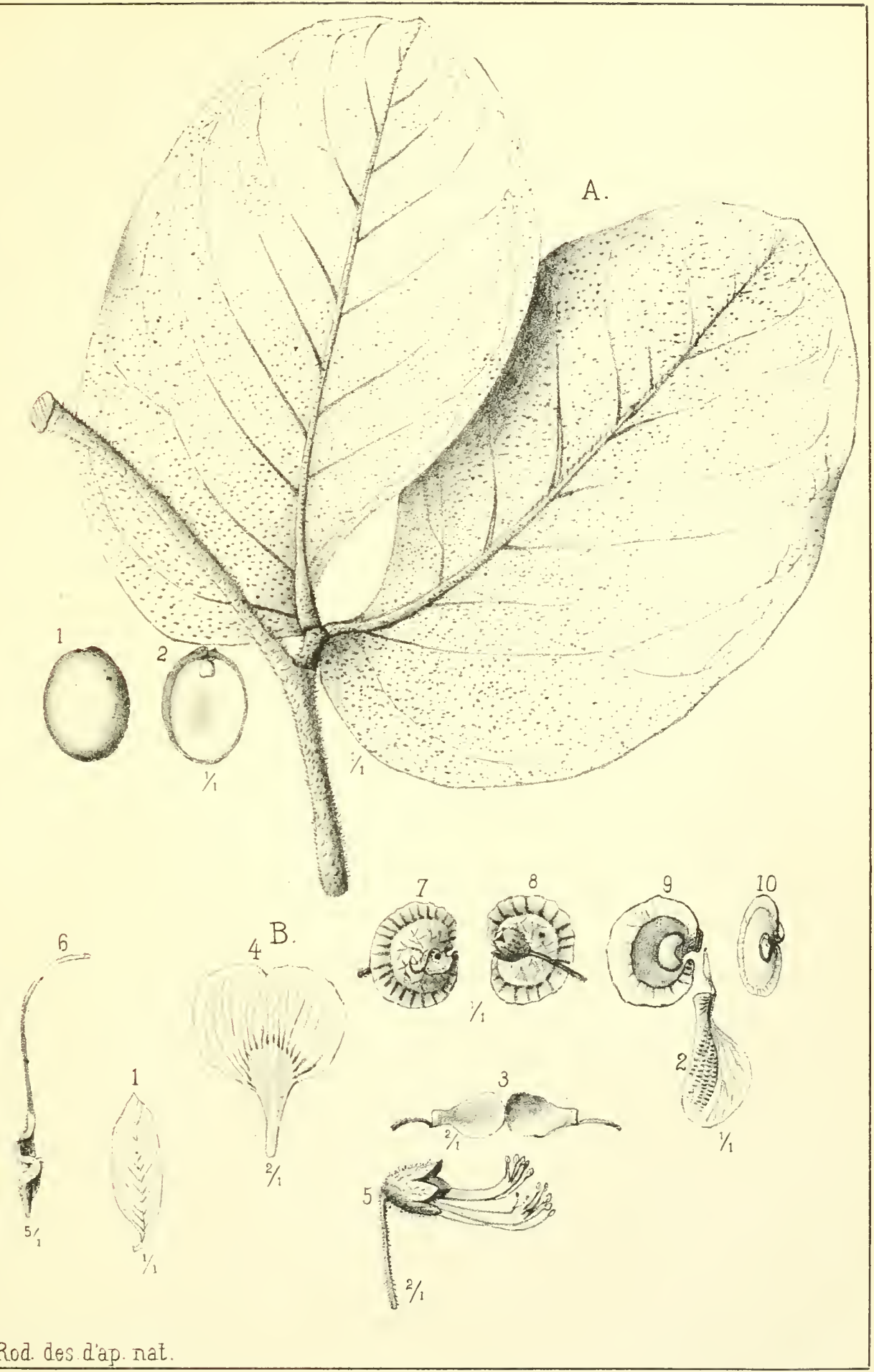

Barb.Rod. des d'ap. nat.

A. HYMENAEA CHAPADENSIS Barb.Rod.

B. PTEROCARPUS PARAGUAYENSIS Barb. Rod. 

Tab.VIII.

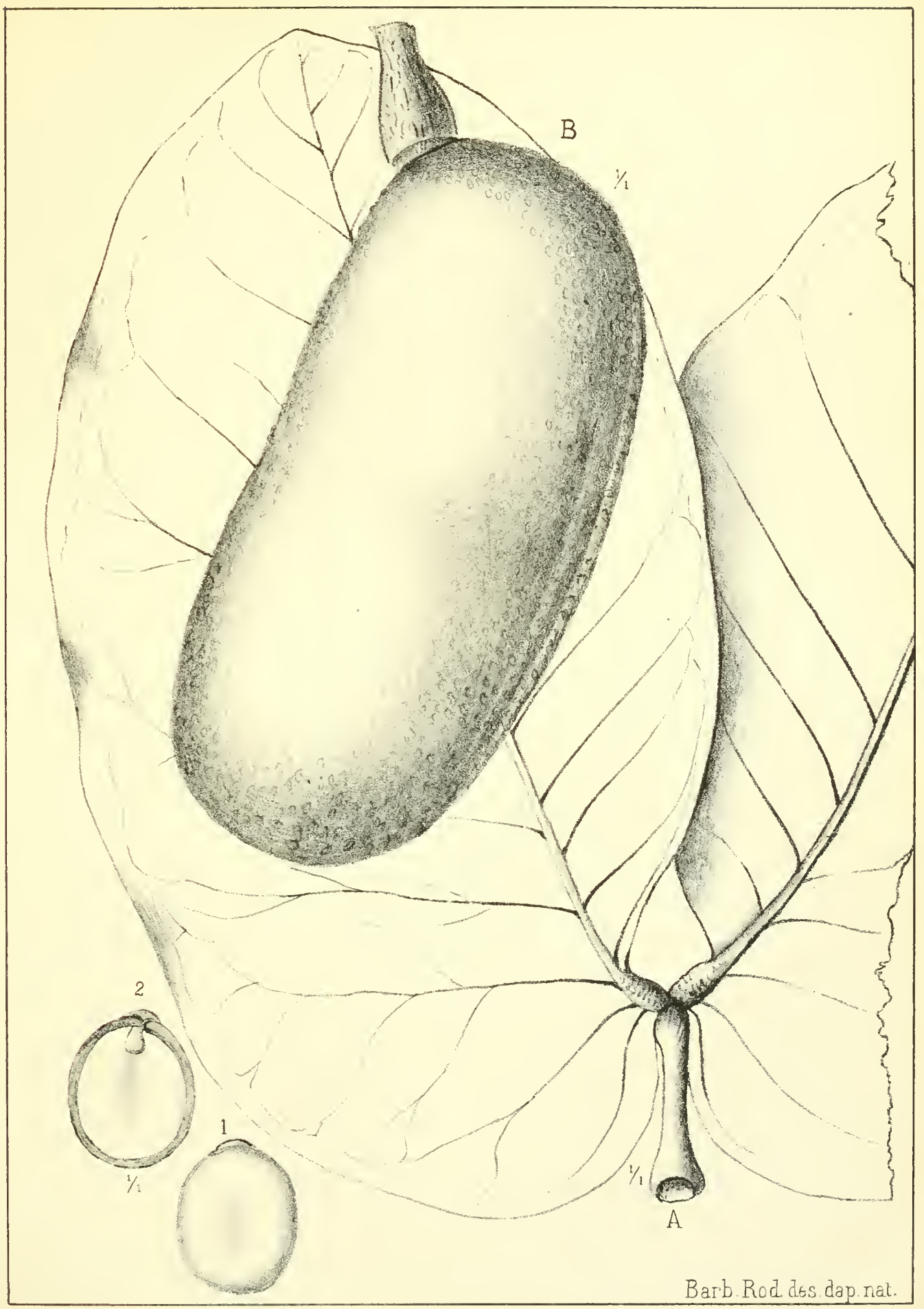

HYMENAEA CORREANA Barb.Rod. 

Tab. IX.

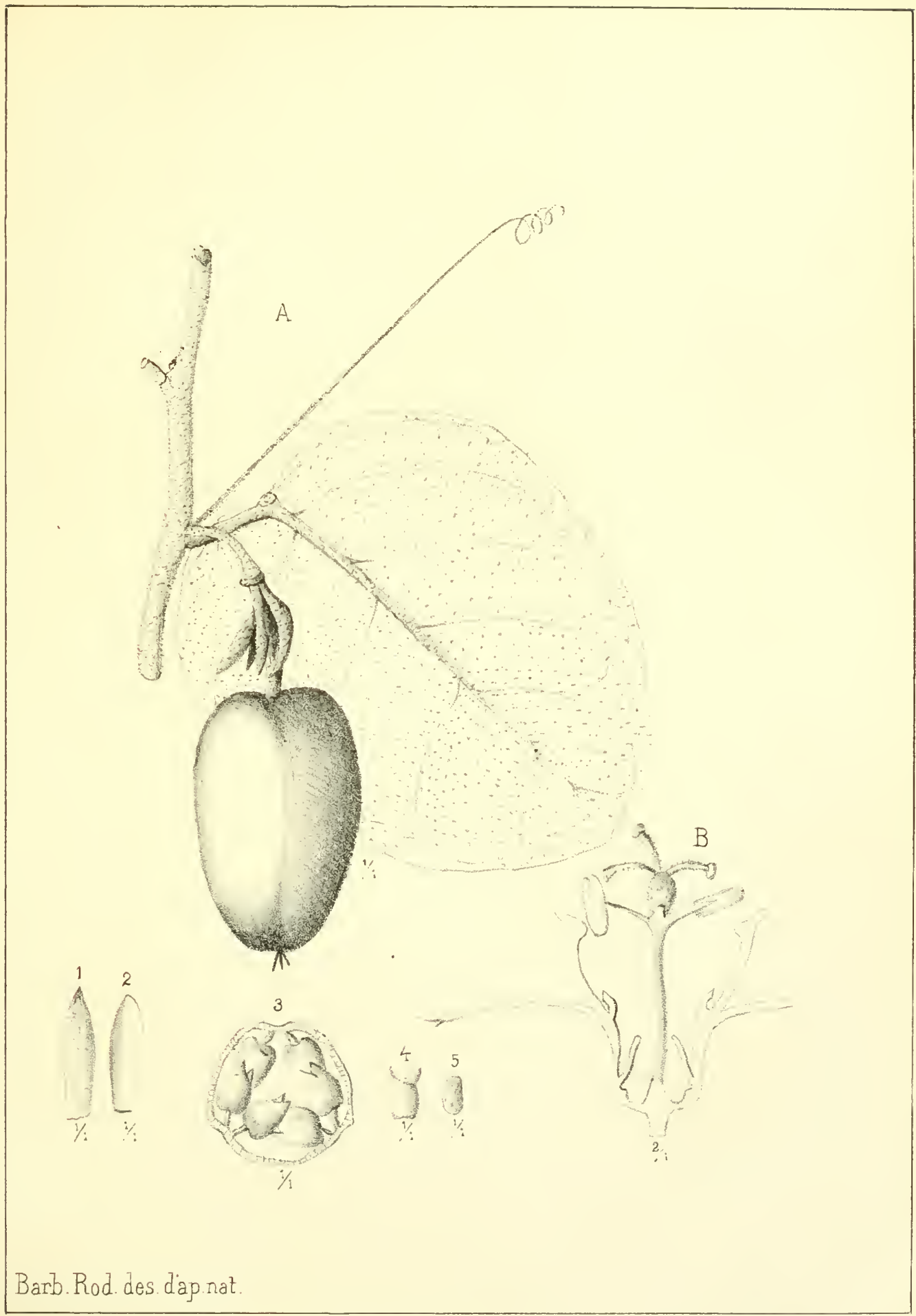

PASSIFLORA CAMPESTRIS. Barb Rod. 

Tab.X.

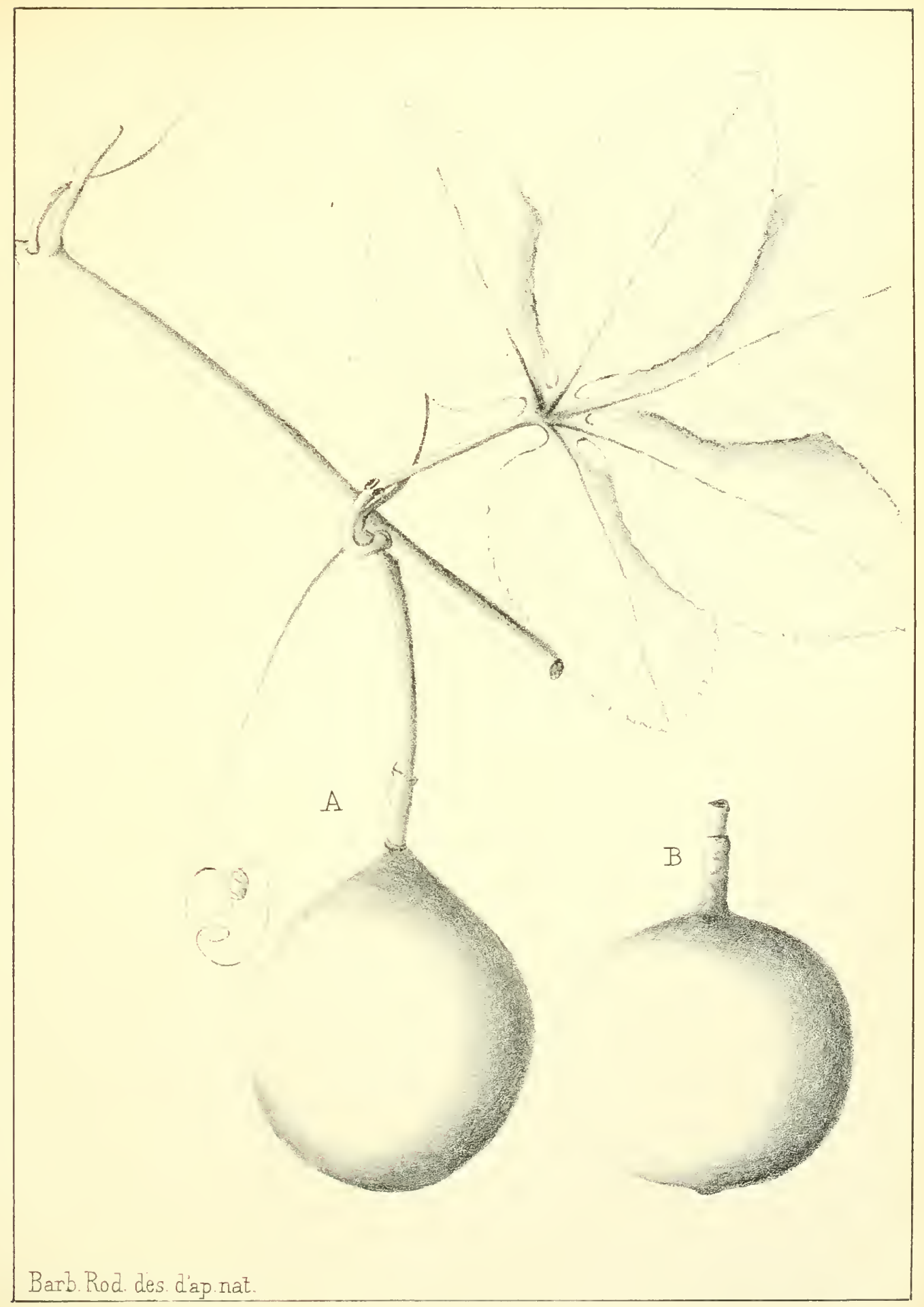

PASSIFLORA CORUMBÁENSIS. Barb.Rod. 

Tab.XI.

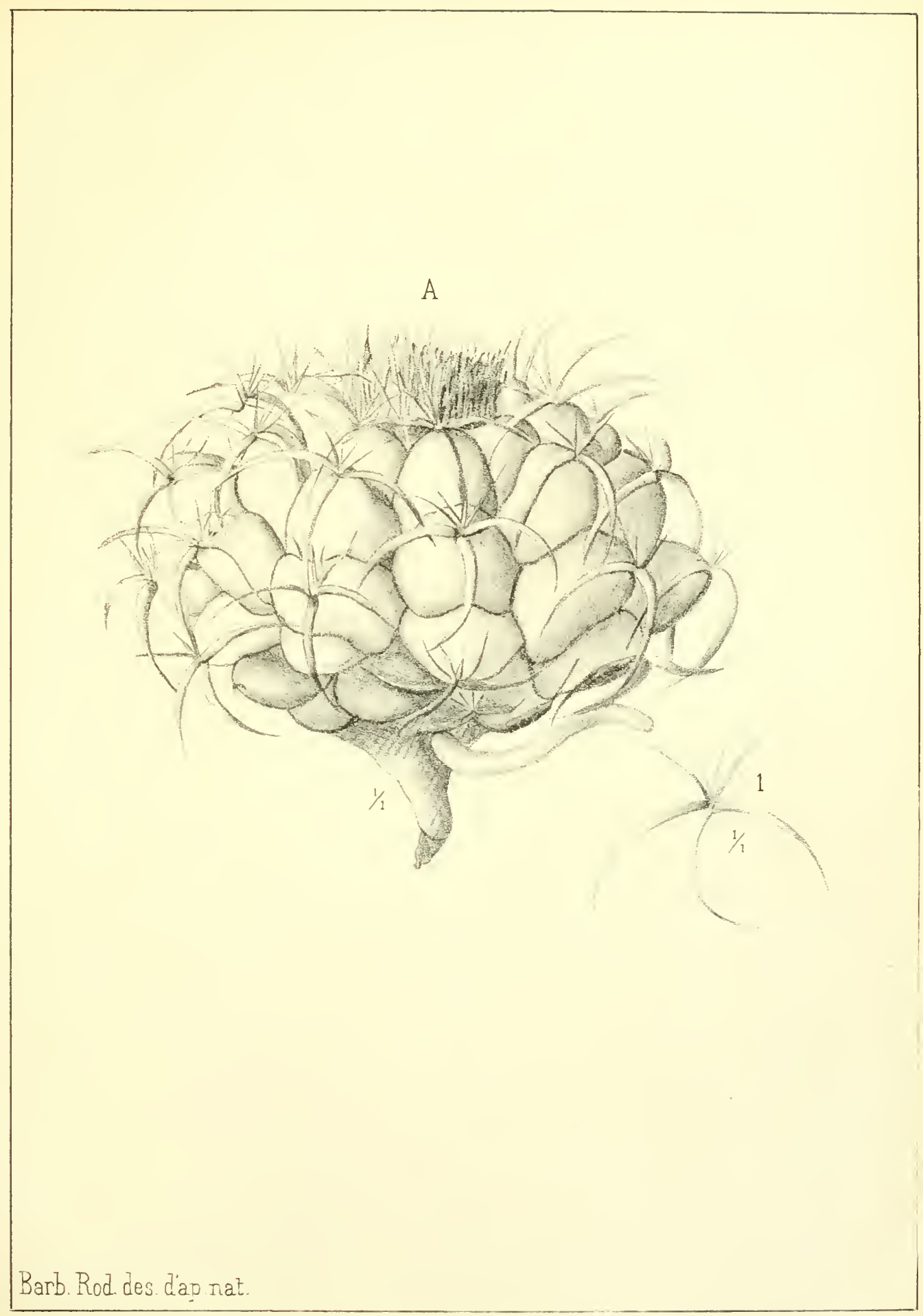





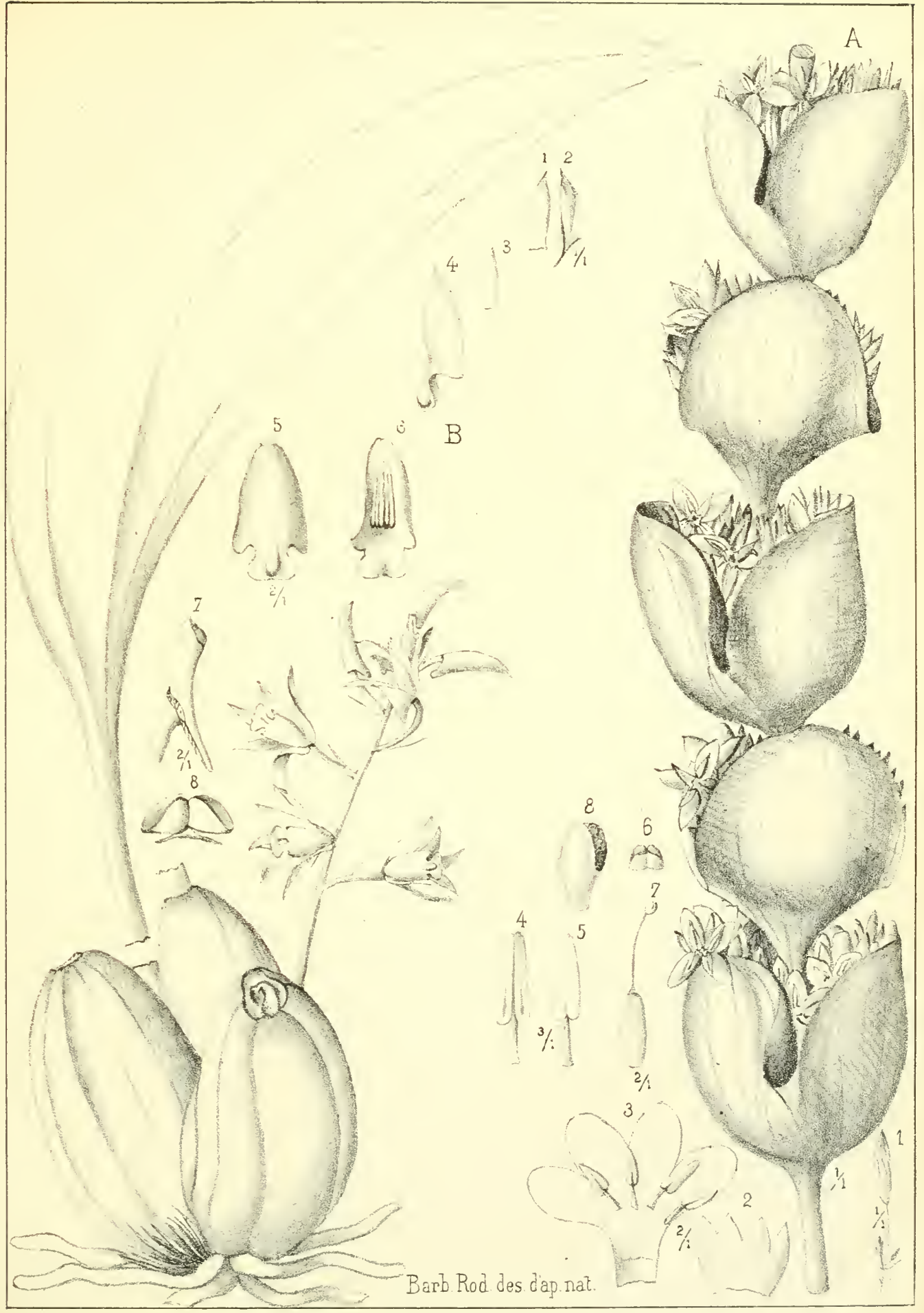

A DEJANIRA CYATHIFOLIA. Barb. Rod.

B. MAXILLARIA CHAPADENSIS Barb.Rod. 



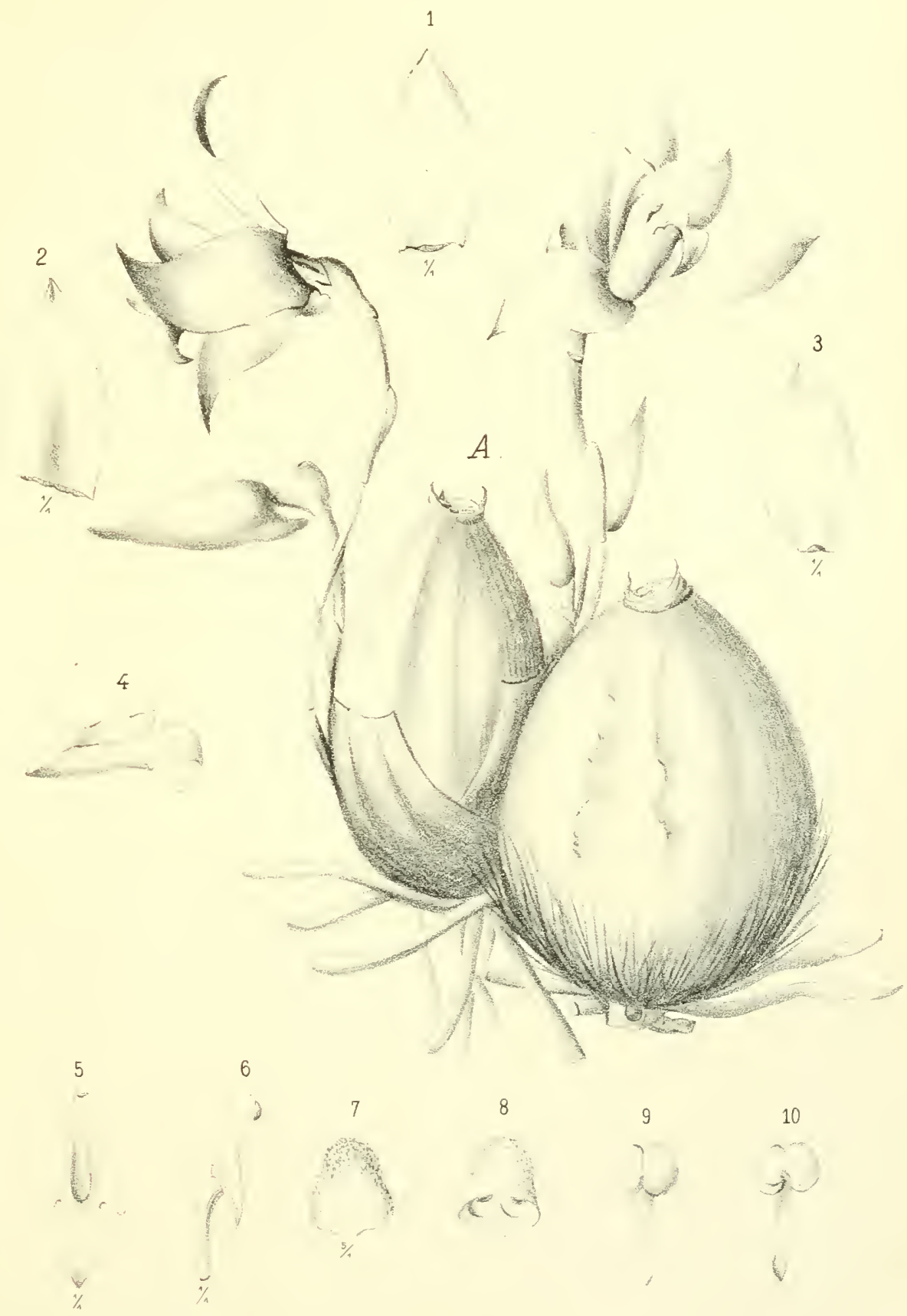

Barb. Rod. fec. at nat. 



\title{
PALMAE MATTOGROSSENSES
}

\author{
NOYAE VEL VINUS COGNITAE
}

QUAS

\section{collegit descripsit et iconibus illustravit J. BARBOSA RODRIGUES}

Eques Antiqui, Nobilıssimi, atque Clarissimi Ordinis Sancti Jacobi a Gladio, Director Horti Botanici Fluminis Januarii,

Socius Effectivus Instituti H storici et Geographici Braziliae, Laureatus ab Instituto Scientiarum Physicarum et Naturalum Florentiae, Socius Regiae Academiae

Scientiarum Olysipponensis, Imperialis et Regalis Societatis Botanicae Vindobonensi, Societatum Botanicae Anedae et Massiliae,

Instituti Conimbricensis, Regiae Societatis Anthropologicae Florentiae, Societatis Friburguensis investigatorum Naturae, Nationalis Academiae Parisiorum,

necnon Societatis Geographicae Parisiorum, et Fluminis Januarii, etc.

$$
\text { RIO DE TANEIRO }
$$

Typographia IFUZINGER

$8704-97$ I 898 


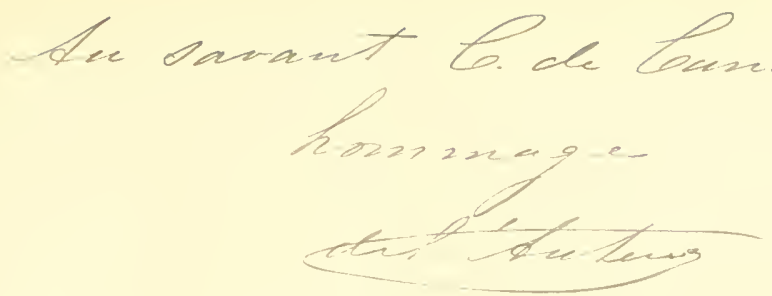

PALMAE MATTOGROSSENSES 



\section{COERIGFNDA}

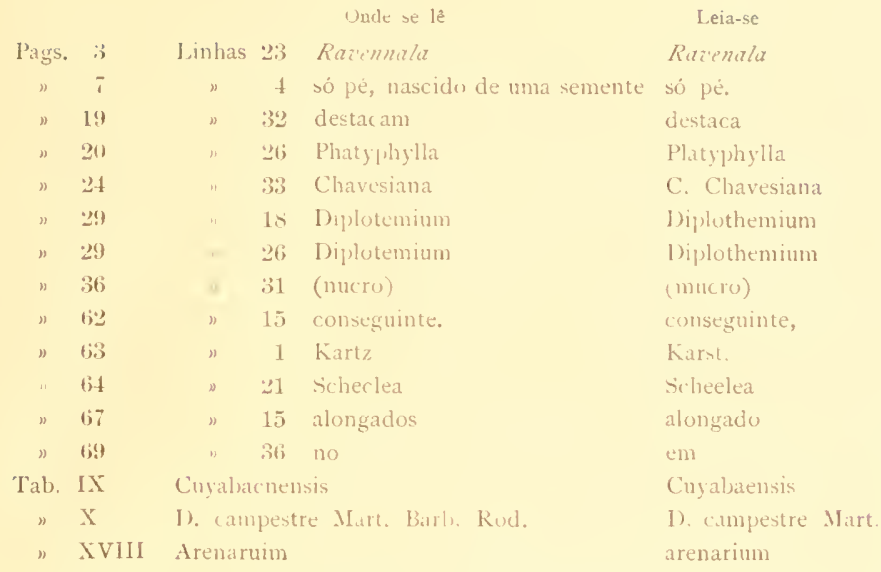

Ainda outros erros encontrará o lestor. pruncipalmente na parte latina, mas que benevolamente corrigurá. 



\title{
PALMAE MATTOGROSSENSES
}

\author{
NOVAE VLL MINUS COGNITAE
}

QUAS

\section{collegit descripsit et iconibus illustravit}

\author{
J. BARBOSA RODRIGUES
}

Eques Antiqui, Nobilissimi, atque Clarissimi Ordinis Sancti Jacobi a Gladio, Director Horti Botanici Fluminis Januarii,

Socius Effectivus Instituti Historici et Geographici Braziliae, Laureatus ab Instıtuto Scieotiarurn Physicarum et Naturalium Florentiae, Socius Regiae Academiae

Scientiarum Olysipponensis, Imperialis et Regalis Societatis Botanicae Vindobonensi, Societatum Botanicae Anedae et Massiliae,

Iastituti Conimbricensis, Regiae Societatis Anthropologicae Florentiae, Societatis Friburgueosis Investigatorum Naturae, Nationalis Academiae Parisiorum,

necnon Societatis Geographicae Parisiorum, et Fluminis Januarii, etc.

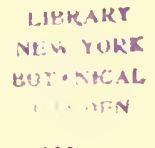

RIO DE JANEIRO

Typographia LEUZING F R 

INTRODUCÇÃO 



\section{AO LEITOR}

I

om o fim de augmentar as collecções de plantas indigenas e adquirir sementes para que a flora do paiz E emprehendi uma expedição ao sul do Brazil oriental, visto como pelas minhas excursões ao extremo norte. já satisfactoriamente ella é representada.

Tendo percorrido todo o valle do Amazonas, e conhecendo o littoral do norte, só me faltava correr o sul, e como é certo o que cantava o poeta nihil ardunm volentibus, com grande dispendio e sacrificios, em fins de Março d'este anno, encetei viagem. Depois de percorrer parte dos Estados do Sul, sendo escala forçada o Paraguay, demorei-me algum tempo em Assumpção, explorando as cercanias, para melhor fazer um estudo comparativo das differentes floras.

Além do fim puramente botanico, outro me obrigava a demorar-me nas terras paraguayas: o do estudo comparativo do abaneenga, conhecido ahi por guarany ou karany e no norte do Brazil por tupy, ou lingua geral, estudo este que ha bastantes annos tambem me occupa. Passando os dias entre as plantas, passava-os tamben com os campesinos, que são hoje os melhores conhecedores da lingua dos nossos avós e os que melhor conhecem os nomes vernaculos das plantas.

Em trabalhos passei os dias e as noites, sine labore nihil, pelo que augmentou-se muito o meu cabedal, não só para a sciencia de Linneo como para o estudo linguistico. 
Se a regiåo platina tem sido visitada por muitos viajantes-naturalistas e sobre ella já bastante se tenha escripto; se a região paraguaya tambem tem sido percorrida, depois de Francia, comtudo a região Matto-Grossense, n'essa parte, não tem sido muito feliz. porquanto, pouco se sabe relativamente ás suas riquezas botanicas.

Visitaram aquellas regiões e a seu respeito escreveram Commerson, no seculo passado; Caldcleugh (1S19-21), Saint-Hilaire (IS21), 1)'Orbigny (1\&26-33), Miers (1\$25-27), Arsène ( $\left.18_{33}\right)$, Isabelle ( $\left.18_{3 \hat{3}}\right)$, Bacle ( $\left.1 S_{35}\right)$, Tweedie $\left(1 S_{35}\right)$, Lorentz (1870-72), Grisebach (1879), Hyeronimus (1882), Balansa (1S86), Parodi (18S6-S8), Mlorong (rSSS-1S9o) e Kerr (IS90-91).

Natto Grosso, que me conste, só foi visitado pelo Dr. Rodrigues Ferreira (1;SS), pelo zoologista Natterer (1S17-32), por Gaudichaud ( $\left.S_{30}-3 \hat{3}\right)$ por D'Orbigny (1S26-33), por Weddell (1S4t), e ultimamente pelos Srs. Spencer Moore, botanico da expedição Charles Ward (1891-92), Drs. Carlos Lindman e Malme (1S95-96). Como geographos, o Dr. Steine, e Meyer e como entomologista Herbert Smith.

Devo tamben notar que, em is 36 , o Dr. Patricio da Silva Manso (1), colheu muitas plantas em Cuyabá, porém foram enviadas para Europa, por Lhotsky. Fazem parte do herbario de Martius e já estão todas descriptas.

Dos primeiros são conheciclas as suas descobertas, apenas não conheço publicação alguma dos resultados botanicos dos estudos de Lindman.

Matto Grosso, entretanto, podia ter hoje a sua flora mais conlecida, se a fatalidade não perseguisse a commissão scientifica, que durante os annos de $1 \$ 25$ a $1 \$ 29$ explorou este Estado, por conta do imperador Alexandre I, da Russia; commissão conhecida por expedição do Conselleiro Jorģe Langrsdorff. Fazia parte d'ella Luiz Riedel. botanico de firmada reputação, unico que escapou, depois de ter atravessado Matto Grosso e o Pará.

(1) Autor da Enumerasao das subsuncius brasilciras que fodem promoater a catarze. $1 S_{3} 6$. 
Para a Russia foram enviados alguns herbarios, porém, segundo affirma o Sr. Visconde de Taunay (1), baseado na opinião do finado Barão de Nelgaço (Augusto Leverger), "todos os trabalhos e até simples vestigios e indicações d'essa importante exploração se perderam».

Se não fôra esse facto, algumas das plantas que hoje descrevo estariam scientificamente determinadas, por quanto algumas são referidas, pelos nomes vulgares, pelo Sr. Hercules Florence, que foi desenhista da mesma comnissão (2).

Como a flora dos campos geraes do planalto Matto Grossense se ligue á do de Goyaz e seja quasi a mesma, não só pela curta distancia. como pela facilidade da dispersão das sementes disseminadas pelos ventos e pelos passaros, para tirar toda e qualquer duvida, procurei ver se não teria a commissão brazileira, exploradora do planalto central do Brazil, encontrado as mesmas especies que aqui descrevo. Para isso, se bem que a commissão fosse brazileira, tive de recorrer ao estrangeiro, por quanto todas as plantas collidas n'essa expedição. por pessoal brazileiro, á custa dos cofres do Brazil, foram remettidas para a Europa a fim de ahi serem classificadas, dando-se uma prova publica do atrazo scientifico do nosso paiz, quando não ha razão para semelliante procedimento.

Releve-se-me o assim expressar-me, porque ha longos annos, como andorinha desgarrada, bato me contra a opinião dos que affirmam que a botanica no Brazil está na infancia e que no Brazil se não póde classificar por falta de herbarios, quando temos muitos exemplos do contrario, dados pelos que trabalham com patriotismo.

Com o fim, pois, de verificar as minhas especies, procurei ver o resultado botanico colhido pelo Sr. Glaziou, botanico da mesma commissão, porém não encontrei um só trabalho scientifico do mesmo senhor e apenas li o relatorio do Sr. Ule,

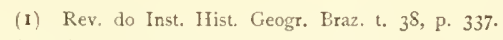

(2) Op. cit. p. 355 . 
outro botanico da mesma commissão, pelo qual fiquei sabendo que as plantas á medida que iam sendo colhidas, iam sendo logo remettidas para a Europa, para ahi serem determinadas. E' o que se collige d'este periodo:

"Antes que as linhas precedentes fossem remettidas á imprensa, recebi ainda algumas communicações (da Europa) sobre os resultados das collecções botanicas, nas quaes, ainda que os phanerogamas se achem apenas determinados até a metade, já se encontram especies novas e dous generos novosn (I).

Não podendo assim colher informações em trabalhos brazileiros ou dos botanicos estrangeiros, estipenüiados pelo governo do Brazil, recorri então a uma publicação do sabio Dr. Taubert (2), de saudosa memoria. um dos botanicos que determinaram as plantas da commissão, e ahi não encontrei nenhuma das minhas especies.

Quanto ás palmeiras de que me vou occupar no referido trabalho. Taubert apenas apresenta uma Geonoma nova que não é nenhuma das minhas.

E' para se notar que os herbarios de Weddell tambem estão, até hoje, quasi sem ser aproveitados, no Museu de Paris.

Portanto o resultado, que aqui apresento da minha excursão botanica póde soffrer alguma modificação. se o meu amigo, Dr. Lindmari, publicou os seus trabalhos, o que eu ignoro; mas creio que não, porque se os tivesse feito, tenho certeza que teria me enviado, como tem procedido o Sr. Malme, seu companheiro de expedição.

Em Maio cheguei á regiāo Matto Grossense, depois de ter percorrido a do Parazuay e de ver que ahi pouco tinha a fazer. Entrando logo nos meus trabalhos notei que tambem na recriio brazileira a época era má, pois que havia cessado a tlo-

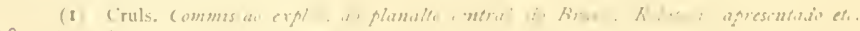

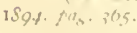

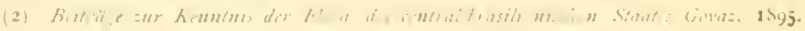


rescencia e os campos estavam seccos, estragados pelo gado ou destruidos pelas queimadas, que principiavam a devorar extensas regiōes.

Apezar d'isso. consegui algum resultado de utilidade para o jardim, que dirijo, assim como para a sciencia; pois foi augmentada com mais algumas observações e mais algumas especies que, acredito, sejam novas.

Foi pelos campos e pelas margens dos rios Paraguay, S. Lourenço, Cuyabá, Coxipó, Aricá, S. Romão, da Casca e outros; pelos serros calcareos do Ladario, Corumbá e Melgaço; pelos campos geraes de Cuyabá; pela serra de S. Jeronymo, gargantas da Bocayna e do Manoel Antonio, na Chapada (1): pelos serrados, capões e mattas das vertentes dos rios, que tirei o resultado que aqui apresento com o fim unico de não perder a prioridade das minhas classificações. A descripção da minha excursão botanica, publicarei mais tarde, passando a descrever aqui as plantas que encontrei e que julgo novas.

Se bem que pequena a messe, por ter sido curto e máo o tempo, comtudo assignala convenientemente a passagem do primeiro botanico brazileiro que pisou as areias auriferas das terras de Matto Grosso, pois não me consta que outro botanicamente tenha d'essas plagas, se occupado.

Podia este trabalho ter, logo após a minha chegada a esta Capital, entrado para o prélo, se não fosse querer consultar tambem o resultado botanico da expedição do Sr. Spencer Le Marchant Moore, publicada em I895, nas Transations of the Limnean Society of London, sob o titulo The phanerogamic botany of the Matto-Grosso expedition 1891-92, afim de que não fosse dar como nova alguma planta pelo mesmo botanico descoberta e classificada. Por isso, apenas cheguei pedi, por telegramma e por intermedio do Exm. Sr. ministro da Viação, ao nosso ministro em Londres, para que, com a maxima brevidade, me remettesse a referida obra. Com effeito, vinte e cinco dias Cuyabá.

(1) Esta sersa fica a $\$_{25}$ metros acima do nivel do mar e a 717 acima da cidade de 
depois a recebi e passando logo a estudal-a cheguei ao resultado de me considerar feliz, porque poucas foram as dicotyledoneas que perdi, não tendo a lastimar o prejuizo de uma só monocotyledonea.

N'essa obra (pags. 498-500), o Dr. Moore trata de poucas palmeiras, apenas dá noticia de tres que suppõe novas, sem as denominar; descreve uma como nova, que o não é, e pelos nomes vulgares trata de quatro.

$E^{\prime}$ verdade que confessa (pag. 272 , em nota), que nåo se importou com as palmeiras. Diz elle: "l did not pay special attention to this group".

Tranquillo, agora posso entregar ao publico o resultado da minha expedição, que dividi em tres partes: Relaşāo botanica, Planta Mattogrossenses nove e Palma Mattogrossenses novo. Sendo hoje de maior interesse esta familia, por ella começo a publicação.

Ordena-me a justiça e a gratidão, que antes de fechar estas linhas, não deixe de aqui perpetuar o meu reconhecimento ao Exm. Sr. Governador do Estado, Dr. Antonio Corrêa da Costa e ao seu digno irmão, o Sr. Dr. Jonas Corrêa da Costa, pelos auxilios que prestaram ao humilde escriptor, na missão que este desempenhava.

A não ser o fidalgo acolhimento, as facilidades e as informações que me proporcionaram, tão bom exito não teria a minha tarefa, pelo que posso dizer que ao mesmo Exm. Senhor cabe a gloria das minhas descobertas. Ao bom e alegre companheiro de expedição, o Sr. José de Góes Peixoto de Azevedo, muito devo pelo que fez afun de me auxiliar, facilitar e ser de utilidade os traballios por que passamos, entregues ás intemperies, ao cansaço e às fadigas; uma recordação e um aperto de mão a esses bons amigos, assim como áquelles que, como o Rev. Mlonsenhor Bento Severiano da Luz e o coronel Sulpicio. tão cavalheirosamente nos receberam sob o seu tecto hospitaleiro, nos campos da Chapada.

Seria injustiça e falta de gratidão tambem não perpetuar 
aqui o nome de um outro Matto-Grossense que, compenetrado da sua alta missão, soube dar valor a este insignificante trabalho, dando-lhe a publicidade, fazendo assim com que fossem utilisados os esforços de seus conterraneos que, sem ella, seriam perdidos. Convencido de que a importancia de um paiz nào está simplesmente nas forças materiaes e que, principalmente, a sciencia é que dá vida ás nações cultas, gentilmente apressou-se em fazer conhecidas do mundo sabio esta pequena contribuição, ordenando que fossem impressas por conta do Governo. Este benemerito foi o cidadão Ministro da Industria, Viação e Obras Publicas, o Exm. Sr. Dr. Joaquim Duarte Murtinho.

Seja me permittido dizer ainda algumas palavras sobre a familia das palmeiras, de que me vou occupar.

Nas regiões quentes e humidas em que se levantam as nossas florestas virgrens, existem madeiros gigantes, como o Giquitibá, que pela sua corpulencia querem, como soberanos, tudo avassallar: mas, tambem apparecem audaciosos cipós, que, apoiados a elles, enroscando-se nos seus galhos, pretendem disputar a sua eminencia e levam assim as suas douradas e roseas paniculas de flores acima dos ramos mais elevados. Essa louca pretenção da multidão vária de ambiciosos entretanto, desapparece ante as esbeltas palmeiras, que, naturalmente, sem auxilio ou sem apoio, são acclamadas as rainhas das florestas e dos campos: a Dea Palmaris.

Não têm ellas a corpulencia nem a força de uns, nem a flexibilidade de outros, mas têm a distincção da raça, a aristocracia da belleza, que tudo avassalla e que as torna involuntariamente rainhas do mundo vegetal.

Ellas mostram no seu porte a exuberancia e a riqueza do solo, e com os seus encantos dão a graça e a vida que se encontra no interior das nossas florestas. 
Symbolisando uma região do sylcbo, symbolisam tambem a sloria eterna, e á sombra de suas palmas se recolhem aquelles que no mundo são merecedores de altos premios, pelos seus feitos, pelo seu saber, pelas suas virtudes ou pela sua santidade.

Se no meio da veçetaçĩo florestal é soberana, nas campinas tambem tem o seu imperio.

Nos campos onde o sol crésta, a terra sécca, a humidade desapparece e o frio mata. se perdem a magestade do porte conservan comtudo o garbo, a elegancia e a altivez de sua linhagem.

Se ás vezes se nivelam ao porte do poviléo. conservam ainda assim a graça, a distinç̧ão, apanagio que as distingue á primeira vista. J'equenas, porém sempre bellas e altivas.

Nos campos, como em geral, não têm a convivencia com outros nembros da familia, aquellas que se afastam e vão viver nos terrenos elevados nunca se isolam, formam grupos de congeneres e em sociedade tudo dominam, offuscando todas as outras plantas que a seu lado apresentam um porte que mostra uma vida constrangida. Ellas, as palmeiras. participam dos effeitos do mesmo meio, mas. na disposição de sua folhagem, ostentam não soffrer e algumas se apresentam isoladas, a)taneiras e graciosas, destacando-se das companheiras para mostrar a sua força e o seu imperio. Humilde, apresenta-se entretanto uma, que parece fugir do fausto das companlueiras, e no meio das gramineas se occulta, e d'ellas se não distingue; é a pequeno Ariry, o Cocos petraca. E' a mais modesta das palmeiras; sempre pequenina, sempre se escondendo. chegando até a occultar algumas vezes as suas flores e os seus fructos no solo de que se alimenta. Da sua modestia nasce, entretanto, o realce que lìe dá o merito.

Sĩo pois as palmeiras membros de uma grande familia que tem o cunho da distincçcio, o orgulho da força e da belleza, e que se nåo confundem com a multidão que as rodeia. Se o grigante Giquitibá disputa o sceptro da realeza pela sua 
força e crescimento, a esbelta e fina Irussara, que cresce a seu lado, ergue-se á mesma altura, eleva a sua corôa acima da folhagem d'elle, com toda a elegancia. e quando o furacão o quebra e o desgalha, esta meneando airosamente a cabeça resiste á sua furia, e passada a tempestade, olha incolume e orgulhosa para os destroços que apresenta o rei das florestas e para os da sua vassallagem.

Tem como as rainhas o apanagio de protectcras dos viajantes e d'aquelles que vivem longe dos bens da fortuna ou no estado selvagem. São as arvores da vida, como as chamam os colonos da Guyana Ingleza.

São ellas que fornecem o fio com que tecem as rêdes en que descançam o corpo; que thes dão a linha para pescar, a isca para o fogo, o tecto para os abrigar, as paredes que os livra dos ventos $e$ dos animaes, os soalhos que os privam da humidade, o lenho para as suas armas, os preparos para os seus ornatos, a palha para os diversos utensilios, a cêra, o oleo e o sal com que se alumian e temperam as suas iguarias; que thes dāo a agua para saciar a sêde, o vinho para as suas festas; que os alimentam com os seus fructos e seus palmitos e até lhes fornecem remedios para seus soffrimentos e doces para seus bailes. Não ha familia vegetal que tanto oftereça ao homen. Quanto não softreria o pobre e o viajante pelas nossas selvas se não fosse a protecção das palmeiras?

O humilde escriptor d'estas linhas, quantas vezes nåo teria de passar as noites exposto ás chuvas torrenciaes, dentro das mattas do equador, se não fossem os instantaneos Mauarys ( $\left.{ }^{1}\right)$, feitos com suas folhas?!

Quantas vezes não the foi saciada a sêde pela agua $e$ pelo vinho de seus fructos! Quantas vezes não the mataram a fome os seus fructos e os seus palmitos!

Pela sua grande utilidade entram nas lendas de quasi todos os povos.

(1) Barracas que se levantam sobre duas forquilbas, feitas e cobertas só de folhas de palmeiras, principalmente do genero Attalea. 
E' considerada arvore sagrada, symbolo do sol, da riqueza, da geração. da força, da resistencia, da immortalidade. da gloria e representa assim a Deusa Victoria, a Dea Palmaris.

Se no paganismo é reverenciada, no Christianismo é abençoada. Quando Maria pelos desertos do Egypto andava foragida. levando Jesus, menino, em seus braços, foram os fructos de uma palmeira que the mataram a fome, e foran as suas follhas que the deram abrigo, pelo que seu sagrado Filho a escolheu para o symbolo da salvação eterna, declarando que com as suas palmas faria a sua entrada triumphal em Jerusalem.

São tantos os seus dotes. que Plutarco diz existir um hymno babylonico que canta os trezentos e sessenta beneficios que ellas prestam á humanidade e Garcia da Orta, nos seus Colloquios fallando das cousas necessarias á vicla humana assim se expressa em relação ás palmeiras: "Dá tantas e necessarias que não sey arvore que dê a sesta parte». E' por isso tambem que tem a supremacia sobre todos os outros vegetaes.

Esta familia, nobre e distincta, viveu entretanto obscura por muitos annos; foi preciso que um membro dos mais proeminentes, tambem da aristocracia do genio e do saber, com ella se encontrasse, para que, tomando-a em suas mãos, the assignalasse o logar saliente que devia occupar na natureza.

Appareceu o mais eminente botanico que tem vindo ao Brazil, o Dr. Carlos Frederico von Martius, e póde-se dizer, com elle appareceram essas formosas phanerogamas. Linneo nåo conheceu mais do que quinze especies, e foi só depois do palmographo bavaro que surgiram os admiradores das soberanas das mattas. Appareceram Blume, Ruiz e Pavon. Liebmann, Hooker, Wendland, Beccari. Drude e outros. As palmeiras principiaram então a ser procuradas com intęresse.

1) Asia, da Africa, da Oceania e da America sahiram dos seus reinos desconhecidos, para tornarem-se o ornamento das estufas reaes e dos jardins publicos e particulares de todo 
o mundo, offuscando sempre com os seus dotes as outras plantas que, com as suas bellas flôres e com seu aroma, prestam-lhes homenagem a fim de melhor realçar a supremacia que the reconhecem.

As palmeiras do Brazil, encanto de nossas mattas, por sua vez tiveram as attenções dos homens cultos e começaram a ser raptadas para os jardins da Europa, onde foram conhecidas pela monumental obra do mesmo Dr. Martius. (1)

Era crença geral que a sua monographia encerrava todo o thesouro do Brazil e que todo o palmetum brazileiro ahi estava descripto, pois suppunha-se impossivel que novas palmeiras houvesse e que tivessem escapado ao operoso viajante. Não obstante no campo virgem que havia sido por elle explorado, appareceu depois o Dr. Ricardo Spruce, e, só no Amazonas, encontrou elle novas especies, com o que parecia ter assim feito conhecidas, então, todas as palmeiras do Brazil.

Entretanto, quanto ainda n'esse campo havia por fazer! Tomei então sobre meus hombros o pesado encargo de respigador e de fazer com que o Brazil, que apresenta a primeira flora do mundo, não deixasse tambem, de nas palmeiras ser o primeiro. Dediquei-me ao seu estudo, e n'estes 25 annos, lutando com os maiores sacrificios, devassando as mattas e os campos, as serras e as vargens; varejando sertōes, pantanaes e desfiladeiros; exposto ás intemperies, curtindo a sêde e a fome, aftrontando os perigos dos animaes ferozes e o furor dos indios; percorrendo assim todo o valle do Amazonas desde as fronteiras; explorando todos os affluentes deste grande rio e transpondo as suas cachoeiras, entrando pelos sertões do interior do paiz, chegando assin até Matto Grosso, depois de dar toda a volta do Brazil, consegui sobraçar o estudo de cento e trinta e quatro especies novas, desconhecidas á sciencia, que pelos seus cultores têm sido recebidas.

Eu que, de mui longe, seguia as pegadas de Martius, o

(1) Ginera at Species Falmarum, MDCCCXXI11. 
palmographo que mais especies tinha descoberto no Brazil, e que occupou sempre o primeiro logar, tambem pelo seu saber, aos poucos d'elle me approximei e consegui alcançal-o na parte numerica das especies.

Elle colheu a messe de un campo inexplorado e virgem, eu respiguei n'um terreno trabalhado.

O seu patrimonio, adquirido no Brazil, contem cento e vinte e oito especies, salvo engano, e no que eu vou formando já tenho um computo que sóbe a cento e trinta e quatro todas por mim encontradas e estudadas nos logares em que crescem expontaneamente (I).

Até 1878, segundo o palmographo Wrendland (2), cxistiam classificadas I.o I especies, comprehendendo 45 minhas, disseminadas por todo o orbe; porém hoje esse numero deve-se elevar a quasi 1.200 , sendo um terço d'essas especies pertencentes ao Brazil. Pelos ultimos trabalhos estão já determinados 4 io especies brazileiras, e pode-se dizer que representam só o trabalho de dois homens, porque apenas cincoenta e uma foram descobertas ou descriptas por diversos outros estudiosos, como melhor se verá na lista que aqui junto.

Orgulho-me por isso, como brazileiro, porque doía-me n'alma ver que todas as nossas palmeiras, até 1872 , tinham sido descobertas e descriptas por estrangeiros, embora amigos do Brazil, e sentia não ver o nome de um brazileiro ligado a individuo algum dessa explendorosa familia, que tanto amo.

As que agora apresento não são todas as que existem em Matto Grosso, apenas relaciono as que encontrei e de que collhi specimens.

Perguntar-me-hão, talyez, os incredulos, os partidarios e amigos de enviarem plantas para serem na Europa classificadas: - Como tendes certeza de que essas especies sejam novas, se naio confrontastes nenhum herbario europeo?

\footnotetext{
1) Iide a relaça das que tersho publicado c que apresento no fim devte trabalho (2) Kerchoven. J.es Iirlmiers, pag. 230.
} 
-Tenho, convictamente responderei, tenho, e não confrontei herbarios. porém passou-me vivo, pelos olhos e pelas mãos, todo o palmetum de Nartius e quasi todo o dos outros botanicos. Não confrontei rebotalhos seccos e incompletos; para identificação, servi-me de seus troncos, vi as plantas como a natureza as apresenta, abriguei me debaixo de suas folhas, saboreei os seus fructos, apreciei o aroma de suas flores, e tambem soffri o effeito doloroso de seus espinhos. Essas filhas queridas as tenho retratadas nos seus menores detalhes e me acompanham, e dia virá em que saiam á luz da publicidade.

Se parece aos incredulos desconhecerem isso, por minha vez dirci: - Perguntae a Bentham. a Hooker, a Wendland, a Parlatore, a Beccari, a Trail, a Kerchoven, a Drude, a Kuntze. a Wawra, a Baillon e a outros; consultai o Index Keruensis e todas essas auctoridades que representam a Inglaterra, a Allemanha, a Italia, a Escossia, a Belgica, a Prussia, a Austria e a França vos responderão, tendo por interpretes o sabio Beccari, quando creou o genero Barbosa: "Colgo quindi l'occasione che mi si presenta, di distinguere questa nobile palma col nome del signor J. Barbosa Rodrigues, distinto botanico braziliano e conoscitore profondo delle Palme del suo paese " (I), ou o Dr. Wawra von Fernsee, quando na sua auto-biographia faz esta referencia: "Un autre botaniste, le fameux palmo et orchidologiste Barbosa Rodrigues »(2).

Alonguei-me, e contra minha vontade tive de fallar de mim, o que nunca fiz, porém não me vituperem, circumstancias especiaes me obrigam a assim proceder, pelo que peço desculpa.

Ao apresentar-me no Rio de Janeiro depois da expedição á Matto Grosso, fui recebido por desgostos, que me fizeram assim exprimir-me, mas esses não impedirão que eu, com ufania, possa dizer:

(I) Malpighia. Anno I. Fasc. VIIT. pag. II.

(2) Morren et Fonsny. Lés Bromeliacées Brésiliennes, ISSI, p. 38. 
- Tomai, patricios meus, mais um punhado de palmas novas, que respiguei nas plagas Matto-Grossenses, para que não preciseis perguntar a estrangeiros quaes as riquezas que possuimos.

Estas palmeiras ides conhecel-as folheando as paginas d'este livro.

VALE.

Jardim Botanico do Rio de Janeiro, em 5 de Setembro de 1897 . 


\section{PALMAE MATTOGROSSENSES}

Ord. PALMAE Mart.

Fam. CORYPHINEAE Mart.

Gen. Copernicia Mart.

COPERNiCIA CERIFERA Mart. Palm. Orbign. t . t. $1 . f \cdot 3$ et XYIV. et Hist. Nat. Palm. III. $27_{2}$; Kunth Enum. Plant. III. 273. ; Walp. Ann. bot. syst. V. p. 817; Grisebach. Symb ad flor. Argent. p. 283; Wendl. in Kerch. Les Palm. p. 241. Drude Flor. Bras. III. p. II p. 547, t. CXXVIII. Morong Ann. of the N. York Acad. of Scienc. V'II. p. 245 .

Coripha cerifera Mart. Palm. Bras. 56 t. 79 , 50 ct sappl. 50 A. $5 t$ f. 5. M. A. Macedo Not. sur le palm. Carnauba, $\quad 1567$.

Encontrei esta bella palmeira, a que Arruda Camara deu o nome de Coryphat, com o nome de Carandí, pelas margens do Rio Paraguay, formando extensas florestas de milhões de exemplares.

Póde-se dizer que quasi toda a região do Chaco (1) é exclusivamente occupada por ella. Encontra-se de todas as alturas, vivendo socialmente. Milhões são derrubadas pela industria e queimadas pelo fogo dos campos, que ás vezes se extende por muitas leguas, porém, apezar disso as florestas continuam com. pactas. Tres variedades são conhecidas pelos naturaes,que não são mais do que differentes épocas da vida. Designam pelos nomes

(I) Não significa banhado, charco, pantano, como se pretende ; é uma corruptella do quichua Chacâ que quer dizer ajuntamento, comparhia. Teve essa regiåo paraguaya esse nome porque foi nella que se reuniram as tribus que fugiram do Perú, ante a conquista Inca e a dos hespanbóes. 
de Palma negra, l'alma colorada e Palmablanca, as tres idades, as novas. as adultas e as velhas, que se distinguem pela côr do Lenho preto, avermelhado e branco. Entretanto, pelas differcnças que estes estados apresentam tambem na folhagem, o 1)r. Morong consideroutas especies distinctas e conservou o nome de Coponicir corifora, para a palma negra, denominando C. alba, á blanca, e C. rubra á colorada.

O Carandí. que é a mesma Camauba do Ceará e do Maranhào. é uma das palmeiras que por si só fornece ao homem tudo quanto precisa. Entretanto no Paraguay só é empregado o lenlo e não se aproveitam do tomento das follas novas e grelos (mangará) para a cêra; apenas das follas fazem abanos, chapéos e outros objectos. Devo aqui fazer sentir que o nome carandá foi modificado no Amazonas para Caraná e no Ceará para Camanba; aquelle designa hoje uma Mauritia, e perdeu pela pronuncia tupy o $d$ que sempre sôa no karany. Carmauba tambem é uma corruptella e já não designa o fructo e sim a arvore. Carnauba significa Camanbcira, isto é Carandá o fructo desse nome e $y b a$ ou $u b a$, a arrore. Carandayba ou Carandáuba. pela pronuncia portugueza, é orthographia correcta, mas que fizeram estropiando Caranáuba e hoje Camanba (I). Noticia circumstanciada desta palmeira, dá o dr. M. A. de Macedo. na sua Memoria sobre a Carnauba, publicada á parss. 281 , do volume $4 .^{\circ}$ (nova serie) do Auxiliador da In-

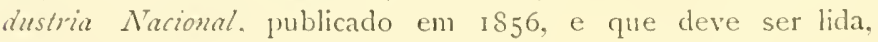
pelo proveito que pode tirar d'ella a industria de Matto Grosso.

Esta especie extende-se até Matto-Grosso onde não è tão abundante.

O nome Carandá é applicado tambem á Trithrinar Brasilicnsis Mart., do Rio Paraná e Rio Grande do Sul.

1) 6) nome (aranili heje applicado a estas palneiras nio klesignava rutrora a me:ma.

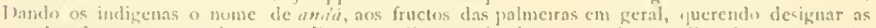

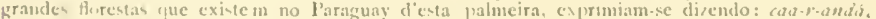

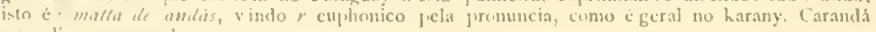

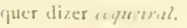


Fam. Lepidocakyeat Mart.

Gen. Mauritia L. fil.

MAURIlia VINIFERA Mart. Palm. Bras. t2.t. 39,$39 ;$ Palm. Orbign. 20. l. 13 et 21 .; Kunth Enum. Plant. III p.2I7; Walp. Ann. Bot. Syst. V. p. S3t; Wendl. in Kerch. Les Palmicrs, p. 25I; Drude, in Flor. Bras. III. p. II, pag. 291. t. LXII. f. III., LXIYII, f. III.

Vulgarmente é conhecida esta util e proveitosa palmeira pelo nome de Burity ou Bority, corruptella de Mbority, d'onde veiu tambem o nome de Murity, dado no Pará á Manurita flixusa, que tambem já fazem Mirity. Mbmily quer dizer o que contem agna, liquido, de Mbró, que contem e ly, agua; com effeito é uma das grandes utilidades d'essa palmeira e donde the veiu tambem o nome scientifico de vinifora. Muitas vidas salvou esta palmeira, saciando a sede do nosso exercito da expedição de Matto Grosso, durante a guerra do Paraguay.'

Nos campos geraes e aridos, quando se avista uma d'essas arvores protectoras, produz o mesmo effeito de um oasis no Sahara, pode-se dizer: "vamos encontrar agua ». Com effeito, sempre junto se encontra alguma fonte ou regato, e quando este esteja secco, encontra-se no seu espique o liquido bastante para saciar a sede de muitos homens. A esta quadra melhor o nome de Arare do viajante do que á Rivennalla Madagascariensis, porque esta só contem nas vaginas de suas folhas o deposito das aguas pluviaes, emquanto que a palmeira brazileira contem en si um reservatorio proprio para todo o anno.

Encontrei grandes borityzaes, então com fructos, quasi maduros, perto de Villa Mendes, aquem do Rio das Areias de S. Miguel, e alguns pés na Serra da Chapada. 
Fam. ARECACEAE Mart.

Gen. Geonoma W'ild.

Sect. scuistospadix Trail.

1. GEONOMA CHAPADENSIS Barb. Rod. Caudex gracilis caespitoso clenso annulatus. Foliis aqualiter pinnatifissis, petiolo quam foliolis majore, foliolis 4-jugis, extimis minoribus, tribus falcato longrissime acuminatis cum uno alterove uninervi intermixtis lineari-acuminatissimo. Spadix paniculatis foliis quadruplo brevior pedunculo spathas minutas breve excedente compressi, rachi ramos inferiores ramificatos et apicales simplices breves mucronatos.

Tab. I.

Caudc $x \quad 2^{\mathrm{m}} \times \mathrm{O},{ }^{\mathrm{m}} \mathrm{O} 25 \mathrm{lg}$., annulis $0,{ }^{\mathrm{m}} \mathrm{O} 4$ inter se distantibus. Folic $10-12$ contemporanea, ${ }^{\mathrm{I}},{ }^{\mathrm{m}}-1,{ }^{\mathrm{n}} 30 \mathrm{lg}$., atroviridia ; vagina $0,{ }^{\mathrm{m}} \mathrm{O} 1-\mathrm{O},{ }^{\mathrm{m}} 15 \mathrm{lg}$., petiolus $0,{ }^{\mathrm{m}} 5 \mathrm{O}-\mathrm{O},{ }^{\mathrm{m}} 7 \mathrm{O} \mathrm{lg}$., super concavus. foliolis inferiore $0,50 \times 0.08 \mathrm{lg}$., S-10 nervis, (Ang. 60..$^{\circ}$, lineare $0,45 \times 0,015$ lg., uninervis, (Ang. 60. ${ }^{\circ}$ ); medio $0,{ }^{\mathrm{m}} 55-0,{ }^{\mathrm{m}} 11 \mathrm{lg}$., 9-10 nervis, (Ang. 50. ${ }^{\circ}$ ). superiore $0,{ }^{\mathrm{m}} 35 \times 0,{ }^{\mathrm{m}} 10 \mathrm{lg} ., 12$-nervis, (Ang. 40. ${ }^{\circ}$ ). Spallics lanceolatis, obtusis, exteriore $0,10 \mathrm{lg}$., interiore $0,{ }^{\mathrm{m}} 09 \mathrm{lg}$., cinnamomeo tomentosis. Spadices tam masculi quam fominii in una eademque stirpe, fusco tomentosi 2 in eadem planta infra folia evoluti; pedunculo asper, erecto, o, ${ }^{\mathrm{m}} \mathrm{l} 3 \mathrm{lg}$., ad basin cinnamomeo tomentoso, compresso; rachi $0,{ }^{\mathrm{m}} 10 \mathrm{lg}$., rami 10-19 laxe inserti, inferiores longe pedicellati et $2-4$ furcati, superiores simplices $0,{ }^{\mathrm{m}} 25-0,{ }^{\mathrm{m}} 27 \mathrm{lg}$., alveoli in interstitiis $0,{ }^{\mathrm{m}} \mathrm{OO} 5$ separati, laeviter immersi, labio emarginato. Flores masc. rami diametrum aequantes; sepala lanceolata. obtusa, concava, extus gibbosa, marginibus minutissimis fimbriatis; petala subdupla majora, oblongo-lanceolata, subacuta, concava; urceolo staminali filamentis subaequilongo; flor. facm, non vidi. Baccac ignotae. 
Hab. rarior in Morrinhos ad Serra da Chapada, Prov. Matto Grosso. Floret Funio. Herb. n. 20.7.

Explic. ТАв. I. - I. Vista, tirada do natural, dos Dous Morrinhos, na serra da Chapada, mostrando o itambé, onde foi encontrada a Pindova. 2. Porção do espique de tam. nat.. 3. Uma folha, muito diminuida. 4. Spathas e espadice, de tam. nat.. 5. Flor macho, quatro vezes augmentada. 6. Filamentos e antheras, cinco vezes augmentados. 7 . Sepala, vista de lado, oito vezes augmentada. 8. Petala, oito vezes augmentada.

Receio que esta especie me seja levada tambem para o cortejo das synonymias, porque se a minha $G$. trijugata, que não se parece tanto com a $G$. paniculigera de Martius, foi levada para a synonymia d'esta, o que não farão com esta, cujas folhas se assemelham na disposiçāo dos foliolos, com as G. Gastoniana, Wittigima, Brognartii, Desmarestii?

Entretanto para quem as conhece do visu, no logar em que naturalmente crescem, nada têm de commum a de que me occupo com as citadas. No habitus, no tamanho, nos spadices e nas flores é inteiramente differente.

Não é o pruriclo, de fazer especies novas, porque, mercê de Deus, já centenas de plantas perpetuam o meu nome, e não será mais uma que influenciará na minha vida. As que já tenho chegam para dar nome a mais de um botanico.

Ven este cavaco a pello, porque n'esta familia, tenho sido infeliz; muitas especies têm servido para dar nome a outros e como não quero ver mais uma perdida, de antemão previno.

Encontrei esta especie crescendo em soqueiras no logar denominado Mominhos, na serra da Chapada, nas bordas de um profundo itambé (') coberto de luxuriante vegetação que cobria um lindo regato, que sobre rochas se espreguiçava. E' conhecida vulgarmente por Pindobinha. Em Julho florescia, porém, encontrei apenas spadices masculinos, pelo que completa não pode ser a descripção, mas, o é tanto quanto basta para o estudo comparativo e fazel-a bem caracterisada.

(1) De itá, pedra e ampé, parede, que por corruptella fizeram itá-amb̉e, itambé. Pedras cortadas a prumo, como paredes. 
2. G. ALTISSIMA Barb. Rod. Caudex gracilis elatus caespitosus remote annulatus foliis longe petiolatis, foliolis trijugatis plurinervis falcato-acuminatissimis rarius linearibus unincrvibus intermistiis. Spadix paniculatis folliis multo brevior pedunculo spathas longas excedente compressi, rachi ramos inferiores ramificatos et apicales paucos simplices exserentes, omnes divaricatos filiformes minutissime mucronatos, alveolis laeviter immersis. labio emarginato.

Tah. $I 1$.

Caudc $x$ clatus, gracilis $4-5,{ }^{\mathrm{n}}+0 \times 0,{ }^{\mathrm{m}} \mathrm{O}+\mathrm{lg}$. Foliu 11 contemporanea, erecto-patentia, congesta. $1,{ }^{\mathrm{m}} 90 \mathrm{l} \mathrm{g} .$. atroviridia, s'a siul $0,{ }^{\mathrm{m}} 25 \mathrm{lg} .$. tomento cinnamomeo adspersa, fetiolus $\mathrm{O},{ }^{\mathrm{n}} \mathrm{SO}-\mathrm{O} .{ }^{\mathrm{m}} 9 \mathrm{O}$ Ig., super concavus, foliolis trijugatis, phurinervis, inferiore $0,{ }^{\mathrm{m}}$ 70X0, ${ }^{\mathrm{m}} 10-0,{ }^{\mathrm{m}} 12 \mathrm{l}$ lis., utrinque 9-10-nervis, (Angr. $\left.30^{\circ}\right)$. medio $0.65 \times 0,{ }^{n 1}{ }_{3}-0,{ }^{m} 1+1 r .$, utrinque $10-12-n e r v i s$, (Ang. 30."), superiore $0,60 \times 0,{ }^{\mathrm{m}} 12-0,{ }^{\mathrm{m}} 13 \mathrm{lg}$., utrinque $12-$ nervis, (Ang. 48."). Spadices $0,{ }^{\mathrm{m}} 20-0,{ }^{\mathrm{m}} 23$ lg., cinnamomeotomentosi ; pedunculus compressus, erectus, asper, $0,{ }^{\mathrm{m}} 20 \mathrm{lg}$., spathis longis. $\left(0,{ }^{\mathrm{m}} \mathrm{I} 6\right)$ lanceolatis tomentosis, rachis $0,{ }^{\mathrm{m}} 12$ lg.: rami 20 arcuati, inferiores longe pedicellati $3-+$ furcati. $0,{ }^{\mathrm{m}} 20 \log$. supremi simplices; alveolis in interstitiis fere 0 , ${ }^{\mathrm{m}} 006$ superpositis, per spiram 2 dispositis, labio breviter emarginato. Fores masc. sepala apice purpurascentia lanceolata. subacuta, concava incurvata; fotala sepala aequalonga, oblonga ad basin attenuata, subacuta, concara: fam. non vidi. Baccac subrotunda, $\mathrm{O}^{\mathrm{n}}, 009$ in diam., atroviolacer.

Has. in silíis Capão secco, ari Serra da Chapada. Pros. Matto Grosso. Floret. Funio. Herb. n. 210. Pixironsma incolorm.

Jixhle. Tar. II. - 1. Purģio do espieque, de tam. nat.. 2 a. 2 b. $2 \therefore$ Fulhas de un mesino exemplar, sendo at commum, b raro. c c rarisimo, muit diminuidas. 3. Spathas e espadice, com fruclos, tam. nat, ; 4. 5 e 6 Sepalos seis vezes augmemados; 7 , S e 9 Petalas, sein veres augmentadis. 
O polymorphismo das folhas é notavel na Geonoma paniculigera, apresentando em uma só soqueira exemplares que destacarlos, serão facilmente tomados por palmeiras differentes, quando pertencem a um só pé. nascido de uma semente. A especie de que me occupo é uma em que tambem as folhas são polymorphas, não tanto como a paniuligera, mas apresentando em uma só soqueira tres fórmas de folhas, das quaes facilmente se conhece qual o typo predominante, porque raras são as modificações. Assim a fig. a, da Est. II., é o typo commum e que caracterisa a especie, que degenera ás vezes no typo $b$ e mui raras vezes no $c$. E' uma especie de folhas trijugadas. mas não se confunde com nenhuma das que citei, tratando da $G$. Chapadensis, das quaes se distingue logo pela sua elevação e grossura do espique.

Esta nova especie encontrei, no logar denominado Capão secco, formado de alta e humida floresta, á sombra da qual crescia em soqueiras, de longos espiques, que disputavam a luz pelos claros das gallhadas das arvores. Estava em Julho com fructos, que não tinham attingido a completa madureza.

Vulgarmente tem o nome de Pindobinha, commum á todas as Geonomas em Matto Grosso como o de Ubimrana, no Ama. zonas.

Das follhas se aproveitam os naturaes para forrarem os cestos de farinha. 
Gen. Enocarpus Mart.

1. CENOCARIUS DISCOLOR. Barb. Rod. Caudex procerus cylindricus gracilis nudus foliis distich is subscrispatis, petiolis et basi latissimâ brevissimé vaginante, abrupte angustatis longibus, foliolis per 2-6aggregatis oppositis vel alternis suberectis et deflexo-pendulis linearibus vel late linearibus acuminatis supra nitentis subtus glaucis. Spadix ferrugineo pulverulentus ferè maximus, ramis longissimis supra pedunculum subito deflexo-pendulus rectis ad apicem attenuatis, petalis masc. oblongis acutis concavis.

Tab. III.

Candex $\mathrm{S}^{\mathrm{m}} \times \mathrm{O}^{\mathrm{m}}, 15 \mathrm{lg}$., cinereo-fuscus, leviter annulatus, annulus $\mathrm{O}^{\mathrm{m}}, \mathrm{O}_{3}-\mathrm{O}^{\mathrm{m}}, \mathrm{O} 4 \mathrm{lg}$. cicatricis foliis xquantibus. Folia 10 contemporanea in comam flabelliformem dense congesta, $4^{\mathrm{m}}, 40 \mathrm{lg}$., arcuata; vagina lanceolata, dorso sub-gibbosa, $\mathrm{O}^{\mathrm{m}} .25 \mathrm{lg}$.; petiolo super-canaliculato, cinereo-tomentoso, $\mathrm{I}^{\mathrm{m}}, 20 \mathrm{lg}$.; rachis subtus convexa, bifacialis, supra sub-concava. versus apicen carinata; foliolis inferiores $\mathrm{I}^{\mathrm{m}} \times \mathrm{O}^{\mathrm{m}}, \mathrm{O} \mathrm{l} \mathrm{lg} . \mathrm{s}$ medio $1^{\mathrm{m}}, 10 \times \mathrm{O}^{\mathrm{m}}, 55 \mathrm{lg}$., superiores $\mathrm{O}^{\mathrm{m}}, 30-\mathrm{O}^{\mathrm{m}}, 40 \times \mathrm{O}^{\mathrm{m}} .015 \mathrm{lg}$. acuminatis. supra atroviridis, nitentis, subtus glaucis, nervo medio superne prominulo satis robusto. Spatha decidua, exteriora lignosa, lanceolata, acuminata, ferrugineo-tomentosa, $\mathrm{O}^{\mathrm{m}}, 50 \times \mathrm{O}^{\mathrm{m}}, 20 \mathrm{lg}$., interiora lignosa. lineari-lanceolata. longe mucronata. ferrugineo-tomentosa, $\mathrm{O}^{\mathrm{m}} \cdot 7 \mathrm{O}-\mathrm{1}^{\mathrm{m}} \times \mathrm{O}^{\mathrm{m}}, 45-\mathrm{O}^{\mathrm{m}}, 50 \mathrm{lg}$.; spadix infra foliis insertus pendulus; rami plurimi. secundi. deflexo-penduli, $0^{m} \cdot 50 \mathrm{lg}$. in ima basi ad longitudinem $0^{m} \cdot 05-0^{m}$. I floribus destituti. Flores dense dispositi, masc. sepalir minima, lanceolata, acumiuata; pelala multo majora, oblonga, acuta, concava; stamiubus inclusis petala demidio minoribus; anthera 6 , lineares, obtusa, ad basim biloba'; germinodio trifido: fam. non vidi. Buacca ignotie. 
$\mathrm{HAB}_{\text {a }}$ in silvis humidis Morrinhos ad Serra da Chapada, prov. Matto Grosso. Floret junio. Pinnona ab incolis denominata. Herb. n. 239.

Explıc. TAB. III. - I. Porte muitissimo diminuido. 2. Uma porção do rachis da folha, para mostrar a inserção dos foliolos, tam. nat. 3. Uma porçà da parte média de $u m$ foliolo de tam. nat.. $4,+a, 4 b, 4 c,+d,+e$. Mostram córtes transversaes do peciolo (4) e do rachis, de tam. nat.. 5. Spathas, dez vezes diminuidas. 6. Uma porção de um ramo, com flores novas. 7. Uma flor masc, na anthese, quatro vezes augmentada. 8. Calyce, oito rezes augmentado. 9. Petala, oito rezes augmentada. Io. Um estame, seis vezes augmentado. 11. Germinodio abortivo, quatro vezes augmentado.

Herborisava nos campos da Chapada, quando, ao chegar a dois morros que entre si formam um profundo desfiladeiro (itambé), no logar denominado Norrinhos, quando avistei, por entre as ultimas ramas das grandes arvores, que do fundo se erguiam, a bella fronde em forma de leque d'esta especie. Corri para ella, lembrando-me saudoso das bacabeiras (CE. distichus) do Pará. e admirado de ver em zona, clima e altitude tão differente crescer esta bella palmeira. Não tinha fructos, apenas espadices com flores. Observando-a cuidadosamente, o seu habitus, e comparando-a com a que a memoria me perpetuava das tantas que vi em diversos lugares do Pará, achava differença, e perguntei a mim mesmo, será a R. tarampabo?

Mais tarde, estudando-a pelas descripções e desenhos de Martius. no seu Palmetum Orbignyanm e nos seus Genera et species Palmamum, comparando as descripções de Drude, na Flora Brasiliensis, e com os meus desenhos, de tamanho natural e coloridos, feitos d'après nature e com as minhas descripções encontrei differenças. Á primeira vista pelo habitus se podem confundir, como se confundem a Mauritia vinifera com a $M$. flexzosa, porém um exame minucioso faz com que se affastem e não se identifiquem.

Os meus desenhos da $C$. distichus são feitos em 1872, por exemplares colhidos em Itaituba, no rio Tapajós.

Uma falta noto nos desenhos de Martius, quer nos do 
Palmetum, quer nos dos Genera, a de nảo representar a maneira pela qual se inserem os foliolos. I disposição d'elles e a fórma que toma a inserção é um bom caracter. Comparando, porém, os meus desenhos, vejo uma differença palpitante entre as cluas especies. Na especie Matto Grossense, os foliolos se prendem ao rachis directamente pelas laminas; emquanto que na Paraense os mesmos formam entre a lamina e o rachis uma protuberancia de cór differente, protuberancia. esta. sulcada que é tambem commum nos Astrocaryuns. Postos que os foliolos tenham a mesma largura, comtudo a fórma por que terminam é differente. No Qinocarpus distichus as pontas são agndas e na especie de que me occupo acuminadas. Estudando eu ambas as especies, vivas. examinando muitos exemplares, que desenhei escrupulosa e fielmente, com o olhar observador de botanico e desenhista, penso que não será facil o engano. As especies são distinctas e passo aqui a estabelecer a comparação cutre as duas especies, unicas do genero da seç̧ão qlie Drude denominou Distichophyllum, com a de que trato.

\section{CENOCARPUS}

\begin{tabular}{|c|c|c|}
\hline distichus Mart. & Tarampabo Mart. & discolor Barh. Rod. \\
\hline $\begin{array}{l}\text { ('. uiter cxcelsus, fracilimus, } \\
6^{\mathrm{m}}-12^{\mathrm{m}}>\mathrm{O}^{\mathrm{m}}, 22 \mathrm{lg} \text {. }\end{array}$ & $\begin{array}{l}\text { Carudex crasse cylindricus, } 8^{\mathrm{m}}- \\
-9^{\text {m }} \mathrm{lg} .\end{array}$ & $\begin{array}{l}\text { Candex excelsus gracilinsus } \\
\quad 6^{\mathrm{m}}-8^{\mathrm{ata}} \times \mathrm{O}^{\infty}, 15 \mathrm{lg} .\end{array}$ \\
\hline $\begin{array}{l}\text { Jilis crispatis, } 10-15 \text { dence } \\
\text { congesta, 5-6n } \mathrm{lg} \text {. }\end{array}$ & $\begin{array}{l}\text { Folitis concinnis } 15 \text { dense con- } \\
\text { gesta } 3^{\mathrm{m}}-4^{\mathrm{m}} \mathrm{lg} \text {. }\end{array}$ & $\begin{array}{l}\text { Filis cuncinnis } 10 \text { dense con- } \\
\text { gesta } 4^{\mathrm{m}}-5^{\mathrm{m}} \lg \text {. }\end{array}$ \\
\hline 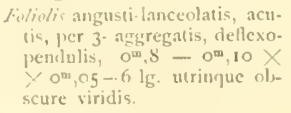 & $\begin{array}{l}\text { Filiclis lineari-lanceolatis, an- } \\
\text { guste, longe acuminatis, per } \\
25 \text { aggregatis, } 0^{m}, 4-0^{m}, 5 \times \\
\times 0^{\infty}, 02 \text { lg, saturate viridi. }\end{array}$ & 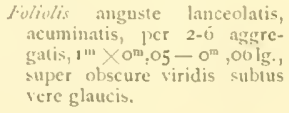 \\
\hline Spathar $\mathrm{I}^{\mathrm{m}}, 30 \mathrm{lg}$ & & Spestha $1 \mathrm{~m}$ \\
\hline $\begin{array}{l}\text { Sfutix fusco-1mulverulento, ma- } \\
\text { amus, ramis longissimis ad } \\
\text { apicem attenuatum, flexuoso- } \\
\text { turtis, } 0^{m}, 60-1^{m} \mathrm{lg} \text {. }\end{array}$ & $\begin{array}{l}\text { Spadix fusco, minot, supra jen- } \\
\text { dulum brevem subito ramifi- } \\
\text { catus, ramis strictis apjicem } \\
\text { yerus attenuatis rectis, } 0^{m}, 50 \\
\lg \text {. }\end{array}$ & $\begin{array}{l}\text { Sfadix pauci ferrugino-pulveru- } \\
\text { lento, ramis longis ad apicem } \\
\text { allentuatis rectis, } 0,40-0,70 \mathrm{lg} \text {. }\end{array}$ \\
\hline $\begin{array}{l}\text { f.hes masc. petala ollonga ob- } \\
\text { tusa. }\end{array}$ & $\begin{array}{l}\text { 1\%ores masc. petala oblonga } \\
\text { lanceolata acuta. }\end{array}$ & $\begin{array}{l}\text { fHeres masc. petala lanceolata } \\
\text { acula. }\end{array}$ \\
\hline Germunt dio trigrino, acuto. & & (irrminodio tripartito. \\
\hline 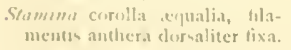 & & $\begin{array}{l}\text { Damind clemicho corolla, fila- } \\
\text { mentis lileris. }\end{array}$ \\
\hline Alutinde crecta. aliturn. & xo-pendu & Inthera merlifixa, sub saygit- \\
\hline
\end{tabular}


Pélo quadro comparativo se vê bem as differenças. A bacabeira, $C$. distichus de Martius, se estende até ao alto Tapajós, mas creio que não chega ao dirortium aquarium, para descer quasi ao baixo Paraguay, e alhi acclimar-se nos campos a mais de 700 metros acima do nivel do mar. E' verdade que Tarampabo vae a 1000 metros nos Andes da Bolivia, mas, essa não desce aos terrenos baixos das florestas do Amazonas.

Se por acaso houvesse emigraçāo, conservaria o nome proprio do Amazonas, o de Bacabar, porquanto outr'ora, como hoje, grande commercio houve entre Matto-Grosso e o Pará pelo Arinos e Tapajós. e os indios civilisados, nas monções, com as sementes perpetuariam o nome vernaculo. Entretanto tem o nome de P'intó ou Pindobr. para uns e para outros o de Pratmeira verdadeira, o que não é mais do que a traducção da palavra Karany Pinds, que significa palmeira, en geral.

Poderá ser uma variedade da $O$ E. distichus devido ao meio, e facilmente os fructos determinariam, porém. como não os vi fica, n'esta especie um ponto de interrogação.

No desfiladeiro onde foi achada encontrei mais de doze exemplares já bastante adultos e alguns ainda muito novos.

Devo notar que vi individuos dioicos sendo os espadices masculinos pela metade dos femininos. Encontrei tambem espadices munidos, de 3 spathas, sendo a terceira interna envaginante a principio e mais tarde bipartida e caduca. Esta spatha não é mais do que o desenvolvimento de uma bractea, que sempre apparece como spatha nos spadices masculinos.

Esta especie estende assim mais a área geographica do genero. vindo do Orenoco, passa pelos Andes Peruanos e Bolivianos e chega ao Sul do planalto do centro do Brazil, depois de espalhar-se pelas terras baixas do valle do Amazonas.

A bem da historia e da verdade devo dizer que esta palmeira foi vista pelo botanico Riedel, na mesma serra da Chapada, perto da villa de Guimarães, hoje freguezia de Sant'Anna da Chapada. 
No Esboso da viagem feita por Mr. de Langsdorff. pelo Sr. Hercules Florence e publicado no tomo 38 , á pag. 464 , da Rerista do Instituto Historico, diz o mesmo autor:

"Nas mattas de Guimarães, foi que vi pela primeira vez a palmeira chamada I'ndoz'a, cujas follias abrem-se n'um só plano como um leque. E' um bello typo da opulenta e magnifica familia das palneiras.

Creio que o Dr. Riedel não colheu exemplares, ou então dormem em algum herbario da Russia, sem determinação: o que não admira porque, milhares cle plantas nossas, estão n'este caso.

Se a Pindor'a vista por H. Florence, e que naturalmente tambem foi vista pelo Dr. Riedel. pois estavam na mesma commissão, fosse examinada e identificada, com os Enocarpus conhecidos, seria esse facto forçosamente mencionado pelo illustre professor 1)rude, na parte geograplica das especies, mencionadas na Flora, o que se não dá. Além d'esta especie o mesmo autor tambem vio o Uaukury e o Uauasu, que tambem não são citados geographicamente na Flora.

Creio que esta especie estende se tambem até aos altos chapadões do Municipio de Montes Claros, em Minas Geraes. porque em uma relação das palmeiras d'este lugar, da Chorographia Mincira (1), encontro esta nota: " e uma especie chamada simplesmente falmeira notavel pela bella forma de leque da folhagem."

(1) Renista do Archivo fublico Minciro. Anno I1. 1S97, Fasc. 3. pas. 576. 
Fam. COCOINE E Mart.

Gen. Cocos Linn.

Sect. Eu cocos Dr.

13. Endocartio lapideo intus gibboso, monospermo, albumen aeyuabile

COCOS ROMANZOFFIANA Chamisso in Choris, Ioyage pitt. autour du monde, p. 5. V et VI (1822) et in Flor., VI. (1823) par. I, 226. - Mart. Ilist. Nat. Palm.. II p. 127, tab. S8. p. VII. et III, p. 321. - Kunth. Enum plant. III, p. 286. - WValpers Ann. bot. sjst., 5, p. Sz3. - Wendl. in Kerch. Palm. p. 241.-Hook. Rep. R. G. Kéw, ISS2 p. 241. - Drude in Mart. Flor. Bras. III, p. II, p. 419, tab. XCII. - Becc. in Malpighia I, fasc. VIII. p. 25, n. 19. Cocos austrilis Mart. Palmet. Orbig. (1847) p. 95, tab. I, f. 2 et tab. 30 C.; Mlist. Nat. Pulm., III. p. 289. et 324. - Walp. Ann. bot. syst. 5, p. 823.-Wendl. in Kerch. Les Palm. 240. - Drude Mart. Flor. Bras. III, pag. II. p. 420. - Hook. in Report. R. G. Kew. I882 (1884), p. 72. -Beccario in Malpigthia I fasc. VIII. pag. 26. - Morong. Plant. coll. in Paraguay Annal. of the N. Iork. Acad. of Scicn. VIII. (1 893 ). pag. 245.

Cocos plumosa Hook f. in Bot. Mag., t. 5180 (1860) et in Rep. R. G. Lew I\$S2, p. 72. Wendl. in Kerch Les Palm., p. 241. - Drude in Mart. Flor. Bras., III, p. II. pag. 412. Becc., in Malpigh. I. fasc. VIII. p. $2 S . n .^{\circ} 22$ ?

Cucos Datil Grisebach et Drude in Griseb. Symb. Fl. Argent., 1879, p. $2 S_{3}$ - Drude in Mart. Fl. Bras. 111, p. 11, p. 4I9, tal, XCIII.- Becc. in Malpigh. I. fasc. VIII, pag. 27, n. ${ }^{\circ} 21$ ? ?

Cocos geribá Barb. Rod. Protest. app. p. 43. (1879). Les Palmiers, p. 27 f. 6. in tab. physiogn. et tab. III, f. 5 a, b, c et fig. 6, a, b. (ISS2). Drude Flor. Bras. III. p. II. p. 703 , in clavis analyp. Beccario. Malpigh. I. p. 28. 


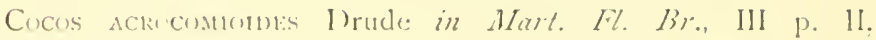
pag. 409, tab. LXXXVII, f. IHI. - Becc. in Malpigh., VI, fasc. V'Ill, pag. $28,11 . " 23$ ? ?

Cocos maktiana Drucle et Glz. in Mart. F\%. Br., III. p. II, pag. +18 .

Tab. II: Frontispicio.

Expre. 'Tas. 1V. - A. I'orte do Geribi, de Minas Geraes e S. L'aulo. $\mathrm{A}^{\prime}$ 1, I a. II 3. 3 a. Fructos do mesmo B. Porte do Gerizía de Nioac e Cul abá. I3' 5, 5 a. Iructos do mesmo. C. E. Purte do Babu de boi do Rio de Janeiro, c do l'inale de Assumpeçào. C' $2, \quad 2 a, \quad E^{\prime} 3,3 a$. Fructos dos mesmos. D. G. Porte do Pinló do Rio Grande do Sul e de liucnosAyres. G' is, is a. 1) 7 , 7 a. Fructos dos mesmos. F. Purte do Coco de cachorro de Santa Catharina. $F^{\prime}+4$ a. Fructos do mesmo. I. Torte do Geritui do Rio Grande do Sul, tranplantado, jí grande. J 1. I a. Fructos do Geribá cortados vertical e transersalmente e de tamanho natural.

TAa: IV A. - $\mathbf{1}, \mathbf{1} a, \mathbf{1} b, \mathbf{1} c, \mathbf{1} d$. Córtes transversaes do pectulo e do rachis, de tam. nat.. 2,2 a, meio e extremidade de un foliolo, tan. nat.. 3. Porção do rachis com dois grupos de foliolos, tam, nat.. 4. Syatha interior, 12 vezes menor. 5. Flor macho, tam. nat. 6. Calyce. 7, 8 c 9 . Petalas, tam. nat.. 10. Flor fem. fecundada, tam. nat.. 11. I mesma. duas vezes augmentada. 12, 13, 14. Sepalas, duas vezes angmentada. $1_{5}$, Petala, duas rezes augmentada. 16. Orario, duas vezes angmentado. 17. Fructo inteiro. 18. O mesmo, cortado verticalmente. 19, O mesmo, cortadu transversalnente.

Entre as palmeiras, por min collhidas no Estado de Matto Grosso, figura a especie acima, a mais vulgar do Brazil. do tropico para o Sul.

Quando descrevi o individuo, encontrado nas mattas dos terrenos montanhosos do Sul de Minas Geraes, conhecido por Geribá, e comparei-o com os que em abundancia e por toda a parte crescem no Rio de Janeiro, tomei logo. o que descrevi, como a especie selvayem, sendo a cultivacta a lo Rio de Janeiro, mas nảo encontrando descripção que quadrasse a nenhuma das especies, com grande sorpresa a tomei como nova (. como til a dei com o nome de $C$. Geribid. Tive razao para isso, apezar de me admirar como sendo tio vilgar no Rio de 
Janeiro, ponto de chegada de todos os botanicos, nem Martius nem nenhum outro a houvesse classificado. A razão é simples, a descripção de Martius foi baseada na descripção feita por Chamisso, nos terrenos salitrados da tha de S. Catharina, pelo que comparada a mesma descripção e os detalhes com os individuos que crescem no Rio e em Minas Geraes, não é possivel a identificação.

Hoje, porém, depois de correr os Estados de S. Paulo, Paraná. S. Catharina, Rio Grande do Sul e as republicas Oriental, Argentina e do Paraguay, e de ter estudado todos os inclividuos, que cobrem as mattas e as ilhas do littoral, os campos do interior e as praças das cictades, sou o primeiro a reconhecer que o meu C. Geribic não é mais do que um synonymo do C. Romanzoffiana Cham. por ser uma e unica especie.

O clima, a natureza do solo, a elevação acima do nivel do mar, tudo contribue, para que essa palmeira se apresente polymorplia.

Assim é que o Coco de safo, do Ceará, o Geribá de Minas, (Cocos Geribá Barb. Rod.); a Baba de boi, do Rio e de S. Paulo, (C. Geribá Barb. Rod.); o Gerizáa de Paranaguá; o coco de caxorro. de S. Catharina. (C. Romanzoffiana Cham.); o Geribáa do Rio Grande do Sul, (C. Plumosa Hook.); o Datil, de Buenos Ayres (C. Datil Mart.); o Pincló, do Paraguay e Montevideo, cujos fructos têm o nome de Ibá-pyttĩ, (C. Australis Mart.); todas estas palmeiras que até aqui têm sido referidas, citadas e perpetuadas como especies diversas não são mais do que uma só especie o Cocos Romanzoffiana Cham. O meio modificando o habitus, e os fructos, tem feito com que pareçam especies distinctas quando o não são.

As descripções feitas para uma variedade não se identificando com outra, occasionou essa grande synonimia. Posso garantir esta asserção porquanto em todos os estados do Brazil e em todos os logares das republicas do Sul que percorri, especial attenção me mereceu o assumpto e de todas as localidades, examinei vivas as plantas e d'ellas colhi flores e fructos, 
e procurei estudar a causa de tão grande modificação. Entre ellas concorre poderosamente a natureza do solo silicoso, ou argiloso, humido ou secco, salitrado ou não. $\mathrm{Vi}$ individuos adultos desde anãos até excelsos. Os vi nos charcos, nos campos seccos, nas praias, nas montanhas e nos logares cultivados de boas terras. Assim é que em Nioac, Matto Grosso, em lugares enxarcados e argilosos são anãos, formam grandes barrigas junto ao solo e não se elevam a mais do que á altura de um homem a cavallo, comprehendendo-se as follas. Os cachos tocam o chão. Nos campos alagados e arenosos do Rio Grande os vi altaneiros, formando grande barriga, junto ás vaginas das follas; nas praias salitradas do littoral de S. Paulo e Paranaguá, os vi tambem altaneiros porém de troncos iguaes e grossos; nos terrenos argillosos salitrados de S. Catharina, encontrei formando barrigas quasi no centro dos troncos; em Montevideo, Buenos Ayres, Currientes, Conception e outros logares, acheios iguaes aos do Rio Grande; nos logares montanhosos e pedregosos vi tornarem-se de tronco fino, excelsos e flexuosos; nas chacaras, nas praças oncle a terra é boa e bem adubada vi tomarem uma altura e grossura extraordinarias, conservando o tronco sempre igual e assim como encontrava molificação no tronco, tamben encontrava nas folhas. nas tlores e principal. mente nos fructos. Pequeno numero de folhas, disvaricadas e crespas, grandes on pequenos espadices com poucos ou muitos fructos, estes grandes, pequenos, oblongos, redondos, allongaclos, agudos, obtusos, fibrosos, nåo fibrosos, muito ou pouco mucilaginosos, com o epicarpo muito fibroso ou quasi pellicular. amarello claro, amarello de ouro. avermelhados, verdes, emfim apresentando uma variedade de forma, tendo apenas sempre immutavel um caracter, o da gibbosidade interna do cndocarpo. Vi exemplares com folhas pequenas e grandes, crespas com foliolos disvaricados e pectinados com longos foliolos pendentes, estreitos ou largos.

Passon-me pelas mãos e pelo men exame todos os Geribis, Coces de cachorro, liabas de boi. Datis, I'indós, nos proprios 
logares em que expontaneamente crescem e reconheci que todos não são mais do que variedades.

Represento aqui na Est $I V$, não só o porte, tirado d'après nature, como os fructos de algumas variedades, por oncle melhor se prova o que affirmo.

Em um trabalho meu (1) quando protestei pelo esbulho que soffri do monographo da Flora Brasilcira, fiz ver que os Cocos Martiana e acrocomiozides. nảo eram mais do que o meu Geribá, descriptos por dois exemplares cultivados no Passeio publico do Rio de Janeiro, donde foram tirados e remettidos para Europa pelo Dr. Glaziou, quando já sabia que era o meı Geribi e agora ainda aqui rectifico o que então disse.

São pois seis especies que figuravam como distinctas e que agora desapparecem, para sómente se apresentarem como cortejo synonymico do Cocos Romanzoffiana Cham.

Em resumo pode-se dizer, pelo que observei, que o C. Romanzoffiana nos logares humidos e alagados torna-se barrigudo em baixo, nos logares arenosos e salitrados em cima, nos humidos e selicosos no centro, tornando-se finos e esbeltos nos logares montanhosos e seccos e direitos e grossos nos logares cultivados.

O estudo que fiz d'esta palmeira lerou-me a estudar todo o grupo do genero Cocos, trabalho que o men amigo Beccario. sabio botanico italiano, tambem já fez, no seu estudo preliminar intitulado Le Palme incluse nel genere Cocus Linn.

Conhecendo de visz as plantas de que se compõe este genero, tendo-as visto vivas, exceptuando o C. Drudci Becc., pude organisar a ligeira chave do genero, que aqui junto, reunindo todas as especies brazileiras conhecidas, excluindo apenas as exoticas que são: na secção $E_{u}$ cocos, o $C$. nucifera, das Indias e na dos Syagrats. os C. argentca Engl., o Sancona Hook, o Chiragua Becc., da Columbia, o Orinocersis de Spruce, do Orenoco e o pityrophylla Mart., da Bolivia.

Em Matto Grosso encontra-se o Cocos Romanzoffuma nos

(I) Les Palmiers, 1882, pag. 24 et 27 . 
alagadiços de Nioac, no Rio Cuyabá e em outros logares já cultivados de sementes d'essa localidade. Em Cuyabá, por exemplo, encontra se em algumas cluacaras, mas ahi, já em terreno silicoso e secco, tomou outro aspecto, já forma tronco alto, conservando sempre uma especie de barriga junto ao solo que gradualnente afina para o apice. Ahi tem tambem o nome de Geribá. Informou me um velho soldado da gruerra do Paraguay; fitho do Ceará, que a mesma palmeira existe no Ceará com o nome de Coco de sapo. Em Buenos-Ayres dão ao fructo dos Pindós o nome Karany de Ybá-fitan, isto é: fructo vermelho.

O nome Gerybi ou Geryerí é uma corruptella, pela pro. nuncia do Karany, de $Y^{\prime}\left(r y^{\prime}\right.$ pegajoso, gommoso. e uí fructo. I a'yuli, fructo gommoso. A aspiraçăo do $y$ passou a $j$ em portuguez e d'ahi jerivá e geribá.

Na estampa IV apresento o porte de varios Geribás, assim como os fructos, que se encontram no Rio de Janeiro, Minas Geraes, Paraná, S. Paulo, S. Catharina, Rio Grande do Sul, Buenos Ayres, Assumpção e Matto Grosso.

Levei todas as formas descriptas como especie para synonymas do Cocos Romanzoffiana de Chamisso, por ser a mais antiga, tendo por isso o direito de prioridade.

Foi achada por Chamisso em 1816 na llha de S. Catharina, na primeira expedição feita á custa do Conde de Romanzoff no Rurich, sob o commando do capitão russo Kotzebue, quando veiu aos mares do Sul da America.

Entretanto o typo d'essa palmeira não é o Cocos Romanzoffiana, deve-se considerar como tal, as variedades que tem o fructo mais oblongo, que são as que se encontram nos logares virgens. O Coco de cachorro é a varieclade que mais se affasta do typo. pelas folhas e pelos fructos e pelo ventre do apice do espique. O typo não apresenta dilataçăo alģuma no espique.

Posto tenham sido representadas as variedacles que tem sido descriptas como especies aqui represento na Tab. IV, os dctalhes da variedade Matto Grossense, que completam as formas do seu polymorphismo. 
Sect. Siagrus

A. Endocarpio lapiteo intus monotituto, monospermo, albumem aquabile

AKUMA

2. COCOS CAMPESTRIS Mart. Hist. Nat. Palm., II. p. I 2 I, tab. $8_{7}$, f. I, et III, p. 324. - Kunth. Enum. P'ant. III, p. 284. - Walpers Am. bot. syst. V, p. 823. - Wendl. in Kerch., Palm., p. 241.- Drude in Mart. F/. Br., IlI, p. II, p. +14.-Hook, in Rep. R. G. Kew, 1892. p. 72.-Becc. Malpighia I. fasc. VIII, p. 22.

Tab. Ir et $T I$.

Explic: Tals. V. - Porte do Coco da serra, de Mhas Geraes, muito diminuido.

Tab. VI. - I. Porte do Akumà̃ de Matto Grosjo. 2. Porção do rachis de uma folha, com um foliolo inteiro, tam. nat.. 3. Rachis e ramo de um espadice, tam. nat.. 4. Flor macho, tam. nat. 5. Calyce seis vezes augmentado. 6. Petala, duas vezes augmentada, 7. Estames, duas vezes augmentados. 8, 9, 10. Sepalos, tam. nat.. Ii, 12 e 13 . Petalas. It. Petala vista de frente, todas de tam. nat.. 15. Androceo e ovario, tam. nat.. I6. Fructo inteiro, ז. $_{7}$ O mesmo, mostrando o mezocarpio e o endocarpio. I8. Endocarpio cortado verticalmente. I9. Fructo cortado transversalmente, mostrando os loculos abortados e a unica facha que apresenta. Tudo de tam. nat.

Commum é esta especie nos campos geraes, das chapadas das serras de Minas Geraes, S. Paulo, Groyaz e Matto Grosso, crescendo sempre nas encostas dos cerrados e dos capões, ou mesmo nos cerradões, formando ás vezes soqueiras.

Não penetra pelas florestas nem se afasta para o campo limpo. Tomam ás vezes, alguns individuos, fórmas elegantes, pela flexibilidade dos espiques; ora deitam-se para levantar apenas a fronde, ora tomam a forma espiralada, ou curvam se como serpente. As vaginas das folhas são cobertas por um alto tomento cotonoso, de mais de tres millimetros de espessura, que facilmente se destacam. Esse tomento. que é a principio, nas 
folhas mais internas, branco, torna-se depois côr de gangra e os naturaes denominam isca. porque d'elle servem.se para accencler foso.

Encontrei nos campos de Cuyabá, e nos da serra da Chapada, principalmente perto dos rios S. Romão e da Casca. onde abundan a formar mattas, nos taquaraes (Chusqueas). Tem ahi rulgarmente o nome de Acuman e nĩo Alamão como dá Drude. Em Minas dão-lhe o nome de Coqueiro do campo ou Coco da ser ra. onde encontrei muitos principalmente na chapada da serra do Agnapé e suas immediações e na serra de S. José d'El-Rey. As follhas são aproveitadas para vassouras.

Esta especie afasta-se dos seus congeneres pelo facto de apresentar o endocarpo sempre pelo lado interior uma larga facha escura em vez de ser liso ou munido de tres, como nos Eu-cocos e Syaurus, pelo que, destacando-a dos verdadeiros Syagrus. estabeleci uma sub-seç̧ão para ella, como se verá da chave analytica que aqui apresento.

B. Endocurpio lapiteo intus trizittato, monossermo, albumine aequatile.

MRIRY

3. C. I'ETRAEA Mart.. Palm. Orbign., p. roo, t. 9, f. 2. et Hist. Nat. Ialm., Ill. p. 290 et 324.-Walp. Ann. bot. syst., I, p. 1009 n. 4. V: p. $\$ 23$, n. $367 .-W$ Vendl. in Kerch. Palm., p. 241. - Drude in Mart., F. Bras. I1l, p. Il. p. 245. tab XCl11, fig. 1. - Cocos mpestris Barb. Rod., in Piot.Apf. p. 45 et Les Palmiers, p. 29.

$\$$ Mhatyphylla Drude in Mart. Flor. Bras. 111 p. Il, 1) 426. Drupa enduviata ovoidea vel subrotunda acuta. $\mathrm{O}^{\mathrm{m}}, \mathrm{OIS} \times \mathrm{O}^{\mathrm{m}}, \mathrm{O} 15$ in diam., epicarpio fibroso tomento ferrugineo tecto, mezocarpio albofibroso, indocarpio tenue ovoidco intus trivittato; semine excavata.

Tab. ITII.

Expac: Tar. V'lll. - 1. Porte muito diminuido. 2. Porte do peciolo c do rachis, tam. nat.. 3. Spathas exterior e interior e espadice com iructos, tam. nat.. 4. Flor macho, tam. nat.. 5. Calyce duas vezes angn:entado. 
6, 7 e 8. Pelalas, tam, nat.. 9. Estames, quatro vezes augmentados. 10. Flor fem., tam. nat.. 11, 12 e 13. Petalas, tam. nat.. I 4,15 e r6. Petalas, tam. nat.. 17. Androceo abortivo e ovario, tam. nat.. 18. Os mesmos, duas vezes augmentado. 19. Fructo inteiro, 20. O mesmo, cortado verticalmente. 2I. O mesmo, cortado transversalmente, mostrando as tres fachas, tudo de lam. nat.

Esta especie foi encontrada por Alcides d'Orbigny na Missão de S. Thiago, provincia de Chiquitos na Bolivia e descripta pelo sabio Dr. Martius. Achando-a em Minas Geraes, no alto da Serra da Tromba, proxima ao Rio Sapucalyy e encontrando differença, na identificação com a descripção de Martius, que, no Palmetum Orbignjanum só apresenta desenhado o porte, considerei-a nova e lhe impuz o nome de rupestris. Nais tarde verifiquei ser o mesmo petraea de Martius. Razão. entretanto. eu tinha, tanto que Drude estabeleceu tres variedades a genuimu, a platyphylla e a alpina. A especie de que me occupo é a variedade platyphylla de Drude.

Como nas descripções só sejam imperfeitamente conhecidos os fructos, que só foram vistos verdes, acima apresento a diagnose dos fructos maduros.

Encontrei pela primeira vez em Natto Grosso esta especie nos campos do alto da Serra da Chapada. completamente occulta pelas grammineas, com as quaes se confunde inteiramente; nas cabeceiras do Rio Coxipó, proximo ao Engenho Burity e depois em quasi todos os campos, com flôres e fructos maduros em fins do mez de Junho.

Em geral o pedunculo dos espadices ficam occultos no solo e só a parte florida e a dos fructos surgem á superficie. Esta mesmo as chuvas ou formigas algumas vezes cobrem de terra.

Ten em geral em Matto Grosso o nome vulgar de Haryry, do Karany Haryb, cacho e $y$, pequenino, qua foi o nome que em geral os caipiras me deram.

Cresce tambem esta palmeira nos campos de Goyaz, onde tem o nome de Acuman rasteiro, assim como, segundo Gardner, 
igualmente se encontra em Piauhy e Pernambuco. E' pois uma palmeira cuja área geographica é muito extensa.

Exple. Tar. IX. - 1. Porte muito diminuiclo. 2. Porçîs do rachis, tam. nat. 3. Spathas e espadice com fructos de tam. nat.. 4. Filor macho, tam. nat.. 5. Calyce, duas vezes augmentado. 6, 7 e 8. Sepalas. tam. nat.. 9. Estames, quatro vezes augmentados, 10. Flor fem.. 11, 12 e r 3 . Spalus. If, 15 e I6. Petalas. 17. Androceo e ovario, tudu de tam. nat.. is. (1) mesmos. duas rezes augmentados. 19. Fructo. 20. O mesmo, curtado verticalmente. 21. O mesmo. cortado transversalmente, mostrando as tres fachar, tudo de tam. nat..

E L

4. CoCos COMIOSA Mart., Hist. Nat. Palm. II p. 122, t. 8s, f. I-II.-Spreng.. Syst. I eg.. II. p. 142.- Kunth., Emum., plant. HI. p. $28+$-l)rude in Mart. N\%. Bras., III. p. II. p. tio. Hook. in Rep. R. G. Kew, 1882, p. 72.- cocos puususi (non Hooker) Lodd., Cat. - stacilis comosa Mart, Palm. Orbign., p. 134 it. Hist. Nat. Palm., III. p. 292 e 324 , tab. 166 , f. V.-Wendl. in Kerch., Palm., p. 257.-svagkus comosa Wendl., Ind. Palm., p. 38z?-Becc. in Malpi. shic I, fasc. VIHL. p. 23. n. I7.

Tab. I'TI.

Cresce esta palmeira socialmente nos campos arenosos da Serra da Chapada, campos estes que se estendem pelo planalto do Brazil até Goyaz, e ahi em varias localidades é encontrada. $\mathrm{Vi}$ em abundancia perto do Rio da Casci, nas proximidades do Rio Coxipó e do Aricá e tambem perto de Sĩo Romån.

lim geral é uma palmeira acaule, e pouco se desenvolve devido ao fogo que annualmente se lança aos campos, que a queina e atrophia, porém, em lograres que o fogno nảo chega ou aquellas já muito adultas, apresentam um longo espique flexuoso com uma pequena fronde muto elegante.

$\mathrm{Vi}$ entre milhares de exemplares acaules alguns que se destacavam com espiques de 5 a 7 metros de alto. tendo 
apenas 0,006 - o,oro de diametro, que davam aos campos um aspecto de magnificencia.

Vulgarmente tem o nome de Gariroba ou garyrobinha, por ter o seu palmito amargo. O nome é corruptella do Haryrob kiarany, que quer dizer halo, cacho, espadice, e palmito, e rob amargo.

Não se deve confundir o nome vulgar que tem com o de uma outra especie que cresce isolada nos campos geraes de Minas Geraes, principalmente nos que marginam o Rio Sapucahy, perto das Serras da Tromba e Aguapé, que é o Cocos doracea Mart. Esta é uma palmeira excelsa, de tronco grosso e fructos grandes, cujo nome é tambem Gariroba.

Cresce a especie de que me occupo, tambem em Goyaz, onde tem o nome de Gariroba do Campo. Os naturaes aproveitam o seu palmito para a arte culinaria e mesmo come-se crú, quando os pés são novos.

Em geral as crianças quando encontram um pé novo o arrancam para comerem o pequeno palmito, que é doceamargo.

A Gariroba de Matto-Grosso, tem os fructos pequenos e a de Minas, grandes. Aquella é social e dos campos e esta solitaria, entrando tambem pelas mattas.

Encontrei a palmeira em questão, com flores e fructos verdes, em Junho.

Explic. 'Tab. VII. - J. Portes da Gariroba. 2. Porção do rachis de uma folha de tam. nat.. 3. Spathas e spadice, reduzida a um quarto do comprimento, 4. Un ramo de tam, nat.. 5. Una flor macho, tam. nat.. 6, 7 e 8. Petalas, duas vezes augmentadas. 9. Estames, duas vezes augmentados. 10. Flor fem., depois de fecundada, tam. nat.. I1, I2 e 13. Sepalas, tres vezes augmentadas. I4. Corolla. I5, I6 e 17. Petalas, duas vezes augmentadas. I8. Androecio e ovario, duas vezes augmentado. 19. Fructo inteiro, tam. nat.. 20. O mesmo, cortado verticalmente. 21. Endocarpio, mostrando as tres fachas externas. 22. O mesmo, cortado transversalmente, mostrando as tres fachas internas, de tam. nat.. 


\section{Chave analyptica das secções e subsecções do genero coCoS, do Brazil}

Nor.. - Os nomes em versalete sto das especies adoptadius e os en italico os dus synonimos.

Gen. Cocos Linn.

Sect. Ev Cocos. I)r.

A Findocarpio lafidio intus leetr, albumens acquabulc

Arilury. Caudex mediocris.

Giynomicranthic.

Fructos moncispermos.

I. Cocos capitata Mart, 2. Lejuspatha Barb. Rod., 3. Schisophylla Mart. 4. Dre dei Bec. (C. Heddellii Dr.)

Intifi, Fructos a a 3 -spermos

5. C. eriospatha Mart. (C. Blumenazin Hort.), 6, odorata Barb. Rod., 7. puldona Barb. Rod.

b. Endocarpio lafictio intus sitboso, monospermo, albumem zequabile

$$
\text { Girrirí. Caudex excelsus }
$$

Gynomicrantha:

8. C. Romakgoffass Cham. (C. Anstrali, Mart, Plimose Hook., Datil Mart., Giribi lasrb. Rnd. Martiana Dr. acrocomioides Dr.

Sect. Sragrus Mart.

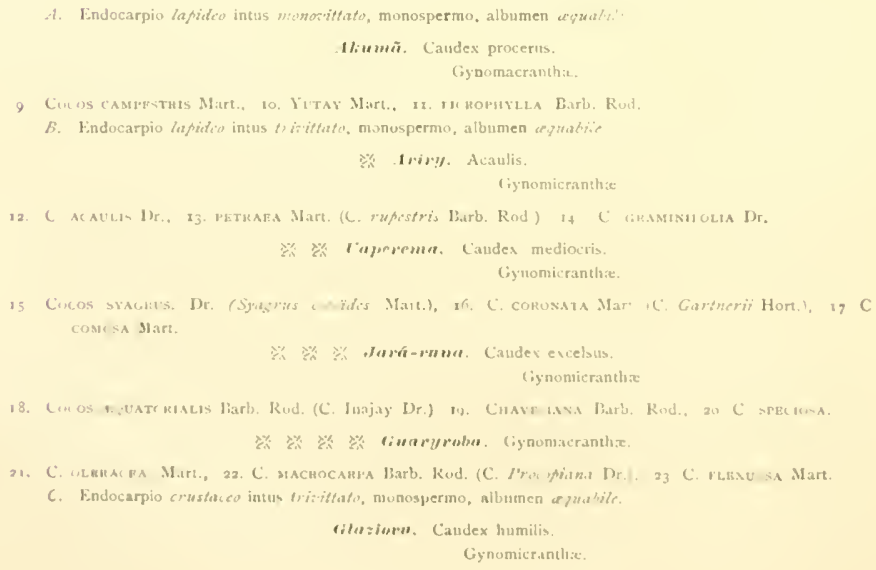


24 C. Wedelchans Wendl (Glaziova elegantissima Hurt., G. Hartiana Gl.), 25. C. INsignis Barb. Rod. (G. insigms Dr.)

D. Endocarpio osseo vel irustaceo, intus irzittato, monospermo, aibsmen rustanato

- Arikuryroba. Caudes mediocris.

26. Cocos Arinukyroba Barb, Kod. (Arisuryroba (iapunenta. Barb, Rod.)

- Birbosa. Candex procerus.

Gynomacranthe

27. Cocos Mrkaniana Mart. (Langsionffa pseudo-cocos Raddi, Barbosa fseudo cocos Bec.)

Dou em seguida uma relação dos nomes vulgares, com que são conhecidas as differentes especies, nos Estados, em que ellas crescem expontaneamente. Alguns nomes são tambem levados para outras especies, por individuos que não as conhecem bem, ou não são naturaes dos logares. 
Nomes inligenas com os seus correspoudentes scientifices co genoro

\section{Cocos Linn.}

\section{liv Cocos}

1. Cabeçudo (Minas Geraes)..... Cocos capitata Mart.

2. Coqueiro do campo (Minas Geraes).......................... C. leiospatha Barb. Rod.

3. Nikury (Bahia).................. C. schizophylla Nart.

4. l'aty (Goyaz) ...................... C. Druxci Becc.

5. Butiá (Rio Grande do Sui).... C. criospatha Mart.

6. Putiá (Santa Catharina)........ C. cdorata Barb. Rod.

7. Butiá-açú (Santa Catharina).... C. pulposa Barb. Rod.

S. Geribá (Minas, S. Paulo, Rio Grande e Matto Grosso).. Baba de boi (Rio de Janeiro). Coco de cachorro (Santa Catharina)

Datil (Buenos $\Lambda$ yres)........

P’indó (Assumpção) ...........

C. Romanzoffiana Cham.

Paty (Bahia)....

Coco de sapo (Ceará)

Imbury de cachorro (Espirito Santo)

Syagkes Mart.

9. Akumã (Matto Grosso)....... $\left.\begin{array}{c}\text { Coco da serra (Minas Ge- } \\ \text { raes) } \ldots \ldots \ldots \ldots \ldots \ldots \ldots \ldots \ldots \ldots \ldots \ldots\end{array}\right\}$ C. campestris Mart.

C. Yutay Mart.

10. I'utay (Rio da Prata).

11. Coco da quaresma (Rio de

Janciro)....................... C. picrophylla Barb. Rod.

12. Ariry (Matto Grosso) ........... C. petraed Mart. 


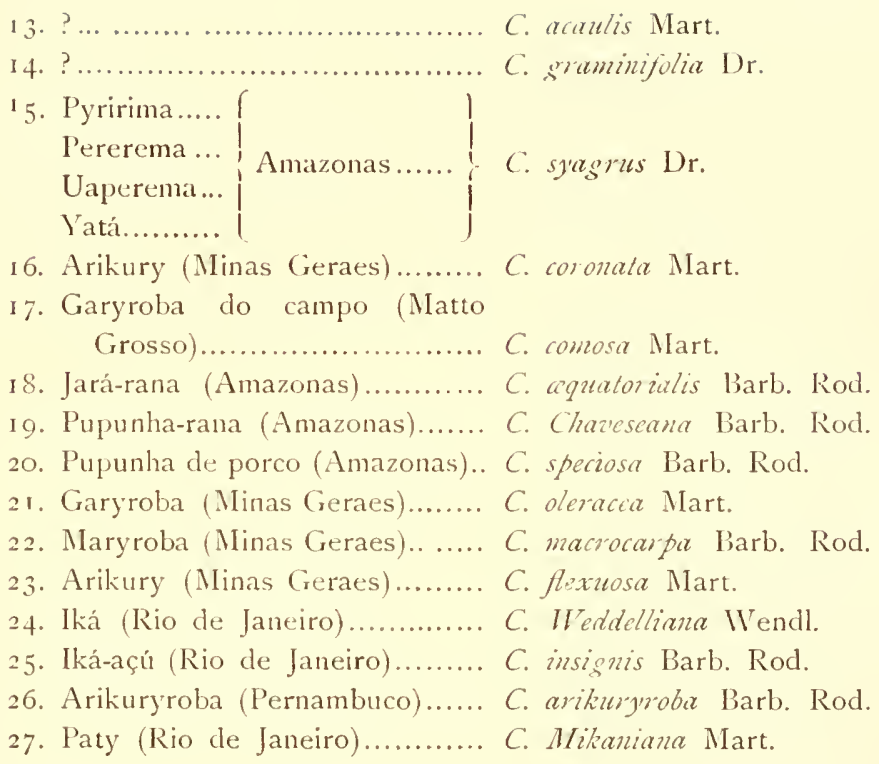


Gen. DIPLOTHEMIUM Mart.

1. DHPLOTHEMIUM LEUCOCALYX 1)rude in Flor. Bras. Ill, p. ll, pas. $429-431$. tab. XCV'lll. f. 1.

Diplothemium Jangadense Moore. Phanerog. bot of the Exp. Mat. Gros. in Trans, of the Linn. Soct. of lond. IV. p. 499. t. 86.

Tab. IX fig. A.

Esta especie foi descripta como nova pelo Professor Oscar Drude, pelos materiaes colhidos em $1 \$ 45$, pelo 1 )r. Weddell, companheiro de Castelnau. em Matto Grosso, do lado das margens do Rio l’araná. Esteve, pois, nos herbarios da Europa 37 annos, sem ser classificada.

Encontrei-a socialmente nos campos do Urucu, em Corumbá e nos das margens do Rio Paraguay, com flores, em Maio. Mais tarde encontrei-a tambem formando grandes soqueiras, nos campos da Serra da Chapada, principalmente nos cerrados ou nos logares em que haviam monticolos formados pelo cupins. Tem vulgarmente o nome de Coco de vassoura ou Gury'y, uma abreviatura de Guary'y, corruptella de hary'y', pela pronuncia castelhana, e que quer dizer o cacho pequeno.

Burchell, tambem a encontrou nos campos do Rio Grande do Sul.

Tem o porte mais desenvolvido do que o do C. campestris Mart.

A especie que, como nova descreveu o Dr. Spencer Moore, não é mais do que o $D$. lencocaly'x de Drude. V'aria muito na forma. Nos campos de Corumbá, quando se encontram socialmente, agglomerados dentro dos cerrados, tomam grande desrolvimento, alongam e multiplicam as folhas, dá longos espadices e quando nos campos descobertos, tornam-se menores e 
pouco se desenvolvem, pelo que modificam tambem os foliolos. Nos campos da Chapada apresentam no porte um aspecto que dir-se-hia uma especie inteiramente differente.

2. D. CAMPESTRE Mart. in Hist. Nat. palm. 11I, p. 109, tab. 76 et $78,-$ Kunth., Enum plant. III p. 290. Walpers, Ann. bot. syst. V. pag. 824. Wendl, in Kerch. Palm. p. 242.-Drude in Flor. Bras. III, p. II, p. 432 . tab. XXIII.

Tab. $I X$ fig. $B$.

Encontrei esta especie nos vastos campos geraes da serra da Chapada, em Matto-Grosso, vivendo socialmente em alguns logares com o D. leucocalyx. Tem ahi o nome de Aryry modificação de sury'ry', e tambem o de coco de vassoura.

Esta especie estende-se pelos Estados de Espirito-Santo, de Minas Geraes, S. Paulo, Rio de Janeiro, Goyaz e Rio Grande e vai á Republica Argentina e á Bolivia.

Os naturaes empregam as folhas no fabrico de vassouras. Os seus fructos são comestiveis.

Explic, TAв. X. Fig. A. - Diflotemium leucocalyx Dr. 1. Porção do rachis, com um foliolo inteiro, tam. nat.. 2. Espadice, tam. nat.. 3. Spatha e espadice, muito diminuido. 4. Flor macho, tam. nat.. 5. A mesma, duas vezes augmentada. 6, 7 e 8. Sepalas. 9, 10, 10 a e ri. Petalas. r 2. Estancs, tudo duas vezes augmentado. 13. Filamento e anthera, quatro vezes augmen. tados. I 4. Flor fem., antes da anthese. 15. A mesma, depois da anthese. I6. A mesma, duas vezes augmentada. 17,18 e r9. Sepalas. 20. Corolla. 21, 22 e 23. Petalas. 24. Androceo e ovario, tudo duas vezes augmentado.

B. fig. B. - Diflotemium iampestre Mart. I. Flor macho, tam. nat.. 2. A mesma, duas vezes augmentada. 3 e 4 . Sepalas, duas vezes augmentadas. 5 e 6 . Petalas de frente e de costas, duas vezes augmentadas. 7. Estames, quatro vezes augmentados. 8. Filamento e anthera de frente, quatro vezes augmentada. 9. Flor fem., tam. nat.. ıo. A mesma, duas vezes augmentada. ir. Sepala e 12 petala, duas vezes augmentadas. I3. Androceo e ovario, duas vezes augmentados. 


\section{Desmoncus Mart.}

1. IEESMONCUS RUDENTUM Mart. in Palm. Orbign., p. 48, tab. I4 et 26. -- Kunth. Enum plant. V, p. 819. - Walpers in Ann. bot. syst. 1, p. I.005, V, p. 819. - Wendl in Kerch. Ind. Palm. p. 243.-Drude in Flor. Bras. III, p. II. p. 305.

Tab. X.

Pelas margens dos Rios Paraguay e S. Lourenço, nos logares que se inundam pelas enchentes, sempre se encontra esta especie formando grandes soqueiras.

Seus espiques flexuosos se entrelaçam, agarrados pelas unhas, que terminam a continuação do rachis, ás arvores, attingindo, como grandes cipós, não só o cimo d'ellas como estirando-se para o lado a quasi vinte metros de distancia. Vulgarmente tem o nome de Urumbambu antes ymubamb, do karany yri cesto, e mbamb que torce, referencia ao longo espique que, em geral depois de rachado e feito em lascas, serve para se fazer cestos, por ser facil torcel-as. Com effeito, em geral, o emprego que tem essa palmeira é n'esse mister, porque é mais flexivel e mais duradoura que qualquer cipó.

E' commum na Bolivia e no Alto Paraguay. Eu a encontrei não só no Rio Paraguay, como nos rios S. Lourenço e Cuyabá, sempre pelas barrancas humidas das margens, em logares que vão ao fundo.

2. D. CUYABÁENSIS Barb. Rod. Caudex longissime seandens tenuis. Folia longe vaginantia, vaginâ versus petiolum et precipue ochreâ aculeis minimis rectis horridâ, petiolo sub nullo, costa aculeis nigris rectis longissimis dispersi armata versus flagellum aculeis destitutiem inermi, foliolis oblongis, acutis $2-4$-jugis alternis utrinque $2-3$ aculeis magnis portantibus, flagello quam costa dıplo breviore 
spinas e basi gibbosâ inferiores foliaceis superiore subulatis 5 -jugis armato. Spatha exteriora longe envaginantia sub inermi, acuminata, iuteriora fusiformi basi invaginantia vi. ridi fusco-tomentosa aculeis brunneis minimis rectis horrida. Spadix foliis triplo brevior, longe pedunculatus, pedunculo supra spathas aculeos minimos brunneos rectos per greges armato, rachi inermi ramos if-contemporaneos densos graciles, $\mathrm{O}^{\mathrm{m}}, \mathrm{I}$ lg., Horibus masc. sepala minima, petala lanceolata acuminata. Baccae ignota.

Tab. $\mathrm{N} \%$

Candex $\mathrm{O}^{\mathrm{m}}$,or in diam.. Folia pedunculi $\mathrm{O}^{\mathrm{m}}, \mathrm{O} 2 \mathrm{lg}$., costa $\mathrm{O}^{\mathrm{m}}, 60 \mathrm{lg}$. aculeis patentes $\mathrm{v}$. deflexis $\mathrm{O}^{\mathrm{m}}, \mathrm{O}_{4}-\mathrm{O}^{\mathrm{m}}, 05 \mathrm{lg}$. flagello $0,40 \mathrm{lg}$. foliolis inferiores $\mathrm{O}^{\mathrm{m}}, 18 \times \mathrm{O}^{\mathrm{m}}, 045 \mathrm{lg}$., medio $\mathrm{O}^{\mathrm{m}}, 1+1 \times \mathrm{O}^{\mathrm{m}}, 40$, superiores $0^{\mathrm{m}}, 15 \times \mathrm{O}^{\mathrm{m}}, 05 \mathrm{lg}$. Spatha exteriora $\mathrm{O}^{\mathrm{m}}, 28$, interiora $\mathrm{O}^{\mathrm{m}}: 45 \times \mathrm{O}^{\mathrm{m}}, 05 \mathrm{lg}$.

$\mathrm{H}$ AB. ad mas gines furii Cuyabá. Nassambará incolunnm. Floret Funio. Herb. n. 220.

Expltc: Tisi. X. fig. A.- I. Spathas exterior e interior, tres vezes menor. 2. Flor macho, tamanho natural. 3. Calyce, muito angmentados. 4. Petala duas vezes augmentada. 5. Estames e antheras, duas vezes augmentado. 6. Anthera, quatro vezes augmentada. 7. Flor fem., cinco vezes augmentada, mostrando o calyce e a rorolla.

TAk. XI.-I. Porção do rachis, mostrando os grupos dos foliolos, vistos pela parte superior. tamanho natural. 2. U1timos foliolos, vistos pelo dorso e flagello, tamanho natural.

Quando em Junho nas minhas herborisações, pelo rio Cuyabá procurava as flores ou os fructos do D. mdentnm, deparei com esta especie em flor que, á primeira vista, me pareceu ser a que procurava. Exame posterior me convenceu do contrario, e comparando-a com as especies até hoje descriptas não a vejo determinada. Tem vulgarmente o nome de Massambará.

Da região Matto-Grossense só são conhecidas os Desmoncus rudentum e leptoclonos de Drude porém ambos são mui differentes. 
Poderia apresentar aqui as differenças que encontro comparada com as da seç̧ão Eu desmoncus de Drude, cujas especies sâo acanthospatha, mas, torna-se superfluo ante a descripção c o desenho que apresento na Est. IV. Tendo-a como nova aqui a apresento. e os mais autorizados que decidam.

Com o nome de Urubamba, vulgar a todos os Desmoncus em Matto Grosso, como o é o Facylara. no Amazonas, encontrou o Dr. Moore, en Santa Cruz, proximo da confluencia do Rio dos Bugres, no Paraguay, uma especie que descreveu (1) e dá como nova sem a determinar especificamente e que suppõe proxima ao D. rudentum. Nart.

Pela sua descripção não se identifica tambem com a que aqui apresento e constitue uma outra especie ou variedade.

(I) Phanerog. bot of the Malto Gros. Exp. p. 798 . 
Gen. Guillielma Mart.

GUILlielia MATTOGROSSEnsis Barb. Rod. Caudex excelsus solitarius aculeis atris longissimis in enternodiis horride armatus annulatus, foliis $10-12$ contemporaneis longis arcuatis crispulis infra albidis, petiolus albo tomen. tosus aculeis brunneis minimis densé armatus, rachi albotomentosa, aculeis brunneis minimis subtus et supra echinata lateraliter laevi; foliolis divaricatis crispatis per acervos 3-4 - arum consociatis secus margines et nervo medio aculeolatis oppositis lineari acuminatis, v. bidentatis utrinque atroviridis. Spatha exteriora lanceolata intus bidentata extus quadri-dentata acuminata albo-tomentosa utrinque aculeis atro-brunneis minimis appresis interiora lanceolata acuminata mucronata extus densé aculeis atro-brunneis echinata. Spadices ferrugineo tomentosus.

Tab. XII.

Caudex $10^{m}-12^{m} \times 0^{m}, 12 \mathrm{lg}$, internodiis ad basin, $0^{m}, 30 \lg$. ad apicem $\mathrm{O}^{\mathrm{m}}, \mathrm{O} \mathrm{t}$, aculeis $\mathrm{O}^{\mathrm{m}}, \mathrm{O} 2-\mathrm{O} .08 \mathrm{lg}$. Folic $10-12$ conten poranea, arenato patentia $2^{\mathrm{m}}, 9^{\mathrm{n}} \mathrm{lg}$. ; vagina et petiolo aculeis nigris horrido, $\mathrm{O}^{\mathrm{m}}, 90 \mathrm{lg}$; foliolis inferiores $\mathrm{O}^{\mathrm{m}}, 65 \times \mathrm{O}^{\mathrm{m}}, 025 . \mathrm{lg}$., médio $0^{\mathrm{m}} .60 \times \mathrm{O}^{\mathrm{m}} 3 \mathrm{o} \mathrm{lg}$.. superiores $\mathrm{O}^{\mathrm{m}} \cdot 35 \times \mathrm{O}^{\mathrm{m}} \mathrm{O} 15 \mathrm{lg}$.; secus margines setis densis ornatis, nervo medio utrinque prominentibus secundariis utrinque $3+$ suffulta. Spadix intra folia marcescentia, pedunculo laevi ferrugineo tomentoso, incurvo, spatha ventricosa. Flores et drupac coccinex ignotx.

Hab. in silzis primaiis. Rio da Casca in montibus Capitão mór ad Serra da Chapada, Prov. de Matto Grosso. Cerriba incolonum. Floret Aug. Herb. n. 212.

Explic. Tab. Xil. - I. I a. I b. I c. I d. I e. Córtes transversaes do peciolo e do rachis, tamanho natural. 2. Porção do rachis com um foliolo inteiro, tamanho natural. 3 e 4 . Spathas exterior e interior, vistas pelo dorso e pela frente, antes de desabrochar, seis rezes menores. 
Nas suas viagens pela America o Barão von 1 Humboldt, achou en Nova Granada uma palmeira ahi conhecida por Gachipacs, da qual os indios muito se utilisavam nåo só para seus instrumentos de guerra como para o seu alimento, visto como a madeira é excessivamente dura e os fructos muito saborosos e substanciaes, e, reconhecendo-a nova, levou-a para o genero Bactris dando para nome especifico o vulgar. Mais tarde o Dr. Martius estudando-a, pelos exemplares que encontrou no Amazonas, viu que se timla muitos caracteres do genero Bactris comtudo apresentava outros que se affastavam, pelo que creou para ella o genero Guillielma, passando a ter o nome de Guilliclma speciosa. Mais tarde d'Orbigny encontrou na provincia de Chiquitos, na Bolivia, outra especie a que Martius deu tambem o nome de Guillielma insignis.

Eram estas especies as unicas conhecidas, sendo que a primeira, no Brazil, nunca foi encontrada em estado selvagem e sim muito cultivada, tanto que Wallace (I) diz "This palm appears to be indigenous to the countries near the Andes. On the Amazon and Rio Negro it is never found wild». o que é exacto, porquanto tendo eu corrido quasi todo o valle do Amazonas até ás fronteiras do Perú e da Bolivia, nunca a vi senão muito cultivada.

Spruce (2) tambem diz: "And when I asked the people where they supposed the palm had originally come from, they pointed westward and said, "From the Cordilleras"; and I got a similar answer from the natives of the Uaupés".

Assim como o Burity e o Murity indicam proximidade d'agua, assim esta palmeira sempre indica uma habitação ou uma tapera, quando encontrada nas mattas.

Como disse, eram conliecidas só as duas especies, quando á Guilliclma spcciosa addicionei mais tres variedades distinctas que descobri: as var. flaz' , coccinca e ochracca.

(i) Palm trees of the Amazin, pag. 95.

(2) Palmat Amasonica in Journ. Soc. Lin. X1. pag. 8t. 
Era de crer que o genero não fosse brazileiro, e sim das raias do Perú e da Bolivia, porquanto a Pupunha do Amazonas ahi por emigração se acclimou.

Tenho agora a felicidade de mostrar que no Brazil tambem existe o genero, porque na minha expedição ao Estado de Matto-Grosso, encontrei nas mattas virgens do morro do $\mathrm{Ca}$ pitão-mór, á margem do Rio Casca, affluente do Rio Manso, que desagua no Cuyabá, na Serra da Chapada uma nova especie, que não desmerece da speciosa e da insignis. Não será d'esta especie, cujas sementes emigrando pelos rios Madeira ou Tapajós para o Amazonas, em tempos idos ahi se aclimasse, a ponto dos exemplares tomarem outro aspecto, perderem quasi os espinhos, avolumarem os fructos e atrophiarem as sementes?

Conheço bem a Pupunha e suas variedades, e das suas sementes que trouxe do Amazonas, já obtive n'este Jardim lindos exemplares, entre os quaes um que breve florescerá pois não só já está com mais de cinco metros de altura, como dando rebentos a formar soqueira, como sóe fazel-o no valle Amazonico a G. speciosa.

Encontrei no centro da floresta virgem, a palmeira de que trato, apresentando individuos sempre solitarios e distanciados, levantando a sua fronde de folhas plumosas com todo o garbo acima das arvores visinhas, onde pela sua belleza tudo dominava.

Infelizmente não apresentavam nem flores nem fructos, mas, a meu lado estava um guia, maior de 60 annos, nascido e ahi criado que bem me informava. Tem vulgarmente o nome de Ceryba ou Ceryoa, ainda corruptella do haryb, karany. Sem as folhas e sem os fructos, perguntava a inim mesmo, estarei ante a Guillielma insignis que não conheço de vista e que tem tambem entre os indios Guarayos da Bolivia o nome de Ceriva?

- De que côr e de que tamanho são os fructos, me diga, já que conhece desde a sua infancia e annualmente os vê? Perguntei eu ao meu guia.

- São vermelhos como pitangas e do tamanho de um tucum, respondeu-me. 
Só isto bastou me para ver que não se tratava da Ceryva boliviana. porque esta tem os fructos amarello de ouro e são da fóma e quasi do tamanho de um oro de gallinha: "1)rupa formâ et magnitudine ovi gallinacei mimoris aurantiacan vi. nha-me á memoria este caracteristico dado por Martius.

Se nåo tinha flores nem fructos comtudo offereciam-me algumas spathas quasi a desabrochar, pelas quaes melhor podia me guiar.

O seu espique é fino e excelso. tendo os entrenós, que, na base têm jo centimetros e gradualmente vão diminuindo para o apice a ter 10 centimetros, inteiramente ouriçados de aculeos negros, que vão de 2 a ro centimetros de comprimento, desde a base até ao apice. As folhas são relativamente pequenas, graciosamente curvas e crespas. apresentanclo o todo uma fórma quasi globular, e tendo o aspecto de um gigantesco tucum ou bactris. A vagina, o peciolo e o rachis das folhas são cobertos de uma grande camada de tomento branco e inteiramente ouriçado de aculeos funos e pardacentos. Os proprios foliolos tem a nervura média, na parte superior, e as margens aculeadas. As spathas exteriores que nas Guili:lmas conhecidas são curtas e agndas do lado interior e pouco aculeadas, nesta têm a spatha exterior quadridentada na parte externa e acuminada na interna, coberta de tomento branco na base e ferrugineo no apice, muito aculeada, sendo os aculeos na parte anterior ondulados e dirigridos para cima e na interior dirigidos para baixo. A spatha interior é tambem coberta de tomento ferrugineo e ouriçado de aculeos de mais de um centimetro a parecer uma pelle animal.

Em vez de ser aguda ou obtusa, como såo as das especies conhecidas såo acuminadas, teminando em uma ponta (nucro) de mais de 2 centimetros. Todas os aculeos são de um preto castanho. Entre muitas differenças que encontro entre esta especie e as conhecilas noto as seguintes: O espique tem os entrenós tão cobertos de longros aculeos que se năo vê a parte cortical, em vez de ter finos aculeos esparsos; as follhas 
são em numero de 10 a I 2 e não de 6 a 10 ; o pedunculo das folhas não é quasi cylindrico, como na speciosa, os foliolos são de um verde escuro de ambos os lados, e não branco por baixo; os mesmos são dispostos em grupos de 3 e + e não de 4 a 6 ; os fructos são coccineos e quasi globulosos e não attingem a mais de 2 centimetros e não aurantiacos e quasi do tamanho de um ovo de gallinha.

Estas difterenças são constantes em todos os exemplares que encontrei.

Breve terei occasiāo de completar a descripção, pois espero não só flores como fructos que me deven ser remettidos de Cuyabá, e mais tarde d'elles darei noticia. 
Gen. Bactris Jacq.

1. B. INFESTA Mart. Palm. Orbig. p. 5t.t. 7 et 27 B. major var. Intesta, Mart.; Drute in Fl. Bras. III. p. Il. pag. 359.

Encontrei esta especie, que d'Orbigny achou na Bolivia e proximo do forte Principe da Beira. nas mattas das margens dos rios S. Romão e da Casca na Serra da Chapada. Foi encontrada tambem em Goyaz, no sertão de Amaro Leite, por Weddell, com o nome de Coco de vinagre. Os habitantes de Matto Grosso, dão entretanto a esta especic o mesmo nome de Tucum mirim.

Cresce em grandes soqueiras, nos logares humidos e sombrios.

Dou aqui a descripção que apresenta Drude, na obra citada, afim que se compare com as que apresento das minhas especies B. Matto Grossensis e Chapadensis.

B. MAJOR var. INFEST Mart. (Sub specie).

Cuudex plrq. $2 \mathrm{~m}$. altus aculeis compressis nisris armatus; petiolus et costa aculcis nonnullis longissimis sparsis vestita : spatha clavata acuta; pedunculus setosus ramos cc. 6 umbellatim exserens; drupa ovoidea oro columbino major riolaceonigricans lacrigata.

2. BACTRIS MATTOGROSSENSIS Barb. Rod. Caudex $3.4 \mathrm{~m}$. alt. aculeis atratis ad apicem internodiis armatus, tomento cinnamomeo vestitus. Petiolus et costa aculeis longissimis complanatis sparsis armata, foliolis 3 jugis aproximatis oppositis oblique acuminatis. Spatha, $0^{\text {th }} .25 \mathrm{lg}$., oblonga acuta-mucronata incurva aculeis atratis minimis adpressis armata, pedunculo inermi ferrugineo tomentoso, rachi sub nulla ramos 5 exserente. Drupa oblonga sub acuta lacvigata.

$$
\text { Tab. XIII fis. IP. }
$$


Cauder $3^{\mathrm{m}}-4^{\mathrm{m}} \times 0^{\mathrm{m}} .05-0^{\mathrm{m}}, 07 \mathrm{lg}$. caespitosus, internodiis cinnamomeo-tomentosus, infra annulos aculeis erectis adpressis armatus. Folia $5-6$ contemporanea, $1^{\mathrm{m}}, 60 \mathrm{lg}$. inaequaliter pinnasecta, vaginâ brevi pauci aculeatâ, petiolo sparsé aculeis, $\mathrm{O}^{\mathrm{m}}, \mathrm{O}_{3}-\mathrm{O}^{\mathrm{m}}, \mathrm{o} 6 \mathrm{lg}$. atratis complanatis armato, $\mathrm{O}^{\mathrm{m}}, 40 \mathrm{lg}$; foliolis $3-S$ congregatis, lineari-lanceolatis oblique acuminatis marginibus setulosis, $\mathrm{O}^{\mathrm{m}}, 20-\mathrm{O}^{\mathrm{m}}, 35 \times \mathrm{O}^{\mathrm{m}}, \mathrm{O} 20 \mathrm{lg}$. Spatha exteriora lineari-lanceolata, tomentosa, interiora longe vaginata, $0^{m}, 30 \mathrm{lg}$, dein fusiformi aculeis minimis $0^{\mathrm{m}}, 01 \mathrm{lg}$. atratis tenuibus appressus obtecta. Spadix $\mathrm{o}^{\mathrm{m}}, 35 \mathrm{lg}$., incurvus, pedunculo compresso, incurvo, tomentoso, $\mathrm{O}^{\mathrm{m}}, 20 \mathrm{lg}$; rachi sub nulla; ramos $\mathrm{O}^{\mathrm{m}}, 15 \mathrm{lg}$., incurvos, rigidos. Flores non vidi. Drupa oblonga atro-violacea, $\mathrm{O}^{\mathrm{m}}, 04 \times \mathrm{O}^{\mathrm{m}}, 025 \mathrm{lg}$., epicarpio laevigato, mezocarpio fibroso-pulposo dulce, endocarpio ovoideo, $0^{\mathrm{m}}, 025 \times 0^{\mathrm{m}}, 018 \mathrm{lg}$.

11AB. in Corrego Fundo prope Cuyabá, proz. Natto Grosso. Tucun-marm ab-incolis nominatur. Fruct junio. Herb. ก. 225 .

Explic. 'ТАв. XIII. fig. B. - Spathas exterior e interior, sendo esta cortada, faltando um pedaço, e espadice. r. Porçâo do rachis, com um foliolo inteiro. 2. Calyce. 3. Fructo inteiro. 4. O mesmo cortado verticalmente, mostrando o embryào quasi no centro. Tudo de tamanho natural.

Entre as especies do genero Bactris, encontrei nas mattas dos terrenos humidos que marginam os rios S. Romão, da Casca e Cabral, quer em baixo, quer em cima da serra da Chapada, a especie em questão, sem flores, porém com fructos maduros, no mez de Junho. Não havendo trabalho algum mais moderno, sobre esta familia, do que a monographia do professor Drude, publicada na Flora de Martius, e ahi estando reunidas todas as especies, não encontrei nenhuma que possa se identificar com a minha. A que mais d'ella se aproxima é a Bactris infesta de Martius, que para Drude é simples variedade ou sub especie do Bactris major de Jacquin. 
Comparando-a com a descripção original de Jacquin, do seu Selectarum Stirpium Americanartm, a pgs. 280 Est. 171 (ed. de MDCCLXIII) e não 135 , Est. $26_{3}$, como por engano Drude cita; estudando tambem a de Martius, no seu Palmetum Orbignyanum, á pags. 54 e Est. 7 e 27 e as de Drude, apenas encontro alguma analogia na forma do fructo.

Entre muitas differenças salientam-se as seguintes: No $B a$ ctris major e mesmo no infesta as folhas são igualmente pinnalisectas ou em grupos pouco espaçados; os ramos do espadice são em numero de 6 a ro e levantados (fastigiatus) o pedunculo é hirto; os foliolos das foihas são em numero de 25 a 35 e os fructos sĩo asporos e sornins fusca, emquanto que, na de que trato as folhas tem os foliolos dispostos em grupos muito distanciados; os ramos do espadice são constantemente em numero de 5 e recurvados; o pedunculo é liso; os foliolos são em numero superior a $3 \mathrm{~S}$; e os fructos são roxo-negro lisos e luzentes.

Como synonima do $B$. major, refere tambem o autor citado, a minha 13 . exaltata, que é uma especie tambem muito distincta, como tambem é distincta a infesta de Martius. O facto de nāo poder o botanico europeu. estuclar a planta viva. não conhecer o habitus da planta. e só lidar com plantas seccas, retalhos que não dão a minima idéa d'ellas, faz com que muitos erros e enganos appareçam. N'esta familia os enganos são faceis, porque a não se ter exemplares muito completos, os especimens se confundem e muitas vezes duas especies muito differentes se identificam e outras, as mesmas se afastam. Quem conhece a familia das palmeiras pelo vivo. ao lançar os olhos sobre uma a distingue logo, embora sem flores ou fructos, o que não acontece com os rebotalhos seccos.

E' conhecida entre os naturaes pelo nome de Tucum mirim. Tendo-a como nova e assim aqui a apresento. Ha muitos pontos de contacto, em certas especies do genero Bactris. que participam clos mesmos caracteres, comtudo a simples inspeç̧áo ocular da planta viva os distingue. 
3. B. CHAPADENSIS Barb. Rod. Caudex arundinaceus, inermis, caespitosus, tomento brunneo adspersus; vagina tenuiter aculeata, aculeis setosis, petiolo albo tomentoso aculeato aculeis longissimis sparsis atratis complanatis; foliolis per acervos 3 congregatis oppositis lineari-lanceolatis oblique acuminatis marginibus setulosis. Spatha exteriora linearilanceolata fulvo tomentosa, interiora longe vaginantia dein oblongo-lanceolata acuta incurva aculeis tenuis brumneis echinata. Spadix incurvus 5 ramosus, pedunculus incurvus fulvo tomentosus setis minutissimis armatıs, rachi sub nulla. Drupa oblonga atroviolacea-laevigata.

Tabula XIII, fig. A.

Caudex dense caespitosus, 5-30 contemporaneis, $1^{\mathrm{m}}-1^{\mathrm{m}}, 50 \times$ $X \mathrm{O}^{\mathrm{m}}, 10-\mathrm{O}^{\mathrm{m}}, 12 \mathrm{lg}$., inermis. Folia elegantissima $\mathrm{O}^{\mathrm{m}}, 95-1^{\mathrm{m}}$ lg., vagina et petiolo albo-tomentoso aculeis longissimis $\left(\mathrm{O}^{\mathrm{m}}, 05-\mathrm{O}^{\mathrm{m}}, 07 \mathrm{lg}.\right)$ atratis armato, rachi albo tomentosa, similiter armata; foliolis lineari-lanceolatis, inferioribus $3^{-}$ jugis, $\mathrm{O}^{\mathrm{m}} .20 \times \mathrm{O}^{\mathrm{m}}, \mathrm{OI}_{5}$ !g., medio 6.S-jugis, $\mathrm{O}^{\mathrm{m}}, 25 \times \mathrm{O}^{\mathrm{m}} . \mathrm{I}_{5} \mathrm{lg}$., superiores $\mathrm{O}^{\mathrm{m}}{ }^{\mathrm{I}} 2 \times \mathrm{O}^{\mathrm{m}}, \mathrm{O} \mathrm{IO}-\mathrm{O}^{\mathrm{m}}, \mathrm{OI} 2 \mathrm{lg}$. Spadix $\mathrm{O}^{\mathrm{m}}, 27-\mathrm{O}^{\mathrm{m}}, 35$ lg., spatha inferiore albo-tomentosa lineari-lanceolatâ, acuminatâ, superiore longe vaginantia dein oblongo-lanceolata, rostrata aculeolis tenuis brunneis echinata, pedunculo compresso, $\mathrm{O}^{\mathrm{m}}, 20-\mathrm{O}^{\mathrm{m}}, 25 \times \mathrm{O}^{\mathrm{m}} .006-\mathrm{O}^{\mathrm{m}}, 007 \mathrm{lg} .$, rachi sub nulla, ramos 5 pedunculo triplo breviores exserente. Flores non vidi. Drupa oblonga, $\mathrm{O}^{\mathrm{m}}, \mathrm{O} 32 \times \mathrm{o}^{\mathrm{m}}, \mathrm{O} 29 \mathrm{lg}$., epicarpio tenui, atroviolaceo, mezocarpio albo fibroso pulposo, endocarpio oblongo.

НAB. in silvis Rio Ariká, in Bocaina Serra Chapada et in Rio da Casca. Tucum mirim da matta nuncupatur Fruct. Junio. Herb. N. 250.

Explic. Tab. Xili, Fig. A.-1. Calyce. 2. Corolla. 3. Fructo inteiro. 4. O mesmo partido verticalmente; tudo de tamanho natural. 
Nas mattas proximas ao Ribeirào Fundo, nas do Ariká e nas do centro da Bocaina da Serra da Chapada e no Rio da Casca encontrei formando graciosas soqueiras esta pequena especie. I ir-se-ha uma variedade pequena da especie antecedente pela forma dos fructos e pelo numero de ramos do espadice, entretanto o habitus as separa á primeira vista e a posição dos operculos do endocarpo as distingue. O espique é pequeno. fino e inerme; a vagina das folhas é curta e finamente aculeada; os foliolos são dispostos em numero de 3 a 4 e muito proximos e o pedunculo e o rachis se bem que longamente aculeado é coberto de tomento branco.

Ten o nome de Tucum mirim da matta. Esta especie é de terrenos elevados e seccos e outra de terras baixas e humidas.

A comparação dos fructos da B. infesta, da Matto Grossensis e d'esta que apparentemente parecem ser de uma só especie. dá un bom distinctivo, a forma do cndocarpo e a posifäo dos póros.

4. BACTRIS CUYABÁENSIS Barb. Rod. Caudex dense caespitosus $2-5^{\mathrm{m}}$ alt. aculeis nigris appressis armatus. Petiolus et rachis aculeis longis rectis complanatis albescentibus nigro acuminatis armata, foliolis per acervos dispositis erectis linearibus oblique acuminatis longissime cuspidatis ad margines aculeolatis. Spadix amplus longe pedunculatus, spatha maxima aculeis flavis nigro acuminatis dense echinata mucronata, pedunculo fulvo tomentoso versus apicem aculeato. incurvo sub-compresso, rachi levi pedunculo paulo minore, ramis rigidis. Drupa subglobosa atroviolacea laevigata.

\section{Tabula XIV.}

Caudex $2^{m}-5^{m} \times 0^{m}, O_{3}-0^{m}, 04 \lg$. aculeis nigris ad apicem internodiis apressis armatus. Folia $5-7$ contemporanea, $1^{\mathrm{m}}$, 7o $\lg$. pinuatisecta, aculeata, petiolo cylindraceo ferrugineo-tomentoso aculeis albescentibus nigro acuminatis $\left(0^{m}, 02-0^{m}, 05 \lg\right.$.) in gregres confetis patentibus, rachi supra carinata subtus acu- 
leis similiter pedunculum armata, foliolis inaequaliter dispositis per acervos $2-6$ jugis alternis, inferiores $0^{\mathrm{m}}, 70 \times \mathrm{O}^{\mathrm{m}}, 035$ $\lg$., medio $0^{\mathrm{m}}, 65 \times \mathrm{O}^{\mathrm{m}}, 030 \mathrm{lg}$., superiores $\mathrm{O}^{\mathrm{m}}, 48 \times \mathrm{O}^{\mathrm{m}}, 015 \mathrm{lg}$., extimis latioribus. Spadix maximus $\mathrm{o}^{\mathrm{m}}, 70 \mathrm{lg}$, spatha exteriora cinnamomeo-tomentosa, lineari lanceolata. acuminata, extus ad apicem arguté aculeata, $\mathrm{O}^{\mathrm{m}}, 20 \times \mathrm{O}^{\mathrm{m}}, \mathrm{O} 4 \mathrm{lg}$., interiora supra partem vaginantem lanceolata, concava, rostrata, incurva, dein fusiformi sulcata aculeis flavescentibus nigro-acuminatis $\left(\mathrm{O}^{\mathrm{m}}, \mathrm{O} 1-\mathrm{O}^{\mathrm{m}}, \mathrm{O}_{3} \mathrm{lg}\right.$.) basi gibbosis rectis vel ondulatis dense echinata; pedunculo $\mathrm{o}^{\mathrm{m}}, 40 \mathrm{lg}$. tomentoso arcuato apicem aculeato, aculeis ondulatis; rachi $\mathrm{o}^{\mathrm{m}}, 30 \mathrm{lg}$., ramos 25 - 30, flagelliformes $\mathrm{O}^{\mathrm{m}}, 20-\mathrm{O}^{\mathrm{m}}, 25 \mathrm{lg}$. Flores: max. non vidi, foem. lato ovoidei, calyce minimo. obtuse patelliformi tridentato, corolla subglobulosa, obtuse tridentata, minutissime aculeolata, quadruplo calyce majora, ovario lato ovoideo. Drupa subglobosa. parva. $0^{\mathrm{m}} .02 \times \mathrm{o}^{\mathrm{m}}, 018 \mathrm{lg}$. epicarpio atro-violaceo, mezocarpio pulposo dulce, endocarpio compresso.

HAB. in ripas inundatas ad Rio Paraguay. Rio S. Lourenço, Rio Cuyabá, Corrego das Areias de S. Miguel ad Serra da Chapada. Vulgariter Tucum. Floret et fruct. in Nor. extemporaliter Funio. Herb. N. $2 \hat{3} \mathrm{I}$.

Expl. TAB. XIV.-1. Porte, copiado do natural, muito diminuido. 2. Parte do rachis, com um foliolo inteiro, tamanho nat. 3. Spathas exterior e interior e espadice, tres vezes menor. 4. Flor femea, tres vezes augmentada. 5. Calyce. 6. Corolla. 7. Ovario, tudo de tamanho natural. 8. Fructo inteiro. 9. Endocarpio e albumen, mostrando a posição do embryão, tudo de tamanho natural.

Comecei a ver esta especie, rara, pelas margens do Rio Paraguay, já em terras brasileiras, mas onde fui encontral-a, bordando completamente as barrancas que se alagam foi nos Rios S. Lourenço e Cuyabá. No corrego das Areias de S. Miguel e nas margens do Aricá tambem o encontrei. E' uma especie commum. Entretanto eu que a tomei sempre pelo $B$. setosa do Rio de Janeiro, estudando-a vi que me enganava. Seria o $B$. 
Brognartii da Bolivia, o piscatorum do Paraguay, o pallidispina ou o Marajá do Amazonas? Confrontei todas as descripções, comparei, mas, com nenhuma destas especies se identifica. O B. piscatorum de Weddell eu o encontrei no Paraguay ás vezes crescenclo junto da especie de que me occupo. Tem quasi o mesmo porte, os espinhos iguaes na côr e na quantidade, as spathas são semelhantes, porém a folhagem o separa immediatamente. As folhas do primeiro são curvas e os foliolos estreitos e crespos, emquanto que os destas são quasi erectas. os foliolos são largos e erectos. Em Abril e Maio. tempo em que florescia o piscatorum, quando Weddell o encontrou, a especie em questão estava sem flores ou fructos, só em fim de Junho encontrei uma soqueira, no Rio Cuyabá. quse extemporaneamente tinha flores e fructos verdes e maduros. A epoca da florescencia d'esta é em Outubro e Novembro. segundo me informaram. A $B$. setosa, que actualmente. Setembro, está em plena florescencia, e con fructos n'este jardim onde abunda, tem tambem grande semelhança. porém a disposição e largura dos foliolos, as flores e sobretudo os fructos a separam. Os fructos da selosa são muito maiores e o calyce desapparece completamente ficando enduviado só pela corolla, emquanto que na especie Matto Grossense os fructos são pequenos e o calyce é perfeitamente desenvolvido e muito visivel.

A pallidispina é um Bactris que sempre vi crescendo á sombra das tlorestas do Amazonas e que tem um habitus mui diverso, posto que com aculeos esbranquiçados. Quer os foliolos, quer os fructos são mui differentes.

Não será difficil a quem não conleça a planta viva, levado por exemplares seccos identifical-a com a setosa, por exemplo; se collocarem duas espathas juntas, uma de uma outra de outra especie, ninguem as tomará por diversas, identificam-se perfeitamente. Entretanto o habitus da planta qualquer individuo distingue e nunca as confunclirá.

Tunho, pois, como novo este Tucum, como vulgarmente é chamado. 
5. B. GLAUCESCENS Dr, in Mart. Flor. Bras. III, p. II. p. 345.. Index Kervensis I. p. 262.

Tab. XV.

Encontrei esta especie, no Rio Paraguay em diversos logares, porém, onde a vi em abundancia foi na Bahia de Caceres, acima da cidade de Corumba. Nas margens do rio Aricá em Cuyabá, no logar denominado Aricá da ponte, os terrenos alagadiços estão cobertos d'esta especie formando grandes soqueiras, porém não attingindo a altura que desenvolve no rio Paraguay. Tem vulgarmente o nome de Tucum mirim de frata aseda, segundo Weddell, a mim porém só me deram o de Tucum mirim, as folhas e os fructos approximam-se muito dos do bidentula de Spruce. E' um dos mais bellos entre os congeneres.

Explic. Taв. XV. - 1. Porção do espique. 2. Porção do peciolo. 3. Porção do rachís com um folılo, tudo de tamnho natural. 4. Flor femea, tamanho natural. 5. A mesma, tres vezes augmentada. 6. Calyce. 7. Corolla, tres vezes augmentada. 8. Fructo inteiro. 9. O mesmo, cortado verticalmente. 10. Endocarpio visto por cima. ri. O mesmo, cortado verticalmente mostrando o embryão. Tudo de tamanho natural.

\section{EMENDA}

BACTRIS VULGARIS Barb. Rod. Protesto-appendice ad Enum. Palm. nov. 1879. p. 42. - Drude Flor. Bras. III. p. II. p. 348. - B. Glaziovana Dr., in Flor. Bras. III. p. II. 1882. p. 348. tab. LXXX.

Ha muito desejava fazer ver que a especie descripta pelo sabio Dr. Drude, na sua monographia, sob o nome de B. Glaziovana, não é mais do que a $B$. vulgaris descripta por mim tres annos antes, mas como se não me offereceu opportunidade deixei de o fazer.

Pelos exemplares remettidos pelo Sr. Glaziou, collidos no Cosme Velho e nas visinhanças do Corcovado, foi feita a des- 
cripçāo da Flora. Esta especie é aulgar (cl'alii o nome scientifico que the dei), não só nas fraldas do Corcovado. como nas mattas d'esse pico, nas da Tijuca, nas da Serra do Mar, sobre tudo em Palmeiras e Rodeio, onde vive com a B. caryo lacfolia Mart. (1) Tanto são identicas que o proprio Dr. Drude, com a sua autoridade, achou tanta affinidade entre ambas que as collocou junto, uma n. 37 e outra 37 A. Esta especie forma grandes soqueiras, que segundo o terreno, tornam-se mais ou menos vigorosas, apresentando os espiques maiores ou menores, com os foliolos tambem mais ou menos longos. A separação d'estas duas plantas, consideradas como duas especies distinctas, prova que assim como se dá esse facto, dá-se o de reunirem-se especies differentes como synonymas, como aconteceu com grande numero de especies minhas que foram levadas á synonymia, quando são perfeitamente distinctas. Os rebotalhos dos hervarios levam a isso, o que não acontece quando o botanista confronta os especimens vivos, como eu faço. Follias e spadices que separados dos espiques e reduzidos a pedaços seccos são confrontados, poder-se-hão identificar, mas si se observar essas mesmas folhas e spadices no espique preso ao solo nos logares em que crescem, qualquer individuo, por menos illustrado que seja, verá que são especies mui distinctas. A estampa do Professor Drude é ben fiel, representa exacta. mente a planta que denominei $B$. aulgar is.

N'este jardin tenho exemplos do que affirmo, nos exemplares cultivados.

Aproveitando a opportunidacle de relacionar aqui diversas palmeiras, consigno o facto, para que de hoje $\mathrm{cm}$ diante. não sejam tomadas como distinctas as duas especies c sim como sencto synonyma da Bactris anlgaris Barb. Rod. a Bactris Glasiorant de Drude.

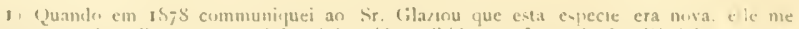

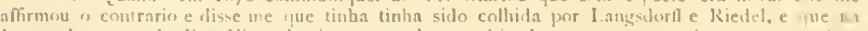

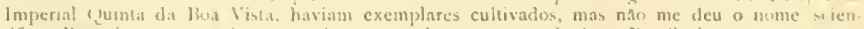
tifico l'nueriormente enviou exemulares, que deram em resultalu a B Cilaziovana 
Gen. Acrocomia Mart.

1. ACROCOMIA MBOKAYÁYBA Barb. Rod. in Plant nov. cult. Fard. Bot. Rio de Fan. V, is96, p. II, Est. IV.

No fasciculo das minhas Plantas nozas cultivadas no fardim Botanico do Rio de Fanciro, publicado em Dezembro de I\$96, á pags. 11, Est. $I^{\gamma}$, publiquei a descripção de uma nova especie, descripta por exemplares seccos que me haviam sido remettidos de Corumbá, em Matto Grosso, e como depois d'esse facto tenha eu estado na mesma localidade e ahi examinado centenas de pés, principalmente no Bacayuval dos campos do Urucu, em Corumbá, completo aqui a noticia passando a descrever outra especie.

O espique é cinzento, liso, na base sem aculeos ou com muito poucos e esparsos, e no apice com a cicatriz da queda das folhas vizivel e com os restos das vaginas aculeadas persistentes, com $6^{\mathrm{m}}-7 \times 0,10-0,15 \mathrm{lg}$.

O gado gosta dos fructos, do qual se alimenta no tempo proprio, engordando e dando muito bom leite.

Esta especie é muito semelhante ao Mbokaýá-Çayzeté, o A. Totaï de Martius, que abunda no Paraguay. Nos arredores de Assumpção vi em grande quantidade. Tem os espiques muito aculeados e os fructos são maiores.

$\mathrm{Vi}$ na estrada da Recoleta dois exemplares, com os espiques, inteiramente cobertos por grandes aculeos negros, que estavam todos virados para cima e embricados uns sobre outros, a ponto de não se ver a côr da parte cortical, sendo estes espinhos, alguns de quasi dous decimetros, maiores do que o comprimento dos entrenós.

Entre os exemplares que estudei devo aqui citar um que vi plantado na Quinta Iduna, do consul da Allemanha Henrique Mangels, no districto da Recoleta. Crescia naturalmente esse individuo em S. Bernardino, junto da Laguna Ypacaráyba. Apresentando uma fórma fóra do commum, muito original, 
apezar da sua altura, mais de 7 metros, e de ser já adulto, o mesmo senhor, com grande custo e dispendio, transportou-o para sua quinta, tendo feito assim uma viagem de muitas leguas. Apezar, porém, de tudo, pegou, medrou e hoje é um bello exemplar. Possuo d'essa palmeira uma photographia, da qual reproduzo o desenho, que se vê na Est. XVI, fig. B.

Os Paraguayos conhecem as outras especies de Acrocomias, tanto que designam, a que ua Bolivia tem o nome de Totay. por Mbocayá-çayicté (1). Em outro logar (2) já dei a etymologia da palavra Mbocayá, e por isso aqui apenas dou a de sayielé. Esta palavra significa: vordadciro grão scdondo, de Hayi, que pela aspiração fazem sayi grão, cousa redonda, e cté, verdadeiro allusão á fórma globulosa dos fructos.

2. A. ODORATA Barb. Rod. Caudex cylindricus, inermis lavis, folia cernua crispata, inermis, foliolis inxqualiter laxoinsertis-linearibus acuminatis. Spadix nutans spatha cymbiformi rostrata extus lana molli ferruginea velutina dense tecta, ramis rigidis flexuosa quam spica masc. paulo breviore flores fem. inter se approximatos gerentibus ovoideooblongos, germine intra petala longa incluso, drupis parvis subglobosis.

$$
\text { Tab. XIT, fis. B. }
$$

Caudex $3^{\mathrm{m}}-5^{\mathrm{m}} \times \mathrm{O}^{\mathrm{m}}, 10-\mathrm{O}^{\mathrm{m}}, 15 \mathrm{lg}$., cinereus. Folia omnia inermi, $20-22$ contemporanea, arcuata, crispata, $2^{\mathrm{m}} \cdot 30 \mathrm{lg} \cdot$; foliolis laxe dispositis, divergentibus, utrinque ad apicem incurvis, inferiores $0^{m}, 30 \times 0^{m}, 005 \mathrm{lg}$., medio $0,75 \times 0$, "'01 $8 \mathrm{lg}$., superiores $0^{m}, 50 \times 0^{m}, 006 \mathrm{lg}$. Spadix $0^{m}, 90 \mathrm{lg}$.. inermis, pedunculo $\left(0^{m}, 30 \mathrm{lg}\right.$.) erecto dein incurvato, spatha $\left(0^{\mathrm{m}}, 95 \mathrm{lg}.\right)$ supraramos incurvata persistente, rachi $0,60 \mathrm{lg}$. ramis $\mathrm{O}^{\mathrm{m}}, 20-$ $-0^{m}, 25 \mathrm{lg}$., dense undique exsertis: Flores masc. ${ }^{\mathrm{m}} .006 \mathrm{lg}$., sepula basi connata. lanceolata-acuta; pelala basi connata,

(I) Carlos Santos, La k'epublita del l'alasway, p. IS.

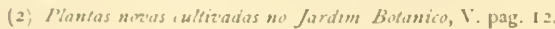


oblonga. acuta, concava, incurva ; flamentis corolla aquantibus; focm. sepala ad basin connata, lanceolata, acuta; petala latissimé lanceolata, imbricata, vel basis comnata, acuta: calyce triplo majora, androeceo abortivo corolla paulo minori, sexdentato; ovario ovato pulverulento. Drupa subglobosa, monosperna, $0.022 \times 0.023 \mathrm{lg}$., epicarpio, viridibrunneo vel havo, mezocarpio, fibroso, gommoso, atırantiaco, odoratissimo, endocarpio lapideo, nigro, $0^{\mathrm{m}}, 016 \times 0^{\mathrm{m}}, 014$ $\lg$. tutrinque actito.

Har, in locis humidis silvis Rio S. Lourenço. prov. Matto Grosso. BACAYUVA DE S. LUURENCO vel BACAYUVA DOS P.NNTANAES nominatur. Floret et fruct. Funio. Herb. n. 216.

Explic. Tar. XVI. A. Porte, muito diminuido, B. Acrocomia Totay Mart. A. \&. Porçào do rachis. I a. Extrenidade de un foliolo. 1 b. Parte média de um foliolo, 2, 2 a. 2 b. 2. c. Cortes transversies do peciolo e do rachis, tudo de tamanho natural. 3. Spatha interior muito diminuida. 4. Uma porção de um ramo, mostrando as disposiçōes das flores machos e femeas. 5. Um ramo, com fructos maduros, tudo de tamanho natural. 6. Uma flor macho, tamanho natural. 7. Calyce, quatro vezes augmentado. 8. Flor macho aberta e vista interiormente, tres vezes angmentada. 9. Um estame e anthera, muito augmentado. 10. Flor femea, tres rezes angmentada. 11. Calyce, tres vezes augmentado. 12. Corolla aberta vista pelo lado exterior. 13. A mesma vista pelo interior, mostrando o androceo abortivo, tres vezes augmentadas. 15. Calyce e corolla, do fructo. 16. Fructo inteiro. 1\%. O mesmo cortado verticalmente, tudo de tamanho natural.

Nos terrenos alagadiços das terras do Rio S. Lourenço, cresce uma outra especie propria l'esse rio, pelo que tem o nome de Bacayuva do S. Lourenço ou dos pantanaes. Vi ahi diversos exemplares, como tambem ahi encontrei a especie de $\mathrm{Co}$ rumbá que descrevi. Seus fructoss ão muito pequenos, e com a casca amarella e luzente, tão fina, que apertada entre os dedos se quebra facilmente despegando-se do mezocarpo, que é côr de laranja, e muito aromatico. O espique completamente liso e fino é inteiramente despido de espinhos; as follhas, vaginas, peciolos, rachis e foliolos são tambem inermes; s.padice, ramos 
tudo emfim inerme, só a spatha é coberta de cerdas pequeninas e tão finas e unidas que parece uma pelle sedosa de animal. Entretanto o habito é o mesmo da B. Mbocayáyba Barb. Rod., porém mais esbelto e gracioso. Em uma chacara de Cuyabá existe já um grande exemplar, cultivado, que em Junho estava com fructos maduros.

Poderia considerar esta fórma uma variedade, se, além do facto de ser totalmente inerme, não apresentasse as flores differentes, assim como tambem os fructos. Em Matto Grosso tem grande reputação esta especie pelos seus bons fructos.

3. A GLAUCOPHYLLA Dr. in Mart. Flor. Bras. III. p. II. p. 393. - Index Kewensis I. p. 33.

Entre as Acrocomias que encontrei e Matto-Grosso, vi perto de Cuyabá e em alguns logares cultivados a especie acima, que muito se approxima da $A$. sclerocarpa Mart., não só pela persistencia dos restos das vaginas, como por ser muito espinhosa e ter o mesmo porte. Apenas a spatha, não é aculeatissima, e sim coberta de um grosso tomento aspero mais ou menos armada de aculeos. Os fructos são iguaes aos da sclerocarpa, com a parte pulposa esbranquiçada, pouco aromatica e com o epicarpo duro.

Tem tambem o nome de Bocayzua. 


\section{Gen, Astrocaryum Meyer.}

Sect. Lelocarpeae Barb. Rod.

1. ASTROCARYUM ECHINATU.II Bar. Rod. Acaule vel caudescens. Caudex brevius proximé annulatus, pauci aculeatus. Folia arcuata aculeatissima, petiolus subcylindraceus antice sulcatus obscure-ferrugineo tomentosus, aculeis longis atratis compressis basi gibbosis armatus, rachi supra tomento albo adspersi et subtus ferrugineo tomentosi, utrinque aculeatissimi, aculeis longis; filiolis duro-divivaricatis incurvatis. per acervos 3-6-jugis, suboppositis, lineari-lanceolatis obliqué acutis subtus albo-tomentosis, marginibus ciliolatis, Spadix erectus, longi pedunculatus rachi inermi albo tomentosi quam pedunculus fulvo-tomentosus breviore spathâ lanceolatâ rostratâ obscure-ferrugineo tomentosâ incurvatâ ; aculeis crebris echinatis vestitâ; ramis gracilis erectis albo-tomentosis infra in scrobiculis 2-3 flores foem. Flores masc. non vidi; foem. oblongo-ovoidei calyce laevi quam corolla minuté setulosa aequante tridentati marginibus fimbriati, urceolo triplo corolla breviore, germine ovoideo. Drupa obovoidea ad basin induviis parvis fulta in vertice acuminato rostrata, epicarpio armeniaco, mezocarpio flavo, endocarpio nigro oblongo subacuto.

Tab. XIII.

Caudex $1^{\mathrm{m}}-1 \quad 1 / 2^{\mathrm{m}} \lg$., $\mathrm{O}^{\mathrm{m}}, 15$ aculeis nigris sparsis armatus. Acaule vel caudescens. Folia 7 contemporanea, $2^{\mathrm{m}} \lg$., pa* ginis ad insertionem valde intumescentibus valide aculeatissimis; petiolo $0,{ }^{m} 70 \mathrm{lg}$. ferrugineo, tomentoso, aculeis validis ad basin gibbosis, (O, ${ }^{\mathrm{m}} 007-\mathrm{O},{ }^{\mathrm{m}} 09 \mathrm{lg}$.) atratis horrido rachi supra albo tomentosi, subtus ferrugrineo tomentosi, aculeis longis utrinque horridi; foliolis $0,{ }^{\mathrm{m}} 8 \mathrm{o} \times 0,{ }^{\mathrm{m}} \mathrm{O} 35 \mathrm{lg}$., superiores abrupte minoribus et angustioribus, $0,{ }^{\mathrm{m}} 2 \mathrm{lg}$.. Spatha: exteriore lanceolata, obtusa, $0,{ }^{\mathrm{m}} 30 \mathrm{lg}$., ferrugineo 
tomentosia setis minimis et aculeis sparsis extus armata, mleriore $0^{m}, 70 \times 0^{m}, 15 \mathrm{lg}$. ferrugineo tomentosa, aculeis parvis $(0,01-0,0 .+\lg$.$) atratis retrospectantibus ad basin. et ma.$ joribus echinatus ad apicem; pedunculo in spatha et in ramis insertiones aculeis minimis compactis areolatis, compresso c.40 lg., ferrugineo tomentoso, raro aculeis sparsis armato, rachi $\mathrm{o}^{\mathrm{m}}, 35 \mathrm{lg}$. albo tomentosa ramis plurimis erectis albo tomentosis. $\mathrm{O}^{\mathrm{m}}, 15-\mathrm{O}^{\mathrm{m}} .90 \mathrm{lg} .$. Drupa $\mathrm{O}^{\mathrm{m}}, 42 \times \mathrm{O}^{\mathrm{m}}, 35 \mathrm{lg}$.

Has. in campis Serra da Chapada, prov. Matto Grosso. Florct Mai. Tucus no cimpu nominatur. Herb. N. 221

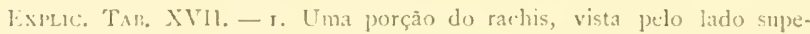
rior, mostrando a disposição dos grupos de foliolos, de tamnho natural. 2 e 3. Lma porção média de um foliolo e a extremidade do mesmo, de tamanho nat mal. 4 . $+\mathrm{a}, 4 \mathrm{~b}, 4 \mathrm{c}$, rórte transwersal do peciolo e diversos do rachis, de tamanho natural. 5. Spatha e espadice, sito vezes menor. 6. Flor femea. 7. Calyce. 8. Corolla. 9. Ovario e androceo csteril, tndo de tamanho natural. 9 a. Corclla, duas vezes ausmentada. 10. Frnclo imeiro. iI. () mesmo cortado verticalmente, de tamanho naturai.

Nos campos pedregosos, entre Burity e a povoação da Cluapada, encontrei alguns cspecimens desta palmeira, com o o nome vulgar de Tucum do campo, Tucum acrmelho. E' uma especie acaule, porém, que, com os annos toma-se caulescente. Vi exemplares com caules de mais de $1 \%$ : metro de altura. Entre o A. I cdddlii e esta especie, logo a primeira vista se notam differenças. Posto que sej:m ambos acaules, entretanto, o primeiro é pequeno, com poucas folhas e este robusto. com muitas folhas, senclo mesmo a disposição dos foliolos diversa. O proprio gado os distin rue, não deixando uma só follha inteira do primeiro e não tocan to nas deste, ainda que os dois se encontrem juntos. E' que as folhas não têm. talve\%, o mesmo grosto.

Será o 1. compestre de Martius, que se encontra em Goyaz, Minas Creraes e Paraná?

Creio que não. pelas differenças que vou apresentar. Differençis que encontro comparando os meus especimens com a 
minuciosa e bem feita descripção de Martius, na sua notavel Historia Nat. Palmarum e com a posterior de Drude, na Flora Brazilcira, sendo que a descripção Martiana é acompanhada de uma estampa $\left(6_{3}\right.$ fig. IV). Só se admittindo que o trabalho de Martius stja mal feito poder-se-ha identificar a minha especie com a sua, o que não posso acceitar.

$$
\text { Astr. campestre }
$$

Folha, rachis com espinhos raros de $2-3 \mathrm{~cm}$. ly. spatha exterior com 6 a 7 polleg.

Spalic pequeno com $2-3$ dic. $1 \mathrm{~cm} . \lg$.

Peduniwls allo pulveruiento armado de aculeos longos e pretos. aculeos de I -

$\mathrm{I}^{1}{ }_{2} \mathrm{~cm}$. de compr em feixes.

Corolla glabra.

Druf a esverdeada.

Find. em Scteml ro e Outubro.

\section{A. echinatum}

Folha, rathis aculeatissimo, coun espinhos de 0,03 a 0.10 lg., spatha excerior com $\mathrm{O}^{\mathrm{m}}, 5$ de ly.

Sfadice grande, com 8 dc. $\lg . \times 0,035 \mathrm{lg}$.

Peilunculo ferrugineo pulverulento, com poucos aculeos dispersos, sendo na inserção das spathas aculeado com aculeos pequenos. Corolla perco aculeata.

Drupa armeniaca. Fiut. en Julho.

Bastam estas differenças para separal-as inteiramente e poder consideral-a não classificada.

Quer o caule, quer as folhas, são completamente ouriçadas de longos aculeos muito picantes. em diversas direcções, de maneira que difficil é se tocar em um fructo. Não é possivel colher-se uma só folha sem que se fique ferido.

Os espinhos são agudissimos e facilmente deixam, sempre, na carne uma ponta, que produz dores por muitos dias.

2. A. ARENARIUMI Barb. Rod. (A. Wendelli Drude?) Flor. Bras. III. p. II. pag. $38_{3}$. Acaule. Folia arcuata aequaliter pinnatisecta aculeata, petiolo ferrugineo pulverulento aculeis atratis longis basi gibbosis sparsis armato, rachi utrimque armati, foliolis 2-3-jugis inaequaliter dispositis, ang. $30 .^{\circ}$, inemibus rectis, lineri-lanceolatis oblique acutis. Spadix parvus pedunculo albo-cinnamomeo pulverulento inermis, spatha basi vaginantia dein lanceolata incurva lana cinnamomeo ferruginea dense intertexta velutino tomentosa, rachi albo-pulverulenta ramos dense exserente quam ipsa demidio breviores: floribus fem. in parte inferiore $2-3$ 
evolventes dein in spicas masc. longiores excurrentes muticos; floribus masc. non vidi., fem. ovoideorun, calyx parum appresse setulosus tridentatis fimbriatis corolla tridentata fimbriata paulo brevior androecei rudimentarii annulo argute sexdentato basi corolla inserto; drupa subglobosa flava in vertice rostellata, endocarpio obuvoideo a basi acuto.

7ab. XVIII.

Folia 3-6 contemporanea, ${ }^{m}{ }^{\prime \prime}, 40 \mathrm{lg} .$. petiolo $\mathrm{O}^{\mathrm{m}}, 25 \mathrm{lg}$., rachi antice bifaciali postice carinata, albo-tomentosa. setis minutissimis et aculeis nigris complanatis $\mathrm{O}^{\mathrm{m}}, 05-\mathrm{O}^{\mathrm{m}}, 06 \mathrm{lg}$. utrinque armata; foliolis utrinque $20-25$ in greges irregulariter $\mathrm{I}-3$ dispositis, apicem versus $4-6$ consociatis, inferiores $\mathrm{O}^{\mathrm{m}}, 30 \times \mathrm{O}^{\mathrm{m}}, \mathrm{Or} 1$, medio $\mathrm{O}^{\mathrm{m}} .05 \times \mathrm{O}^{\mathrm{m}}, 24 \mathrm{lg}$., superiores $\mathrm{O}^{\mathrm{m}}, 20 \times \mathrm{O}^{\mathrm{m}}, 12 \mathrm{lg}$., nervo medio super prominente flavo. Spadix $\mathrm{O}^{\mathrm{m}}, 26 \mathrm{O}^{\mathrm{m}}, 60 \mathrm{lg}$., spatha int. $\mathrm{O}^{\mathrm{m}}, 30 \times \mathrm{O}^{\mathrm{m}}, 1 \mathrm{O} \mathrm{lg}$. , ferrugineo-lanata, lanceolata, incurva, mucronata; pedunculi laeviter ferrugineo lanati, inermi, subcompressi, $\mathrm{O}^{\mathrm{m}}, \mathrm{O} 2 \mathrm{lg}$.; rachis $\mathrm{O}^{\mathrm{m}}, 1 \mathrm{O}-\mathrm{O}^{\mathrm{m}}, 15 \mathrm{lg}$., ramis $25-40$ contemporaneis. albotomentosis, $\mathrm{O}^{\mathrm{m}}, 08-\mathrm{O}^{\mathrm{m}}$, $10 \mathrm{lg}$., brevissime pedicellatis, flores fem. I -3 evolvit, spicis masc. $\mathrm{O}^{\mathrm{m}}, \mathrm{o} 6 \mathrm{lg}$. Fiores masc. non vidi. Flores fem. $\mathrm{O}^{\mathrm{m}}$.or $\mathrm{lg}$., calyce tridentato fimbriato, minutissime aculeato corolla inclusa breviter tridentato fimbriato, androcei annullari, ovario ovoideo in stigmata excurrente. Drupa $\mathrm{O}^{\mathrm{m}}, 035 \times \mathrm{O}^{\mathrm{m}}, 033 \mathrm{lg}$.. flava, rostrata, rostro

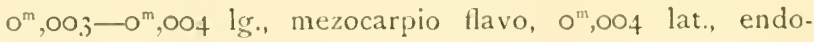
carpio $\mathrm{O}^{\mathrm{m}}, \mathrm{O}_{3} \times \mathrm{O}^{\mathrm{m}}, \mathrm{O}_{24} \mathrm{lg}$., nigro, lineis irregulariter reticulatim connexis.

HaIs. in campis sablonosis ad Serra da Chapada, Prov. Matto Grosso. Tucum liso v. Tucun Rasteiro vicanorum. Fruct. Junio. Herb. n. 2 I 4 .

Explec. Tals, XVIII. - r. Pórte, muitissimo diminuido. 2. Uma porção do rachis, vista pela parte superior, mostrando a disposição dos foliolos, de \{amanho natural. 3. Córte transversal do peciolo, $3 a, 3 b, 3 c, 3 d$, córtes 
transversaes do rachis. +. Uma parte média de um foliolo. 5. Parte terminal do mesmo, tudo de tamanho natural. 6. Spatha e spadice com fructos, reduzidos a $1 \mathrm{~m}$ quar1o. 7. Um ramo, com flores femeas e destituido das masculinas, de lam. nat. 8. Calyce. 9. Corolla. 10. Androceo e ovario, tudo de tam. nat. if Fructo inteiro. I2. O mesmo, cortado verticalmente. 13. O mesmo, cortado transversalmente, tudo de tam. nat.

Sempre que encontrava esta especie, a considerava como sendo o Astrocaryn IVeddellii que Drude descreveu, depois de ter sido descoberto por Weddell em i 845 e de dormir por conseguinte nos herbarios por espaço de 37 annos. Tinha-a como tal, não só por ter sido descoberto em Goyaz, em campos da natureza dos da Chapada, como por ter o mesmo nome vulgar de Tucum rasteiro, mas, não obstante esta mesma prevenção, comparando a minuciosa descripção de Drude, feita por bom exemplar e varios exemplares com os desenhos do mesmo autorizado professor. (Est. LXXXIll da Flor Bras.) sou obrigado a dar como nova a de que me occupo, considerando bem feita a descripçāo do mesmo palmographo, como os seus desenhos, que são por assim dizer herbarios graphicos.

Notaveis são as differenças que encontro não só nas folhas, como no espadice, nas flores e nos fructos. Serão estas differenças motivadias pelo meio? O vulgo mesmo distingue dando o nome de Tucum liso do campo, para mostrar que as follas não são crespas. E' verdade que o sertão de Amaro Leite, onde Weddell encontrou a especie, fica dois gráos ao norte e quatro ao nascente, isto é, mais ou menos retirado So a 100 leguas para um lado e quarenta para o norte, mas esse espaço que separa os dois especimens, não é sufficiente para fazer variar uma especie que se desenvolve sem cultura, tanto que, temos especies mesmo n'esta familia, cuja distancia quer em latitude e longitude sendo muito maior não se modifica e como exemplo temos o Cocos campestris, o Diplothemium campestre para só citar especies campesinas e da mesma região. 
As differenças principaes que encontro e me levam á duvida são as seguintes, que aqui comparo.

Ast. Weddellii lir.

Follias crespas.

Rachis com un avelludado ferrugines armado de cerdas e aculeos.

tolivios longe caudato-acuminados.

Pidumalo do espadice picante peias cerdas ferrugineas (de I a 3 milimetros) de que é colverto.

Sipatha obtusa

Drupa obovoidea.
Ast arenarium B. Rodr.

Folhis lisat e crectas (I).

Rachis com tomento, sem cerda, e sú aculeado no dorso e na frente.

Foliolos obliquamerte agudos.

Pithu culo glatro, tomentoso aculeos ispa su .

Spathe aguda com ponta.

Drufa subglolosa.

Não menciono aqui a differença das flores, que se podem apreciar pela comparação das descripções e das estampas.

E' una palmeira de vida social, muito procurada pelo gado, que é avido de suas folhas e pelos homens, que d'ellas tiram uma fibra fortissima com que preparan linhas e corclas para diversos misteres.

Encontrei nos logares arenosos e seccos dos campos da serra da Chapada e nos campos em baixo da serra. nas proximidades do rio S. Miguel das Areias, proximo á serra de Melgaço e do Rio Cuyabá. Em Junho tinha fructos maduros c raras flores.

Attendendo-se aos pontos de contacto que existe. poderse-ha tomar por uma subespecie do A. Weddeliii. mas creio que s: não identificam. entretanto curvar-me-hei ante juizo mais autorizado.

3. A. LEIOSI'ATHA Barb. Rod. Caudex caespitosus gracili speciosus albo-cinereus subtus annulos dense aculeatus, aculeis longissimis divergentibus, foliis sub-arcuatis aculeatissimis, in facie inferiora pallidis, petiolo aibo-pulverulento aculeis nigris varia magnitudine ad basin rribbosis horridissimo, rachi albo-pulverulenta aculeis sparsis nigris longrissimis horrida, foliolis per acervos irregulares dispositis 
patentibus erectis lineari-oblique acuminatis secus margines setigeris et supra nervo medio aculeis longis armatis. Spadix erectus longi pedunculatus pedunculo inermis, albopulverulento quam rachis aculeatis minora spatha fusiforme acuta laevi albo-pulverulenta, rarissime acl basin pauci aculeata ad apicem dorsaliter bicarinata. ramis plurimis erectis albo-pulverulentis laevis in porte inferiore pediceliiformi recta vel parum flexuosa, flores fem., 2-3 inter se distanti. Drupa ex induviis brevis oblonga in vertice rostellata, endocarpio utrinque acuto.

Tab. NIX.

Caudex $2-4^{m} \times \mathrm{O}^{\mathrm{m}}, \mathrm{SO}-\mathrm{O}^{\mathrm{m}}, 9 \mathrm{O} \mathrm{lg}$., ad apicem internodiis aculeis nigris $\mathrm{O}^{\mathrm{m}}, 1-\mathrm{O}^{\mathrm{m}}, 12 \mathrm{lg}$., horridus. Folia $5-7$ contemporanea, $2^{\mathrm{m}}-2^{\mathrm{m}}, 50 \mathrm{lg}$., cinereo-ferrugineo pulverulenta, aculeis nigris compressis divaricatis $\mathrm{O}^{\mathrm{m}}, 05 \mathrm{O}-\mathrm{O}^{\mathrm{m}}, 15 \mathrm{lg}$., horricla, pedunculo sub-cylindraceo aculeatissimo; foliolis gregis irregulariter aproximatis, supra nervo medio aculeis nigris $0^{m}, 02-0^{m}, 06$ $\lg$., armatis, inferiora $\mathrm{O}^{\mathrm{m}}, 40 \times \mathrm{O}^{\mathrm{m}}, 20 \mathrm{lg}$.. superiora $\mathrm{O}^{\mathrm{m}}, 10-\mathrm{O}^{\mathrm{m}}, 15 \times \mathrm{O}^{\mathrm{m}}, \mathrm{O}$ 10 $\mathrm{lg}$., aculeis marginibus fere $\mathrm{O}^{\mathrm{m}} . \mathrm{O} \mathrm{lg}$. Spatha exteriora lineari-lanceolata, acuta, $0^{m}, 50 \times 0^{m}, 0+\mathrm{lg}$., utrinque setis nigro-ferrugineis minibus densissime vestita, interiona $1^{\mathrm{m}}, 10-\mathrm{I}^{\mathrm{m}} \cdot 30 \times \mathrm{O}^{\mathrm{m}}, 13-\mathrm{O}^{\mathrm{m}}, \mathrm{I} 5 \mathrm{lg}$.. erecta, albo pulverulenta, inermi vel aculeis minimis ad basin armata; spadix $\mathrm{I}^{\mathrm{m}}, 3 \mathrm{O}-\mathrm{I}^{\mathrm{m}}, 40 \mathrm{lg}$., pedunculo $\mathrm{O}^{\mathrm{m}}, 40-\mathrm{O}^{\mathrm{m}}, 50 \mathrm{lg}$.. inermi, rachi ad basin sparsi aculeata, ramis $\mathrm{O}^{\mathrm{m}}, 2 \mathrm{O}-\mathrm{O}^{\mathrm{m}}, 3^{()} \mathrm{lg}$., sursum decrescentibus. Flores masc. non vidi; fem. calyce corolla triplo minora, edentato, corolla tridentata, androcei annuliformi vix ad demidio corolla adnato; ovario obovoideo. Di upa o $\mathrm{o}^{\mathrm{m}}, \mathrm{O} 4-\mathrm{O}^{\mathrm{m}}, \mathrm{O} 25 \mathrm{lg}$., lutea.

HAB, in Cachoeirinlra, ad ripas Rio Cuyabá, et in silvis humidis ripas Rio Sumidouro, Rio Cabral, in Bocaina, Serra da Chapada. TUcum AÇU in vernacule audit et incolis utilissima ut propter filar ex foliis adolescentibus praparanda in usum funium, etc. Fruct. Funio-ful. Herb. n. 206. 
Expl.ic. Tab. XiX. Fig. A.-I. Uma porção do espique, dez vezes diminuido. 2. Córte transversal do peciolo, de tam. nat. 3. Uma parte do rachis da folha, vista do lado superior, mostrando a inserção dos foliolos, tendo um inteiro de tam, nat. 4. Parte inferior de um ramo, mostrando a disposição das flores fem., de tam. nat. 5. Spathas e espadice, seis vezes reduzidos. 6. Extremidade da spatha interior, vista pelo dorso, de tam. nat. 7. Uma flor femea. 8. Calyce. 9. Corolla. 10. Corolla vista interiormente, mostrando o androceo. 11. Ovario, tudo duas vezes augmentado. 12. Calyce e corolla, que persiste no fruclo, visto pelo lado externo, de tam. nat. 13. Fructo inteiro. 14. O mesmo, cortado verticalmente, de tam, nat.

Encontrei esta bella palmeira em diversos pontos, sempre com o nome de Tucum-asu.

No logar denominado Cachoeirinha, no Rio Cuyabá, achei uma grande soqueira en terreno arido, no meio de bromelias finguins, e depois nas serras da Bocaina, de Manoel Antonio, nas cabeceiras do Rio Sumidouro, nas margens do Rio da Casca, nas do Rio Cabral, sempre em logares humidos e á sombra das mattas.

Fórma grandes soqueiras e torna-se notavel pelo seu aspecto. Os caules esbranquiçados, as vaģinas, os peciolos, os rachis, a parte inferior dos foliolos, as spathas, tudo é branco, que faz sobresahir o ouriçado de grandes espinhos negros e luzentes e o verde escuro da parte superior dos mesmos foliolos, contribuindo para que se destaque e chame a attenção. A não ser o $A$. Mйumuı u, não conheço especie algunıa, que seja mais espinhosa e que tenha aculeos tão grandes.

Nas proximidades do Forte Principe da Beira e do Rio ltenez, no Guaporé. e na Bolivia, Alcides d'Orbigny encontrou com um nome indecente, não sei por que, dado pelos Guarayós, Huaimy-tacoca, uma palmeira que muito se approxima d'esta. é o Ast. Huaimi, que Martius descreveu. Pareceu-me dever identificar a especie por mim encontrada com a de d'Orbigny, mas, taes differenças encontro nas descripções e nos desenhos, que sou obrigado a considerar nova especie.

Infelizmente nåo encontrei, em Maio e Junho, senão flores femininas e fructos maduros. 
Apresento aqui, comparativamente, as differenças principaes que encontrei. O facto de ter a corolla maior do que o calyce, não é caracteristico bastante, porque outras especies congeneres como o Ast. tucuma Mart., I'auperiense, Barb. Rod. e acaule Martius tambem tem este distinctivo.

\section{A. Huaimi}

Caule com aculeos voltados para baixo.

Peciolo com duas pollegadas de comprimento. Foliolos equidistantes linear-acuminados, regularmente dispostos, com cerdas nas margens.

Espadice com pedunculo curto e aculeado, de $\mathbf{I}^{\text {m }}$ de $\mathrm{lg}$.

Spatha aguda, vestida de expessos aculeos.

Fructos de $31 / 2 \mathrm{~cm}$. de comprimento.
Ast. leiospatha

Caulc com aculeos divergentes só na parte inferior do circulo da cicatriz da quéda das folbas.

Peciolo de $0^{m}, 60-I^{m}$ de comprimento.

Foliolos irregularmente divergentes lineares, obliquamente acuminados, com cerdas nas margens e ornado de $2-3$ aculeos grandes, na parte superior da nervura média.

Espatice com longo pedunculo inerme, de I"I) a I I $^{\text {, }}, 60 \mathrm{lg}$.

Spatha lisa, coberta de tomento branco, pulverulento, tendo em alguns individuos (raros) alguns (poucos) pequenos aculeos exparsos na parte inferior.

Fructos de $\& \mathrm{~cm}$. de comprimento.

Os caracteres differenciaes que apresento são tirados das descripções de Martius e de Drude. Outras differenças encon. trar-se-hão cotejando as descripções.

Certo de que não serão modificações occasionadas pelo clima e pelo meio, visto como encontrei outras plantas de zonas mais longinquas e sempre com os mesmos caracteres, não trepido em apresentar esta nova especie.

Var. SABULOSUM Barb. Rod. Caudex roseo-ferrugineo pulverulentus, caespitosus, inermis; folia multo minus aculeis armata, pedunculo dorsi inermi lateraliter aculeis armato, foliolis-lineri-lanceolatis, in acervos remotis, dispositis. Drupa $\mathrm{O}^{\mathrm{m}}, \mathrm{O}_{4}-\mathrm{O}^{\mathrm{m}}, \mathrm{O}_{34} \mathrm{lg}$.

Explic. TAB. XIX. FIG. B. - ז. Fructo cortado verticalmente, de tam. nat. 3. Córte transversal do peciolo, de tam. nat.

Nos campos humidos e arenosos das margens do Rio S. Miguel das Areias, proximo affluente do Rio Aricá e nas bocainas da serra da Chapada, encontrei grandes soqueiras 
d'esta variedade, que se distingue da especie typica, não só pelo caule que é inerme e coberto de tomento pulverulento roseo ferrugineo, como tamben pelas folhas que têm os foliolos mais largos, com os grupos muito mais distanciados, e com poucos aculeos, como tambem pelos fructos, que são maiores.

Uma differença pratica apresenta. Da especie typica os naturaes extrahem dos foliolos uma fibra longa e muito forte, com que fazem linhas e cordas, sendo que o gado é avido das suas folhas, emquanto que esta variedade não só não dá fibras boas. cono tambem o gado a regeita. Tem o mesmo nome de Tucum acu. ou mais vulgarmente Tucum da sera.

Tratando dos Astrocaryuns, não posso deixar de aqui apresentar algumas especies, que perpetuam um engano. A primeira é synonyma de outra e a segrunda não é um Astrocaryum e sim um Bactris.

\section{EMENDA}

ASTROCARYUM TLCUMA Mart. in Palm. Bras. 77 t. $65 \mathrm{f}$. Kunth. Enum. plant. III. p. 274 ; - Wath. Ann. bot. syst. V. p. 822. II: Wallace Palm. tree Amaz. Io7 t. XlLI et II f. 5 ; Drude in Flor. Bras. Il]. p. 1I. p. 380. n. 15 ; Wendl. in Kerch. Index Palm. p. 232. Index Kewensis 1. p. 240. Ast. tucumcides I)rude in Fl. Bras. IIJ. p. II. p. 381 . tab. LXXXI. fig. VI (analysis).

Entre as plantas cultivadas no Passcio Publico do Rio de Janeiro, existe uma soqueira do Astrocaryum tucumá Mart. cujas sementes vieram do Pará. D'esta especie o Snr. Glaziou. remetteu para a Europa amostras, que deram em resultado a nova especie descripta por 1)rude, que nåo é mais do que o Tncuma-firanga, taio vulgar e tão conhecido em todo o Estado do Pará.

Quem conhece e estudou o turumi l'araense, nio se engana ante a palmeira do Passeio Publico. Tanto isso é ver- 
dade. que é o proprio monographo Drude quem diz na Flora Brasiliense :

"Crescit in Brasilia aquatoriali: Glazion! " So6o (specim. cultum in Rio de Fanciro); In cultura (Rio) floret Novembrr (Glazion in litt.)

Esta especie apezar de passar da zona equatoria! para a tropical, apezar da cultura, não modificou os seus habitos. Informações inexactas levaram o illustre professor a crear uma especie. quando é a mesma descripta por Martius. $\mathrm{O} A$. tucumoides de Drude é synonymo de A. tucumá de Martius. O mesmo professor baseia.se tambem na opinião de Wallis, quando diz: "Tucurí incolorum. qui (ex nota Hallis) hanc speciem ab antecedonte c sequente discernun(). Conheço todos os astrocaryuns do Amazonas e do Pará, estudei-os todos, se existisse esta nova especie, com certeza durante a minha estada no Amazonas, de 1872 a 1875 e de 1883 a 1889 havia de a ter encontrado. A especie tucumoides (do Rio) conheço-a tambem, é simplesmente o Tucumá-piranga, apezar da opinião de Wallis.

BACTRIS INTERRUPTE-PINNATA Barb. Rod.-Astrocaryum humile Wallace, Palm-trees Amaz. 115. t. XLV. - Drude in Flur. Bras. IIl p. II p. 386.

Esta especie é mui commum nas capoeiras e nas mattas das proximidades da cidade de Belem, no Pará e em muitas outras localidades do mesmo Estado, onde cresce sempre á sombra das arvores, em logares em geral humidos. E' uma palmeira quasi acaule, e que dá em soqueiras. Quando os exemplares são velhos criam troncos muito espinhosos, em geral curvos, mas que não excedem a $1^{2} / 2$ de altura. Tem os fructos cinnabarinos e com pequenos aculeos caducos. E' semelhante ao meu Bactris Tammanensis e tambem ao meu Bactris acanthocarpuides, porem esta se afasta da de Martius em ter longo caule, fructos amarellos e as spathas inteiramente diversas, assim como as flores. 
Reivindico aqui ainda uma vez (1) esta especie, que sem razão foi levada por Drude para synonyma da acanthocarpa.

Creio que o professor Drude, apresentou a especie de Wallace, sem ver os materiaes, porque se os tivesse visto, estou certo que não confundiria os dois generos. O desenho de Wallace, caracterisa bem um bactris e bem representa a especie. Com quanto já em 1882 (2), fizesse esta correcção, ainda aqui a faço para que não continue perpetuado o engano.

A proposito d'esta especie devo aqui registrar um facto, que observei en um $A$. Mumbaca Mart.. que cresce socialmente com esta.

Nas mattas do Curro, no fim da Estrada de S. João, em Belém do Pará, encontrei em 1872, um pé de Mumbaca, que teria tres metros, e que na altura de dous metros, mais ou menos, tinha tido o tronco partido, perdendo, por conseguinte. completamente a fronde.

Assim decepado, o espique apresentava em roda da cicatriz dezesete rebentos, de varios tamanhos, muito unidos e incurvados. Os maiores tinhão seis decimetros de altura. com as folhas desenvolvidas e bem caracterisadas. Este exemplo é uma boa contribuição para o estudo anatomico da structura e evolução dos espiques das palmeiras.

(I) Já fiz esta reivindicação no meu trabalho Les Palmiers, á pag. 16.

(2) Obr. cit. pag. 18 


\section{Gen. Scheelea Kartr.}

1. SCHEELEA ANIZITZIANA Barb. Rod. Acaule excelsa; foliis elongatis erectis subarcuatis, pedunculo marginibus laceratis, foliolis per greges 2-3 aggregatis sub oppositis. lineari-lanceolatis acuminatissimis. Spadix monoecis, masculis et androgineis simul evolutis, spatha int. ventricosa crasse lignosa profunde sulcata longe rostrato-acuminata. Flores masc. parvi calyce vix conspicuus, petalis teretibus carnosoclavatis roseis post nigro-violaceis stamina feré dimidium corollae attingentia; fem. multo majores ovoidei sepalis petalisque lato cordiformis acutis ad apicem nigro-violaceis sub aequilongis convolutis, androcei abortivi cupula basin germinis cingente, stigmatibus exsertis.

Tab. $X X$.

Folír 10-1 2 contemporanea, $5^{\mathrm{m}}, 30 \mathrm{lg}$. petiolo concavo, $\mathrm{O}^{\mathrm{m}}, 70 \mathrm{lg}$.; foliolis per greges aggregatis. gregibus ad basin remotis dein approximatis, inferiores $1^{\mathrm{m}}, 32 \times \mathrm{O}^{\mathrm{m}}$.o $5 \mathrm{lg}$.. lineari-pendentibus, medio $\mathrm{O}^{\mathrm{m}}, 90 \times \mathrm{O}^{\mathrm{m}}, 45 \mathrm{lg}$., divaricatis, superiores $\mathrm{O}^{\mathrm{m}}, 20 \times \mathrm{O}^{\mathrm{m}}, 006 \mathrm{lg}$., suboppositis. Spadices $2-3$ evolventis, spathis rubiginoso-tomentosis, masc. $0,90 \times 0,24 \mathrm{lg}$., rostrato, androg. 0,70 X0,26 lg., longi-rostrato, minoris; rami masc. $0,09 \mathrm{lg}$., gracilis ad iman basin flexuosis, floribus denudati. Flores rami fem. 0,01-0,04 lg.; fem. I-4 consociati, inter se $0,105-0,01$ distantes, scrobiculis patelliformibus unilateralibus inserti, $0,02 \times 0.015 \mathrm{lg}$., calyce et corolla aequali structura. stylo brevi in stigmata tripartita excurrente. Drupa non vidi.

Hab. in Matto Grosso, et culta ad Assumpção, Paraguay, Floret May'o. Herb. n. 223.

Explic. TAB. XX. - I. Porte muito diminuido, 2, $2 a, 2 b, 2 c$. Cortes 1 ransversaes do rachis da folha; de tam. nat. 3. Uma parte do rachis mos. trando a disposição dos foliolos, de tam. nat. 4. Flor masculina de tam. nat. 
5. Uura petala e um estane, duas vezes angmentalos 5. Estame e anthera, quatro vezes augmentadi. 7. Flor femea, de tam. nat. 3, 9, ro. Sepalas de lam, nat. I I, 12, I3. Petalos de tam. nat. 1. Androceo e ovario, de am. nat.

Entre as plantas cultivadas na bella quinta /duna do consul allemão Yangels, no districto da Recolleta. en Assumpçĩo do Paraguay. encontrei este soberbo especimen, com dois grandes espadices de flores um masculino e outro feminino. Ahi levado pelo meu amigo o professor hungaro João Daniel Anizitz, nem este. nem o proprietario da quinta me souberam informar com exactidào qual a localidade propria d'essa palmeira, sabendo apenas que era originaria de Matto Grosso.

O genero Scheelea nunca tinha siclo encontrado no Brasil e só se fez representar depois de iS91, epoca em que nas minhas Plantas Noous, publiquei a descripçāo de duas especies e mais tarde em 1S96, no $\mathrm{V}$. fasciculo, tornei a tratar das mesmas e the dei a patria. Entretanto vejo hoje que nāo só no norte do Brazil se encontra este genero como tambem no sul, em Natto Grosso. Ahi cresce uma especie, commum tambem á Bahia e esta, que se suppõe ser los lados do Rio Paraná.

E' uma especie acaule, porém gigantesca. Approxima-se na inflorescencia da minha Scheclea anylacea (1), porém afastase en ser acaule, ter as follas muito mainres e as flores differentes. Procurei esta especie em Matto Grosso e não a encontrei, não se podendo confundil-a com o Akury' ou Motacu, que aos milhares encontrei não só em Matto Grosso, como na Bolivia.

Considerando-a nova impontio-lhe o nome de Scheclea Aniziziana, como homendgem prestada ao meu companheiro de excursões no laraguay, o professor hungaro Joảo Daniel Anizila que tão bons serviços tem prestado á botanica e particularmente á minha expedição prestou.

2. S. PRINCEPS Karst. in Linnaea XXVlll (1856) p. 269. - Wendl. in Kérch. Les palm. Index. p. 256.-Wálp. Ann. bot. sy'st. V. p. $\$ 55$ n. 5. Hort. Kiai. IN p. $\$ 23$.

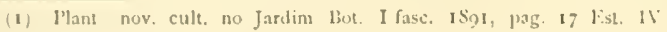


Attalea Princeps Mart. in Palm. Orbign. 113.t. 4. f. 2 et 31 .; Hist. nat. palm. 298. t. 167. f. 1.-Kunth in Enum. plant. III. p. 277.- Walp. Ann. bot. syst. I. p. I008., V. p. 824. Drude in Flor. Bras. III. p. II. p. $44^{2}$.

Tab. XXI. fig. B.

Encontrei esta bella palmeira nas margens dos rios S. Lourenço, e Cuyabá, assim como nas mattas da Chapada, crescendo socialmente, apresentando grandes caules, tornando-se mesmo uma palmeira excelsa.

Achei em Junho, com fructos maduros. E' a palmeira mais commum em Matto Grosso, onde tem vulgarmente o nome de Acury, Uacury, Guacury e Rucury. Na Bolivia, Bahia de Caceres, os indios Chiquitanos me deram o nome vulgar de Motacu; que concorda com o que deram a d'Orbigny, em Santa Cruz de la Sierra, onde foi encontrada pela primeira vez. Cresce tambem na Bolivia, nas provincias de Moxos e de Chiquitos.

Os fructos quando maduros são amarellos e cobertos de tomento fusco. Comem-se cozidos. As sementes dão oleo que os indios empregam contra a calvicie. Quando os fructos são novos empregam em Matto Grosso, a agua contra as ophtalmias. Depois de seccos, na Bolivia, servem-se d'elles para defumar o Cáucho ou borracha.

Spencer Moore que encontrou esta especie com o nome de Goacury e d'ella levou fructos para Londres, diz á p. 500 do vol. IV das Transations of the Linnean Society of London o seguinte: "The fruits differs from all described by Drude, and belongs in all probability to a new species».

A desconfiança do illustre botanico inglez de que não seja a mesma especie é baseada no facto que observei; não só o porte da planta, como o tamanho do cacho e dos fructos e sua quantidade varia segundo as localidades. Encontram-se exemplares com grandes fructos e com pequenos, mais ou menos oblongos ou alongados, porém, todos pertencem á mesma especie. 
3. SCHEELEA PRINCEPS var. CoRumbaensis Barb. Rod. Acaulis, raro caudice humili crasso, folíis erecto-arcuatis, foliolis per acervos $2-6$ oppositis divaricatis, linearis, oblique acuminatis. Spadix tabacino tomentosus erectus, fructifer denique cernuus, ramis androgynis fores fem. 1 exserente. Drupa longi-oblonga vel ovoidea rostellato-acuminata, trisperma.

Tab. $X X I$ fig. $A$.

Caudex. O vel usque $\mathrm{I}^{\mathrm{m}}-\mathrm{I}^{\mathrm{m}}, 50 \times \mathrm{O}^{\mathrm{m}}, 20 \mathrm{lg}$., Folia $10-15$ contemporanea, $3^{\mathrm{m}}-4^{\mathrm{m}} \mathrm{lg}$., foliolis inferiores $\mathrm{O}^{\mathrm{m}}, 8 \mathrm{O} \times \mathrm{O}^{\mathrm{m}}, 005 \mathrm{lg}$., acuminatissimis, medio $\mathrm{O}^{\mathrm{m}}, 55 \times \mathrm{O}^{\mathrm{m}}, \mathrm{O}_{2} 2 \mathrm{lg}$., superiores plures aproximatis, sub oppositis, multi minoribus, extimis $0^{m}, 15 \times 0^{m}, 007 \mathrm{lg}$. Spatha interior masc. lignosa $0^{\mathrm{m}}, 70 \times 0,{ }^{\mathrm{m}}, 10$ $\mathrm{O}^{\mathrm{m}}, 12 \mathrm{lg}$, abrupte rostrato-acuminata, sulcata, tomento ferrugineo vestita, fem crasse lignosa, rostrato acuminata, longitudinaliter sulcata, $0^{m}, 40 \times 0^{m}, 1_{2}$, tomento ferrugineo vestita. Drupa $0^{\mathrm{m}}, 65 \times \mathrm{O}^{\mathrm{m}}, 24$ vel $\mathrm{o}^{\mathrm{m}}, 55 \times \mathrm{o}^{\mathrm{m}}, 3 \mathrm{O}-\mathrm{o}^{\mathrm{m}}, 32 \mathrm{lg}$., epicarpio fibroso, flavo, ferrugineo-tomentoso, mezocarpio flavescenti, farinaceo, endocarpio brunneo, lapideo, $\mathrm{I}-3$ spermo.

Hab. in locis humidis ad Corumbá. Guacury vel Akury ab indigenis appellatur. Flor. et fruct. May. Herb. n. 2 IS.

Explic. Tab. XXI. $-A$. I, Porte muito diminuido. 2, Extremidade de um foliolo. $3,3 a, 3 b, 3 c, 3 d$, Córtes transversaes do rachis da follha, de tam. nat. 4. Extremidade da spatha interior, de tam. nat. 5, Porte do rachis do spadice, com flores masculinas, de tam. nat. 6, Uma flor masc. de tam. nat. 7, A mesma, duas vezes augmentada. 8, Uma pelala, com dous estames, duas vezes augmentada. 9, Uma parte do ramo com uma flor femea, de tam. nat. 10, 11, 12, Sepalas. 13, 14, 15, Petalas. 16, Androceo e ovario, com quatro estigmas, tudo de tam. nat. ${ }^{17}, \mathrm{Um}$ fructo inteiro. 18 , Um outro fructo, para mostrar as duas fórmas que apresenta. 19, Córte vertical do mesmo. 2o, Córte transversal do mesmo, tudo de tam. nat.

B. Porte da Schcelca Princeps, muito diminuido.

Nos terrenos humidos e calcareos que circundam a cidade de Corumbá, encontrei centenas de exemplares todos acaules, em plena florescencia no mez de Maio. 
Tres ou quatro exemplares vi com caules de um metro, mais ou menos, porém, pelo seu estado mostravam ser muito velhos. Encontrei tambem alguns cachos de fructos maduros. Não sei se devido ao terreno, o certo é que o aspecto é diverso; não só a planta é menor como os espadices das flores. Os cachos n'esta variedade são pequenos e os fructos muito oblongos e acuminados, emquanto que na especie caulescente os troncos são altaneiros, os cachos de alguns, de mais de metro de comprimento, com os fructos grandes. As petalas das flores masculinas quando novas são de um bello roseo e depois roxas e as sepalas e petalas das femininas de um branco de marfim com as extremidades tambem roseas e depois roxas. Tem vulgarmente o nome de Akury, Guacury ou Uakury, que não é mais do que uma corruptela de Uakuriy, de $u \dot{a}$ fructa e kuriy do formato de pinhão, alongados.

Considerando uma variedade distincta aqui a consigno. 


\section{Gen. Orbignia Mart.}

1. ORBIGNIA MARTIANA Barb. Rod. sub. pr. tab.-Attalea sr'eciosa Mart. Palm. Bras. 139. t. 96 f. III. 3. 4. 5. 6. (sub nom. A. excclsa); Hist. nat. palm. III. 29S. t. 160. f. IV. et Palm. Orbign. 117; Wallace Palm.trees Amaz. p. II7. Tab. 46; Kunth. Enum. plant. III. P. 277; Walpers Ann. bot. syst. V. p. 824; Wendl. in Kerch. Les Palm. p. 233 ; Drude in Flor. Bras. III. p. II. p. 444.; Index Kew. I. p. 248. - Coco Nayá. M. Arruda Camara, Disc. sobre a util. dos jard. p. 35.-Oribignu Lrde Drude in Flor. Bras. 1II, p. II, p. 448, Tab. C11. Caudex procerus recte cylindricus Iavis, foliis erecto-patentibus amplis concin nis tortis ad apicem flexuosis recurvis, foliolis elongatis rigidis inter se approximatis oblique acuminatis, in plano verticaliti patentibus. Spadix validissimus ramosus pendulus, ramis rigidis bracteatis dense exserentes, androginis flores fem. multos sessiles gerentibus dein in spicam masc. abortivam paucifloram ex. currentibus; flores masc. calyce exiguo petalis 2 rarissime 3. biquadridentatis incurvis imbricatis; staminibus 24 per greges 8 divisas, antheras loculis irregulariter inter se pluries contortis, germinodium sub nullum; flores fem. plurimo majores ovoideo-oblongis, bibracteatis, ferrugineo tomentosis, sepalis lato oblongis obtuse, carinato acuminatis, petalis paulo minoribus oblongis marginibus irregulariter serratis ad apicem longi triclentatis, androecei abortivi cupula petalis dupla minore germen in stylum crassum ferrugineotomentosum sensim excurrens cingente, stigmatibus 3-6. Drupa magna obovali-oblonga conico-rostrata fere ad dimidium induviata ad basis ferrugineo-tomentosa et acl apicem albo-tomentosa aureolata 3-6 sperna.

$$
\text { Tab. XXII et NXIII. fig. } 1 \text {. }
$$

Caudex $15-20^{\mathrm{m}} \times \mathrm{O}^{\mathrm{m}}, 45 \mathrm{lg}$., " superne, vaginis diutius persistentibus involutus, denique denudatus. Folia ${ }_{15}^{-20}$ congesta 
comam formantia, exteriora patentia ", dum nova flavo-striata, albo-tomentosa, $9^{\mathrm{m}}, 40 \mathrm{lg}$., rachis $8^{\mathrm{m}} \mathrm{lg}$., foliolis inferiores majoribus, angustis, medio $\mathrm{I}^{\mathrm{m}}, 2 \mathrm{O} \times \mathrm{O}^{\mathrm{m}}, \mathrm{O} 38 \mathrm{lg}$., superiores minoribus, glauco-tomentosis; spadices intra-folia, 4-6 simul evoluti, androgyni 2,20 lg., pedunculo $\mathrm{I}^{\mathrm{m}}$, IO $\times \mathrm{O}^{\mathrm{m}}, 07 \mathrm{lg}$., compresso, spatha exterior lanceolata, apice rotundato, $\mathrm{O}^{\mathrm{m}}, \mathrm{I} 5$ lata; interior magna, erecta, incurva, lanceolata, sulcata, apice in rostrum anceps $\mathrm{O}^{\mathrm{m}}, 50$ attenuato, dorso bicarinata, ferrugineo-tomentosa, ad basin vaginantia. Drupa cum acumine conico, $\mathrm{O}^{\mathrm{m}}, 1 \mathrm{I} \times 0,{ }^{\mathrm{m}} \mathrm{O} 77 \mathrm{lg}$., epicarpio fibroso, mezocarpio pluposo-farinaceo, endocarpio lapideo, brunneo, oblongo. ad apicem acuto. $\mathrm{O}^{\mathrm{m}} .605 \times \mathrm{O}^{\mathrm{m}}, 062 \mathrm{lg}$., semina irreguriter oblonga sub-vertice incrassata, $0^{\mathrm{m}}, 043-0,050 \times$ $\mathrm{O}^{\mathrm{m}}, \mathrm{OI} 2-\mathrm{O}^{\mathrm{m}}, \mathrm{O} 19 \mathrm{lg}$.

$\mathrm{HAB}_{\text {A }}$ in Brasilia aquatoriali et orientali, in silvis Rio Arinos, serra dos Parecis, Rosario, Rio Cuiyabá, S. Miguel das Areias, Tombador, in Matto Grosso. Aguaçu. Guaguaçu vel Baguaçu ab incolis nominatur; etiam in silvis prope fumen Tapajós, Madeira, Purus, prope flumen Amazonum superius, UAUAçU incolonm. Culta in Jardim Botanico Rio de Janeiro, n. ${ }^{\circ} 398$.

Flor. et fruct. Funio.

Explic. TAв, XXII, - I. Porte, muitissimo reduzido. 2. Peciolo, muitissimo reduzido. 3. Fructo inteiro. 4. O mesmo, cortado verticalmente. 5. O mesmo, cortado transversalmente, tudo de tam. nat.

TAв. XXIII. A. 1, 2, 3, + e 5. Córtes transversaes do rachis da folha, de tam. nat. 6. Parte superior do rachis da folha, visto do lado superior, mostrando a inserção dos foliolos. 7. Uma parte de um foliolo. 8. Apice de uin foliolo, tudo de tamanho nat. 9, го. Duas flores masculinas, de tam. nat. 1 I e I2. Duas petalas, vistas de frente, de tam. nat. I3 e it. Dois estames quatro vezes augmentados. I5. U'ma flor femea, depois da anthese, de tam. nat. 16. A mesma, mostrando só a corolla, de tam. nat. 17. Androceo e ovario, de tam. nat.

Occupar-me-hei agora de uma das mais bellas, mais excelsa e mais graciosa das palmeiras do Brasil. Malfadada entretanto tem sido! Estende-se desde as Guyanas, pelas florestas do Amazonas, entra no Matto Grosso e vae á Bolivia. É o Uauaçu, 
do Amazonas, Aguasu, Baguasu, ou Guaguafu de Matto-Grosso. Encontrei-a não só cultivada en Cuyabá, como fui depois vel-a em estado selvagem, formando grandes florestas, em que se via desde a semente que germinava até aos velhos troncos centenarios. Encontrei felizmente com flores e fructos, não só verdes, como maduros.

Esta palmeira, noticiada por Martius em 1823 (I), em pequena diagnose só do fructo, foi mais tarde em I847 (2), detalhadamente descripta pelo mesmo monographo, que deu entåo alguns caracteristicos do caule, descripção que repetiu em 1850 (3).

Esta foi baseada por exemplares colhidos no Valle do Amazonas, onde Martius penso que não viu a planta e sim só os fructos. Martius conhecia, sob o nome Guaguą̧u, a especie de Matto Grosso, pela noticia que das palmeiras the deu em carta o Dr. Silva Manso e que identificou com o Uauaçu do Amazonas, a Attalea speciosa (4).

Mais tarde, de 1848 a 1852 , Alfredo Wallace, percorrendo o Amazonas, encontrou-a, mas tambem, apezar de ter visto a planta, da qual deu um bem feito desenho do porte (5), todavia tambem não viu as flores.

O Dr. Spruce, que tambem explorou o Amazonas na mesma epoca, não a noticía, e eu, que por tantos annos percorri n Amazonas, que vi centenas de exemplares, nunca tambem pude encontrar flores, tendo, comtudo, desenhado não só o porte, como os fructos, esperando sempre ver as flores, o que não me foi possivel. Depois de nim, o professor Trail tambem percorreu parte do Amazonas, e não se occupou d'ella, e assim todos os botanicos que percorreram o valle do Amazonas, por não ter visto as flores deixaram que corresse mundo um engano, que

(1) Mart. Pulm. Bras. loc. cit.

(2) Mart. Pulm. Orbign. loc. cit.

(3) Mart. Jlist. Nist. I'ulm. loc. cit.

(5) Wallace I'alm.trees of the Amazun. 1553, p. 117, tall. . IT. I\%.

(4) llist. Nitt. J'alm, I, pag. Cl.XX1X. 
se perpetuou até hoje, isto é, por mais de 74 annos. Em Matto Grosso, posto que percorrido tambem por alguns botanicos, nenhum a mencionou, mesmo o Dr. Spencer Mloore. Cabe-me, pois, a ventura de destruir hoje o engano e levar a especie para o genero a que pertence.

A Attalea speciosa de Martius é uma Orbignia !...

Drude, com razão, na sula monographia da Flora Brasiliense, a incluiu nas species inserta sedis. É a especie que maiores fructos dá no Brazil, e d'ahi o motivo pelo qual os nossos indigenas deram o nome de $U \dot{a}$-ıąu, fructo grande, corrompido pela pronuncia castelhana em Aguaca, Bagua६u, Guaguaçu. Os naiores fructos que vi, foi no alto Tapajós, proximo á Cachocira da montanha. Ahi vi exemplares quasi do tamanho de um Cocos nucifera ou Coco da Bahia. Con estes fructos, assim como com os do Urukury (Attalea excelsa Mart.), os seringueiros defuman a borracha. O tamanho mais vulgar é o que representa na Est. XXII, sendo que pelo grande numero que dá em cada cacho, que dois homens não carregam, quasi sempre são comprimidos pela pressão que uns exercem sobre outros.

Como disse, é das palmeiras uma das mais bcllas e das mais graciosas, vista de longe, porém de perto, quando nos collocamos junto á ella, é bruta, pelo tamanho e grossura do caule, pelo tamanho das folhas, das espathas e dos espadices, e mesmo pelos fructos.

Cresce nos logares humidos e nas florestas. Encontrei entre villa Mendes e as Areias de S. Miguel uma grande floresta composta só d'esta especie, que apresenta de longe um lindo aspecto. As vanillas amam esta palmeira; por ella sobem e estendem-se até pelo rachis das folhas.

Devo observar que esta palmeira, em 1827, foi encontrada tambem pela commissão Langsdorff, quando passou por Matto Grosso.

Desfazendo, pois, o engano em que todos laboravamos, denomino-a Orbignia Martiana, dedicando-a á memoria do sabio palmographo que primeiro a descreveu, cumprindo um dos 
dos artigos da lei botanica e rendendo uma homenagem ao mestre.

Devo observar que na minha descripção aproveitei o que na de Irude havia de exacto.

Agora devo corrigir outro engano.

Na monographia citada, da Flora Braziliensis, vem descripta, como especie nova, pelo illustre Professor Oscar Drude, a Orbignia Lydiae, que pelas informações do collector Glaziou é originaria da região do Pará e introduzida no Passeio Publico do Rio de Janeiro. Dos exemplares d'este Passeio, foi remettido o material que serviu de base para o estudo do Professor de Dresda.

Por muito tempo procurei conhecer de visu a Orbignia Lydiae, porém, nunca a encontrei. Conhecia alguns pés de Uauassu, que os tinlia por Allalea speciosa, porém, nunca vi no mesmo Passeio Publico especie que pudesse tomar pela que procurava. Conhecia tambem um magnifico exemplar que existe n'este Jardim, ha mais de 40 annos, verdadeiro Uauassu, e que se identificava com os exemplares do Passeio Publico e Campo da Acclamação, porém, nunca suppuz que esses exemplares fossem os que forneceram material para a apparição da Orbignia Lydiae.

Depois de ter determinado o Baguaş de Matto Grosso, e o identificado com o Uuzassu do Amazonas, desconfiei que a $O$. Lydiate, que não encontrava, talvez fosse o mesmo Uauassu e para certificar-me dirigi-me ao mesmo Passeio e ahi pedi ao Sr. Mallemont, jardineiro-mór, companheiro do Sr. Glaziou, que me mostrasse os exemplares da O. Lydiac. Qual nåo foi a minha admiração vendo-me ante á antiga Allalea spcciosa, que outr'ora, quando nova, foi acaule, mas que hoje já tem um espique de $\delta$ metros de comprimento !...

O facto de ter sido dada por acaule pelo Sr. Glaziou não é novo, e, entre muitos, citarei o da Manihot Glazioini, cuja descripção foi tambem feita sobre informações do mesmo senhor. A Manisoba, (M. Glaziovii) è uma arvore excelsa dos 
Estados do Norte. entretanto a descripção diz que é do Rio de Janeiro e que só attinge a altura da mandioca vulgar. Habitus speciminum ut in M. utilissima et in M. palmata, v. Aipi. (1)

O exemplar que serviu para esta informação é hoje uma das arvores mais altas d'este Jardim.

Não conhecendo o collector Glaziou exemplar algum com espique. tomou-a por acaule e remetteli logo para a Europa, material para uma nova especie. Depois de publicada na Flora, o mesmo administrador a mencionou em uma relação de plantas por elle cultivadas no Passeio Publico e Praça da Acclamação e que foi publicada em um dos Relatorios do Ministerio da Agricultura. Então ainda a planta era acaule.

Felizmente, além da affirmativa do jardineiro, a especie estava com flôres e fructos que corroboraram a minha opinião.

A Orbignia Lydiae, do Passeio, era a Attalea grande, nome com que outr'ora era conhecido o exemplar d'este Jardim, e se identificava com o Bagıı̧̧ de Matto Grosso e com o Uauassu do Amazonas. Em vista, pois, d'isso sou obrigado a levar para synonymia da O. Martiana a $O$. Lydiae.

Parece que devera conservar o nome Lydiae para a Attalea speciosa, visto ser nome mais antigo. mas como não foi o autor da Orbignia Lydiae que reconheceu o genero do Uauassu e applicou este nome a uma especie que julgava inteiramente distincta, entendo dever conservar o nome que impuz por ser elle applicado á propria especie descripta por Martius, passando a $O$. Lydiae a figurar como synonyma. Além disso o nome speciosa, já eu o tinha empregado em outra especie, (2) pelo que não póde d'esta ser tirado.

Se o nome Lydiae fosse dado por engano ou por outro autor á mesma palmeira. convenho que devera ser o nome adoptado, mas, tendo sido dado a outra planta que o proprio

(I) Flor. Bras. XI. p. II. p. 446.

(2) Plant, now. cult. no jart. Bot. 1891. 1. t. 32. tal. IX. 
autor considerava distincta, tanto que conservou a Altalea speciosa, na mesma monographia, não posso admittir.

O autor teve em suas mãos os originaes de ambas $e$ as distinguiu, portanto não póde o seu nome ligar-se á especie que não reconheceu nem separou.

Assim penso, entretanto os mais versados que decidam se a Altalea speciosa de Martius, deve ser Orbignia Martiana de Barbosa Rodrigues, que reconheceu o genero e identificou as duas especies, ou se $O$. Lydiae de Drude, que conservou especies distinctas de dois generos differentes.

Devo dar algumas explicações sobre a O. Lydiae. Por ter tido um material incompleto e falsas informações o illustre Professor Drude cahiu no engano. Este professor nåo viu as spathas. nem os espadices, apenas examinou a porção superior de um espadice androgyno, que the foi remettida e por isso disse que os ramos têm I-2 flôres femeas, quando têm muito mais, nos médios e nos inferiores.

As flôres masculinas que examinou foram as poucas que dão nas espigas terminaes dos ramos superiores, que são quasi sempre differentes, não só das que acompanham as flôres femeas, como as dos ramos dos espadices masculinos. Deramlhe tambem um desenho do porte de um individuo novo, que provava ser acaule, e por esse e outros motivos caliu no engano, não suppondo que se occupava com o material da Attalca speciosa.

2. O. MACROCARPA Barb. Rod. Acaulis vel caudice mediocri superne petiolorum basibus coronato, foliis per quinques spiras dispositis, elongatis, robustis, foliolis decrescentibus, ad basim in acervos 2-3 aggregatis et ad apicen aggregatis oppositis, lineari-lanceolatis, oblique acuminatis, subtus glaucis; Spadices monoeci, masculi it androgyni 2-3 simul evoluti spathis int. lanceolatis sulcatis rostrato-acuminatis, masc.: ramos plurimus unilateraliter evolventes ad basim minuté bracteatos; masc. androg. : 
ramos unilateraliter in spiras dextrorsas dispositos, brevissimis flores fem. secundi singulos, dein et spica mas. apicale abreviata evolventes. Flores masc. secundi parvi calyce conspicuo, petalis geminatis, incurvis, irregulariter lanceolatis concavis bi-tridentalis staminibus 20 densi insertis; flores fem. oblongo-ovoidei sepalis cucullato-obtusis quam petala tridentata marginibus serrulatis longioribus, androecei abortivi cupula inaequali germen in stylum nullum cingente, stigmatibus 6 .

\section{Tab. XXIII, fig. B. XXIV.}

Caudex $2^{\mathrm{m}}-5^{\mathrm{m}} \times 0,{ }^{\mathrm{m}} 25 \mathrm{lg}$., Folia 8 contemporanea, in spiras dextrorsas 5 disposita, densa congesta $5^{\mathrm{m}} \mathrm{lg}$. ad caudicem marcescentia, petiolis diu persistentibus, petiolo albo-tomentoso viridi-punctato, $\mathrm{O}^{\mathrm{m}}, 90 \mathrm{lg}$., folioli inferiore $1^{\mathrm{m}}, 50 \times 0,016$ $\lg$., media, $\mathrm{O}^{\mathrm{m}}, \mathrm{SO} \times \mathrm{O}^{\mathrm{m}}{ }^{\mathrm{O}} \mathrm{O} 5 \mathrm{lg}$., superiore $\mathrm{O}^{\mathrm{m}}, 35 \times \mathrm{O}^{\mathrm{m}}, \mathrm{OO} 1 \mathrm{lg}$., spadices $2-5$ simul se evolventes, erectus. masc.: spatha lanceolata. mucronata. dorso sulcata, $\mathrm{O}^{\mathrm{m}}, 60-\mathrm{O}^{\mathrm{m}}, 90 \times \mathrm{O}^{\mathrm{m}}, 10-$ $\mathrm{O}^{\mathrm{m}}, 13 \mathrm{lg} \cdot ;$ pedunculo compresso, $\mathrm{O}^{\mathrm{m}}, 20-\mathrm{O}^{\mathrm{m}}, 45 \times \mathrm{O}^{\mathrm{m}}, 015-$ $\mathrm{O}^{\mathrm{m}}, 018 \mathrm{lg}$., laevi, rachis $\mathrm{O}^{\mathrm{m}} .15-\mathrm{O}^{\mathrm{m}}, 30 \mathrm{lg}$., postice plana, antice convexa, rami secundi, $\mathrm{O}^{\mathrm{m}}, 10-\mathrm{O}^{\mathrm{m}}, 11 \mathrm{lg}$., ad imam basin floribus denudati, ad apicem densissime scrobiculati, scrobiculis secundis, minimi bi bracteolatis purpureo-nigris. Flores $\mathrm{o}^{\mathrm{m}}$, or lg. Spadix fem. erectus, crassiore, pedunculo $\mathrm{O}^{\mathrm{m}}, 25$ lat., compresso, rachis $\mathrm{O}^{\mathrm{m}}, 40 \mathrm{lg}$. postice plana, antice convexo, rami minimi. Flores fem. singuli, ad basim tribracteati $\mathrm{O}^{\mathrm{m}}, \mathrm{O}_{3}-\mathrm{O}^{\mathrm{m}}, \mathrm{O} 4 \mathrm{lg}$. Drupa ad basin induviata, 5-7 sperma, epicarpio fibroso, viridi-flavo, ferrugineo, endocarpio osseo, cinnamomeo, $\mathrm{O}^{\mathrm{m}}, 09 \times \mathrm{O}^{\mathrm{m}}, 066 \mathrm{lg}$.

Har. ad Capão Bonito prope Serra Quebra Cabeça in Prov Matto Grosso. InDAYÁ-AÇU, incolarum. Flor et fruct Funio. Herb. n. 217 .

Expltc. Tab. XXIV. - I. Córte tranversal do peciolo. 2. Uma parte da extremidade do rachis, vista superiormente. 3. Uma porçåo de um foliolo. 
4. Extremidade do mesmo, tudo de tam. nat. 5. Córte transversal do pedunculo do spadice, de tam, nas. 6. Parte inferior do rachis do spadice, de tam. nat. 7. Spatha interior, reduzida a um derimo. 8. Uma for femea, de tam. nat. 9. A mesma, duas vezes augmentada. 10, 11. Duas petalas, duas vezes augmentadas. 12. Um fructo inteiro. $x_{3}$. () mesmo corlado verticalmente. 14. O mesmo cortado transveralmente. 15. Androceo, que acompanha o fruclo, tudo de tim. nat.

Achan -se descriptas, até hoje, apenas oito especies d'este genero, sendo tres, a humilis, a phalerata e a dubia, de Martius, da Bolivia e todas as outras do Brazil. Estas foram classificadas, tres por Martius, tres por Drude e duas por Barbosa Rodrigues. A este numero accrescento agrora, mais quatro especies, sfudo tres novas que descobri em Malto Grosso, e uma Attalea, de Martius, que passei para este genero. o que eleva o numero a doze.

Tratarei aqui da primeira, do Inday'í-aşi como vulgarmente é conhecicla em Matto Grosso.

() sabio Dr. Martius, conlsecia pelos nomes rulgares algumas palmeiras de Matto Grosso, conhecimento adquirido pelas informações, que, por cartas, o Dr. Silva Marso lhe dava. Este Indayd the era assim conlsecido, e o tinha pela Allatea compla, como nol-o diz em inma nota (1).

O nome vulgar levou-o a este engano. Com os nomes vulgares de Ndayá, Indayá, Inay'ú, Nay'd, Inaja, Anujä e Findobus, são conhecidas, em todo o Brazil diversas palmeiras dos greneros Maximiliana, Attaléa, Pindaréa e Orbignia (2). pelo facto de terem os cocos muito duros $e$ as folhas luzentes.

Os nossos indigenas applicavam, ora um, ora ontro nome ás especies d'estes generos, acompanhados de adjectivos que serviam para distinguir n'uma localidacle, uma das outras especies. Abaixo dou a etymologia das duas palavras.

1) Hive, Nat. Ialm. 1, pag. (I.X.IX, Adnet. IV'.

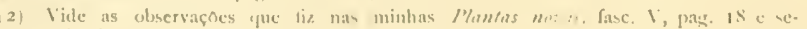
guntes, tratando de meu genero l'in insen. 
Sabendo que era conhecida em Matto Grosso uma palmeira tambem por este nome, procurei encontral-a e depois de muitas difficuldades e trabalho, fui encontrar, em Junho, no Capano Bonito, perto da Serra do Quebra-cabeça, nos campos que ficam fronteiros á Itaicy, nas margens do rio Cuyabá, esta especie, vivendo quasi socialmente, e então com flores e fructos.

E' uma bella palmeira bastante elevada, que muito se assemelha a $O$. Martiana, mas que facilmente se distingue pelas follas, cujos apices não são flexuosos e os foliolos não são voltados a tomarem a direcçảo perpendicular, que é um dos caracteristicos do Uauaçu. As flores femeas são dispostas em espiral da esquerda para a direita, sobrepostas, apparentando tres a seis fileiras. Os fructos são grandes e na apparencia se confundem com os pequenos que n'aquella especie não se desenvolvem ou são de exemplares fracos. Dão em grandes cachos pendentes, e exteriormente são cobertos de tomento tabacino na base e esbranquiçado no apice.

$\mathrm{Na}$ minha excursão ultima, tive occasião de verificar que os Indayás de Santa Catharina, S. Paulo e Rio de Janeiro são todas do meu genero Pindaréa e se identificam com a minha Pinctaréa fastuosa (1).

Devo dar tambem aqui a etymologia do nome Indaýá. Esta palarta não é mais do que a corruptella da palavra indigena Andaya, isto é: fructo duro. Em geral os nossos indios dão o nome le Andá, modificação de ankĩ $y a ́$, fructo duro, aos fructos de todas as palmeiras, mas, para designar as que têm fructos verdadeiramente duros, porque são lapideos, como os dos generos Attalea, Maximiliana, Orbignya e Pindarea dão nos fructos desses generos o nome de Andá y'á, d'onde Indiayà, e suas modificaçōes.

A palavra Pindoz'a vem de Pindó ob. e Pindó significa lustroso, brilhante, luzente, e $o b$, folla. Com effeito todas as palmeiras conhecidas por este nome tem as folhas luzentes.

1) Pinntas novens cuth. no fardin Bot, do Rio de Jan. V. pags. 23. Est. V. fig. A. 
3. O. CAMPESTRIS Barb. Rod. Acaulis. Folia erecta breve petiolata, foliolis concinnis, ad basim 2 aggregatis dein singulariter suboppositis, lineari-lanceolatis, longissime acuminatis, subtus albido-glancis. Spadices masc. gracilis spatha fusiformi in rostrum excurrente dorso sulcata; androgini ramos brevissimis bracteatos exserentes, floribus fem. singulis secundis dispositis; flores masc. secundi biseriali, calyce conspicuo, corolla bipetala, petala inxqualia oblongo tridentata et lato-oblongo vel subrotunda apice longe tridentata, staminibus 16-1 $\$$ dense insertis, filamentis inaqualibus; flores fems. ovoidei sepalis cucullatis obtusis ad apicem carinatis quam petala mucronata marginibus crenulatis longioribus, androecei abortivi cupula crenulata germen albo-tomentoso demidio cingente, stigmatibus 6.

Tab. $X X Y$.

Foliu 5 contemporanea, $2^{\mathrm{m}}, 7 \mathrm{olg}$., foliolis inferiores $\mathrm{o}^{\mathrm{m}}, 55 \times \mathrm{o}^{\mathrm{m}}, \mathrm{or}$ lg., médio $\mathrm{O}^{\mathrm{m}}, 56 \times \mathrm{O}^{\mathrm{m}}, 003 \mathrm{lg}$., superiores $\mathrm{O}^{\mathrm{m}}, 17 \times \mathrm{O}^{\mathrm{m}} .003 \mathrm{lg}$. . Spadix masc. erectus, spatha interior lignosa, sulcata, extus pallida, intus rubiginosa, $\mathrm{O}^{\mathrm{m}}, 45 \times \mathrm{O}^{\mathrm{m}}, 06-\mathrm{O}^{\mathrm{m}}, \mathrm{o} 7 \mathrm{lg}$. Rami secundi $\mathrm{O}^{\mathrm{m}}, 006-\mathrm{O}^{\mathrm{m}}, 007 \mathrm{lg}$., rachin $\mathrm{O}^{\mathrm{m}, 1}, \mathrm{O}^{\mathrm{m}}, 14 \mathrm{lg}$., Florcs masc. calyce minutissimi, corolla $\mathrm{O}^{\mathrm{m}}, \mathrm{O} 1 \mathrm{lg}$., slaminibus a 16 -I $\mathrm{S}$ formato corollam dimidio aquante, antheris convolutis. Spadix fem. floribus masc. feré destitutus, pedunculo compresso, $0^{m}, 2 \lg$. bractea magna munito; rachis $0^{m}, 85$ lag., postice plano, antice convexo, flores fem. $\mathrm{O}^{\mathrm{m}}, 03-\mathrm{O}^{\mathrm{n}} .035 \mathrm{lg}$., sessili, secundi, sepalis orato-lanceolatis, pctulis secus margines eroso-crenulatis et in apice ipso mucrone valido uncinato aculeatis: androecei cupula $0^{\text {m }}, 007$ alt., Drupa 5 sperma, globosa, vertice acuminato, $0^{m}, 06 \times{ }^{m} 0,55 \mathrm{lg}$. . cpicarpio fibroso, subaurantiaco, tabacino-tomentoso ad apicem albo-tomentoso, mezocarpio Havedo, farinaceo, indo. carpin lapideo albido.

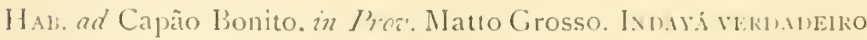

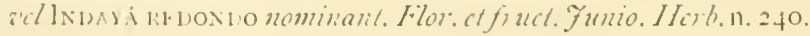


Explic. Taв, XXV. - 1. Córte transversal do peciolo. 2. Dito do rachis da folha. 3. Uma parte do rachis mostrando a disposição dos foliolos, com um inteiro, tudo de tam. nat. 4. Uma flor macho, de tam. nat. 5. A mesma, duas vezes augmentada. 7. Um estame $e$ anthera, quatro vezes augmentada. 8. Ramo com tres flores femeas. 9, io e 1 I. Sepalas. 12, 13 e 14. Petalas. 15. Androceo e ovario com seis estigmas, tudo de tam. nat. 16. Fructo inteiro. 17. O mesmo cortado verticalmente. 18. O mesmo cortado transversalmente. 19. Androceo que acompanha o fructo, tudo de tam. nat.

Nos campos do Capão Bonito, que se estendem até á serra do Melgaço, encontrei esta outra especie crescendo socialmente, fechando grandes espaços de terreno. E' acaule e tem entre os naturaes o nome de Inday'á verdadeiro ou Inday'á redondo.

Os seus cachos são erectos e com poucos fructos, perfeitamente redondos e agudos, cobertos exteriormente por tomento ferruginoso, que no apice se torna esbranquiçado. Quando, em Junho. encontrei com fructos, davam tambem numerosos espadices de flores, sendo em maior numero o de flores masculinas.

4. O. LONGiBRACTEATA. Barb. Rod. Acaulis foliis erectis in facie inferiore albido-glaucis lineari-lanceolatis oblique acutis supra nitentibus per gregas 2-3 proximé aggregatis versus apicem solitariis divergentibus dense insertis. Spadices masc. erectis spatha lineari-lanceolata dorso sulcata ad apicem bicarinata in rostrum anceps excurrente, pedunculo lyypogroeo, flores masc. secundi biseriali; petala 2-3 bidentata, staminibus 16-24, in fundo corolla insertis; androgyni ramos minutissimos secundis biseriatos longiter bracteatos laxe exserentes, floribus fem. in racheos simplicis solitariis sessillibus secundis, oblongis, sepalis lanceolatis acuminatis dorso carinatis petalis subaequantibus, petalis lato-ovoideis mucronatis margines eroso-denticulatis androecei abortivi cupula germen albo-tomentoso dimidio cingente. Drupa oblonga acuta in basin induviata 3-6 sperma, epicarpio fibroso ferrugineo-tomentoso ad apicem albido, mezocarpio albo amylaceo, endocarpio lapideo brunneo.

Tab. IXIT. 
Folue 5 contemporanea, petiolo hypogoeo, rachis, $1^{\mathrm{m}} .60 \mathrm{lg}$.; foliolis inferiores $\mathrm{O}^{\mathrm{m}}, 65 \times \mathrm{O}^{\mathrm{m}}, 004 \mathrm{lg}$., medio divergentibus, $\mathrm{O}^{\mathrm{m}}, 40 \times \mathrm{O}^{\mathrm{m}} .03 \mathrm{lg}$., superiores divergentibus $\mathrm{O}^{\mathrm{m}}, 08 \times \mathrm{O}^{\mathrm{m}}, 003 \mathrm{lg}$. Spadix masc. $0,{ }^{\mathrm{m}} 25-0,{ }^{\mathrm{m}} 30 \mathrm{lg}$. erectus, rami secundi $\mathrm{O}^{\mathrm{m}}, 1 \mathrm{lg}$; androgyni $\mathrm{O}^{\mathrm{m}}, 4 \mathrm{O} \mathrm{lg} \cdot ;$ pedunculo compresso $\mathrm{O}^{\mathrm{m}}, 23 \times \mathrm{O}^{\mathrm{m}} \mathrm{O} 2$, Ig. bractea longa ornato; rachis $\mathrm{O}^{\mathrm{m}}, 23 \mathrm{lg}$., postice plano, antice convexo, anceps, rami brevissimi, biseriali, secundi, longi bracteati, bractea longissime acuminata, deflexa. o, "'O3 —o. ${ }^{\mathrm{m}} 04 \mathrm{lg}$. Filores fem. sessilibus, $\mathrm{O}^{\mathrm{m}} .025$ alt. Drupa oblonga $\mathrm{O}^{\mathrm{m}} .06 \times 0,{ }^{\mathrm{m}} \mathrm{O} 45$.

Har, in Capão Bonito. fere Serra do Melgaço. Indayá mirim ab incolis nominatur. Flor. et Fruct. mense funio. Herb. n. 239.

Explic. TAB. XXYI. - 1. Parte do rachis de uma folha, mostrando a disposição dos foliolos, com um d'estes inteiros, de tamanho natural. 2. Spatha interior reduzida a um quinto. 3. Uma parte do rachis do spadice, mostrando as longas bracteas, de tamanho natural. t. Uma flor macho, de tamanho natural. 5. A mesma, duas vezes augmentada. $6, i$ e 8 . Tres petalas da mesma flor, duas vezes augmentadas. 9. Calyce, duas vezes augmentado. 10. U'm estame e anthera, quatro vezes augmentado. 11. U'm germinodio, tres ve\%es augmentado. 12. Uma for femea, inteira. 13. Uma sepala. 14. Corolla. 15. Uma petalis. I6. Ovario e androceo, tudo de tamanho natural. 17. Um fructo inteiro. 18. O mesmo, cortado verticalmente. 19. O mesmo, cortado transversalmente, tudo do tamanho natural.

Esta especie tambem é acaule e cresce nas proximidades da antecedent', e ás vezes mesmo com ella. porém, se differencia immediatamente pelas suas folhas que são mais erectas com os foliolos divergentes, principalmente para o apice das folhas, o que dá outro aspecto.

Ten vulgarmente o nome de Indayi-mirim, ou pequeno, porque o porte. os cachos e os fructos são menores. Encontrei-a em Junho, com flores e fructos.

Comparando-a com a $O$. Inmilis, le Mart. affasta-se inteiramente, a nå ser em ter as folhas 11 m pouco semelhantes mas, apezar d'isso uma tem os foliolos crespos e outra lisos e divergentes. 


\section{ADDFNDA}

DIPLOTHEMIUM PECTINATUMI Barb.Rod.-¿D.CAUDESCENS Mart. Palm. Bras. pag. 111. tab. 51, fig. 7, 7o et 77 ; Kunth Enum. plant. III. pag. 121; I)rude Flor. Bras. III. pag. 430? Caudex excelsus cylindricus lave et proximus annulatus, foliis validis concinnis pectinatis, foliolis xquidistantibus regulariter insertis patentibus e basi conduplicata ad apicem oblique acuminatis supra nitentibus subtus tomento denso albo argenteo. Spadix in pedunculo quam rachis majore spatha sup. tenuis lignosa leviter sulcata longe acuminata inclusus, racheos duo tertio inferiore androgyno caudam masc. terminalem demidio superante floribus masc. inter femineos alte erectis staminum pluremorum inter petala late lanceolata evolventibus; drupa obovoiclea subcompressa glabra versus verticem concava in centro apiculatum albo tomentosa, endocarpio brunneo obovoideo apiculato intus trivittato, albumine ruminato.

\section{Tab. XIVII.}

Caudex cinereus, proxime annulatus, cylindricus $2^{\mathrm{m}}-15 \times \mathrm{O}^{\mathrm{m}}, 10-$ $0^{\mathrm{m}}, 15 \mathrm{lg}$. Folir 10 contemporanea, $4^{\mathrm{m}}-5^{\mathrm{m}} \mathrm{lg}$. petiolo et vagina $1^{\mathrm{m}}, 35 \mathrm{lg}$., albo fusco tomentoso, foliolis $\mathrm{s} 0 \mathrm{u}$ utrinque, xqualiter dispositis, inferioribus $\mathrm{O}^{\mathrm{m}}, 55 \times \mathrm{O},{ }^{\mathrm{m}} \mathrm{O} \mathrm{O}$, medius $\mathrm{O}^{\mathrm{m}}, 60 \times \mathrm{O}^{\mathrm{m}}, 055 \mathrm{lg}$. superioribus $\mathrm{O}^{\mathrm{m}}, 3 \mathrm{O} \times \mathrm{O}^{\mathrm{m}}, \mathrm{OI} \mathrm{lg}$. Spadix I-5 contemporaneus, inter interiores foliis enascens, patens, $1^{\mathrm{m}}, 10-1^{\mathrm{m}}, 20 \mathrm{lg}$. pedunculus subcompressus, brunneo lepidotus, $0^{\mathrm{m}}, 50 \cdot 0^{\mathrm{m}}, 60 \times 0,02 \mathrm{lg}$., rachis $\mathrm{O}^{\mathrm{m}}, 60 \cdot \mathrm{O}^{\mathrm{m}}, 65 \mathrm{lg}$., parte inferiora androgyna $\mathrm{O}^{\mathrm{m}}, 020-{ }^{\mathrm{m}}, 25 \mathrm{lg}$. Spatha ext. lineari-lanceolata, acuta, ad apicem bipartita, $\mathrm{O}^{\mathrm{m}}, 050-\mathrm{O}^{\mathrm{m}}, 60 \times$ $\times \mathrm{O}^{\mathrm{m}}, \circ 8 \mathrm{lg}$., albo-ferrugineo tomentosa, interiora incurva, lineari-lanceolata, acuminata, ad basin attenuata vaginante, 
tenui lignosa, laviter et argute sulcata, $1^{\mathrm{m}} \cdot 90-2^{\mathrm{m}} \times \mathrm{O}^{\mathrm{m}}, 10-$ $\mathrm{O}^{\mathrm{m}} . \mathrm{I} 2 \mathrm{lg}$., albo-ferrugineo tomentosa. Flores masc. $\mathrm{O}^{\mathrm{m}}, \mathrm{O} 2 \mathrm{lg}$., sepalis lineari-lanceolatis, basi gibbosis, dorso acute carinatis acuminatissimis, corollam fere longitudine íquantibus, inferne connatis. Petalis obovatis, vel sape oblique acuminatis, subconcavis, ima basi connatis; Stamina 96-100 dense intertexta. minore corolla: filamentis filiformibus, anthere infra medium infixis; anthero lineares. basi subagittatxe, apice minutissime mucronate. Rudimcntum fistilli nullum. Flores fem. $\mathrm{o}^{\mathrm{m}} . \mathrm{or} \mathrm{lg}$., ante anthesin acuti sepalis petalisque subxquilongis. lato-ovato-subrotundis acutis: androccei rudimentarii cupulari, sexclentati, ovario demidio minori. Ozario ovato, albo tomentoso, stigmalibus elongatis. acutis. Drufa induviata, $0^{\mathrm{m}}, 05 \times 0^{\mathrm{m}} .035 \mathrm{lg}$. epicartio viridi-flavo, levi, tenui-fibroso, mezocarpio albo, endocarfio osseo, castaneo, ad apicem acuto. $0^{\mathrm{m}}, 0.4 \times 0^{\mathrm{m}} .029$, $\lg .$, albumine cavo, profunde ruminato.

HAB, in silis frov. Espirito Santo, Minas Geraes et Rio de Janeiro. Culta in Jardim Botanico, Rio de Janeiro, N. 38 . Flor. el fruct. Noombr. Palia branca, Imburi appellatum.

Explic. Tar. A. Fig. I. Córte de peciolo. I $a$, I $b$, I $c$ e $~ I d$. Córtes do rachis, de tam. nat. 2. Uma porção do rachis, na parte media, mostrando a disposição de todos os foliolos. 2 a. Parte lerminal de um foliolo. 3. Espathas reduzidas a um decimo. 4. Uma flor masculina. 5. Calyce. ó. Corolla. ; e 8. Petalas vistas pelo exterior e interiormente de tam. nat. o. L'm estame de tam. nat. 10 e ix. O mesno visto pelo dorso e jela frente, duas vezes augmentado. 12. Bractea que acompanha as flores, tam. nat. 13. Uma flor femea. 14 t 15. Sepalas vistas de lado. 16, 17 e 18. Petalas. 19. Ovario, tudo de tim. nat. 20. Ovario, duas vezes angmentado, 21. Androceo esteril. tam. nat. 22. Fincto inteiro, tam. nat. 23. O mesmo coltaclo verticalmente. 24. () mesmo cortado transversalmente. 25. Endocarpo mostrundo as tres faxas, tudo de tam. nat.

13. Fig. 1. Uma porçåo do rachis e foliolos. 2. Fspatha interior, reduzida a um decimo des tam. nat.

Estas figuras sĩo cxtrahidas da obra de Martius flara servir para comparaçĩo. 
Com o nome de Mbory ou Imbury. desde Pernambuco até á Bahia, é conhecida uma palmeira, que o Dr. Martius descreveu sob o nome de Diplothemizm caudcscens. Esta palmeira Gabriel Soares (I) a noticiou em 1587 da seguinte maneira: "Ha outras palmeiras que chamam Bory, que tem muitos nós, que tambem dão cocos em cachos. mas são mindos ".

O Principe Maximiliano de Wied Neuwied (2), que tambem d'ella se occupou. disse: "produit une grappe de petites noix dures qui ne sont mangeés que par les sauvages".

Pol estas informações e pelas descripções do mesmo Dr. Nartius (3), assim como pela do Dr. Oscar Drude (4), não me parece ser aquella de que me accupo. Se tem caracteres que as identificam, apresenta, comtudo, outros que as affastam. A especie que aqui apresento é do Espirito Santo, Minas Geraes e Rio de Janeiro, onde as encontrei em Itabapoana, Muriahé, Campos e S. Gonçalo com o nome de Palha branca e tambem com o de Imhury.

Centenas de exemplares que vi apresentavam todos os mesmos caracteres que dou aqui, não só os que cresciam nos terrenos baixos e descampados, como nos das serras e das florestas. Um exemplar, que póde ser visto. cultivado n'este jardim o confirma.

Se pelas descripções noto differenças, tambem as encontro quando estırdo os desenhos de Martius (5). As follıas e a spatha sem a menor duvida ou contestação não pertencem a esta especie. A ser esta especie a mesma, não trepidamos affirmar que a spatha representada pelo sabio palmographo, por fatal engano, foi dada como do Imbury (D. Caunescens) quando me parece pertencer a alguma Scheelea ou Attalea.

As descripções da spatha são deficientes, e só apresentam um caracter que não tem a de que trato, a da espessura.

\footnotetext{
(1) Tratado deccriptivo do Rrasil: Rev, do Inst. Ilist. Liras. Vol. Xil. pag. 191

(2) Voyage au Bras. 11. pag.

(3) Gen. et Spec. Palm. pag, I 1 1. Tali, 70 et 77. Fig. 1, 2.

(4) Flor. Bras. I I1 p. I1. pag. 430,

(5) Loc. cit.
} 
Só a forma das flores se identifica com as da minha especie em alguns caracteres. Entretanto a forma e inscrção dos foliolos as separam extraordinariamente.

Por muito tempo vacilei em considerar especie distincta, mas ante as differenças que aqui aprescnto, nảo podendo ter como mal feitas as descripçôes dos mestres sobre exemplares de differentes localidades, animo-me a apresentar esta especie, cujos caracteres diffcrenciaes são sufficicntes para distinguił-as. O ter o mesmo nome vulgar nada implica. porque o mesmo nome é ás vezes dado a especies de familias differentes. L'ma unica cousa que confirma o que penso, mas me confunde, é a nota dada pelo professor 1)rude, laseado cm informações do Sr. Glaziou: a de que cxistem cxcmplares cultizados nos jardins do Rio de Fanciro, onde säo muito estimados. O mesmo senhor enviou amostras de Villa Nova e de Macacu. do verdadeiro D. candescons, a que se referem as clescripções e a nota. Sinto ignorar os jardins cm que estão cultivados, para examinal-os. Nos que são publicos, como o Passeio publico. o Campo de SantAnna. o largo do Rocio, a Ouinta da Boa Vista, do Jardim Botanico, não existem, os que ha se identificam com o que aqui descrevo e não com o descripto por Martius e Drude. Talvez haja alguns em chacaras particulares mas esses ignoro onde possa encontral-os. Toda a duvida desappareceria se podesse confrontar os meus especimens com os dos quaes o Sr. Glaziou tirou amostras, que se identificam com os collidos por Martius em Santo Amaro e Cachocira, na Bahia. isto é. os que tem as follhas e a spatha iguaes ás descriptas e reproduzidas d'apois nature por Martius.

Muito infeliz seria o $/$. caudescens para ser victima de um engano de Martius, nas folhas e na spatha exterior, engano que se nåo desmanchou, mas antes foi confrmado pelos expecimens de Glaziou.

l'elos exemplares Glaziovianos, vê-se que, com efieito, o Diplothcmium caudescons, tem as follhas crespas e os foliolos em srupos e linear-acuminados. 
A não se admittir que a planta que aqui descrevo seja differente da de Martius, forçosamente tem de soffrer as correç̧ões que aqui apresento, e addicionar-se-lhe a descripção do fructo. A nota do fructo, que em duvida o Dr. Drude dá. tambem não se identifica com os d'esta especie. Vejam-se os meus desenhos feitos exacta e escrupulosamente d'après nature, pelos fructos maduros, e ver-se-ha que tenho razão. Ainda mais, para melhor comparação represento aqui, muito diminuido, mas na mesma proporção dos dos meus desenhos os de Martius, d'après nature. não só da spatha como dos foliolos. Estes meus são representados na mesma altura do rachis que Martius representa os seus. por onde se vê que a forma do rachis é tambem differente.

O fructo dado por Drude. como do D. caudescens, que Martius não viu, tanto que diz drupa ignota, creio que não pertence ao Imbu'y, porém, apezar d'isso. pela especie que apresento, foi elle collocado bem junto ao D. Torallyz.

A especie de Martius, não obstante parece-me que tem os fructos pequenos porque assim o dizem Gabriel Soares e - Principe Neuwied, a não ser que estes considerassem pequenos, fructos de 0,05 de comprimento.

Devo observar que o endocarpo da especie de que trato é muito semelhante aos dos Syagrus, tendo como estes as tres faxas escuras e luzentes, porén com o albumen ruminado, como o Arikuryroba Capancmac, facto este não mencionado por Drude, nem por Martius no D. Torallÿ̈. Em duvida, comtudo, apresento a discripção dos Imbury's que estudei, que se. por acaso, for o mesmo D. caudescens, não dou como trabalho inutil o que tive, visto como servirá para corrigir as faltas que se notam nas descripções de Martius e de Drude, ou constituirá uma variedade.

Aqui apresento as differenças mais notaveis que encontro, para facilitar a comparação. 
Diplothemium caudescens

Martits

Tinnat in gregin sul opositis sexquipollicen vel nyrsximatis que sub crispike

Pinnis incaribus lange acuminatis in gregis sul, opposizis approximatio I rundibus sub crispac.

Spadi: bupedalis et lon

girr. Spizlitt int. duos pedes vel duos cum dimidio longa.

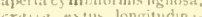
liter profunde sulcitit

Stamituz 50

Antheras atricem in $\mathrm{mu}$ cronem ac utiss im 4 m

Stigmatitus lerevi

$$
\begin{gathered}
\text { Drende } \\
\text { Candex inferdum in } \\
\text { medio pastum incrassatis. }
\end{gathered}
$$

D. pectunatum medio paulum jucrassattis.

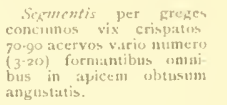

Foli lss alernin, cons. pertinate, pratentes, xecuas. liter dispositis, ominibus in apsicem oblique acumin ustis argute crenulatis.

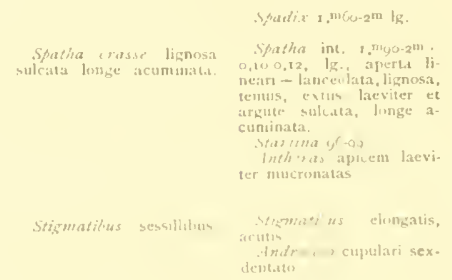

O aspecto desta especie. pela disposição dos foliolos, é o do Astrocaryum mumumu Mart., ou o de uma Attalia compla.

Pelo tamanho, largura e clisposição dos foliolos as folhas. são como as das Attaleas, aproveitadas para cobertura de casas, sendo longa a sua duração. Os espiques, posto que de fibras esbranquiçadas, são muito duros e por isso aproveitados para esteios e ripas. Fornece tambem um palmito amargo, que é muito apreciado, emquanto que os seus fructos não o são.

Nuta. - Devo fazer aqui uma otserviçăo. Por um infortunis perdeu-se a bordo do vapor, fue me conduziu, um volume que continha uma parte do material que devia servir para as descripçōes das qquatro especies tuitimas, pelo qque nio vio muito minuciosas. Felizmente tinha os desenlons. ficts. fcitus e an notan tomadas no campo, que me serviram cum us ma-

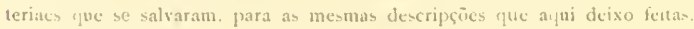




\section{IISTA}

por ordem alphabetica das especies e variedades de palmeiras do Brazil

DESCRIPTAS E DESENHADAS PELO

AUTOF

$1872-1897$

Como complemento a este trabalho apresento aqui uma lista das palmeiras que tenho descoberto e que estão representadas, por perto de duzentos desenhos coloridos de tamanho natural, feitos d"après nature, e com todos os detalhes analypticos.

Lstas especies foram reconhecidas pelas autoridades citadas, e, se algumas, poucas, figuram na monographia do Dr. Drude. publicada na Flora Brasitiensis, como synonymas de outras, sem razão assin foram classificadas. como já protestei por mais de uma vez, tanto que outras autoridades as aceitaram e as reivindiquei.

As especies que verdadeiramente perdi vão em italico.
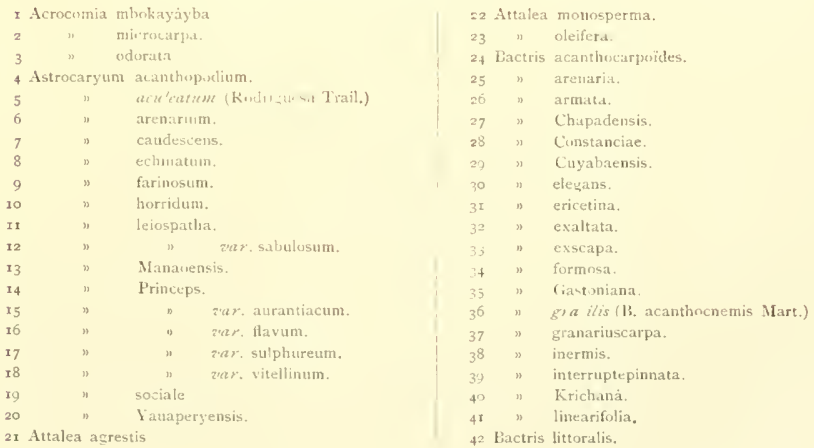



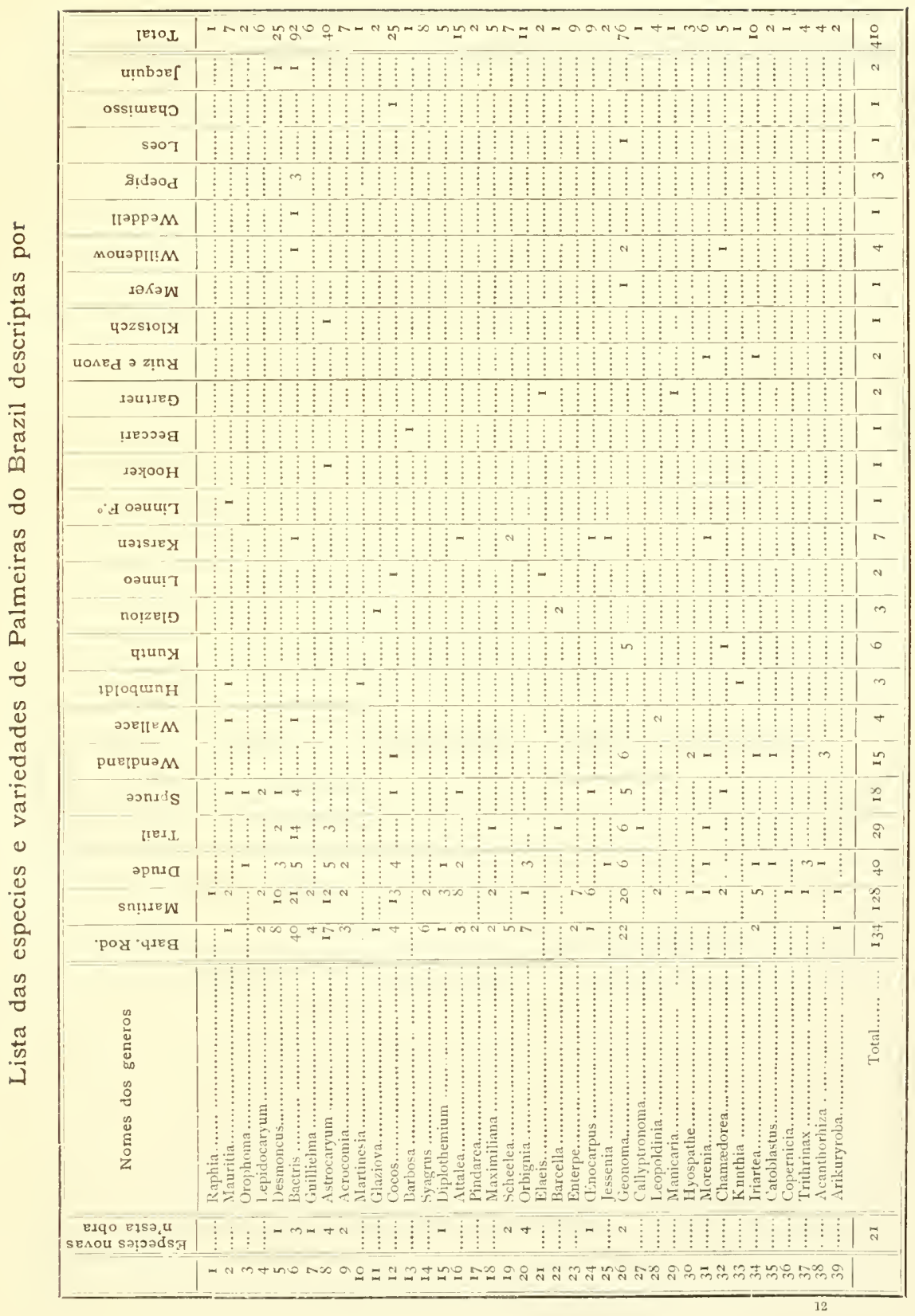





\section{Indice das Palmeiras contidas n'este volume}

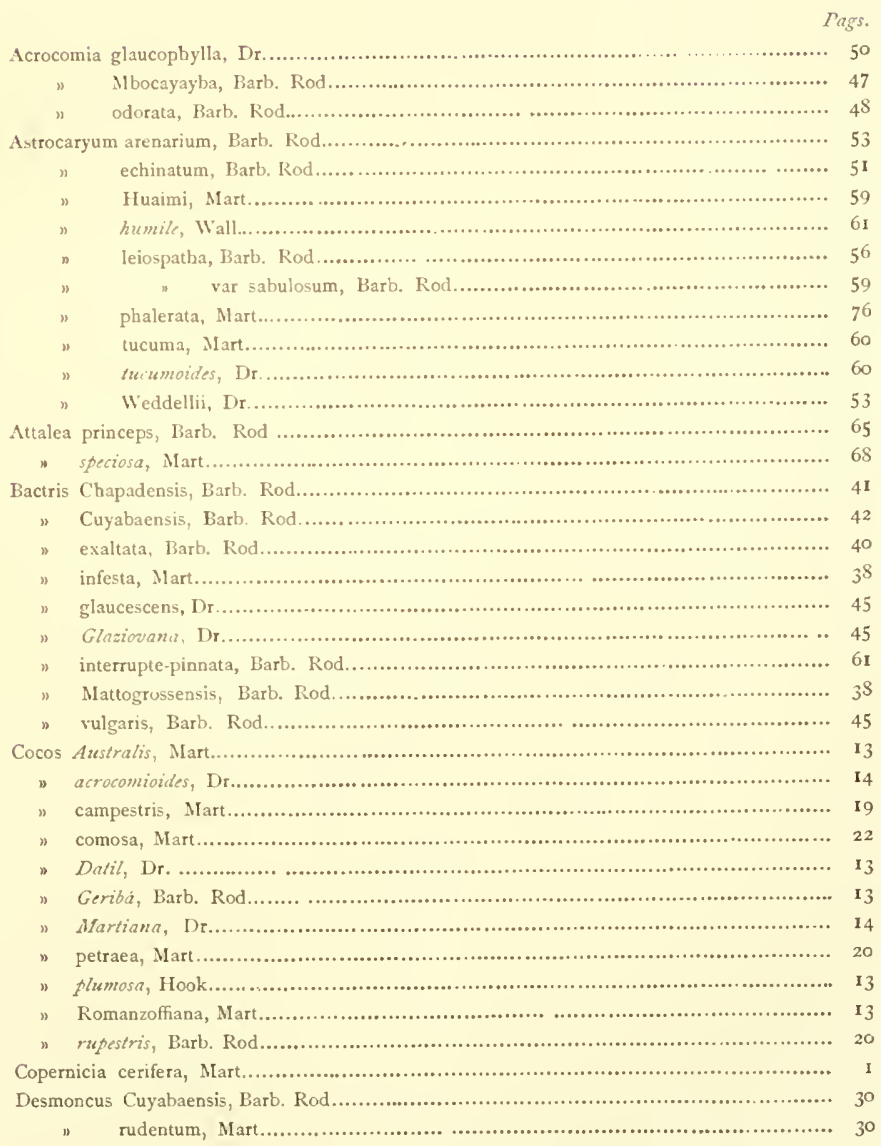




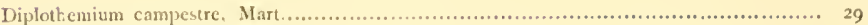

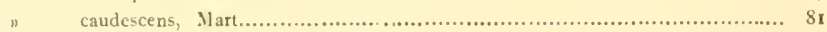

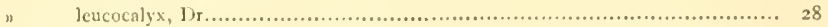

" pectinatuni, liarb. Rod.................................................. $8 \mathbf{1}$

Geonoma altissima, Barb. Rod........................................................... 6

"Clapadensis, Barb. Rod.......................................................... 4

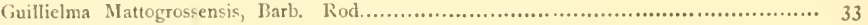

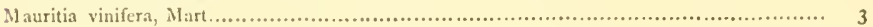

(Inocarpus discolor, Barb. Rod......................................................... 8

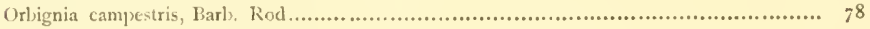

" longibracteata, Barb. Rod....................................................... 79

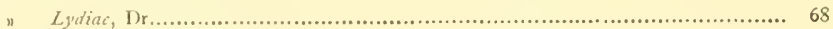

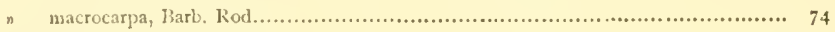

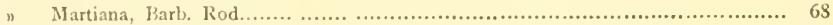

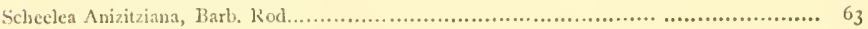

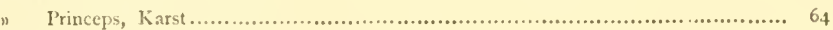

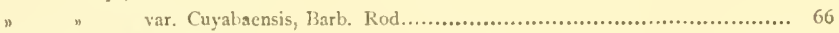

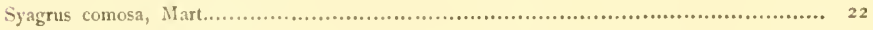

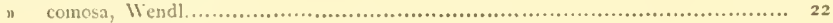




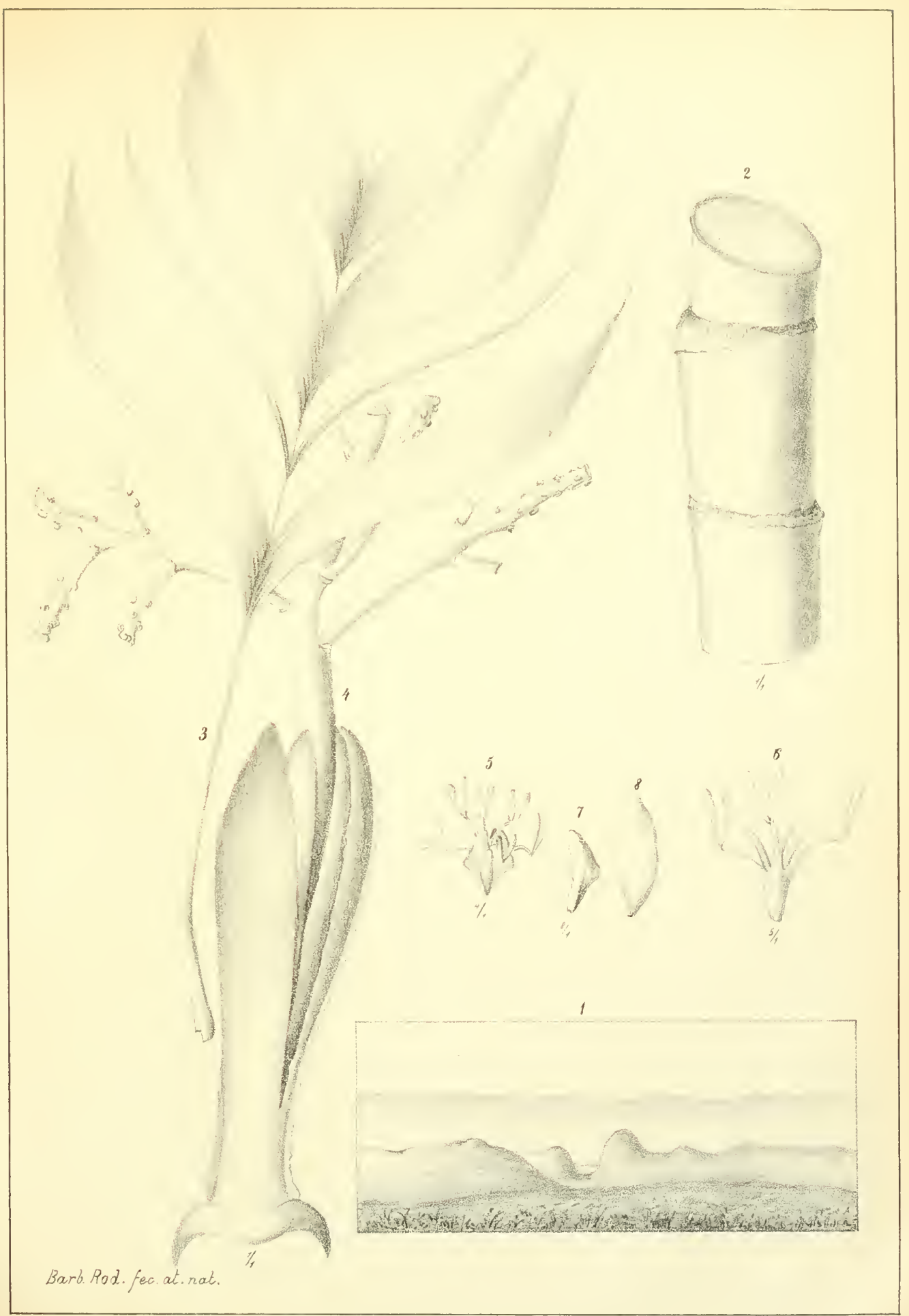

GEONOMA CHAPADENSIS Barb.Rod. 


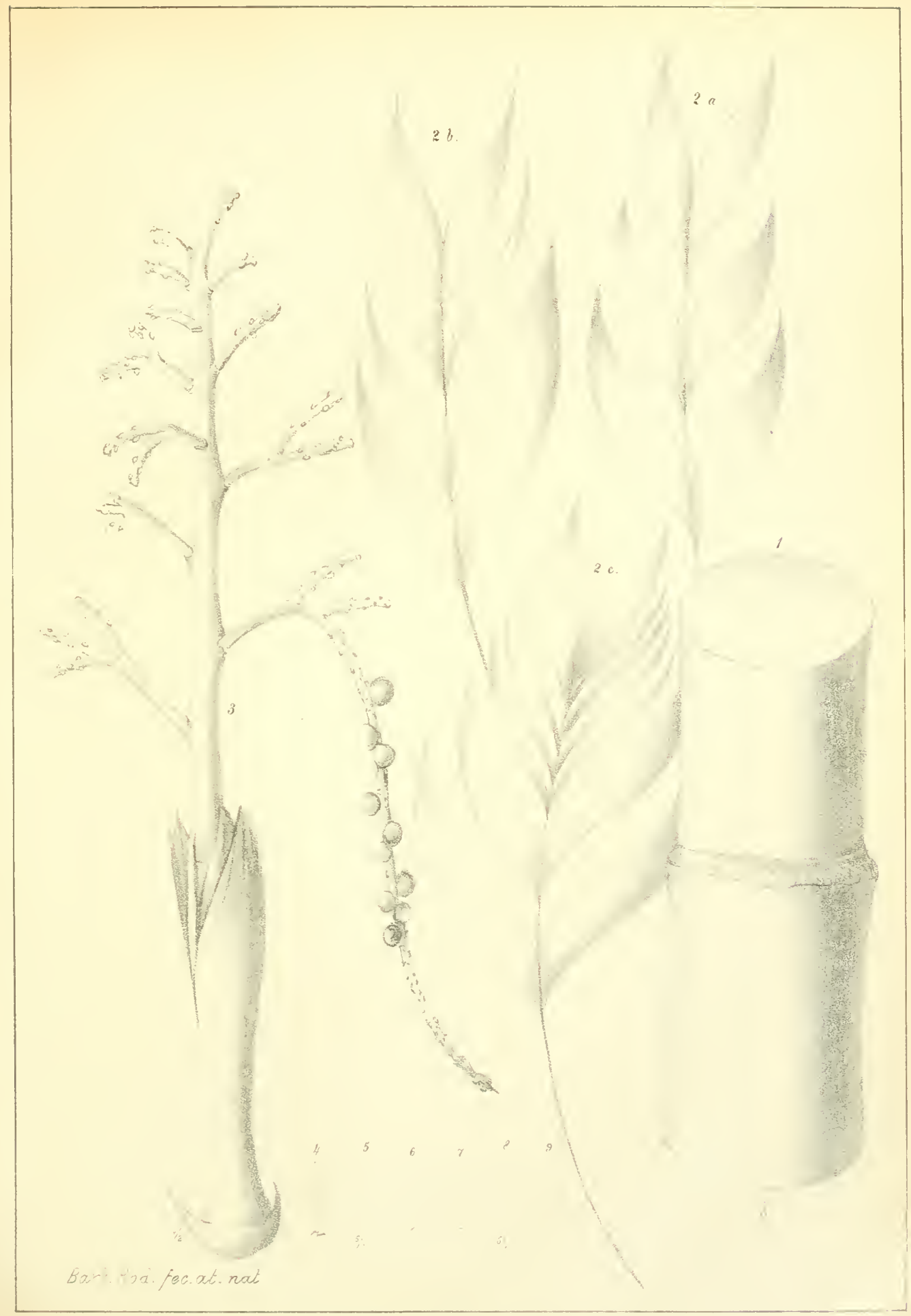

GEONOMA ALTISSIMA Bart. Rod 

Tab. III.

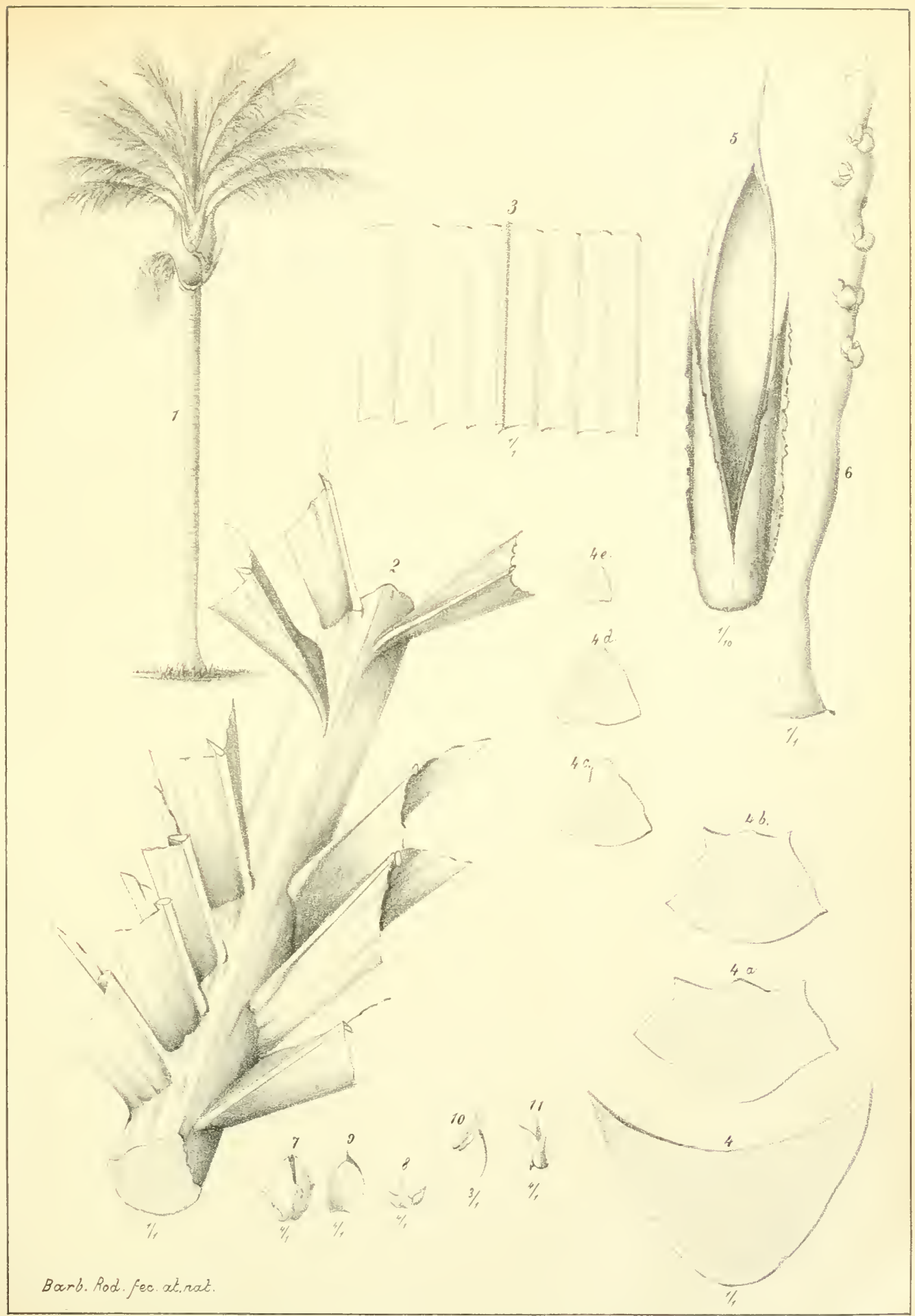





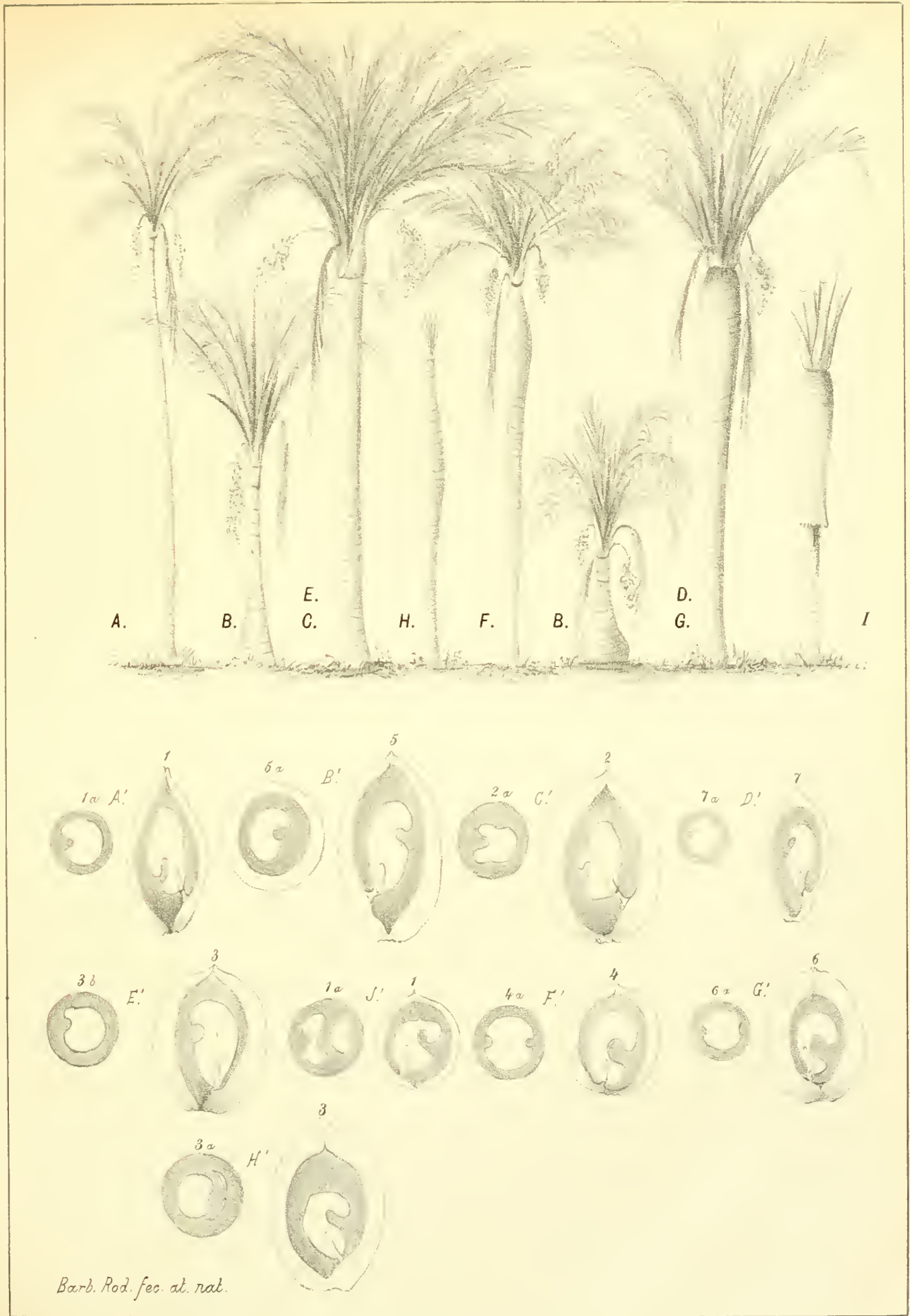




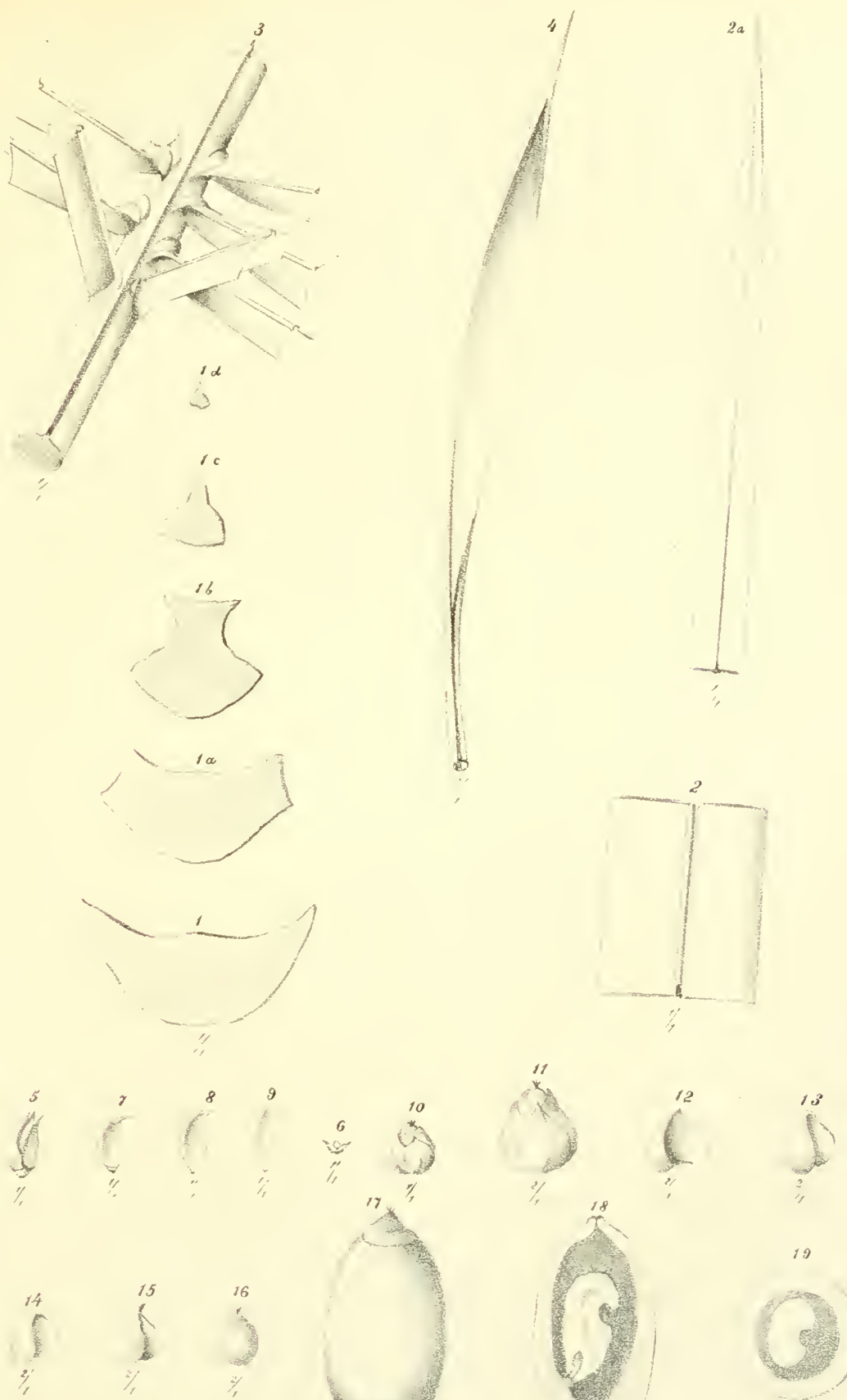

Barb. Rod. fec at. nat.

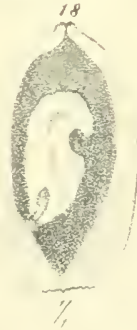

19
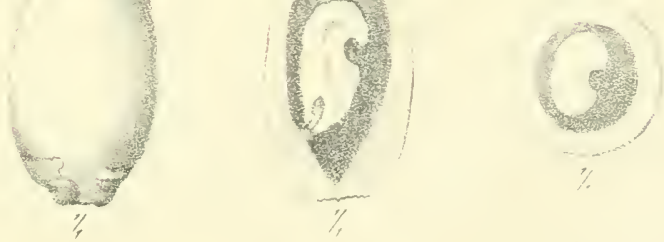



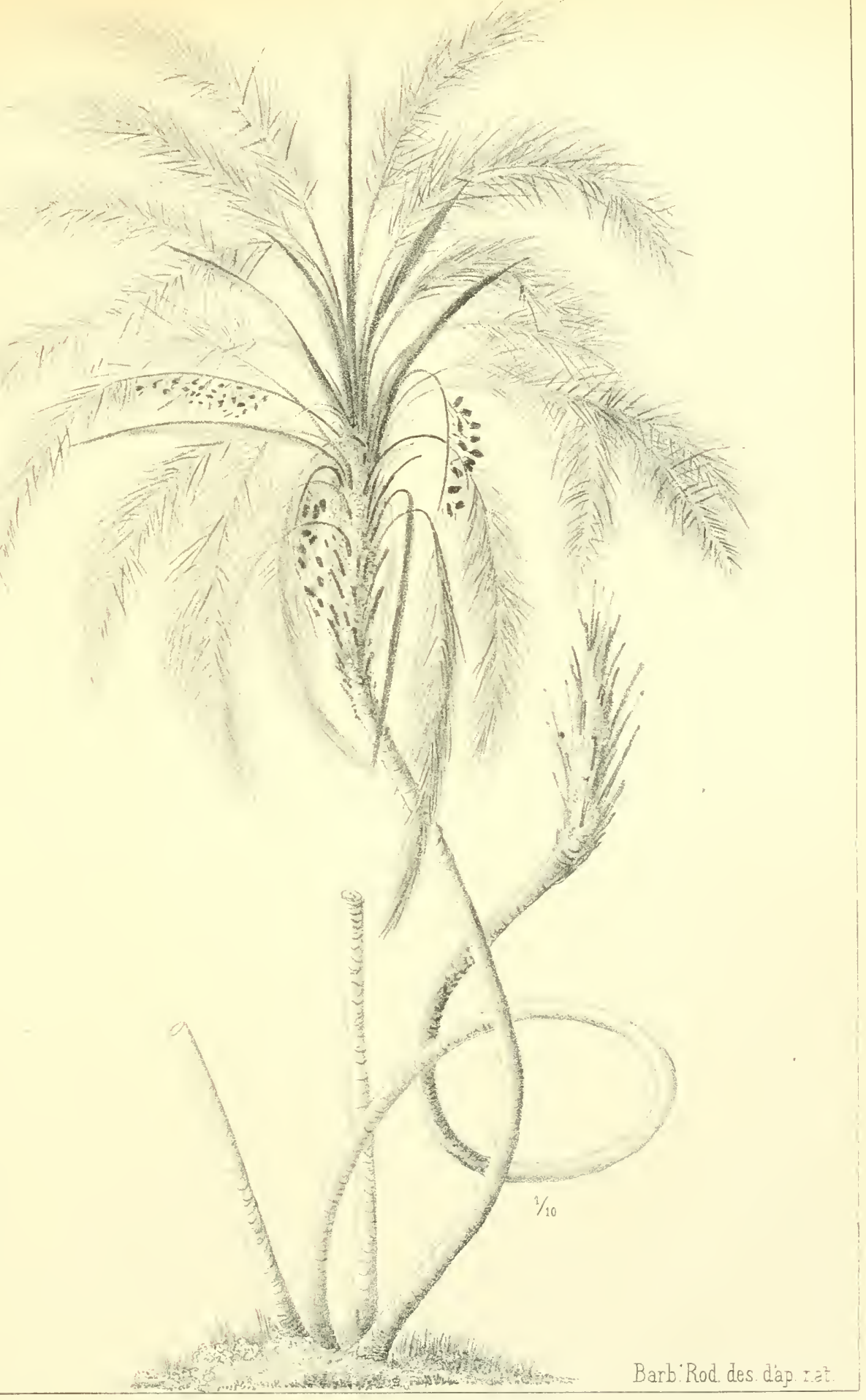

COCOS CAMPESTRIS MART. 

2
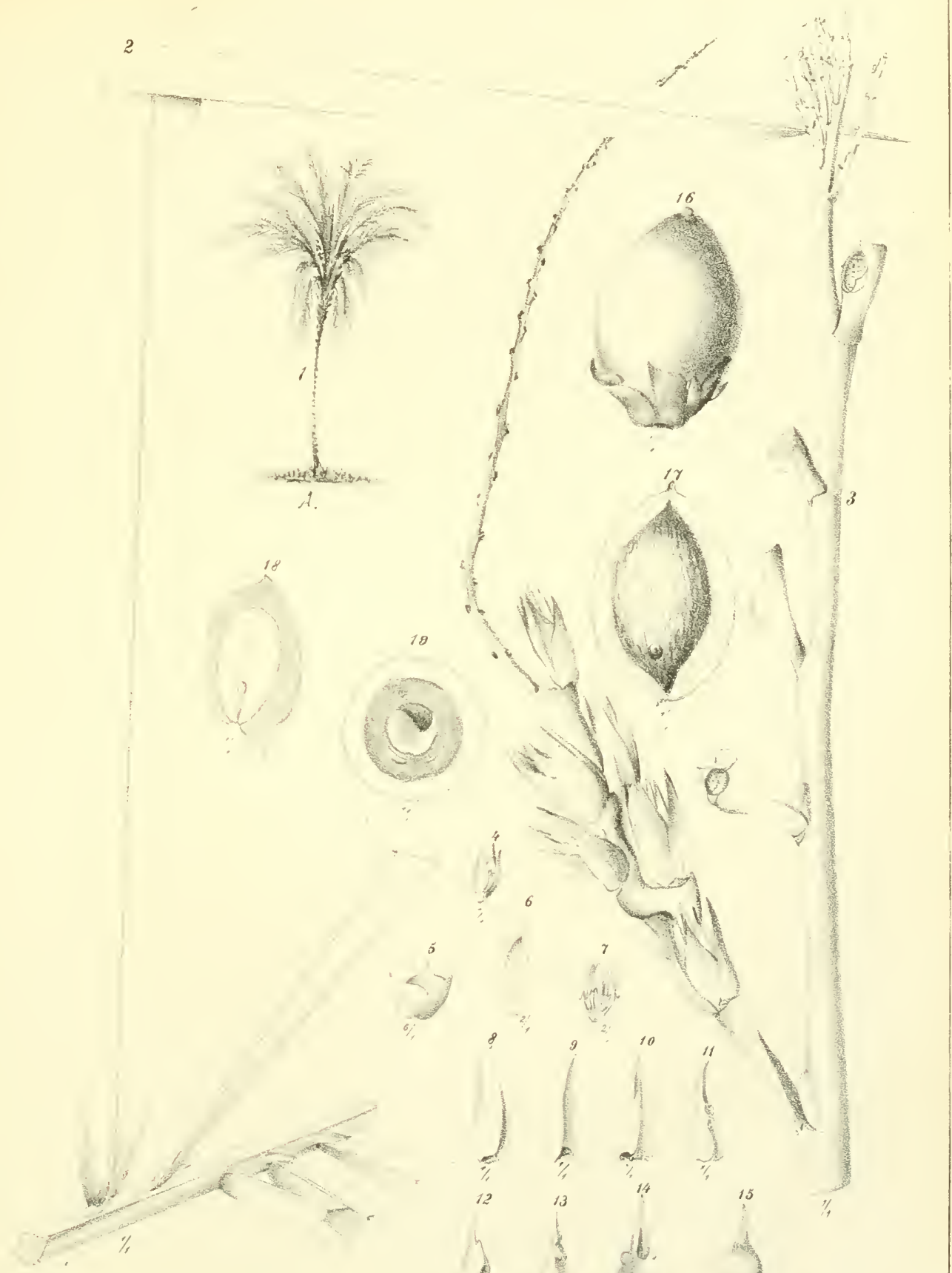

Barb. Rod. fec at nat:
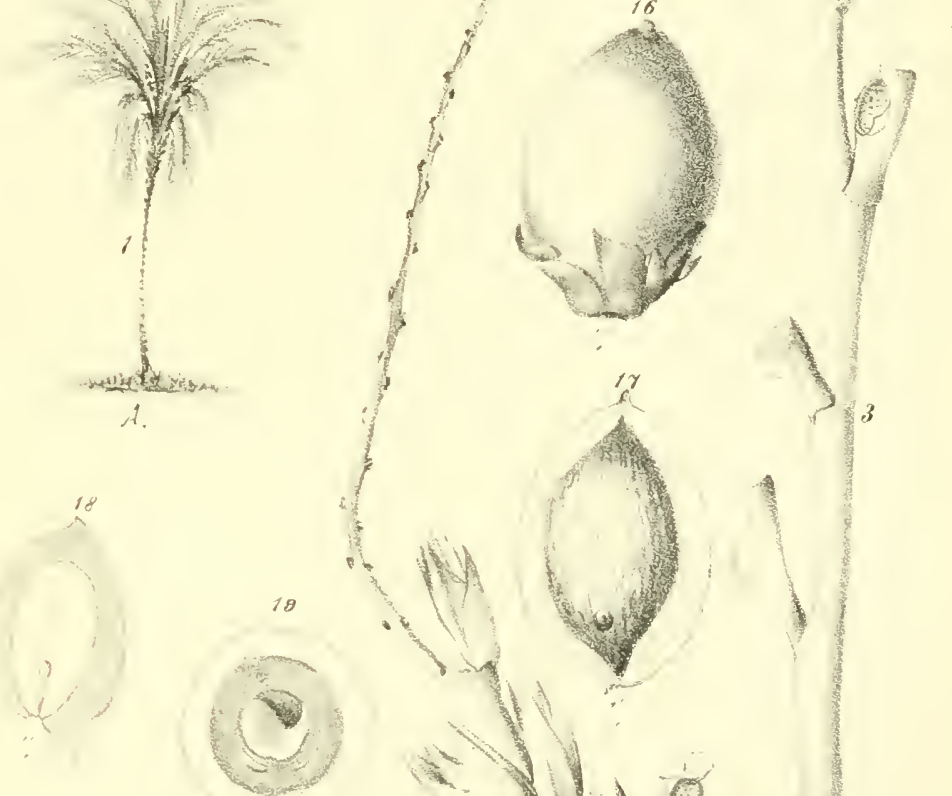

손
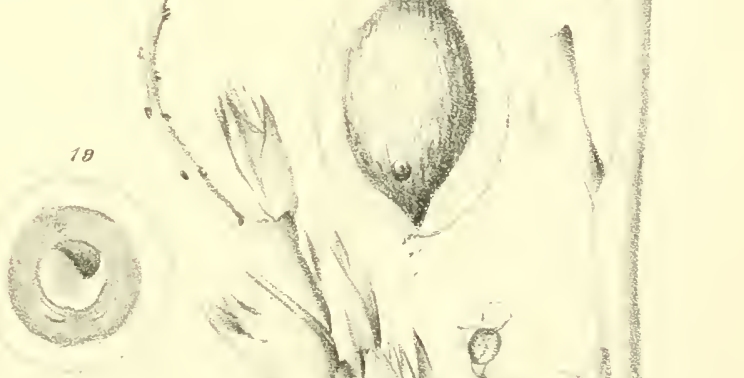

Ho
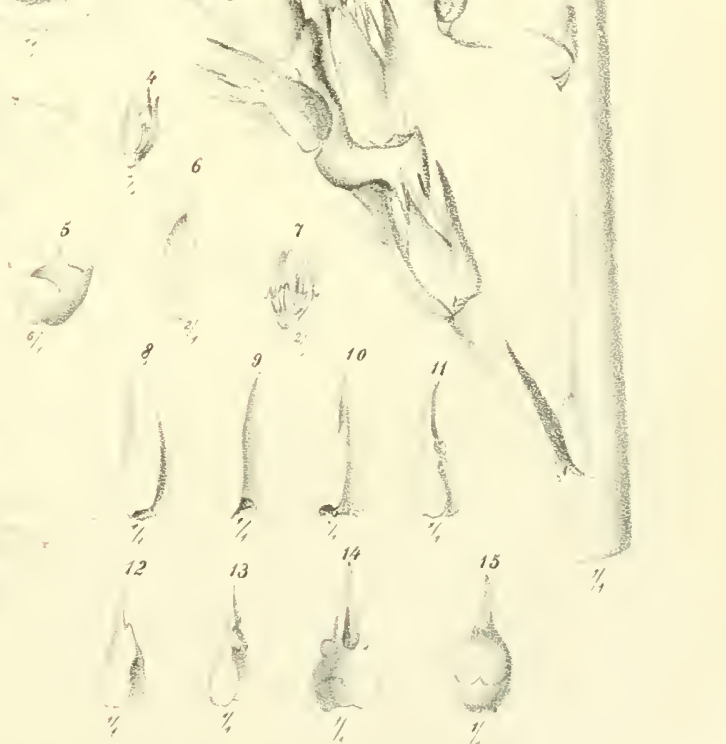



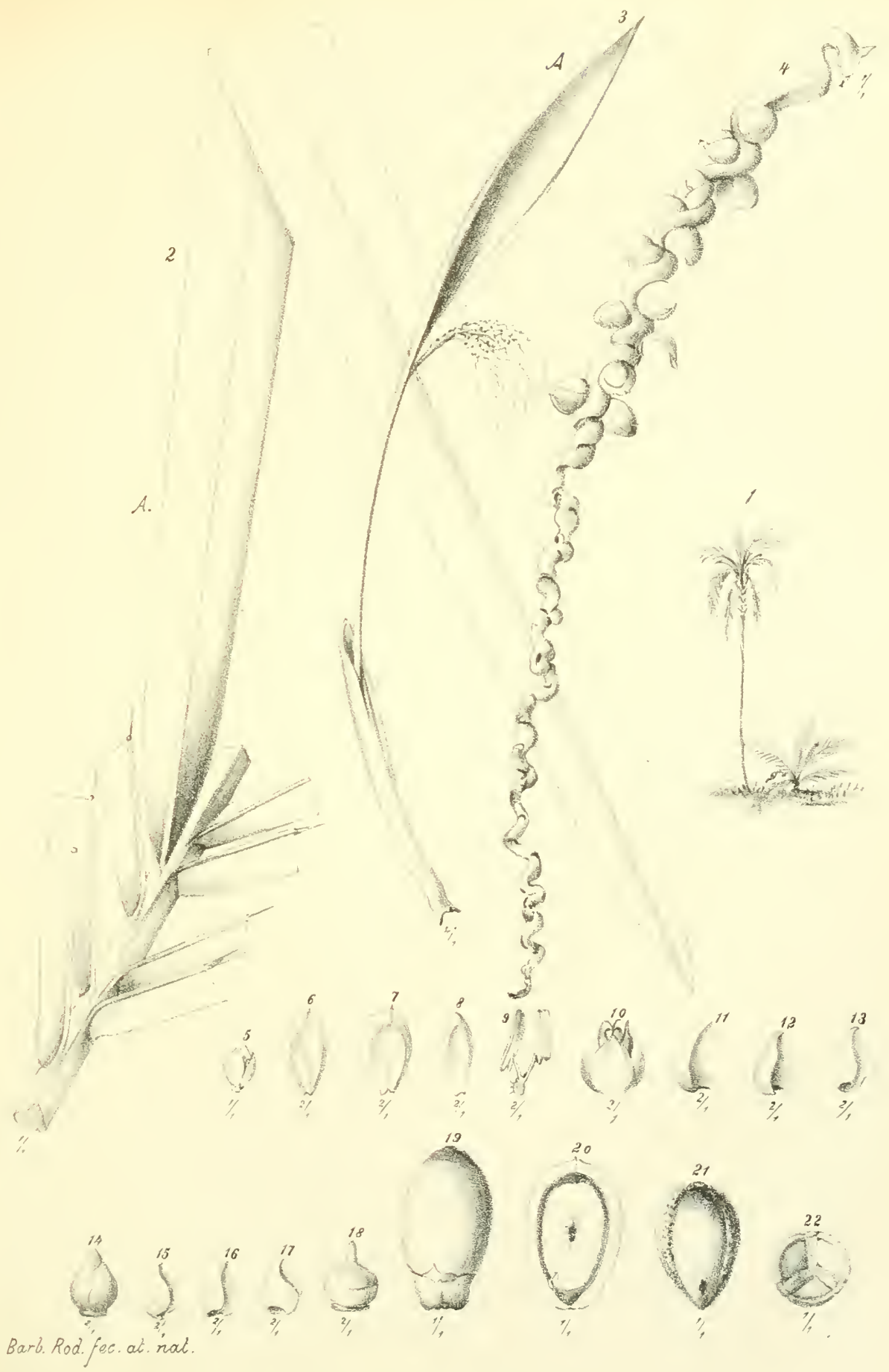





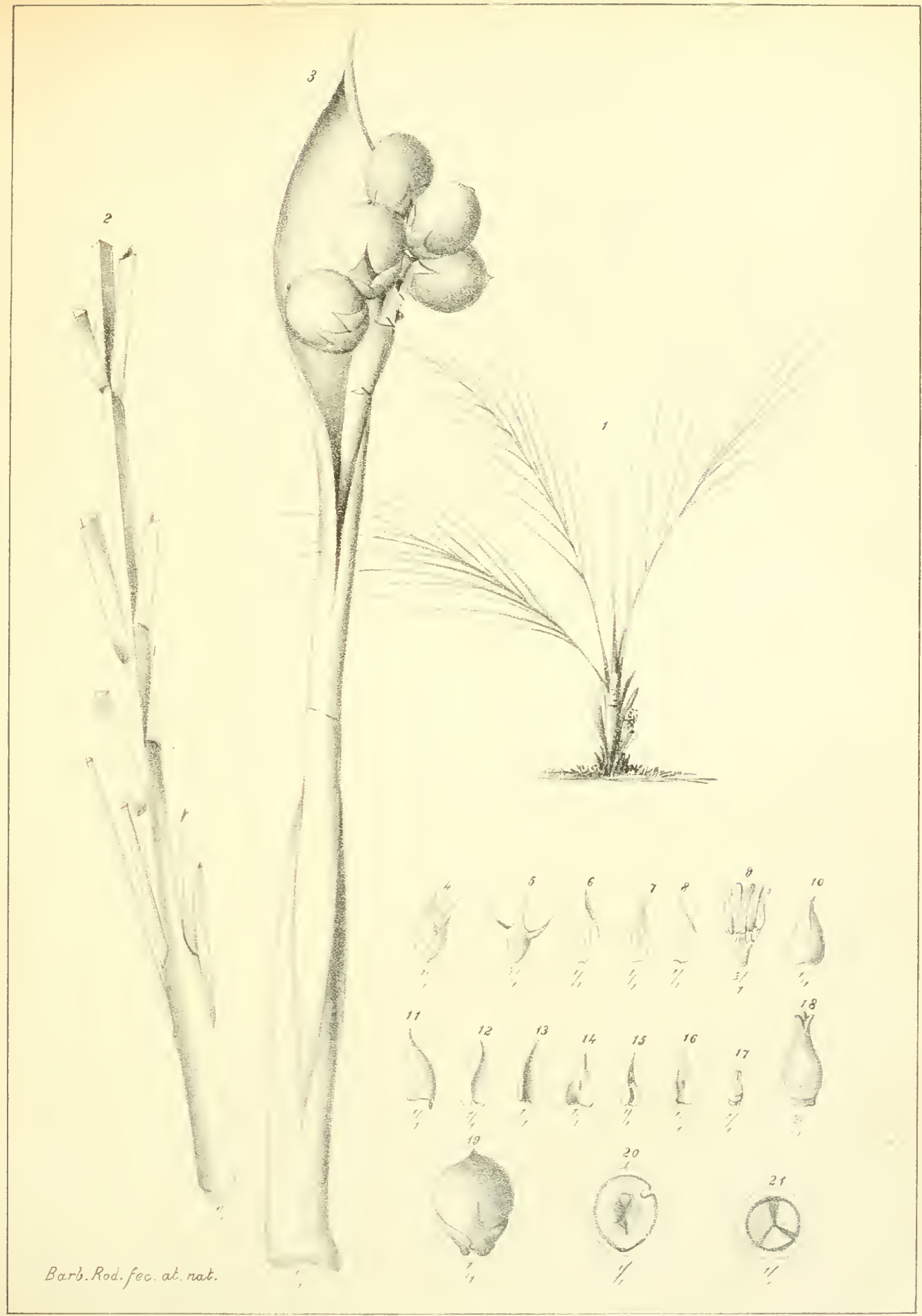

COCOS PETRAEA Var P!atiphylla Dr 



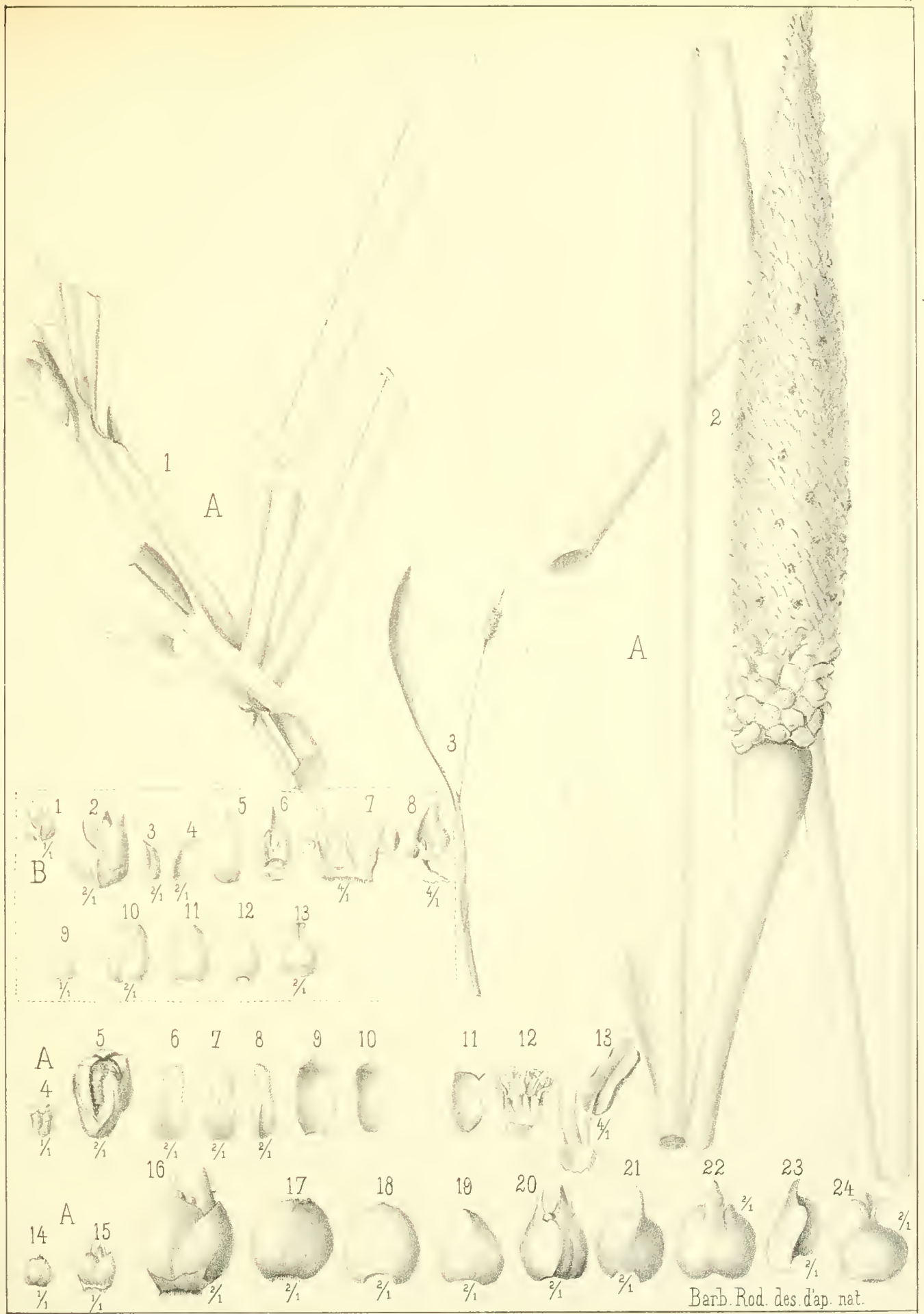

A. DIPLOTHEMIUM LEUCOCALIX DRUDE. 



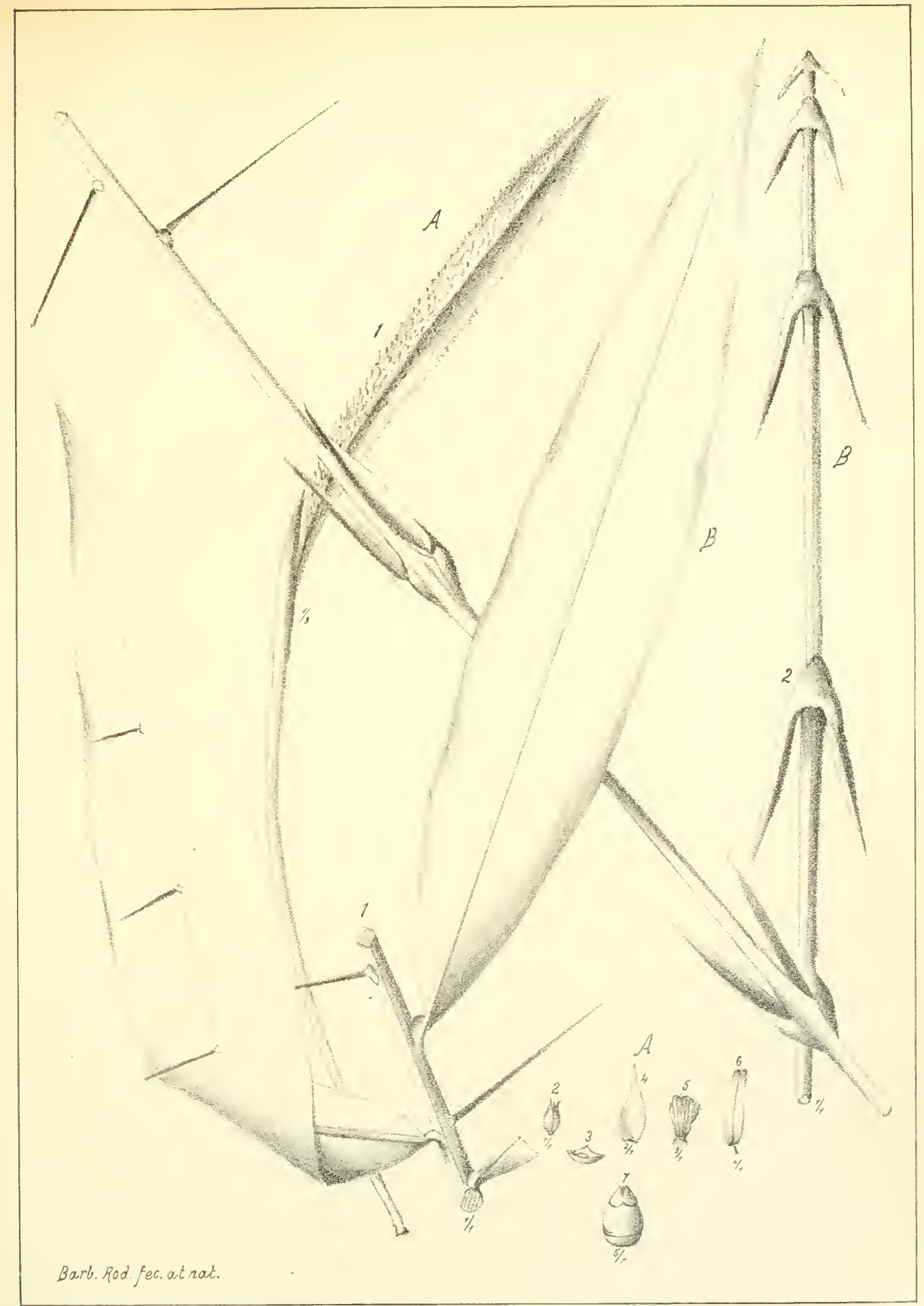

B. DESMONCUS RUdENTUM Marl. A. DESMONCUS CUYABÁCNSIS. Barb.Rod. 




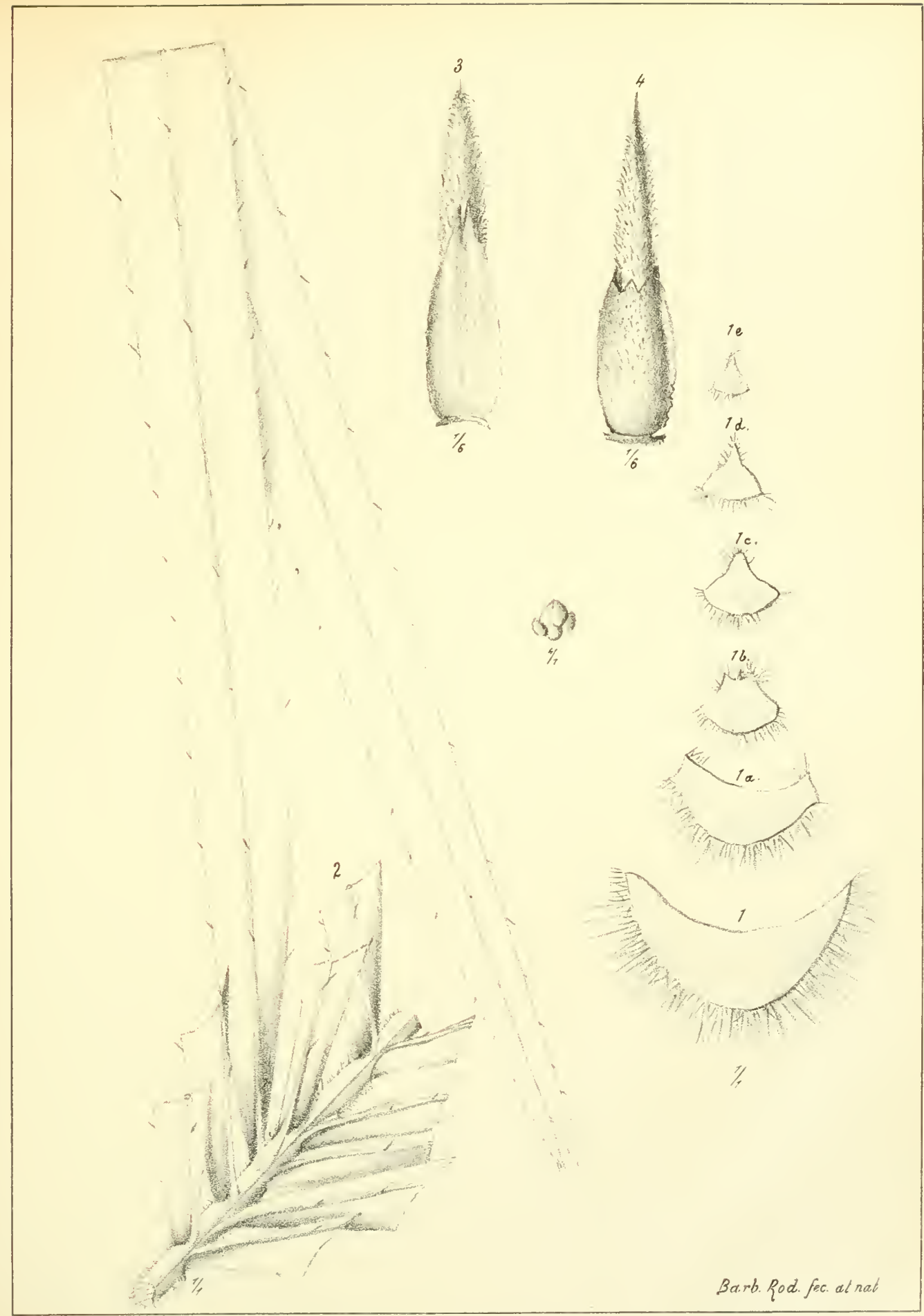



Tab. XIII.

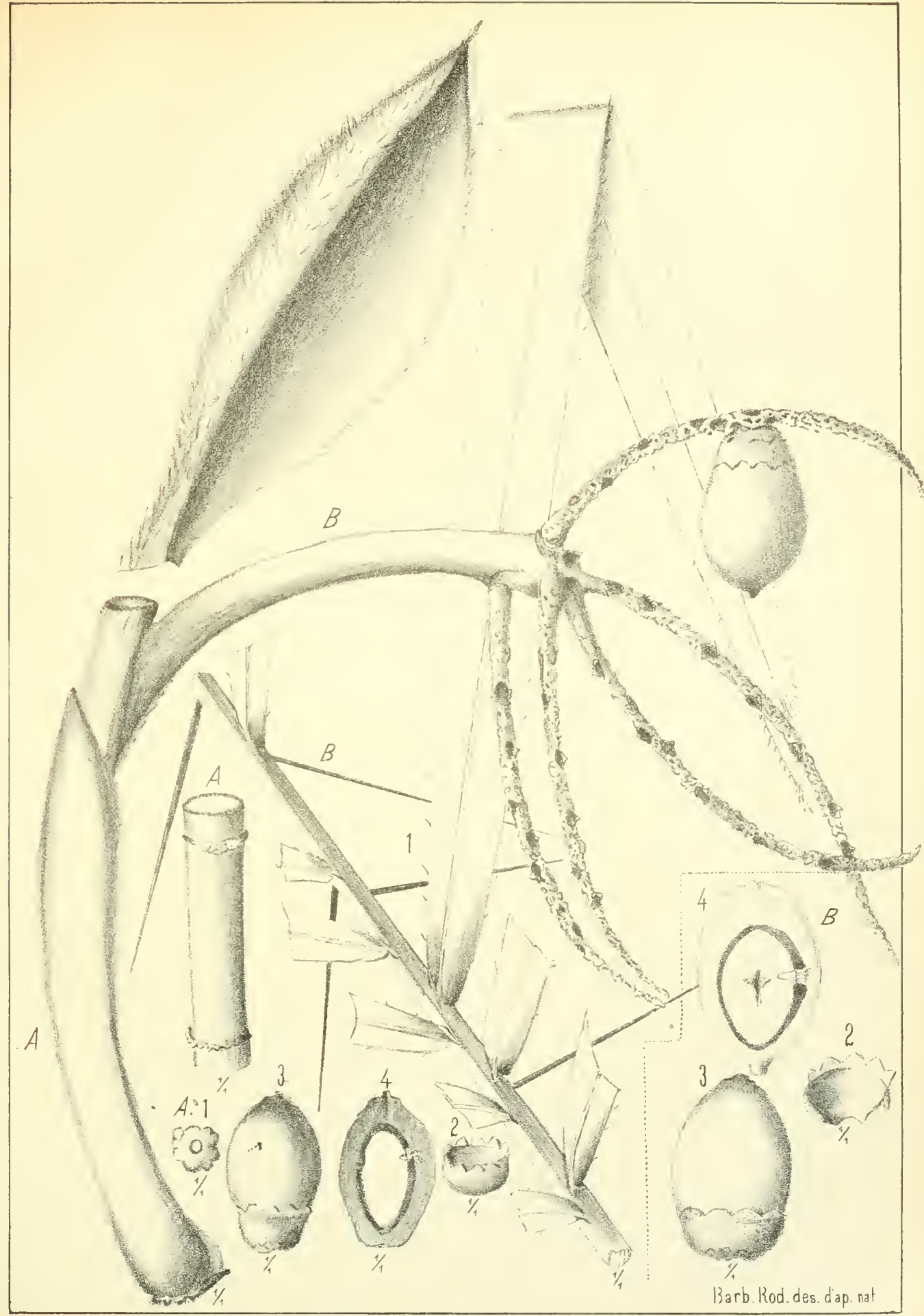

A. BACTRIS CHAPADENSIS Barb. Rod. B. BACTRIS MATTO GROSSENSIS Barb. Rod. 





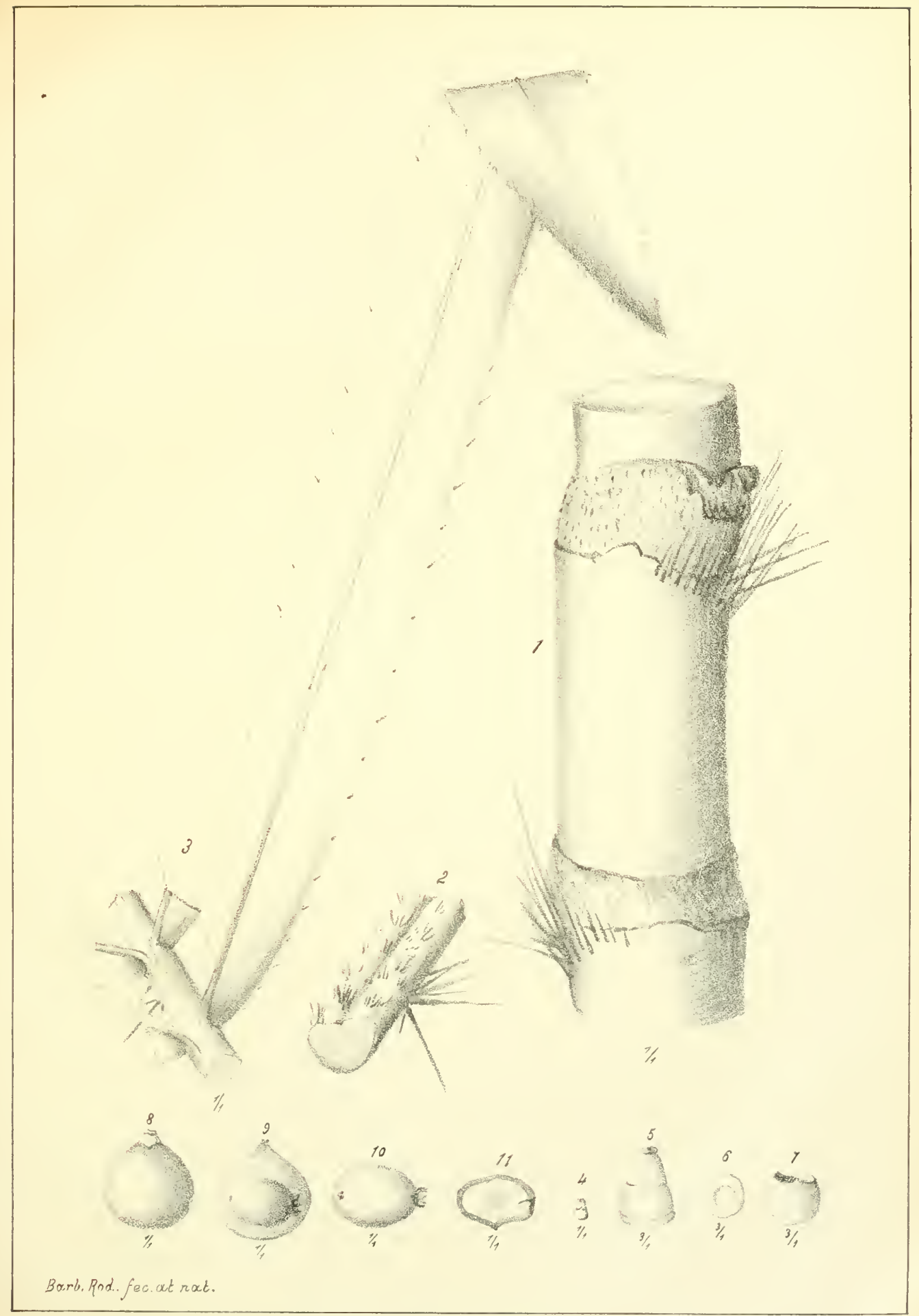

BACTRIS GLAUCESCENS Dr. 



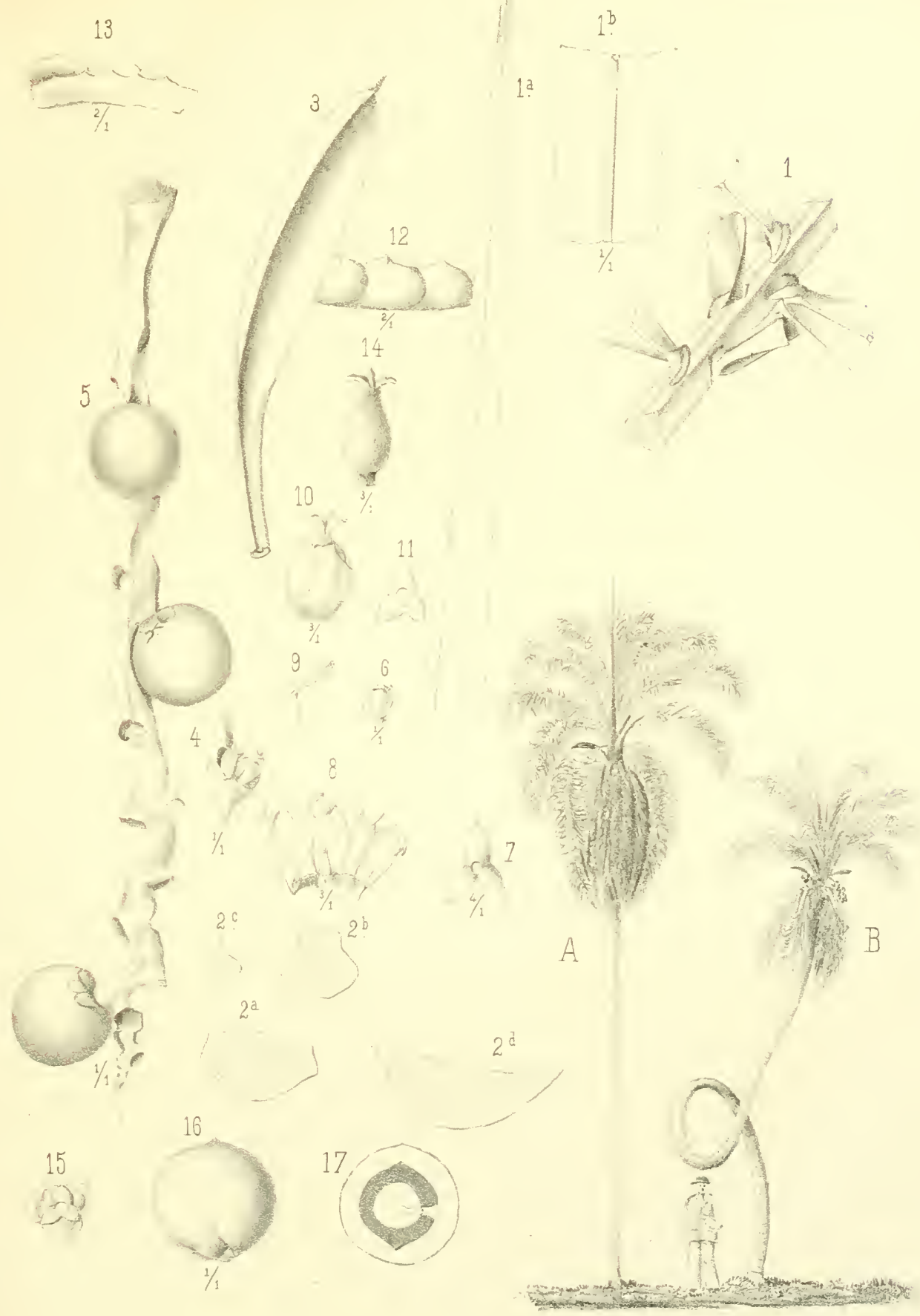

Barb. Rod. des dap nal. 




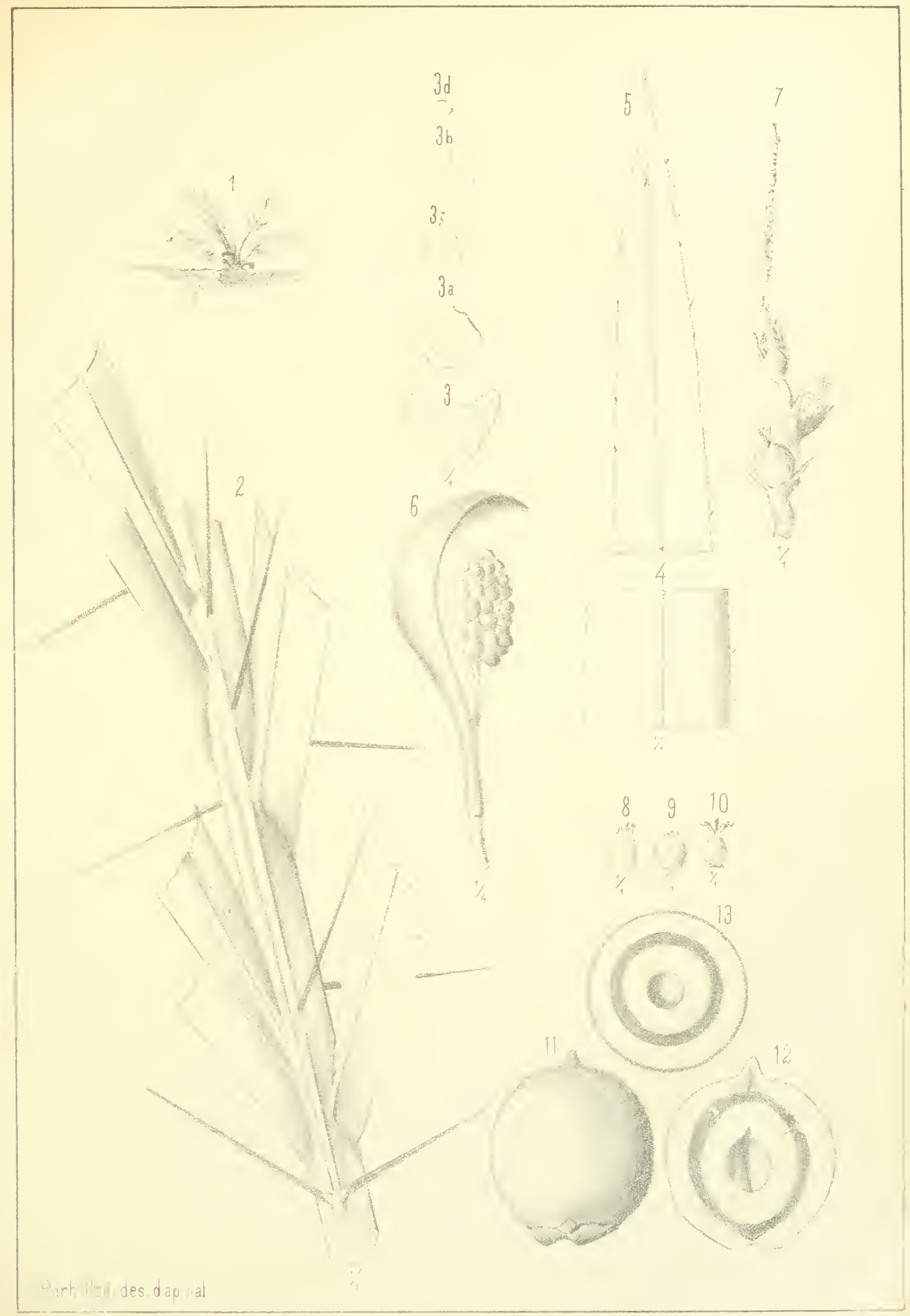

ASTROCARYUM ARENARUIM Barb. Rod. 
. 


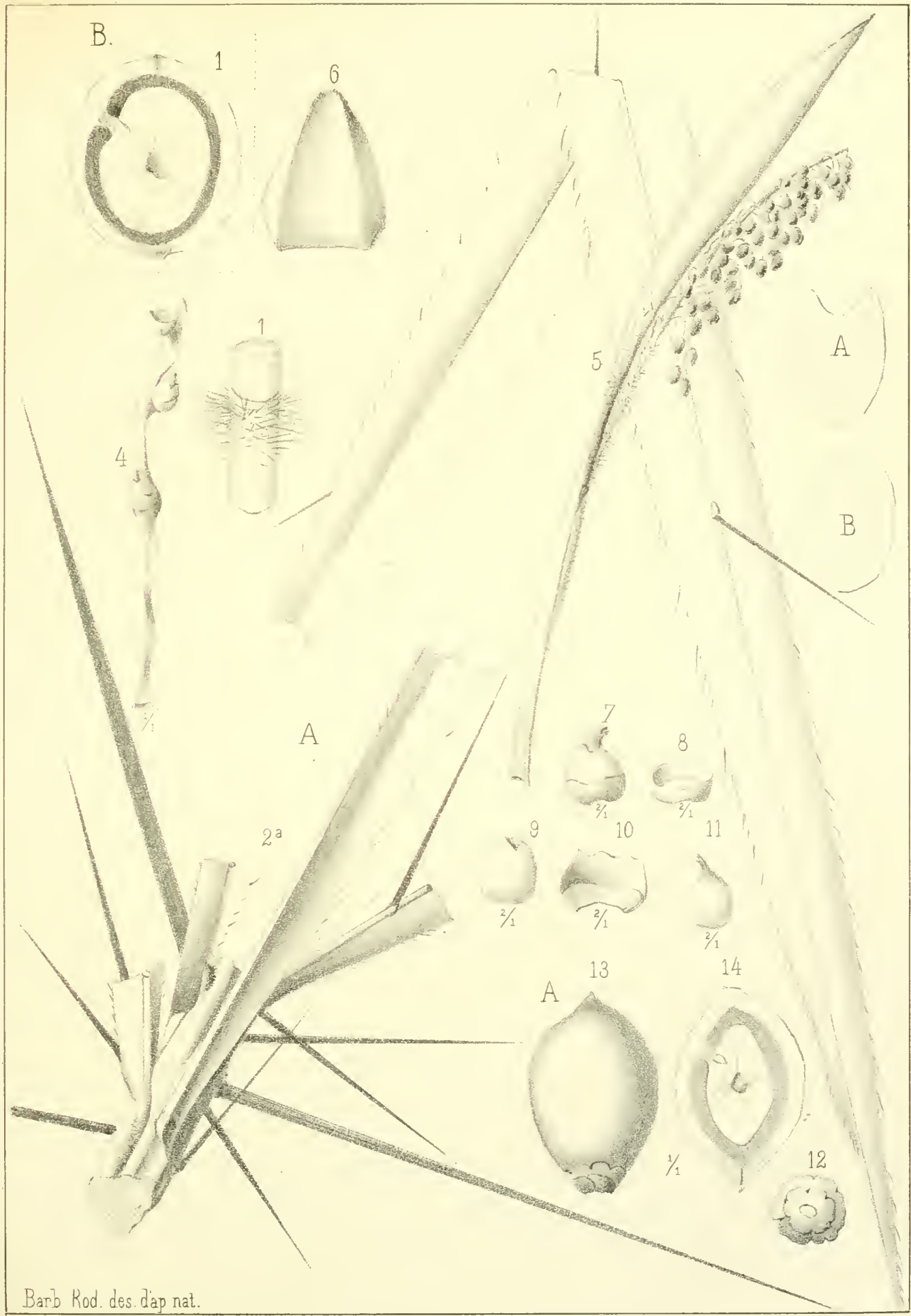





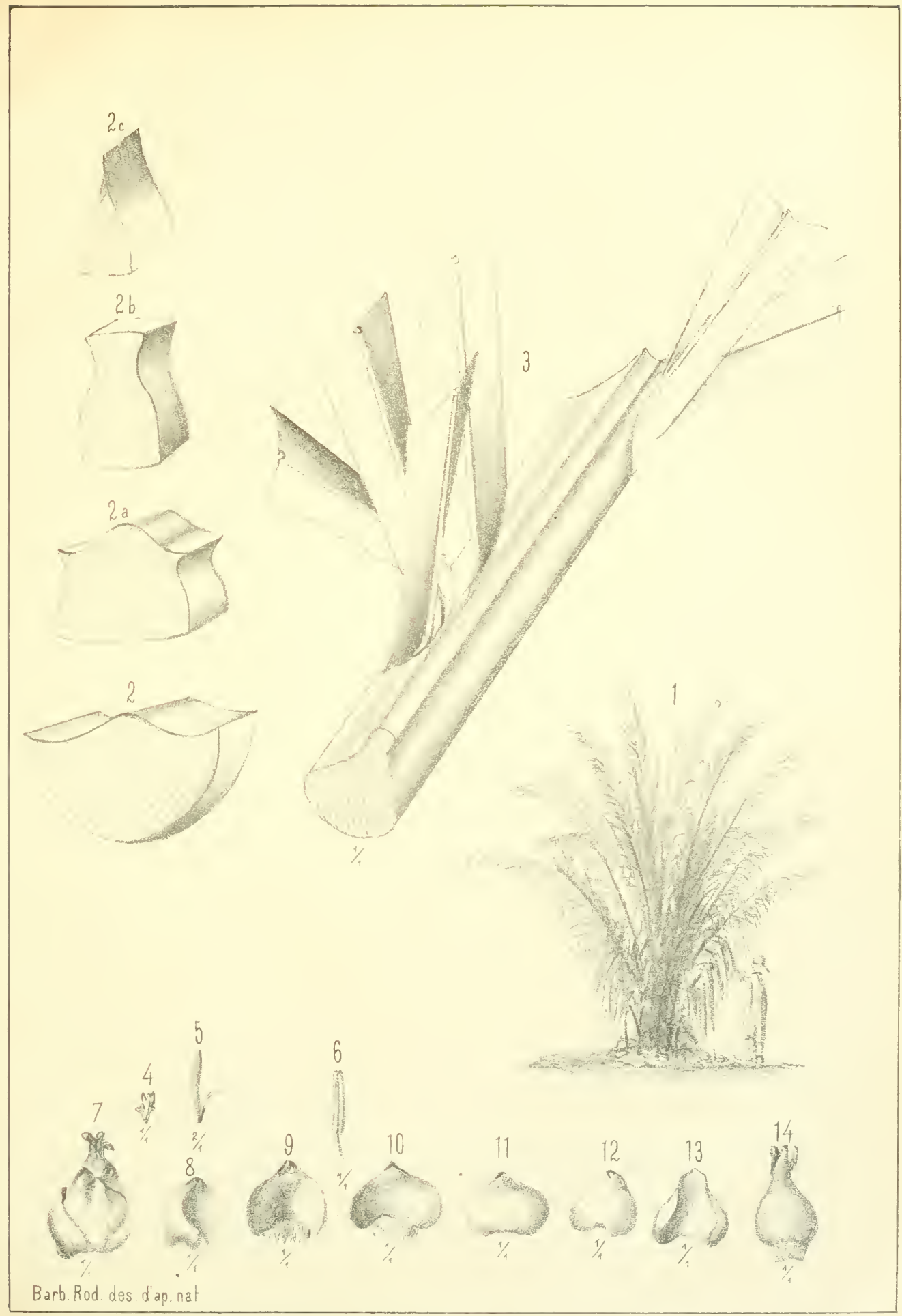





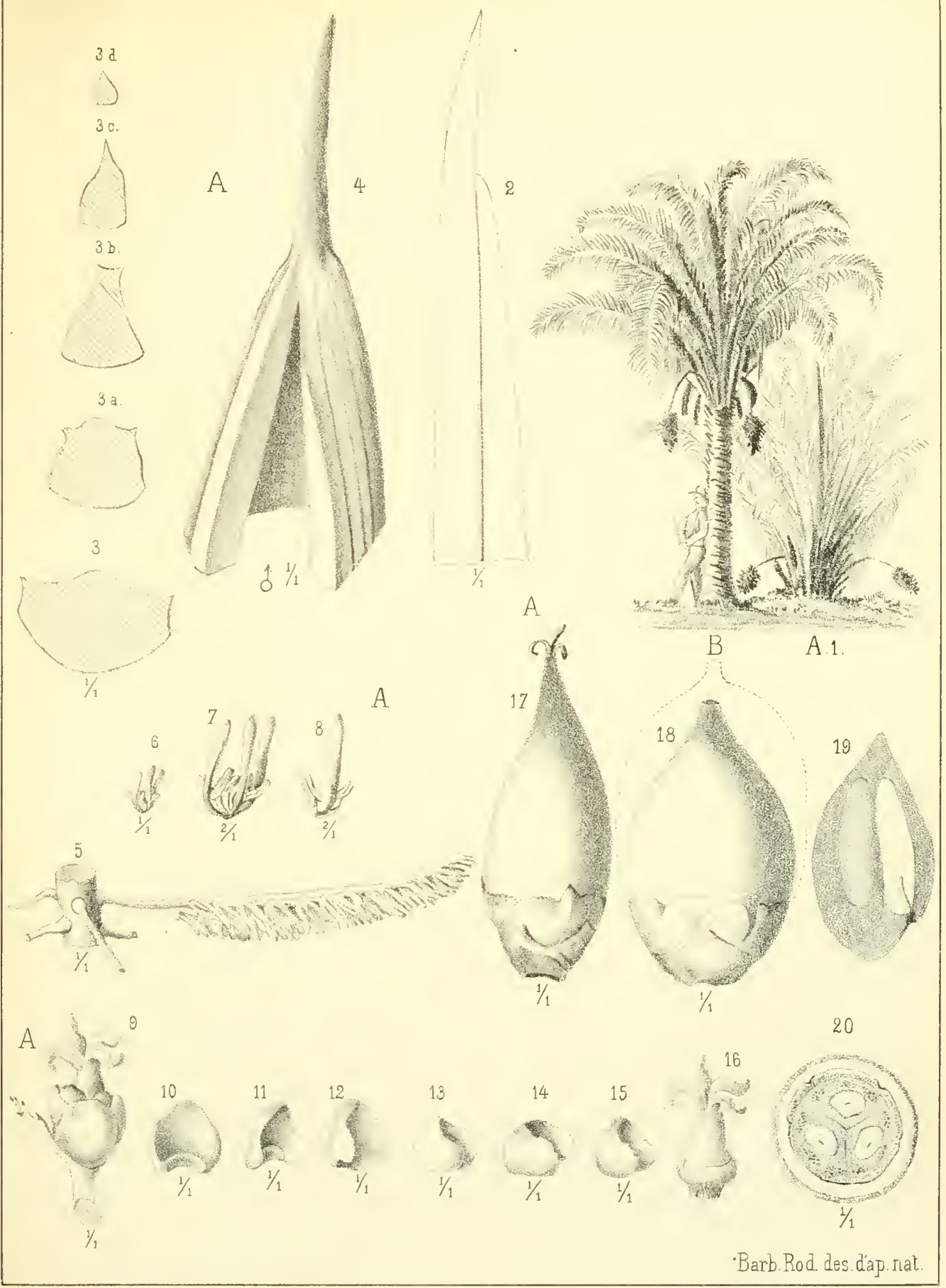

SCHEELEA Princeps var Corumbáensis Barb.Rod. 



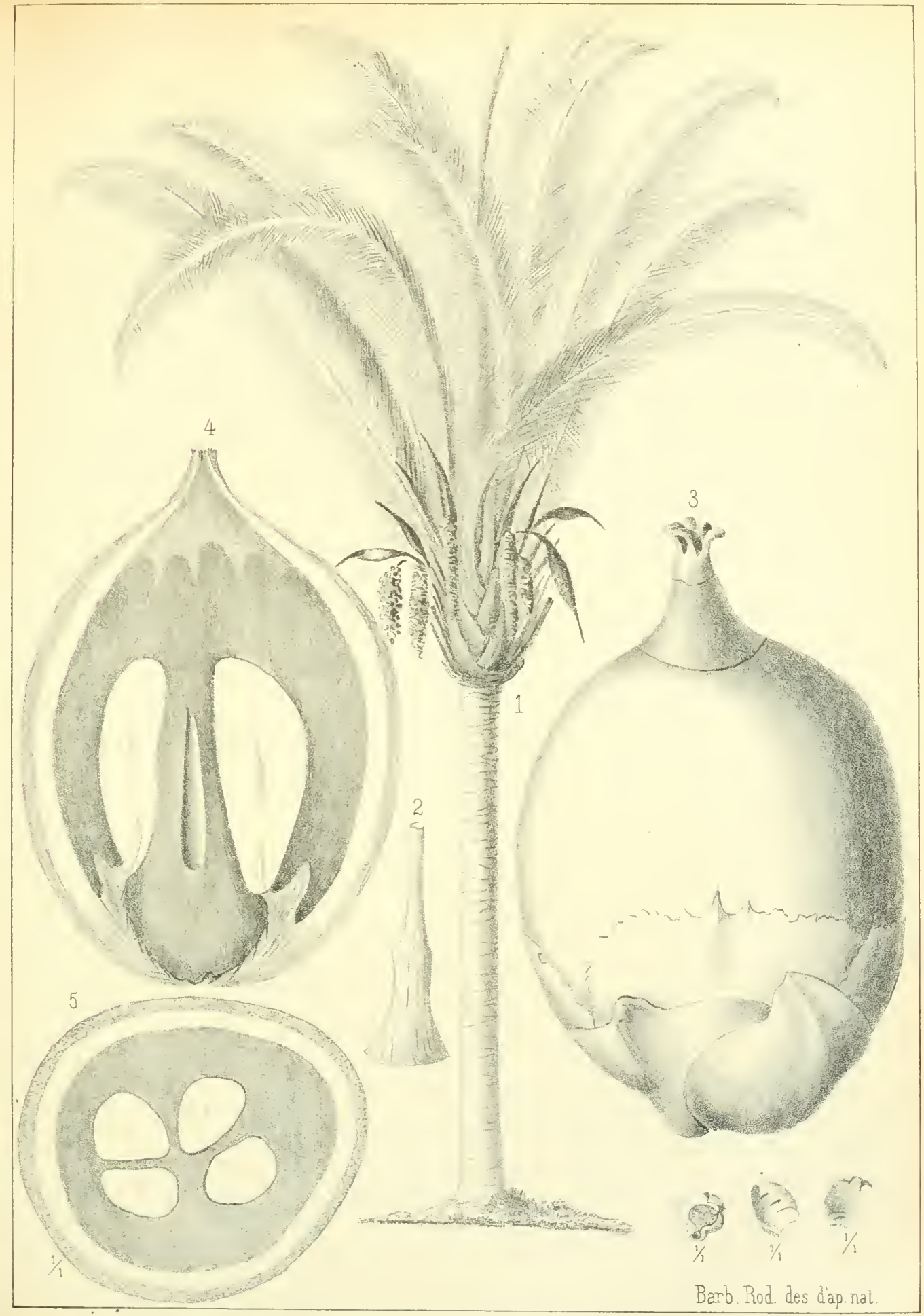

ORBIGNIA MARTIANA Barb.Rod. 



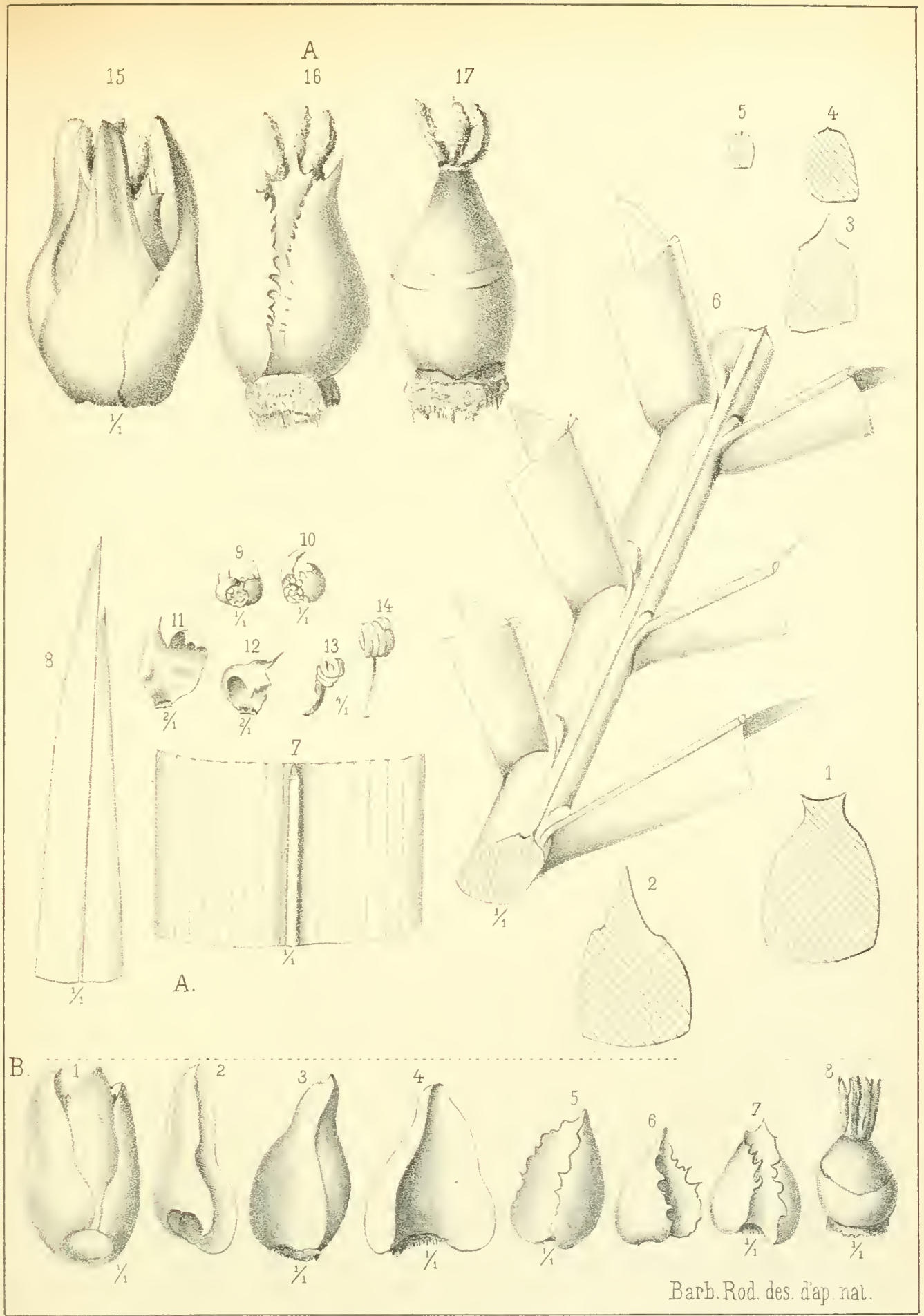

A. ORBTGNIA MARTIANA Barb Rod | B. ORBIGNIA MACROCARPA B.Rod. 



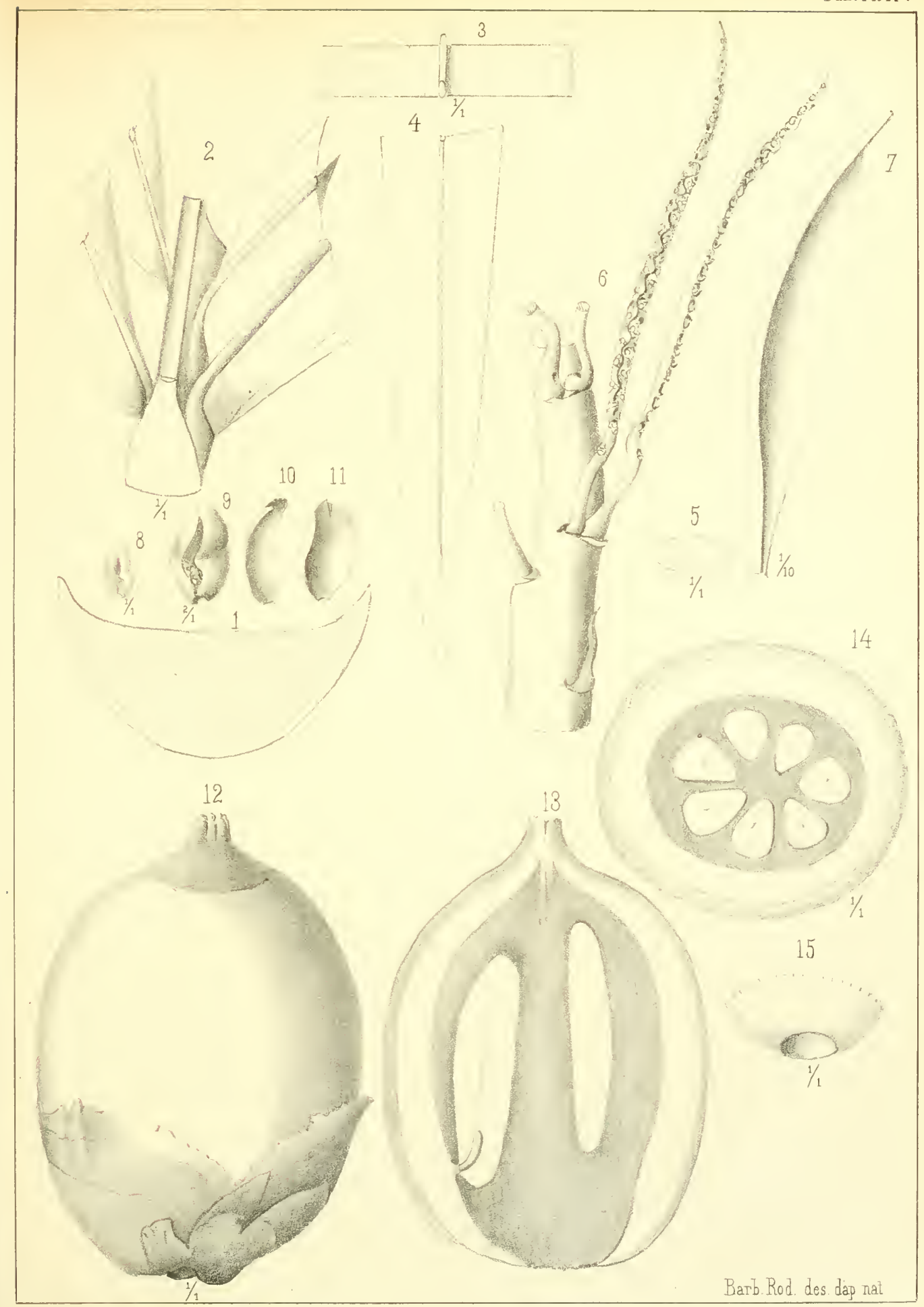

ORBIGNIA MACROCARPA Barb. Rod. 



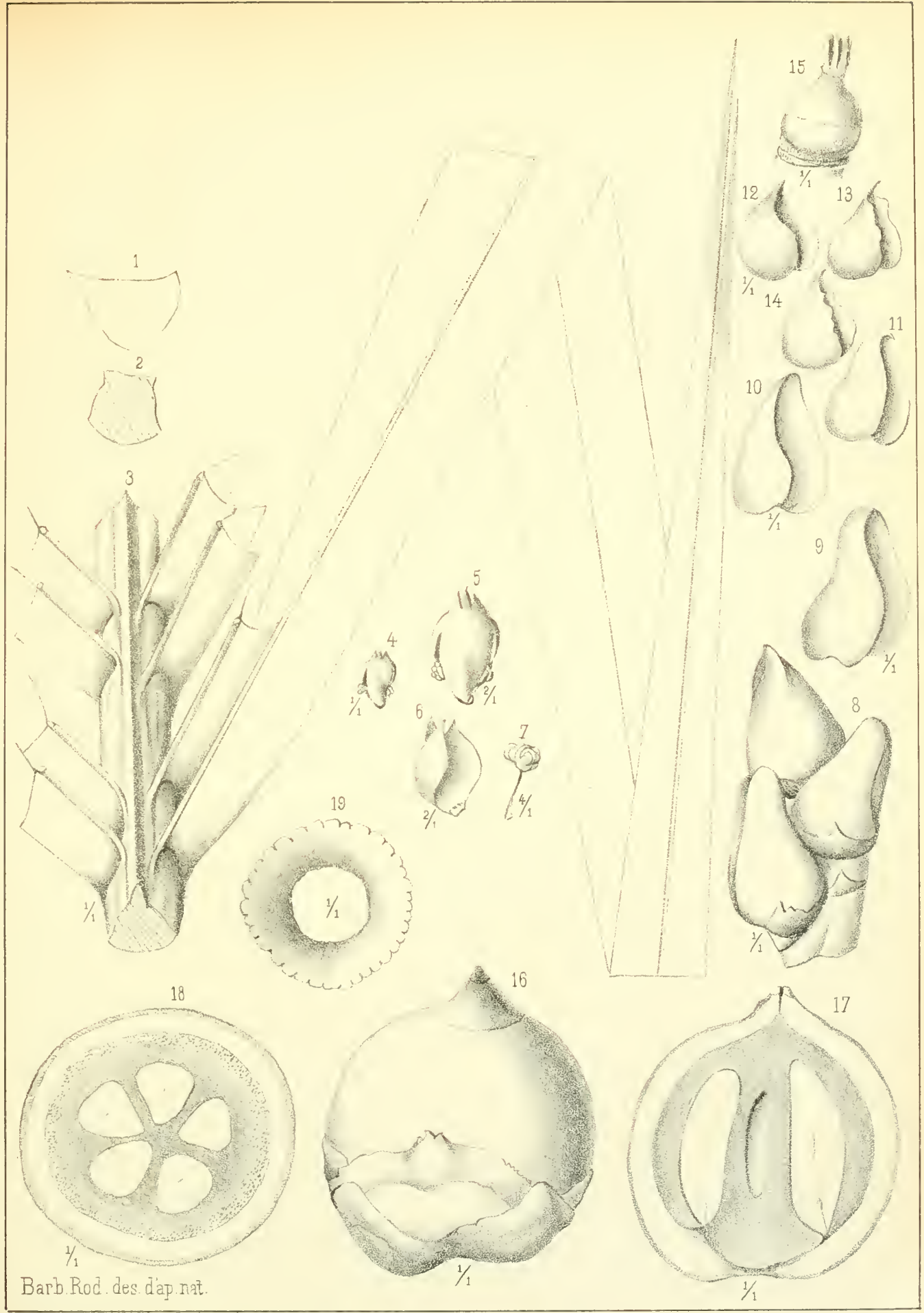

ORBIGNIA CAMPESTRIS Barb.Rod. 



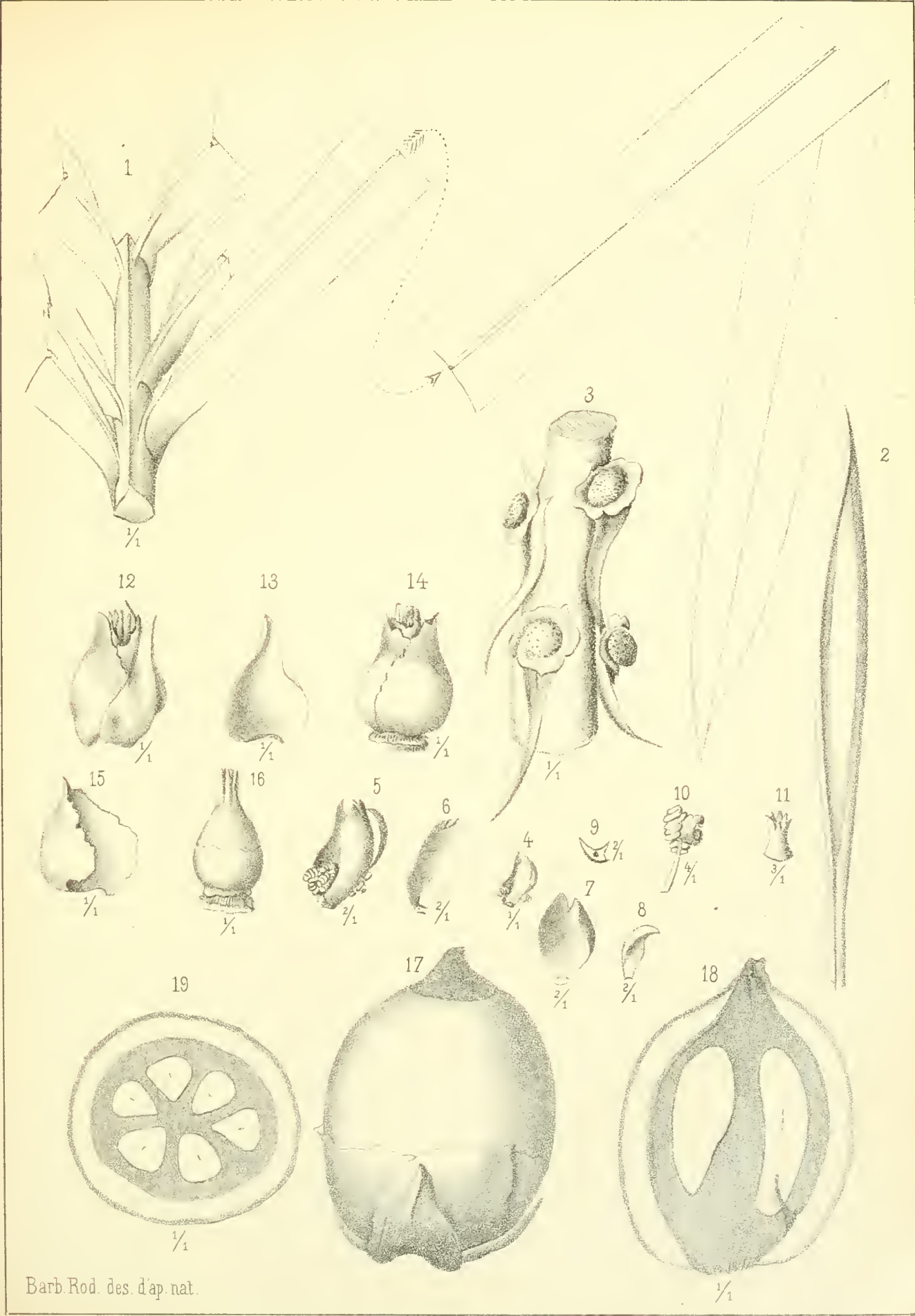



Tab. XXXII

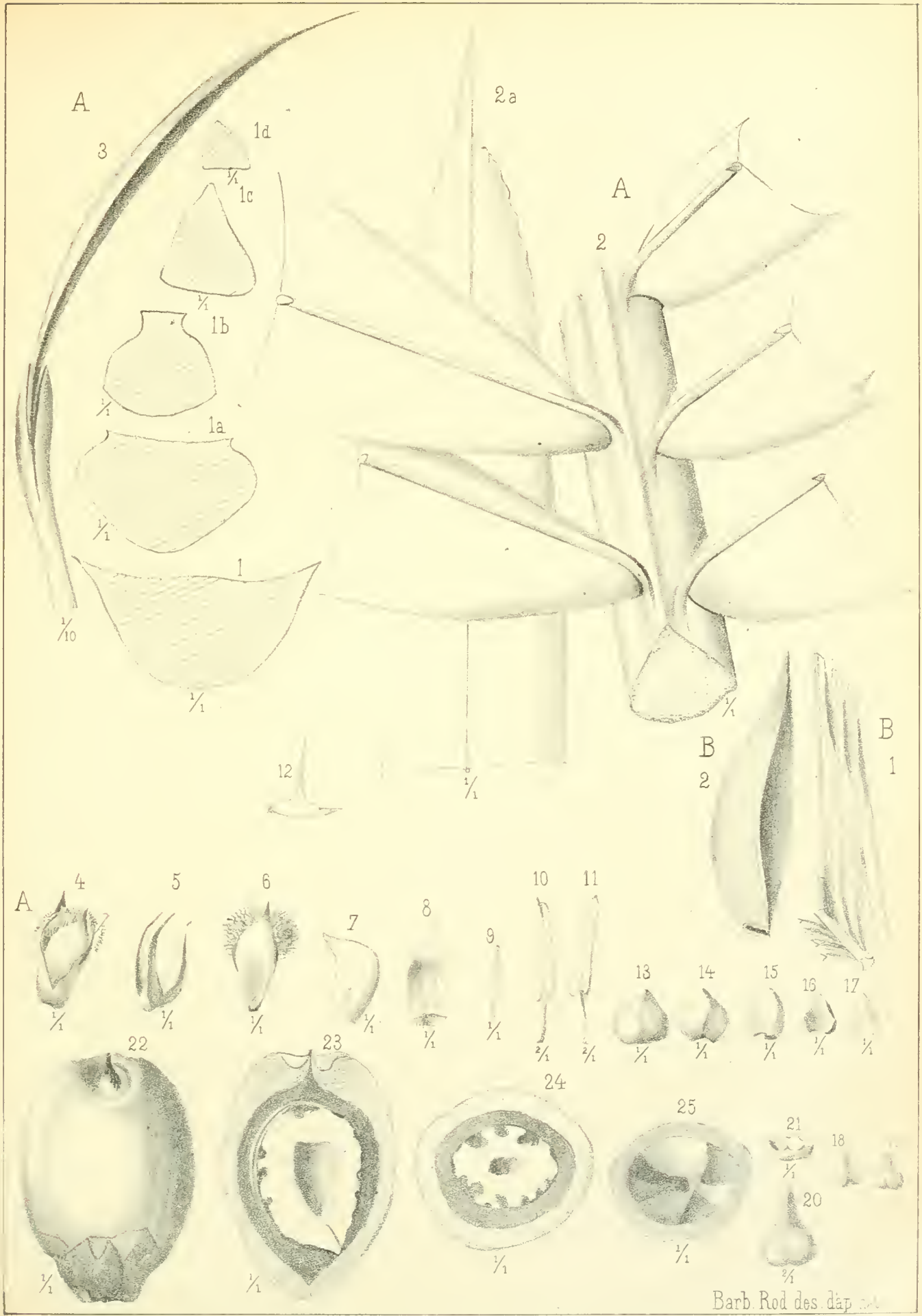

DIPLOTHEMIUM PECTINATUM Barb. Rod. 



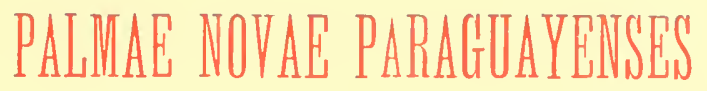

QUAS

DESCRIPSIT E'T ICONIBUS ILLLSTRAVIT

J. BARBOSA RODRIGUES

DIRECTOR HORTUS FLUMINENSIS

Rio de Janeiro

'I'POGRAPIIIA I, FUUINGIH

1899 



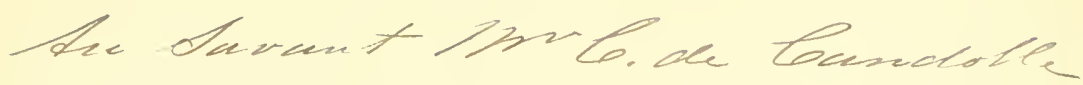

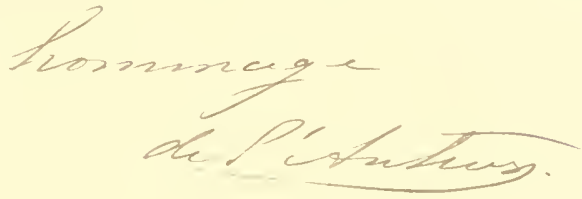

PALIIAE NOVAE PARAGLAIENSES 



\section{PALMARE NOVAE PARAGUAYPISSES}

QUAS

DESCRIPSIT ET ICONIBUS ILLUSTRAVIT

J. BARBOSA RODRIGUES

DIRECTOR HORTUS FLUMINENSIS

RIO DE JANEIRO

TYPOGRAPHIA LEUZINGFR

1899 
extraordinario, porquanto póde-se dizer que as terras paraguayas estão quasi virgens de pesquizas botanicas.

Como sabemos, a Republica do Paraguay descle a sua descoberta por João Caboto, em 1525, até 1813. época em que começou com a Republica o seu captiveiro com a dictadura de Francia, até a terminação la guerra com o Brazil em 1870, que a libertou, nåo tinha sido explorada por naturalistas.

No seculo passado apenas alguns missionarios jesuitas, para uso de suas missões estudaram empiricamente algumas plantas medicinaes, e escreveram alguma cousa. O trabalho mais notavel é o do Padre Pedro Montenegro, que escripto em I710, ainda se conserva manuscripto, existindo do mesmo trabalho dois originaes, um, o mais completo, que estudei e existe no Rio de Janciro em mãos de un particular, e outro que está na bibliotheca da Marqueza de Oduna, em Madrid.

De então para cá poucos estudos botanicos foram feitos, por viver, por assim dizer, o Paraguay sequestrado do resto do mundo, sendo prohibida a entrada de estrangeiros, no seu territorio. O que poderia ter feito muitos estudos, foi o infeliz companheiro de llamboldt. o sabio Aimé Bompland, mas este, penetrando no sólo do dictador Francia, em IS2o, ahi foi logo preso e perseguido, só podenclo occupar se da lavoura, sem poder se arredar clo logar marcado para o seu exilio e muito menos se occupar de trabalhos scientificos, pelo que d'elle nada temos.

Lim 1821, Attgusto de Saint Hilaire, entrou no terreno das missões; mas voltou logo ao Rio Grande do Sul, sendo já conhecidos os elementos botanicos colhidos n'essa regriáo por esse notavel botanico.

Riedel, botanico, companheiro de Langsdorf, em 1 S25: subiu o Paraguay quando foi para Matto-Grosso, mas não classificou uma só palmeira.

I) epois, em $1 \$_{45}$, o Dr. Weddell, companheiro de Castelnau penetrou no Rio Paraguay pelos confins de Matto-Grosso, 
porén as palmeiras por elle descobertas são todas hoje conhecidas. De entio até o triumpho das armas brazileiras, que franquearam os portos e as terras paraguayas, não foram estes visitados, senão pelo sabio e infeliz Dr. Everard Monck de Rosenkiöld, da Universidade de Upsala, que indo para o Paraguay em I $\$ 42$, ahi vivendo na intimidade, como medico, de Solano Lopes, occupou-se muito da flora do paiz; mas, sendo fuzilado, a mandado do mesmo Lopes, en i869. e os seus bens confiscados, todos os seus trabalhos desappareceram, não se sabendo até hoje o paradeiro de seus manuscriptos, que, querem alguns, têm sido aproveitados e publicados por outrem.

Depois de livres as aguas paraguayas, só em 1886, appareceu Balansa, o primeiro colleccionador.

M. Balansa, demorou-se 22 mezes estudando a flora; mas dá apenas 7 especies de palmeiras ao Paraguay (') sem descrevel-as. As suas plantas têm sido todas publicadas.

Mais tarde, de $1888-1890$ D. Thomaz Morong, por conta do Torrey Botanical Club, explorou os arredores de Assumpção e em i 890 o Sr. Grahan Kerr, explorou tambem parte do Rio Pilcomayo.

Os Srs. Lindman e Malme, de Upsala, exploraram ultimamente parte do Rio Paraguay; porém os seus trabalhos não estão ainda publicados; Lindman revê agora as Leguminosas que n'essa republica conheceu e as que já estavam determinadas. As Acanthaceas de ambos já foram descriptas por G. Lindau $\left(^{2}\right)$.

De I885-1895 o Dr. Emilio Hassler, commissionado pelo Governo Paraguayo, para colher productos para as exposições de Paris e de Chicago, teve occasião de colleccionar, nas cordilheiras centraes, no norte do Grão Chaco e nos arredores de Ipacaray, muitas plantas que foram determinadas, em

(1) Revista Mensal.-Assumcion, I896; tom. I, n. I0, pag. 295.

(3) Acanthaceai Americanae et Asiaticae novae \% minus cognitae. Ilerb. Boissior, V. n 8 , Geneve, 1897. 
Genebra, pelo Dr. Chodat ('). Entre ellas não figura especie alguma da familia das Palmeiras.

O Sr. Domingos Parodi, no tempo de Lopes, colheu tamben alguns dados sobre algumas plantas, fez mesmo um herbario, publicando um trabalho $\left({ }^{2}\right)$ que não é phytographico.

Não admira, portanto, que como os outros, n'essa região inexplorada ainda, encontrasse plantas desconhecidas á sciencia, principalmente en uma familia despresada por quasi todos os botanicos, pela difficuldade de seu estudo.

Se mesmo estiverem alguns especimens em herbarios curopeus, isso nada influe, tanto que as palmeiras de lVeddell estiveram descle 1845 a $18 S_{2}$ de conserva nos museus e segundo o Sr. Hemsley, de Kew, "most of the novelties collected by 'Tweedie in the region of Buenos Ayres nearly' sixty' years ago, still lie undescribed in the Kew herbarium".

Com os elementos. pois, que me forneceu o l'rofessor Anizitz. composto de caules, folhas, espadices, flôres e fructos, se bem que, não tão completos como o era necessario, sufficientes, entretanto, para uma determinação, para quem conhece a familia, fiz o presente trabalho, que é mais uma contribuição á botanica da America do Sul.

Relacionadas aqui vão todas as palmeiras conhecidas do I'araguay, até hoje. senclo quasi, senåo todas, tambem brazileiras, e que se elevam ao numero. apenas de 15. Nuito natural é, comtudo, que esse numero seja muito inferior ao do que deve existir, que será conhecido logo que novas explorações sejam feitas. Tenho esperança de que talvez muito kreve, tenha de augmentar a contribuição que agora apresento.

Além d'estas indigenas existem outras inquilinas, como a Orbignia Marliana, Barb. Rod., o Cocos nucifera, a Mauritiu vinifira, Mart., e outras.

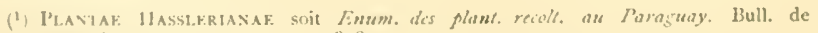
l'Herb. Boissier 6. ${ }^{\mathrm{m}}$ Année. App. «. 1. 1898.

(2) Nivas sobre alyouas plantas unuales del Paraguay, de Corrientes yr de Missiones. Buenos Ayres. 1886. 
Devo dizer, como sempre, que talvez liaja engano nas minhas determinações, porque estou longe dos grandes centros de estudo; mas cono brazileiro prefiro cahir n'um engano a despresar o que é nosso para ser apreciado fóra do paiz.

Devemos sempre nos lembrar que se a Flora Fluminensis de Velloso appareceu, deve-se a um rasgo de patriotismo. Chegando ás mãos do Sr. D. Pedro I, em 1\$24, o primeiro fasciculo dos Nova Genera et Species, do Dr. Martius, elle exclamou: "Como é isso? Então é preciso que os estrangeiros descrevam as nossas plantas? Nós não o podemos?»

Immediatamente, de accôrdo com Frei Antonio de Arrabida, Bispo de Anemuria, que era o seu confessor e bibliothecario, ordenou a impressão dos trabalhos do notavel botanico brazileiro, que se immortalisou, legando á patria um monumento, hoje reliquia litteraria.

Ao terminar não posso deixar de fazer publica a minha gratidão ao sabio professor 1). Juan Anizitz, que, como bom companheiro, muitos auxilios me prestou nas minhas excursões e presta a este Jardim.

$$
\text { O Hutor. }
$$

Jardim Botanico, em 28 de Setembro de 1898. 



\title{
PALMAE NOVAE PARAGLAIENSES
}

\author{
Ord. PALMAE Mart.
}

Fam. CORIPIINEAE Mart.

Gen. Copernicia Nart.

COPLRNICIA CERIFERA Mart. Palm. Orbign. 7 t. $1 . f \cdot 3$ ct I.VIT, et Hist. Nat. Palm. III. 272; Palm. Bras. 56 t. 19. 50 et suppl. 50 et suppl. 50 A. 51 f. 5. M. A. Macedo Not. sur le palm. Camauba, 1867. Kunt. Enum. Plant. III. 273.; Walp. Ann. bot. sy'st. I: p. 817: Grisebach. Symb ad for. Argent. p. 283; Wendl. in Kerch. Les Palm, p. 24I. Drude Flor. Bras. III. p. II p. 547, t. CXXVili.; Morong Ann. of the N. Hork Acat. of Scicnc. VII. p. 245 .

Copernicia alba Morong. Ann. of the N. York Acad. of Science.

VII. p. 245 .

Com o numero $S$ e o nome Caranday o professor Anizitz encontrou na Estancia de Tagatiyá, proximo ao Rio Apa, - Carandáy-moroty, dos karanys ou palma-blanca, dos hespanhoes que o Dr. Morong. considerou especie com o nome de C. alba, para distinguil a da Carandáy-hu, palma negra, como já o fiz ver nas minhas Pulmae Matto-Grossenscs Nozae.

Quanto a esta especie reporto-me a tudo quanto disse sobre ella na mesma obra a pags. I e 2 . 
Gen. Trithrinax Mart.

1. TRITHRINAX BHLABELLATA larb. Rod. Caudex erectus gracilis vaginis in spinas validissimas excurrentibus horridus, foliis rigidis biflabellatis longe petiolatis, cristî anticé acutâ posticé emarginatâ, laminâ usque prope basin profundius incisâ laciniis linearibus in acumina duo pungentia profonde fissis. Spadix gracilis amplus divaricatoramosus, spathis pluribus pedunculum involventibus longe reticulato fumbriato dissolutis et ramos I. suffulcientibus integris cymbiformi-clilatatam acutam, ramis horiferis rigidis arcuato-patentibus.

Tab. $I$.

Caudex $2^{\mathrm{m}}-5^{\mathrm{m}} \times \mathrm{O}^{\mathrm{m}} \mathrm{O}_{5}-\mathrm{O}^{\mathrm{m}}, 07 \mathrm{lg}$.. adolescens usque ad imam basin vaginis involutus. Frolia 10-12 contemporanea, rigida, vix $1,{ }^{m} 20 \mathrm{lg}$., vaginis $\mathrm{O}^{\mathrm{m}}, 20-\mathrm{O}^{\mathrm{m}}, 25 \mathrm{lg}$., exclusis spinis $(S)$ crassis pungentibus oram armantibus $0^{m}, 05-0^{m}, 15$ lg., petiolus $0^{\mathrm{m}} 6-0^{\mathrm{m}}, 8 \mathrm{lg}$. laminam plrq. acquans, compressus et anceps; lamina rotunda, $\alpha=\mathrm{cc} 220^{\circ}$, foliolis cc 25 , extimis $\mathrm{O}^{\mathrm{m}}, 20-\mathrm{O}^{\mathrm{m}}, 24 \times \mathrm{O}^{\mathrm{m}}, 005 \mathrm{lg}$. mediis $\mathrm{O}^{\mathrm{m}}, 45-47 \times \mathrm{O}^{\mathrm{m}}, 2 \mathrm{lg}$., intimis $0^{m} 40-0^{m}, 42 \times 0^{m}, 00.4 \mathrm{lg}$., omnes usque fere ad basin in acumina duo pungentia fissis. Spadices $0^{\mathrm{m}} \cdot 50-60 \mathrm{lg}$. erecto-patenti, pedunculus $\mathrm{O}^{\mathrm{m}} .25-\mathrm{O}^{\mathrm{m}} .3 \mathrm{O} \mathrm{lg}$. compressus inter spatharum interiorum tubum occultus spathis 6, fere aequilongis tubulosis dense imbricatis involutos. 1 exterior lanceolato ad apicem bipartido utrinque acuto. 5 interioribus ad apicem fibroso dissolutis, extimis ochreatis 6 decrescentibus cymbiformis, acutis, integris; rachis valida. ondulata, $0^{m}, 25 \mathrm{lg}$.: ramos $6-7$ excerentes, ad basin spathis ochreatis protectos, inferiores $\mathrm{O}^{\mathrm{m}}, 2 \mathrm{O}-\mathrm{O}^{\mathrm{m}}, 2 \mathrm{~S}$ lg.. supremus $\mathrm{O}^{\mathrm{m}}, 15 \mathrm{lg}$., recurvos, rigridos. Flores petalis $\mathrm{o}^{\mathrm{m}}, 004 \mathrm{lg}$., sta. minibus excertis, conicis; calix $0^{t h}, 002$ alt., trifilus, acuminatus; petala late-obovata, $0^{m}, 00+$ alt. filamenta $0^{m}, 005$ alt., lata, plana, antheris emarginatis ad basin sagittatis; ovaria oblong"i, $0^{\prime \prime}, 002$ lr., styli triplo majore - Baccae ignotae. 
HAB. in Paraguay Departamento S. Salvador, at Arroyo Porongo prope Togatiyá et in Chaco inter fumina Pilcomayo et Negro-Flor. Febr. Carandál incolorum.

O genero Trithrinax foi creado pelo 1)r. Martius ( ${ }^{\mathrm{I}}$ ) para uma especie, achada por Sellow, no Rio Grande do Sul, que teve o nome de T. Brasiliensis.

Por muitos annos só esta especie representou o genero; porén. depois o professor Drude, en 1878 . descreveu uma especie $\left({ }^{2}\right)$, a que tenho cultivado neste jardim, T. acanthocoma, tambem dos campos do Rio Grande do Sul, seguida de uma outra achada na Republica Argentina e que o mesmo professor e Grisebach, descreveram en $1879\left(^{(3)}\right.$ a $T$. campestris. Ultimamente na Flora Brasiliensis o mesmo professor Drude, considera a $T$. brasiliensis achada na Bolivia e figurada pelo mesmo Dr. Martius, no seu Palmetum Orbignyanum $\left({ }^{4}\right)$ como especie distincta e lhe deu o nome de $T$. schizophylla.

Até hoje são estas as nnicas especies conhecidas sendo duas brasileiras, propriamente e as restantes uma da Bolivia e a outra da Republica Argentina. Agora tenho a satisfação de apresentar uma quinta especie nova, do Paraguay, que, creio, cresce tambem no nosso territorio.

Infelizmente não posso apresentar uma descripção completa, como o quizera. porque faltam-me os fructos.

Foi achada com o nome de Carandáy, pelo professor Anizitz, no Departamento de S. Salvador, nos pantanos are. nosos do Arroyo Porongo, na estancia Tagatiyá, na excursão que ahi fez em Fevereiro. época em que estava sem fructos. Cresce tambem no Chaco, entre os rios Pilcomayo e Negro. D'ella tirou uma photographia, de varios especimens, e colheu

(1) Palm. Bras. Suphl. p. 150, rof-Palm. Orbisn. n. ff-tab. X.XV f. A.

(2) Regel. Gartinfora XxviI p. $3^{61}$ tab. 959.

(3) Symb. Flor. Arsentinan 1879 p. 283.

(अ) Tab. If fig. 1 . 
exemplares do caule, das folhas e da espatha completa. Sobre este material fiz o estudo que aqui apresento.

Das especies conhecidas se approxima da $T$. schizophylla, tendo tamben alguma affinidade com a $T$. Brasiliensis, mas, creio que não me engano considerando-a especie distincta.

O professor Drude diagnostica as especies conhecidas, pelos caracteres que achou mais salientes e importantes tirados das folhas e do calyce e com esses caracteres fez a sua chave especifica.

Apresento a chave diagnostica do professor Drude, accrescentando eu os caracteres da minha especie.

a. Folia adolescentia in facie superiore tomento denso appresso sericea, sulutus glabrescentia, rigitissima acute mucronata.

$$
\text { I. T. campestris Dr. A. Ciriseb }
$$

b. Folia glalura, rigida vel chartacea.

Xamina rigida laciniis in acumina 2 pumsentia fissis.

Spadicis rami crassi arcuato-patentes. Calyx trifidus.

$$
\text { 2. T. Brasiliensis Mart. }
$$

$X \times$ Lamina rigida laciniis usque versus dimidium bifidis.

spadicis ramis gracilis patentes. Calyx trilobus.

3. T. schizophylla Dr.

$X, X$ Iamina temuiter chartacea laciniis brevisinit fissis

spadicis rani gracilimi erecto patentes. Calyx trifidus.

4. T. acanthocoma Ir.

$\times \times$ Lamina liflalellata laciniis ion, rissime fissis.

Spadicis rami crassi arcuato-patentes. Calyx trifidus.

5. T. biflabellata Barb. Roul.

Apresento aqui todas as differenças que encontro. As vagrinas que são de um tecido fibroso finamente reticulado, para o apice apresentam, rematando-se. em frente ao peciolo, $\&$ grandes espinlos, cuja base é largamente reticulada. Na 
schizophylla estes espinhos são menores e têm a fórma diversa, como diversa tambem é a base, como bem se vê, na sua Est. CXXX ('). A folha é biflubellada, como a das Acanthorizas ou mesmo como Martius representa a sua Brasiliensis no Palmetum, que foi por Drude considerada especie distincta, como já vimos. Entretanto, Drude não fala desse caracter, nem nos genericos. Se a especie boliviana, de Martius, tivesse os foliolos longamente fendidos, eu a consideraria identica á minha. Além d'isso, a folha tem os foliolos quasi livres, apenas um a quatro centimetros são ligados na base. Os foliolos são tambem profundamente bifenclidos, pelo espaço de mais de dois terços do comprimento. Esses mesmos foliolos são lineares muito acuminados, terminando em ponta dura e pungente. As cristas da folha são: agudas na parte superior e emarginadas na inferior.

Drude dá para a schizophylla as spathas em numero de cinco, sendo tres exteriores, entretanto, a especie de que me occupo, apresenta só uma exterior e muito distincta (semelhante ás de outros generos), e cinco interiores, que envolvem imbricadamente o pedunculo, além de mais seis, degeneradas em ochreas, que protegem os ramos quando novos e os acompanham mesmo depois de velhos.

O espadice é erecto, com o rachis ondeado e os ramos recurvos.

A folha, na especie de Drude, tem um angulo de $200^{\circ}$; na minha attinge a $220^{\circ}$. Além d'estas differenças, deve-se tambem notar que as especies conhecidas são de campos seccos e de logares elevados e esta é dos pantanos e dos logares baixos em que se dão certas especies de Bactris.

Drude separou mais a T. Brasiliensis Boliviana, da Brazileira, identificada por Martius, pelo caracteristico dos foliolos mais fendidos e pela fórma do calyce, e, se isso foi bastante,

(1) Flor. Braz,, III p. 11 p. 55 1. 
de sobra são os que apresento para nåo identificar a especie paraguaya com a boliviana.

Comparem-se os meus desenhos com os de Martius e os de Drude e vêr-se-ha se tenho ou nåo razão. Os spadices em geral, nas Trithrinax, são muito semelhantes e poucos caracteres de valor apresentam.

Comparando-se as hlores vemos que o calyce tem a metade do comprimento da corolla, na de que trato é trifido e acuminado e não breve trilobado, com '/3 de comprimento; que as pétalas são mais largamente obovaes e não ovaes e agudas, e que só tem um ovario e não tres, como está representado.

Pelos motivos apontados considero especie nova.

Os naturaes tiram muito proveito desta palmeira e das especies congeneres. Os fructos, que são adocicados, servem de alimento para o gado; fermentados extrahem, por distillação, uma aguardente de bom paladar; das sementes, trituradas, extrahe-se oleo; das vaginas das folhas fazem filtros e das follhas abanos e vassouras.

Os espiques empregam-se tambem para esteios de cercas. 
Fam. CocoINex Mart.

Gen. Cocos Linn.

Sect. EU $\operatorname{cocos}$ I) $r$.

B. Findocarpio lapileo intus grbboso, monostermo, allumen cequabile

COCOS ROMANZOFFIANA Chamisso in Choris, Voyage pitt. autour du monde, p. $5 \mathrm{~V}$ et VI (1822) et in Flor., VI. (IS23) par. I, 226. - Mart. Hist. Nat. Palm., II p. 127, tab. 8S. p. VII, et III p. 32r, - Kunth. Enum. plant. III, p. 286. - Walpers Ann. bot. syst., 5 p, \$23. - IVendl. in Kerch. Palm. p. 241 . - Hook. Rep. R. G. Kere, ISS2 p. 241. - Drude in Mart. Flor. Bras. III, p. II, p. 4I9, tab. XCII. - Becc. in Malpighia I, fasc. VIII. p. 25, n. 19. Barb. Rod. Palm. Mattogross. (г898) p. I3.

Cocos australis Mart. Palmte. Orbig. (1847) p. 95. tab. I, f. 2 et. tab, 30 C. ; Hist. Nat. Palm., III, p. 289, et 334. - Walp. Ann. bot. sj'st. 5, p. 823. - Wendl. in Kerch Les Palm., 240, - Drude Mart. Flor. Rras. IIII, pag. II. p. 420. - Hook in Report. R. G. Kew. 1882 (1884), p. 72. - Beccario in Malpighia I fas. VIII. pag. 26. - Morong. Plant. coll. in Puraguay Annal. of the N. York. Acad. of Sien. VIII. (1893). pag. 245 .

Cocos plumosa Hook f. in Bot. Mag., t. 5180 (1860) et in Rep. R. G. Kew is82, p. 72. Wendl. in Kereh. Les Palm., p. $24 \mathrm{I}$. - Drude in Mart. Flor. Bras. III, p. II. pag. $4 \mathrm{I} 2$. Becc. in Malpigh. I fasc. VIII. p. 28. n. 22 ?

Cocos Datil. Grisebach et Drude in Griseb. Symb. Fl. Argent., 1879. p. 283. - Drude in Mart. Fl., Bras. III, p. II, p. 419. tal, XCIII. - Becc. in. Malpigh. I. fasc. VIII, pag. 27, n. ${ }^{\circ} 21$ ? ?

Cocos geribá Barb. Rod. Protest. app. p. 43. (i 879). Les Palmiers p. 27 f. 6. in tab. physiogn. et tab. III. f. 5 a, b, c, et fig. 6, a, b. (1882). Drude Flor. Bras. III. p. II. p. 403, in clavis analyp. Beccario Malpigh. I. p. 28. 
Cocos ackocomomes Drude in Mart. Fr. Br., p. II, parg. 409, tab. LXXXVII, f. III. - Becc. in Malpigh., VI. fasc. VIII, pag. $28, n .^{\circ} 23$ ? ?!

Cocos martaxil Drude et Glz. in Mart. Fl. Br., III. p. II, pas. 418.

Pelo polymorphismo do seu porte, forma e côr do fructo, torna-se natural esta especie, que tem levado varios autores, que têm encontrado os especintens distanciados sem os poder comparar a tomar por especies differentes, pelo que longa é a sua synonymia. Esta que apresentei e aqui repito, foi baseada no estudo comparativo de milhares de individuos. oriundos de varios estados, que crescem em terrenos e climas mui diversos.

Assim do Rio de Janeiro ao Paraguay e Matto-Grosso, comparci e o resultado foi o que expendi nas minhas Palmae Mattogrossenses e que por isso deixo aqui de referir, pedindo ao leitor que as consulte. Um caracter constante apezar da mudança da forma do fructo é o da forma do endocarpo e por conseguinte do albumen. Só esta especie apresenta o callo saliente na parte interna, como se poderí ver nas figuras da Estampa da referida obra.

O Pindó, que é o seu nome vulgar no Paraguay, é muito commum por toda a parte, e ahi mesmo apresenta differenças de um para outro individuo. Apezar, porém, das differenças tem tal traço caracteristico no porte que á primeira vista se reconhece e se não confundirá com outra qualquer especie. As folhas são muito usadas para levantar ou adelgagar os cavallos de corridas. Tendo já me occupa lo desta especie na refericla obra passo a occupar-me de outras. 
Gen. Cocos Lin.

Sec. Syagrus Mart.

A. Endocartio lafideo intus monovittato, monosperno, albumen aequabive

Ak M.i. Gynomicranthae.

9. COCOS PARAgUAYENSIS Barb. Rod. Acaulis. Raro caulescentes, foliis arcuato-patentibus breve vaginantibus petiolo leviter spinoso-serrato, segmentis confertis aequaliter distantibus lineari-acuminatissimis supremis filiformibus. Spadix erectus longissime pedunculatus spathâ interiore lineari-lanceolatâ extus laeviter sulcatâ glaucâ, rhachi brevi ramos aequilongos articulatim exserente ; flores masc. quam fem. minores calyce triphyllo sepalis linearibus petala duplo minoribus, antheris inclusis; flores fem. oblongo ovoideis sepalis cordato-ovatis ad apicem incurvis, petalis convolutis mucronatis, androceos abortivo minimo annulare, ovario elongato acuminato; drupa carnosa oroidea attenuata, endocarpio oblongo utrinque acuto intus monovittato, vittâ laevi supra porum adscendente.

Tab. II.

Candex nullus, v. $1^{\mathrm{m}}-2^{\mathrm{m}}$ alt. Folia altus $\mathrm{I},{ }^{\mathrm{m}} 60-1,{ }^{\mathrm{m}}$ So $\mathrm{lg}$.; vagina $0,{ }^{\mathrm{m}} 2 \mathrm{lg}$. ad oram in fibrillas dissoluta et sensin in spinas minimas petioli nultas validas transiens; pendunculus $0,{ }^{\mathrm{m}} 45-0,{ }^{\mathrm{m}} 48$ lg., glaucus, super concarus, subtus convexus, foliolis ad basin alternis ad apicem oppositis, inferioribus $0,{ }^{\mathrm{m}} 45-0,{ }^{\mathrm{m}} \mathrm{OO} 3$ $\mathrm{lg}$., mediis $0,{ }^{\mathrm{m}} 50 \times 0,{ }^{\mathrm{m}} \mathrm{O} \mathrm{l} 3 \mathrm{lg}$., superioribus $\mathrm{O},{ }^{\mathrm{m}} \mathrm{O} \mathrm{I} \times \mathrm{O},{ }^{\mathrm{m}} \mathrm{OO} 2 \mathrm{lg}$., utrinque $36-40$, rigidis, infra glaucescentibus. Spadices $0,{ }^{\mathrm{m}} 70-0,{ }^{\mathrm{m}} 75 \mathrm{lg}$., spatha interiore longe vaginantia, linearilanceolata, acuta, laevis. glauca, pedunculus $0,{ }^{\mathrm{m}} 42 \mathrm{lg}$., subrotundo-compressus, laevis; rachis $0,{ }^{\mathrm{m}} 20 \mathrm{lg}$, ramos $25 \sim \hat{0}$, inferiores $0,{ }^{m} \mathrm{I} 6-0,{ }^{m} 1 \mathrm{~S} \lg$., superiores $0,{ }^{\mathrm{m}} 10-0,{ }^{\mathrm{m}}: 4 \mathrm{lg} .$. bra- 
cteis brevis acuminatis ad ramorum insertionem. Flores

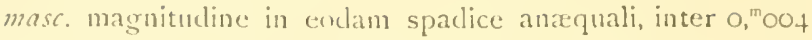
et $0 .{ }^{m}$ oos lg., sepalis linearibus dorso carinatis; petalis lanceolatis subobtusis, $0,{ }^{\mathrm{m}} \mathrm{OO} 6 \times 0,{ }^{\mathrm{m}} \mathrm{O} 02 \mathrm{lg}$., staminibus inclusis petalorum dimidiam altitudine superantibus, antheris ad basin sagittatis; flores fem. 2 supra ramorum basin, 0, "I014 X0," $0,008 \mathrm{lg}$.. sepalis petalisque quam ea paulo minoribus arcte inter se convolutis, androceo abortizo o," alt., Drupxe induviis usque medium longis involutae tlavae,

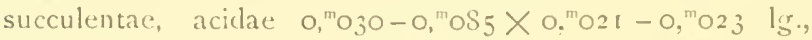
mezocarpio crasso, endocarpio osseo, $0,{ }^{\mathrm{m}} 025 \times 0,{ }^{\prime \prime 01} 3 \mathrm{lg}$. oblongro, utrinque acuto, brunneo.

11.sk. in Parasuay. ad S. Salvador prope Tagatiyá. Yativ inco. lorum. Firor. Fan.

Entre as (specics conhecidas, do genero Cccos, existe a que Martius denominou Cocos I'ulay, encontrado por Alcides d'Orbigny, em Corrientes e Entre Rios, assim como por Lorentz, na Concordia, com o nome de Yatay', que the dão os indigenas. Esta especie tive occasião de encontrar e de revel-a conservada no Museu de Montevideo. O nome Kalí-y' dado pelos karanys é o mesmo que os tupys do Amazonas dão ao Syugras cocoüdés Mart. da sua regiåo. Em Monte Alegre e nas serras do Ereré e Paytuma alıi os indios só lhe dåo o nome de y'alí, que é uma abreviatura de y'ud on y'á, fructo e atá, duro. Yatá-y é o fructo duro; porém. ( $y^{\prime}$ ) pequeno. E' nome que no valle do Paraguay aplicam aos fructos de varias palmeiras de diversos generos, como veremos.

lintre as diversas palmeiras que estudei, do herbario Anizitz. uma, tem o nome vulgar. tambem, de lirlicy. mas que náo é o mesmo de Nartius, e que os indios do Amazonas dariam o nome de Jaliz'rana, por se parecer com o verdacleiro e nåo o ser. Com effeito, se fossemos levados pelo nome vulgar e pela simples apparencia, o tomariamos pela mesma especie, o que nos levaria a um erro. Na falta de un hervario, poder- 
se-ha comparar a minha estampa, conscienciosa e mathematicamente copiada do natural, as com estampas de Martius ( $\left.{ }^{1}\right)$ e de Drude $\left({ }^{2}\right)$, que julgo tambem fidelissimas, e as descripções e ver-se-ha que são differentes as especies se bem que proximas. Comparem-se as folhas, o tamanho e forma do spadice, a forma das flores e dos fructos e ver-se-ha que tenho razão. Poderão não admittir que seja uma verdadeira especie, mas sim uma variedade, produzida pela structura geologica do terreno, do meio, etc. como acontece com o Cocos Romanzoffiana Cham.

Entretanto sou forçado a consideral-a especie ou sub-especie, pelas differenças que encontro e que apresento na confrontação dos caracteres juntos.

B. Enlocarpio capideo intus tRIVITtato, monospermo, albumen aequabile. Uaperema. Caudex mediocris. Gynomicrantae B.

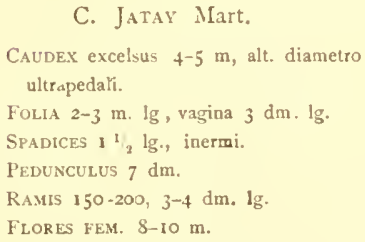

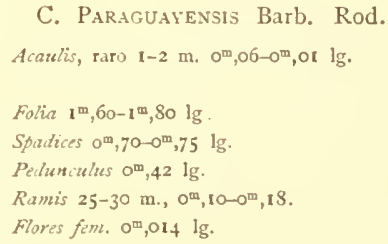

Basta só considerar-se que uma é caulescente e outra só quando muito velha apresenta um caule que, rarissimas vezes, vai até a 3 metros. Compare-se o tamanho do spadice e o numero de ramos e ver-se-ha que a ser variedade é uma variedade nana.

O fructo é amarello, azedo e apresenta um cheiro de acido oleinico ou palmitico, em quanto que as do yatás de Martius "la pulpa de las fructas es muy dulce» segundo Hieronymus nas suas Plantae diaphoricae.

(1) Palmetum Orbignianum, tab, 1 et 30.

( $\left.{ }^{2}\right)$ Flor. Braz. III. p. II. tab. XCIV et XCV. 
3. C. SAPIDA Barb. Rod. Candex mediocris columnaris nudus crassus, foliis densis concinnis, petiolo longo, foliolis linearibus per greges alternis. Spadix patens spathâ interiore elongrata longitudinaliter argुute sulcatâ tomento cotonoso cinnamomeo tectâ, rostratâ, rachi ramos numerosissimos rigidos dense exserente, glomerulos androgynos usque ad medium evolventibus, floribus masc. femineos ovoideos requantibus, sepalis petalisque fem. lato-ovatis acutis, androceo sterile sexdentato, ovario oblongo tomentoso, drupa parva oblonga acuta, mezocarpio oblongo utrinque acuto intus trivittato.

Tab. III.

Cautix $2^{\mathrm{m}} \times \mathrm{O}^{\mathrm{m}}, 20-0^{\mathrm{m}}, 25 \mathrm{lg}$, annulatus, cinereus, Folia $12-16$ contemporanea, patente-recurvo, longe petiolata, breve inva. genantia, $2^{\mathrm{m}}, 7 \mathrm{o} \mathrm{lg}$., petiolo $\mathrm{O}^{\mathrm{m}}$, So $\mathrm{lg}$., foliolis bi-trijugatis, greges alternis. linearibus, oblique acuminatis, inferiores $\mathrm{O}^{\mathrm{m}}, 50 \times \mathrm{O}^{\mathrm{m}} .02 \mathrm{lg}$., medio $\mathrm{O}^{\mathrm{m}}, 5 \mathrm{O}-\mathrm{O}^{\mathrm{mi}}, 56 \times \mathrm{O}^{\mathrm{m}}, \mathrm{O} 17 \mathrm{lg}$., superiores $0^{\mathrm{m}}, 18 \times \mathrm{O}^{\mathrm{m}} .04 \mathrm{lg}$., Spadices $1^{\mathrm{m}} \cdot 30 \mathrm{lg}$. spatha interior $\mathrm{I}^{\mathrm{m}} .20 \times \mathrm{O}^{\mathrm{m}}, \mathrm{I}_{3} \mathrm{lg}$., lanceolata, rostrata, extus arguté sulcata, tomento-cotonoso tecta, erecta, peinunculus $0^{\mathrm{m}}, 70 \times \mathrm{O}^{\mathrm{m}}, 18 \mathrm{lg}$. subrotundo-compressus, tomento-cotonoso cinnamomeo tectus, recurvus, rachis, $\mathrm{O}^{\mathrm{m}}, 40 \mathrm{lg}$. ramos numerosissimos, inferiores $\mathrm{O}^{\mathrm{m}}, 30 \mathrm{lg}$., superiores usque ad $\mathrm{O}^{\mathrm{m}}, 15 \mathrm{lg}$., decrescentes evolvens, bracteis minimis ad ramorum insertionem. Flores masc. $0^{\mathrm{m}}, 008 \mathrm{lg}$., petalis lanceolatis, concavis, acutis, staminibus paulo brevioribus, autheris ad basin sagitatis et ad apicem acutis, germinodio trifido: flores fim. 20-30 contemporanei, sepalis petalisque lato ovatis acutis subarquan. tibus arcte convolutis; androceo sterile annulare sexdentato; ovario oblongo, tomentoso, stigmatibus erectis acuminatis. Drupa llava, induviis ad basin imvoluta, $0^{\mathrm{m}}, 35 \times \mathrm{O}^{\mathrm{m}}, 20 \mathrm{lg}$., endocarpio brunneo, $\mathrm{O}^{\mathrm{m}}, 30 \times \mathrm{O}^{\mathrm{m}}, 15 \mathrm{lg}$., utrinque acuto. intus trivittato; allbumen solido, oblongo, $\mathrm{O}^{\mathrm{nl}}, \mathrm{O} 5 \times \mathrm{O}^{\mathrm{m}}$, oro. 
HAB. In Paraguay, departamento de S. Salvador, prope Tagatiyá et in Sta. Maria de Missiones. Jatáx-pindó incolorum. Floret et fruct. Fan.

Mais uma especie nova se me apresenta sob o n. I, no referido herbario, e que, como o C. Ramansofana Cham., tem tambem o nome Pindó, mais vulgarmente Fatáy-findó.

Como sabem, este nome indigena significa pura e simplesmente palmeira e por isso ás folhas de qualquer dão o nome de pindob, de pindó e ob. follha que já se faz pindoba, nome vulgar de algumas Attaleas e Orbignyas, tomando-se a parte pelo todo.

Para o leigo na sciencia de Linneo, pelo nome vulgar a especie en questão seria o Cacos Australis Mart. que, como vimos, não é mais do que o mesmo Ramanzoffiana. O indio, porém, que bem o distingue, o denomina Fatáy-pindó, palmeira de fructos duros e pequenos, para distinguil-a de outros.

E' uma bella especie que pelo facies logo se distingue pela disposição das folhas e dos foliolos. O seu aspecto, sendo gracioso, é mais severo do que o d'aquelle que é mais esbelto e elegante.

Não sendo alto tem, comtudo, um tronco grosso.

Seus fructos são muito saborosos. 
Gen. Diplothemium Mart.

Este genero foi creado pelo Dr. Martius e publicado no segundo volume da sua Historia Naturalis Palmarum, mais conhecida por Genera et Species Palmarm ( $\left.{ }^{1}\right)$. que o reproduzio no terceiro volume $\left(^{2}\right)$ e no Palmetum Obignyanum. ( $\left.{ }^{3}\right)$.

No Genera apresentou as especies maritimum, campestre, littorale e caudescens e no terceiro volume accrescentou o Torallyi, que no Palmetum havia publicado. Estas especies foram as unicas conhecidas até a publicação da monographia de Drude $\left({ }^{4}\right)$, que accrescentou mais uma a lcucocaly'x, achada por WVeddell, em Matto Grosso, e duas variedades do campestre. Kunth $\left(^{5}\right)$ e IValpers $\left({ }^{6}\right)$ tambem só apresentaram as especies Martianas. Endlicher ( $\left.{ }^{7}\right)$, Benthan e Hooker $\left({ }^{8}\right)$ e Baillon $\left({ }^{9}\right)$, todos apresentam os caracteres genericos do fructo sem apresentar um caracter muito especial, que tem o endocarpo ou putamen, caracter este tão significativo, que é um dos que caracterisa o genero Syagmus, para distinguil-o do Cocos; o das tres faixas negras e luzentes, que tom internamente o endocarpo, correspondentes aos seus tres poros.

Creio que isso não foi determinado por falta de exame dos fructos, nåo estando elles estudados convenientemente en todas as especies. A melhor estudada, que foi o littorale. essa mesma nåo tem mencionado o caracter a que me refiro. A prova de que não foi visto este caracter, está em ter o professor Drude affirmado que não tem fairas, quando diz: Drupa ex induviis sacpe soiuta monosperma putamine laeitigato ad basin foramina 3 crolvente vitTIS ET CALLIS DESTITUTO LAVI.

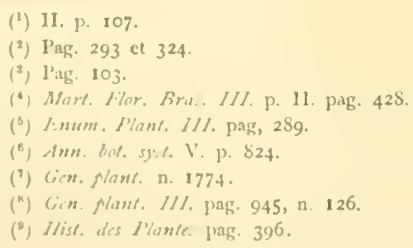


Todavia posso garantir que o caudescens tem tres largas faixas, o pectinatum, especie minha $\left(^{\mathrm{r}}\right)$, não só tem as tres faixas como callos, o leucocaly'x, o campestre, o Anizitzii e o maritimum, todos têm as tres faixas mais ou menos escuras; mas, perfeitamente distinctas e muito luzentes, como se poderá ver na Est. III e na XXVII das minhas Palmae Mattogrossenses. Nào sei se o $D$. Torallyi, que é boliviano, faz excepçåo porque só o conheço pela descripção e figuras do Palmetum Orbignyanum; mas, é de suppôr que não se afaste dos congeneres.

Aqui, mau grado meu, corrijo esse engano, levado sómente pelo desejo de ver bem caracterisadas as nossas palmeiras, não se omittindo caracteres salientes, que a sciencia manda perpetual-os para exactidão das classificações. $O$ albumen, tambem dado por todos como solido, não o é; tem o interior mais ou menos excavado e ruminado.

Um outro caracter tem sido tambem omittido. Todos os autores dizem que as flôres femeas nåo tem o estaminodio ou androceo abortivo, quando todas ellas apresentam sempre esse orgão bem distincto e desenvolvido e acompanha a induvia.

Devemos notar, que devido ao terreno selicoso, calcareo ou argiloso, mais ou menos humido, os Dipl. maritimum e campestre, apresentam uma grande variedade no crescimento e nas folhas. Nos terrenos selicosos os pés são pequenos e de folhas curvas e muito crespas e nos logares argilosos as folhas são longas, erectas e não tão crespas e assim tambem o comprimento do spadice e tamanho dos fructos.

Os que aqui represento são os fructos estudados entre milheiros, nos logares em que expontaneamente crescem. Nos mesmos logares encontram-se individuos com grandes e pequenos espadices, com fructos maiores ou menores, todos mais ou menos angulosos pela compressão, tomando apenas

(1) Palm. Mlattogros. pag. 81. 
a sua fórna propria, quando por ventura abortam algumas flôres e outras isoladamente se desenvolvem livre da compressão. N'este caso tomam a tórma mais ou menos oboval.

O D. campestre é o que no seu porte e no tamanho dos espadices apresenta mais variedades, pelo facto de, annualmente, soffrer a acção do fogo, que os aniquilla e pela devastação que soffre pelo gado, no seu pascigo. Os que melhor se desenvolvem são os que crescem nos comoros formados pelos cupins ou á sombra das arvores dos capões. Que soberbas moitas vi assim, contrastando com as que, rachiticas, cresciam nos campos de Matto Grosso e Minas Geraes!

1. DiplotheniUn ANIZITZII Barb. Rod. Folia plus minusve arcuata foliolis ad basin per greges $2-5$ consociatis lineari lanceolatis oblique acuminatissimis inter se valde distantes arctissime congestis et ad apicem solitariis lineari acuminatis, in facie superiore viridibus, in inferiore glaucescentibus. Spadix validus spathâ fusiformi-compressâ arguté longitudinaliter sulcatâ, compresso-mucronatâ, longuissime pedunculatıs, racheos parte inferiore androgynâ quam cauda masc. multo longiore; drupa oblonga mutua pressione angulata ad verticem concava breviter apiculata ad basin induviata aurantiaca tomento escamoso brunneoferrugineo denso terta.

Tab. IV.fig. $A$.

Folia $1^{\mathrm{m}} \cdot 30-1^{\mathrm{m}} \cdot 50 \mathrm{lg}$., longissime petiolata, petiolo rachin $\mathrm{mi}$ nore; folioli $50-60$ plrq. $2-5$ in gregem commune sociata, inferiora et superiora sensin augustiora, inferiora $\mathrm{O}^{\mathrm{m}}, 22 \times \mathrm{O}^{\mathrm{m}}, 004 \mathrm{lg}$., média $\mathrm{O}^{\mathrm{m}}, 36 \times \mathrm{O}^{\mathrm{m}}, 014 \mathrm{lg}$. , superiora $\mathrm{O}^{\mathrm{m}} .07 \times \mathrm{O}^{\mathrm{m}}, 003 \mathrm{lg}$. Spadix $\mathrm{o}^{\mathrm{m}}, 90-\mathrm{I}^{\mathrm{m}} \mathrm{Ig}$., pedunculo sub rachi dilatato; rachis $\mathrm{O}^{\mathrm{m}}, 10-\mathrm{O}^{\mathrm{m}}, 13 \mathrm{lg}$., spathu breviter compresso-obtuso rostrata intus castanea, extus pallidebrunnea. $\mathrm{O}^{\mathrm{m}}, 15 \times \mathrm{O}^{\mathrm{m}}, 006 \mathrm{lg}$. Flores masc. et fem. non vide. Sepalis tlor. fem. ex induvia. Drupa $0^{m}, 27 \times 0^{m}, 017 \mathrm{lg}$, 
mezocarpio vittelino, glutinosofibroso, $\mathrm{o}^{\mathrm{m}}, \mathrm{0}+4$ lat., endocarpio $\mathrm{O}^{\mathrm{m}}, 2 \mathrm{O} \times \mathrm{O}^{\mathrm{m}}, \mathrm{O} 1 \mathrm{lg}$., brunneo, utrinque acuto, albumen excavato $\mathrm{O}^{\mathrm{m}}, \mathrm{OI} 5 \times \mathrm{O}^{\mathrm{m}}$,oos $\mathrm{lg}$., germen recurvo.

Hab. in Paraguay in campis prope Santa Maria de la Sierra et prope Tagatiyá. Yatá-Y-POÑy vel Jatahy Rasteiro Fruct. fan.

Entre as palmeiras que me foi dado estudar, do herbario Anizitz, d'entre ellas, se apresenta esta que só posso determinar pelos fructos, visto como só um espadice fructifero e uma espatha recebi. Entretanto, os fructos determinam bem, porque comparando os com os das tres especies acaules, vê-se que de todas se affasta. O campestre tem os fructos glabros, as do littoral têm a base e o apice lisos e os do leucocalyx só o apice tomentoso, emquanto que o Anizitzii é da base ao apice muito coberto de escamas tomentosas, além da sua fórma e as da induvia. Se o espadice, á primeira vista, se confunde com os de todas as outras especies, pela fórma dos fructos tambem se affasta e vê-se que pela fórma das divisões da induvia, as flores femininas devem apresentar fórmas e tamanho tambem differentes. As folhas e as flôres masculinas poderiam fornecer caracteres mais seguros, mas creio, pela pratica que tenho, que não me engano affirmando ser outra especie. Comparando os fructos de todas as especies bem se notam as differenças.

Esta é abundante nos terrenos calcareos de Santa Maria de la Sierra e nos campos da Estancia de Tagatiyá. Comparando os seus fructos com os do leucocaly'x, que encontrei nos terrenos calcareos de Corumbá e nos de Melgaço, são bem differentes. Tem vulgarmente o nome de Fatá-y-poñy ou I'atá-y'rasteiro. Os fructos são doces e um pouco aromaticos.

Em homenagem ao incançavel professor hungaro, correspondente d'este Jardim, D. Juan Anızıтz, que nas suas herborisações, pelas terras paraguayas, descobriu esta especie, perpetúo o seu nome. 
Gen. Acrocomia Mart.

1. ACROCOMia TOTAI Mart. Palm. Orbign. p. 78 , tab. IX, fig. I, et XXIX B. Hist. nat. Palm. III, p. 286; Walp. Ann. Bot. Syst. I. 1007, V. p. 822; Index Kew. I, p. 53; Hieronym. Plant. diaph, flor. Arg. p. 475.

E' uma das palmeiras mais vulgares do Paraguay e d'ella tiram os naturaes grande recurso dos seus fructos. que socados e reduzidos á massa, dão excellente sabão, não só para o uso ordinario de lavagens, como para o de toilette. Os restos do preparo do sabão dão uma massa empregada no alimento das aves domesticas. Além deste emprego comem os fructos, fazem d'elles aguardente e extrahem oleo, quer do mezocarpo, quer das sementes.

Do tronco extrahem excellente farinha, que fermentada dá o Mrocay'a ty', uma bebida inebriante.

Esta especie confunde-se facilmente com a Acr. mbocayayba Barb. Rod., de Matto Grosso. 
Gen. Bactris Jacq.

1. BACTRIS GLAUCESCENS Dr. Flor. Bras. III. p. II. p. 345, Tab. LXXVII; Index Kew. I p. 262.

Segundo o professor Drude, pelas notas do Dr. Weddell, foi a especie encontrada por este notavel botanico, autor da Histoire naturelle des quinquines, em 1845 no Alto Paraguay, com flores em Abril e Maio, obtendo dos naturaes o nome vulgar de Tucum mirim de fructa azeda.

Eu o encontrei, não sómente, no Rio Paraguay, acima de Corumbá, como no interior de Matto-Grosso. Nos alagadiços, proximos ao rio Aricá da Ponte, encontrei-o socialmente, não tão desenvolvido, como nos alagadiços paraguayos, parecendo até pela altura e comprimento das folhas, de muito menores dimensões, ser uma variedade.

Entretanto creio que esse facto é devido a ser constantemente devorado pelo gado, que é avido de suas folhas.

2. B. PISCATORUM IVedd., Fl. Bras. III. p. II. p. 334. Index Kerw I. p. 262.

Esta especie que foi tambem encontrada pelo mesmo Dr. IVeddell, em mattas humidas do Rio Paraguay; eu a encontrei em logares alagadiços.

Creio que encontrou em territorio brazileiro, tanto que deram para ella o nome vulgar de Tucum mirim de fructa doce. Não o vi em flor; mas o mesmo botanico o encontrou florescendo em Março e Abril. Dá em soqueiras, tendo o caule es. pinhoso de uns cinco centimetros de diametro.

3. B. ANIZITZII Barb. Rod. Caudex gracilis nigro aculeatus. Vagina petiolus cinamomeo floccosus aculeis nigris per greges horrido armatus, foliolis distantis 4-8 gregatis linearilanceolatis acutis. Spatha lato-lanceolata mucronata incurva aculeis brevibus nigris obtecta. Spadix magnus pedunculo 
inermi flocoso ramos 50-60 confortos gracilis deceres centibus ex serens, corolla fem. calyce 5-plo longiore laevi. Dupra matura non vidi.

Tab $V$.

Candex gracilis, $2^{\mathrm{m}}-3 \times 0^{\mathrm{m}}, 05^{-0^{\mathrm{m}}}, 06 \mathrm{lg}$., aculeis compressis nigris armatus. Folia $1^{\mathrm{m}}:$ jo lg., vaginâ clense floccosâ aculeis $\mathrm{O}^{\mathrm{m}}, 005-\mathrm{O}^{\mathrm{m}}, 025 \mathrm{lg}$., nigris per greges horridâ antice longissimé acuminatâ, petiolo $\mathrm{O}^{\mathrm{m}}, 35 \mathrm{lg}$.. subrotundo antice profunde et angustissime canaliculato albo lloccoso denique nudato et aculeis 2-4 gregatis nigris armato $c c \mathrm{O}^{\mathrm{m}}, \mathrm{O}_{2}-\mathrm{O}^{\mathrm{m}}, \mathrm{O}_{4} \mathrm{lg}$., rachi $1^{\mathrm{m}} \cdot 10 \mathrm{lg}$., aeque floccosi aculeos rariores minores evolventi denique tomento denudati. Foliola utrinque $3 S-40$, per acervos $3^{-S}$ formatos, inferiora $\mathrm{O}^{\mathrm{m}}, 45 \times \mathrm{O}^{\mathrm{m}}, 025 \mathrm{lg}$., media $\mathrm{O}^{\mathrm{m}}, 5 \mathrm{O} \times \mathrm{O}^{\mathrm{m}}, \mathrm{O} 25 \mathrm{lg}$. superiora $\mathrm{O}^{\mathrm{m}}, 23 \times \mathrm{O}^{\mathrm{m}}, \mathrm{O} 24 \mathrm{lg}$., omnia a basi conduplicata, lineari-lanceolata, acuta, secus margines argute nigro ciliata, nervo medio superiorite relevato. Spadix $\mathrm{O}^{\mathrm{m}} \cdot \mathrm{fl}^{\mathrm{l}} \mathrm{lg}$. longe pedunculatus, compressus, tomentosus, $s p a$ thâ interiore pedunculum longe vaginante angustâ dein cy'mbiformi rostratâ aculeis $\mathrm{O}^{\mathrm{m}} .01 \mathrm{lg}$., patentibus, nigris horridâ, ramos confertos $\mathrm{O}^{\mathrm{m}}, \mathrm{I} \mathrm{lg}$. extremis minores a basi usque ad apicem densifloros exserente. Flor. masc. non vidi. Flor. fem. a basi usque versus apicem ramorum inter masc. sparsi sub cylindrici, $\mathrm{O}^{\mathrm{m}}, 004 \mathrm{lg}$., calyce auguste annulari minute tridentato corrolî calycen 5 plo longiorî breviter tridentata, ovario oblongo a basi angustâ. stigmatibus late sessilibres. Drupa viridia agria.

HAB. in locis arenosis et inundatis aipas Rio. Paraguay ad São Salvador in adversum Grão Chaco. Carandá incolomm. Flor. Febr.

Esta especie é tambem, das terras humidas, arenosas e sujeitas annualmente ás inundações do Rio Paraguay, foi encontrada en S. Salvador, defronte ao Grão Chaco. Tem vulgar- 
mente, o que me admira, o nome de Carandá, que, como sa bemos, é dado á Copernicia cerifera e à Trithrinax Braziliensis. E' muito commum na localidade acima, onde cresce em soqueiras. Sendo esta especie muito proxima ao $B$. glaucescens, entretanto, só pelo porte e pelas folhas se afastam. Os naturaes o empregam, por ter o espique muito duro, em bastões e bengalas.

O nome especifico que the impuz é uma homenagem ao seu descobridor o professor D. Juan Anizitz. 
Gen. Desmoncus Mart.

1. DESMONCUS RUDENTUM Mart. Palm. Orbign. $48 \times 14$ et 26. Walp. Ann. bot. sy'st. I p. 1005 V p. 819 . Flor. Bras. III p. II p. 306; Kunth Enum. plant. III p. 8I9. Index Kow. II 739; Barb. Rod. Palm. Mattogres. p. 30 tab. X fig. $B$.

E' muito commun nos terrenos alagadiços do Rio Paraguay, onde forma grandes soqueiras, que lançam seus largos caules sobre a vegetação que as cerca e as torna impenetraveis. Tem vulgarmente o nome de Unbamba, e se estende até MattoGrosso; corresponde ao Jacytara, que dão, no Amazonas, as especies do mesmo genero. Barrere $\left({ }^{x}\right)$ a tornou conhecida por Atitara que o Dr. Otto Kuntze, quer que seja o nome generico que deve predominar, por direito de prioridade.

(') Marcgraf. Ensai d'hist. nat. Franc. cquin pag. 20. 
Gen. Scheelea Karsten.

1. SCHEELEA QUADRISPERMIA Barb. Rod. Acaulis vel rarissime caudice humili crasso, foliis elongatis erecto patentibus ad apicem arcuatis, foliolis per greges et inaequales aggregatis lineari-oblique obtuse acutis. Spadice monoeci, masculi et androgini plures simul evoluti spathis masc. fusiformis longitudinaliter sulcato-imbricatis rostrato acuminatis, fem. minoribus latioribus longitudinaliter sulcatis minus crassis rostrato-acuminatis; ramos masc.: graciles floribus a basi ad verticem obtutos, androgyni: supra basin scrobiculis florum fem. unilateraliter excavatos dein in spicas masc. breviores mutatos. Flôres masc. calyce minutissimo, petalis claviformis teretibus acutis stamina 6 triplo corollae minore; fem., multo majores oblongei sepalis petalisque subaequilongis convolutis, androccei abortivi cupula ovario usque medium includente, stigmatibus excertis; drupa induviata oblonga acuminata $2-4$ sperma.

Tab. VI.

Caudex. O vel usque $\mathrm{I}^{\mathrm{m}}, 50 \times \mathrm{O}^{\mathrm{m}}, 20-\mathrm{O}^{\mathrm{m}}, 30 \mathrm{lg}$. Folia $10-1 \mathrm{~S}$ contemporanea, dense congesta $3^{\mathrm{m}}-4 \mathrm{lg}$. foliola inferiora $\mathrm{O}^{\mathrm{m}}, 8 \mathrm{O}-\mathrm{O}^{\mathrm{m}}, 90 \times \mathrm{O}^{\mathrm{m}}, \mathrm{OI} \mathrm{lg}$. per acervos $2-3$ remota, média $\mathrm{O}^{\mathrm{m}}, 50-\mathrm{O}^{\mathrm{m1}}, 60 \times \mathrm{O}^{\mathrm{m}}, 03 \mathrm{lg}$., per acervos 6-10 approximata, superiora $0^{\mathrm{m}}, 60 \times \mathrm{O}^{\mathrm{m}}, 20 \mathrm{lg}$. per acervos $2-3$ sub opposita, suprema $\circ^{m}, 25 \times 0^{m}, 01$ solitaria sub opposita. Spadix, erectis, masc. : $\mathrm{O}^{\mathrm{m}}, 80 \mathrm{lg}$., peduncalo tereti, $\mathrm{O}^{\mathrm{m}}, 45 \times \mathrm{O}^{\mathrm{m}}, \mathrm{OI}_{3} \mathrm{lg}$., brunneo flocoso-tomentoso, rachi ramos $0^{m}, 1 \mathrm{lg}$, decrescente, spatha interior $\mathrm{O}^{\mathrm{m}}, 90 \times \mathrm{O}^{\mathrm{m}}, 13 \times \mathrm{O}^{\mathrm{m}}, \mathrm{O} 12 \mathrm{lg}$., ferrugineo tomentosa; spadix androgyn: $0^{\mathrm{m}}, 65 \mathrm{lg}$. , pedunculo $\mathrm{O}^{\mathrm{m}}, 40 \times \mathrm{O}^{\mathrm{m}}, 02 \mathrm{lg}$. compresso brunneo tomentoso, rachi ramos $\mathrm{o}^{\mathrm{m}}$,o6 lg., ad basin bi-triflorus fem. exserenti et ad apicem flor. masc. paulo ornati, bracteae ramorum latae, angustae, acuminatae; spatha interior $0^{\mathrm{m}}, 55 \times \mathrm{O}^{\mathrm{m}}, \mathrm{I} 5 \times \mathrm{O}^{\mathrm{m}}, 005 \mathrm{lg}$., ferru- 
gineo-tomentosa, lato lanceolata, mucronata. FLôRES masc. secundi, $\mathrm{o}^{\mathrm{n}}, 008 \mathrm{lg}$., petalis, clavatis, incurvis, teretibus, acutis. stamina 6 erecta petalis tertio breviora, antheris linearibus versatilibus quam filamenta paulo longioribus. utrinque emarginatis. FlôRES fem. 2-3 consociati inter se $\mathrm{O}^{\mathrm{m}} .01$ distantes, $\mathrm{O}^{\mathrm{m}}, 018 \mathrm{lg}$., calyce e corolla aequali structura, androceo abortivi annuliformi, ovario ovato, tomentoso, stigma 3-4 recurva. Dmpa $0^{m}, 06 \times 0^{m}, 033 \mathrm{lg}$. flava, ferrugineo-tomentosa, mezocarpio $\mathrm{O}^{\mathrm{m}} .005$ lat., fibroso. amylaceo, endocarpio $\mathrm{O}^{\mathrm{m}} .05 \times \mathrm{O}^{\mathrm{m}}, 023 \mathrm{lg}$. brunneo, osseo, fibroso; semina angustissime oblonga, embryo incurvo.

Hab. in Paraguay, ad ripas Arroyo Y'akã in Pulé-cué, ad Santa Maria de la Sierra et in ripas Rio Apa. Incolon YATA-r-GUAZU audit. Flor. et fruct. Febr.

Esta Scheelea, que a principio tomei pela $S$. Princcps de Karsten. attendendo ao seu maior ou menor desenvolvimento, segundo os logares em que cresce, como tive occasião de ver, não só nas margens do Paraguay, como na Bolivia, e em terras centraes de Matto Grosso, mais tarde fui obrigado a consideral-a differente. No Paraguay os indios karany's denominam a Princeps de Uakury e na Bolivia de Motacu, entretanto, que esta os proprios indios a differenciam, tanto que the dão o nome Yatíl Glizu; Yatá-y grande, quando nas proximidades existe o Uakury. Elles nunca se enganam na sua classificação empirica e sempre com razão, como, já mais de uma vez o tenho dito, por observação propria.

A Princeps é uma palmeira de caule excelso, magestosa, e não acaule, a nåo ser a minha variedade Corumbaensis. Quando mesmo os individuos são novos, antes de se apresentar o caule, tem uma fórma muito differente do das palmeiras acaules. Quem confundirá uma palmeira nova, das caulescentes, com uma acaule? A direcção e o tamanho das folhas, a sua fórma, tudo indica o que o vulgo chama um filhotio e nåo uma palmeira adulta. Os peciolos das follhas 
emergem do solo, estas são longas, erectas e direitas, emquanto que quando a palmeira é acaule, vê-se logo a inserção da vagina, as follas se curvam mais ou menos e distingue-se que são folhas adultas e não primordiaes. Um Uakury novo, ainda sem caule, não se confundirá com uma outra congenere acaule.

O espique formado pela vetusticidade de uma palmeira acaule é muito differente na fórma, do de um do mesmo tamanho de uma palmeira caulescente nova. E' muito rijo, as cicatrizes da quéda das folhas muito unidas, toroso, quasi sempre irregular no diametro, attestando pelo seu estrago a sua longevidade.

A palmeira de que me occupo é uma d'estas. E' acaule, mas coberta de annos adquire um espique irregular, que não attinge a mais de um metro e cincoenta centimetros, mas coberto de cicatrizes. Os fetos e os phylodendruns amam esses troncos, porque encontram n'elles, pelo deterioramento do tempo, um meio que os alimenta, tendo a sombra das folhas para os proteger.

Além de afastar-se pelo facto de ser acaule, ainda se afasta pelas folhas e pelas flòres e mesmo pelos fructos, que são menores e quasi sempre 4 spermos em vez de 2-3 spermos.

Foi encontrada no departamento de S. Salvador, no logar Pulé kué, perto de Santa Maria de la Sierra, com flôres e fructos em Fevereiro.

2. S. ANIZITZIANA Barb. Rod. Palm. Mattogrossenses pag. 63 tab. XX.

D'esta especie tratei nas Palmae Mattogrossenses, onde a descrevi, pelo que reporto-me ao que então disse.

3. S. PRINCEPS Karsten in Linnea XXVIII (1856) 269; Walp. Ann. Bot. Syst. V. p. 855. Index Kew. IV, p. 832.

Attalea princeps Mart. Palm. Orbign. $113 \times 4 ;$ f. 2 et $3 \mathbf{I}$; Hist. Nat. palm. III $298 \times 167$, f. I, Flor. Bras. III, p. II, p. 442. Barb. Rod. Palm. Mattogr. nos. p. 64 XXX, p. B. 
Descrevendo uma variedade a S. Corumbaensis, que encontrei nos terrenos calcareos das margens do Rio Paraguay, occupei-me da S. Princeps, que em abundancia cresce nas margens do mesmo rio, estendendo-se pelo interior de Matto-Grosso, até a Bolivia, onde é vulgarmente conhecida por Uakury, Guacury e Motacu. E' a palmeira mais nobre do Paraguay, pela sua altura, forma e belleza. 
Gen. Attalea H. B. K.

1. ATTALEA GUARANITICA Barb. Rod.

Acaulis. Spadix masc, erectus, spathâ int. fusiformi rostratoacuminatâ erectâ ramis unilateraliter scrobiculatis; flores masc. singuli in scrobiculis, 12 andris, staminibus $1 / 2 \mathrm{co}$ rollae longitudinis aequantibus, sepalis lanceolatis acuminatissimis dorso angulosis, petatis lineari-lanceolatis acuminatissimis, drupae ablongae in vertice umbunatae monospermae rara bispermae.

Tab. IV.fig. D.

Spadix masc. $0,{ }^{\mathrm{m}} 30 \mathrm{lg}$. spathâ $0,{ }^{\mathrm{m}} 50 \times 0,{ }^{\mathrm{m}} \mathrm{O} 7 \mathrm{lg}$. . lignosa extus argute sulcatâ, rami plurimi inferiores $0,{ }^{\text {mo }} \mathrm{Og} \lg$. superiores $0,{ }^{\mathrm{m}}{ }_{4} \mathrm{lg}$. Flores masc. ${ }^{\mathrm{m}}{ }^{\mathrm{m}} \mathrm{O} 2 \mathrm{lg}$., antheris hastatis. Drupa $0,{ }^{\mathrm{m}} 65 \times 0,{ }^{\mathrm{m}}+5 \mathrm{lg}$. brunneo-tomentosa, mezocarpio $0,{ }^{\mathrm{m}} \mathrm{OO}_{4}$ lat., endocarpio o, ${ }^{\mathrm{m}} \mathrm{O} 09$ lat. Semina $0,{ }^{\mathrm{m}} \mathrm{O} 29 \times 0,{ }^{\mathrm{m}} \mathrm{OO} 7 \mathrm{lg}$., oblonga, excavata, textâ reticulatâ.

Haв. in Paraguay, ad Cordillêra dos Altos, propre pueblo Valenzuela, ad ripas Rio Y-akã. Mbocayí guazu, vel Coco de la Cordillêra ab indiginis appellatur. Flor. et fruct. Fan.

Vai incompleta, por emquanto, a descripção desta especie, porque o material encontrado no herbario tambem o era ; mas, foi-me sufficiente para poder distinguil-o das especies d'este genero conhecidas, que não são muitas, e me são familiares. Os naturaes dão-lhe o nome de Coco de la Cordillera ou de Mbocayá guazu, por ser expontanea na Cordillera de Altos, perto do pueblo Valenzuela e do Cerro Paraguary nas margens do Rio Y-akã, onde floresce em Janeiro.

Da especie que mais se approxima é da $A$. exigua de Drude, achada tambem por Weddell, nos campos entre Goyaz e Cuyabá, com o nome de Indayá rasteiro. A descripçāo de Drude, muito incompleta tambem, me leva á duvida. Se bem 
que descreva as folhas, comtudo, nada diz sobre os fructos o que muito adiantaria.

Entretanto comparando a descripçåo Drudeana feita sobre u m material igual ao meu, tendo o seu folhas, que o meu não $t \in m$, mas faltando fructos que o meu possue, vejo que quanto as flores masculinas na especie de Drude såo maiores. tendo o calyce menor, munidas de 9 estames, emquanto que a minha tem sempre I2. As espathas e o espadice são muito semelhantes, mas estas nåo fornecem bom caracter, porque os masculinos se assemelham em quasi todas as especies.

Tendo o nome de Inday'á, a especie de IVeddell, para quem conhece a indole e os costumes dos indios, vejo que a $A$. cxigua deve ter fructos bi-quadrispermos. com o mezocarpo e o epicarpo com structura diversa, porquanto se fossem monospermos os indigenas dariam outro nome, porque então se aftastaria muito da fórma dos polyspermos.

A minha especie é monosperma, raro bisperma. Na forma e na structura se affasta muito dos Inday'ás, pelo que os indios não confundiriam, elles que differenciam até caracteres minimos.

Creio nåo ser a minha especie a exigua, e mais tarde lealmente o direi, porquanto espero novo material para estudo ulterior. 


\section{Uma anomalia nas flores de uma palmeira.}

Depois da descripção de algumas palmeiras, que tenho como novas, passo a tratar de um facto, que me põe em duvida si se trata de um caracteristico ou de uma anomalia. Se é um caracter é novo e refere-se a uma nova especie, e, se é apenas uma anomalia, creio que a especie é o Cocos Romanzoffiana descripto por Chamisso. Em todo caso é importante o assumpto e contribue para alargar o estudo da ordem das palmeiras.

O sabio Dr. Martius occupando-se das monstruosidades das flores das palmeiras não apresenta o caso de que me vou occupar, que penso não ser um facto teratologico proprio e sim uma anomalia com aspecto de um desdobramento (diremptio glandularis) da flor, ou causado por um deslocamento de forças vitaes; uma peloria segundo Moquin-Tandon.

Inclinando-me para este lado e não para um caracter especifico, por ir elle contra a lei natural a da symetria a que está sugeito todo o vegetal, por mais irregular que pareça, passo expondo o historico da planta, a mostrar o que de anormal encontrei e que me obriga a fazer aqui um registro.

Ha seis annos recebi do correspondente deste Jardim Joaquim Candido de Abreu, tres mudas pequenas de palmeiras do genero Cocos, que o mesmo encuntrara no sertāo de Minas Geraes, remettendo-as sem indicar a localidade do achado. Plantadas, aqui cresceram e vão se desenvolvendo bem. Uma é o Cocos campestris de Martius, outra espero a florescencia para determinar e a terceira é a de que me vou occupar.

Não está ainda no seu completo desenvolvinıento, mas já apresenta um espique de dois metros de altura com $0^{m}, 15$ de 
diam., e um aspecto que nos mostra que será uma palmeira alta e graciosa. Floresceu este anno; porém, o espadice não me parece ter o desenvolvimento que supponho deve ter. Se bem que desenvolvido apresentava poucas flores femeas e a disposição dos ramos me indicavam nåo terem attingido o seu completo vigror. Poderei estar enganado. mas o facto, que se deu, de ter custado a sahir o espaclice completamente da espatha, me leva a crer ter sido falta de vigor. Seria a mesma fraqueza que produziu o pequeno numero de flores femininas? Seria um atrophiamento que produziu o facto, que me parece anormal, e que vou referir? Creio que nào porque quando se da o facto de um desdobramento numa flor é signal, antes, de vigor e excesso de vida, pelo que poder-se-ha tomar cono normal na especie em questão, e na duvida, tive de sacrificar os fructos, inutilizando no estudo as flores, que me apresentaram todas os mesmos caracteres.

Se é anomalia, deu-se em todas as flores femininas.

O facto é o seguinte:

Como sabemos os espadices das flores do genero Cocos são androgynos, isto é no mesmo pé e no mesmo cacho se apresentam as flores femininas na base dos ramos e as masculinas no apice. As especies, principalmente do sub genero Syagrus, as flores masculinas são providas de um germinodio esteril e as femeninas de um androceo, tambem esteril, que sempre é annular mais ou menos tri-sexdentado.

$\mathrm{Na}$ especie em questão, encontrei algumas flores masculinas, que destituidas de germinodio, produziu o facto de, com o seu abortamento, desenvolverem-se uma a tres antheras que tomaram a forma approximacla e structura de um ovario. esteril.

Este facto não obstante ser accidental e poder ser considerado uma monstruosidade, que mais de uma vez tenho observado, se liga a um outro das flores femininas que nao parece ser accidental oll teratologico. porquanto é regular, symetrico e constante, pelo menos em mais de vinte flores que 
examinei, tantas quantas o espadice produziu, com quanto seja diminuto o numero para o que devia apresentar os ramos.

$\mathrm{O}$ androceo esteril nas flores femininas é annular e occupa apenas a quarta parte da altura do ovario, mas em vez de ser sexdentado apresenta alternadamente seis dentes dos quaes tres acuminados, da altura do annel, e os outrostres desenvolvidos, mais ou menos ovaes, carnudos. convexos de ambos os lados, apparentando a forma do ovario e terminado como este no apice em estigma, com papillas iguaes ás do verdadeiro estigma. Este androceo desenvolvendo-se em um pseudo pistillo, pela sua espessura, adapta-se sobre o ovario e fórma n'este depressões que o torna triangular com os lados concavos.

Os dentes que se desenvolvem em pistilos rudimentarios são da altura do ovario e os dois estigmas alternam-se com os verdadeiros. A parte do ovario coberta pelos prolongamentos do androceo é lisa e lustrosa e a que fica descoberta é munida de um tomento branco e cotonoso. Vide as figuras E da Est. III.

Em mais de uma flor encontrei tambem este desenvolvimento em todos os dentes, isto é, apresentando o annel seis pistillos rudimentares.

Este caracter ou esta anomalia nas flores das palmeiras, que me conste, ainda não foi observado por botanico algum e é inteiramente novo. Será uma aberração ou constituirá um verdadeiro caracter especifico? O futuro m'o dirá, com o auxilio de Deus, pois espero ver se nas florescencias vindouras - facto se repetirá.

O desenvolvimento deste androceo, transformado em germinodio, na induvia, pela compressão deve modificar a forma do fructo como modificado se desenvolve o ovario. Infelizmente para o estudo e verificação do facto, sacrifiquei os fructos que as flores deveriam produzir, reservando apenas duas que abortaram posteriormente.

O phenomeno de um desdobramento sendo um signal de vigor, ás vezes póde tambem ser de fraqueza; mas n'este caso sempre um orgão se desenvolve á custa de um que aborta, 
n'este caso está o la transformação da anthera em pistillo nas flores masculinas da especie de que trato, mas que se năo repete nas flores femininas que se apresentam perfeitas com signal de muito vigor. Se houve um desvio das forças vitaes das tlores masculinas para as femininas, estas deviam, como é natural e regular, se apresentar em grande numero e não transformadas. Dá-se entretanto o caso contrario, poucas flores e estas com os androceos methamorphoseados. Seria por isso que as flores foram em pequeno numero?

A força que devia produzir maior numero de flores desviou-se para transformar um orgåo masculino esteril em um um outro feminino? A fraqueza do espadice augmentaria o vigor das poucas flores femininas? O desdobramento participa sempre do orgão que se the segue e por isso a anthera e o androceo passaram a participar do ovario na flor masculina e feminina, mas, pergunto ainda, seria por algum atrophiamento, por fraqueza que se deu essa aberração ou será um caracteristico? A planta mostra-se alentada e vigorosa, sem indicios de soffrimento. Deve-se attribuir á prematura florescencia por ser muito nova a planta e não ter adquirido toda a sua robustez?

E' verdade que, em geral, os espadices primordiaes das palmeiras sempre são menos robustos dos que posteriormente se the seguem, mas nunca observei por isso anomalia alguma en suas flores, nas especies dos seus diversos generos.

Tenho encontrado verdadeiras monstruosidades, mesmo em espadices vigorosos; mas nunca o facto que ora apresento. que se naio affasta e transforma-se regular e symetricamente.

Ulterior estudo talvez melhor esclareça o facto, que por emq̨uanto deixo aqui consignado, o que observei.

Outra questão se apresenta ainda relativa a esta especie: será uma nova especie ou sendo considerado um facto anormal este mascarou a especie que é uma das conhecidas? Mas qual será ella? Será o polymorpho Cocos Romanzofiuma? Pergunto. porque un habitus apparece affinidade nåo só no porte como 
nas folhas. O Geribá, Cocos Romanzoffiana, é tambem de MinasGeraes, mas ahi sempre tem o nome vulgar acima, emquanto que a especie de que me occupo foi recebida com outro nome vulgar, julgo que Catolé, e os naturaes que dão outro nome vulgar é porque os distinguem. Presumo ser o nome Catolé, mas não affirmo, porque tendo-se perdido a etiqueta, só de memoria o digo.

Se tivesse recebido a planta com o nome de Geribá não a plantaria em logar distincto, por possuir d'essa especie milhares de especimens não só adultos como novos em viveiros. O que affirmo, porém, é que não me foi remettido com o nome de Geribá e sim com outro que infelizmente se perdeu.

A pezar, porém, disso creio que a especie é a mesma de Chamisso, o que mais tarde será averiguado pelos fructos, que dirāo a verdade.

Apresentando. como vimos $\left({ }^{2}\right)$, o Cocos Romanzoffiana um polymorphismo no habitus e nos fructos, que deu logar á grande synonymia scientifica e a ter os nomes vulgares de Coco de baba de boi, de cachorro, Geribá, Pindó, Datil etc., creio que apresenta agora outra anomalia nas flores, que deformando o ovario, naturalmente tambem deformará os fructos.

Apresento aqui esta noticia afim de ficar registrado o facto e adiantar o conhecimento da planta. Mais tarde voltarei ao assumpto para maiores esclarecimentos.

Jardim Botanico, 2 de Dezembro de 1898.

(1) Palmae Mattogrossenses novae, pag., ${ }^{\circ}$ 3. Tab. IV. 



\title{
AS NL'PCIAS I)AS PALIIEIRAS
}

\author{
(Prineikas Notas)
}

Sob o titulo O calor das flores masculinas da Guilliolnu speciosa Mart.. no sexto fasciculo das Puntas nozis cullizadas no Fardim Botanico a pag. 29, me occupei do excessivo desprendimento do acido carbonico das flores d'essa paineira no acto da sua fecundação e aqui, agora, vou me occupar do mesmo assumpto, apresentando novas observaçōes em outras especies.

E’ sabido que no acto da fecundação das plantas ha sempre um augmento de temperatura nas Hores, maior ou menor; sendo a maior a observada na abertura das espathas das Aroideas. Balfour $\left.{ }^{1}\right)$ diz, tratando do Arum maculatum, que: When the spathe opens, the staminal organs schow the greatest heat, and after the pollen is discharged, their temperature falls.m

Nas palmeiras dá-se o mesmo facto no acto nupcial para assegurar a fertilisação, porque para isso, a natureza foi previdente. A dichogamia protandrica ou protogynica é que nos mostra o acto providencial do Creador, com a duração do calor, que sempre é relatiro ao apparecimento do momento em que os orgãos femininos tornam-se aptos a receber o germen fecundador.

O poder fertilisante do pollen tem sido observado que dura mais ou menos dias, segundo as especies de plantas, podendo perdel-o logo ou durar horas, dias e mesmo mezes. Mas, se bem for estudado o facto, ver-se-ha que, em cada especie, esse tempo é o necessario para a boa fecundação. Depende da

(1) Class book of botany: $18_{71}$, pag. 522 ; Manual of bot. 1849, pag. 232. 
structura e da fórma das llores, da sua duração e do desenvolvimento dos seus orgãos reproductores. Se o do Tabaco tem o podur fertilisando só por 4 S horas, o das Lobelias por 8 a 10 dias e o dos Orchis por dois mezes, observe-se que alguma necessidade ha para isso, e que esta não se aftastara do plano harmonico e mathematico da natureza.

As funcções preventivas para as nupcias, que dão a re. producção da especic. não se darão simultaneamente. ou dependerão de circumstancias que obrị̧uem o pollen a conservar suas propriedacles durante o tempo necessario para a completa madureza dos orgãos sexuaes e, mesmo, da resicula embryonaria.

Ña natureza tudo è tăo symetrica e harmonicamente feito. tudo está tão ligado. imperceptivelmente, que uma pequena circumstancia póde aniquilar um facto e por isso ella é previdente providencialmente tudo regulando.

Passo a apresentar algumas das minhas observações.

Apresentando a Orbignya speciosa Barb. Rod., cultivada n'este jardim e que como nova descrevi no fasciculo das Plantas novas ( $\left.{ }^{1}\right)$, uma magnifica spatha, ancioso e pacientemente esperei a sua dehiscencia. Com effeito no dia $S$ de Norembró apresentou um esplendido espadice, cujas flores começaram a se lesprender no dia seguinte com certa elasticidade. Aproveitei o momento em que se operava a fecunclação e quando em şrande numero as flores masculinas saltavam dos ramos, apanhei uns quinhentos centimetros cubicos d'ellas que colloquei en uma capsula de porcellana, cobrindo a base de um thermometro. Esperei a mudança da temperatura.

O dia estava excessivamente quente, e, se bem estivesse limpa a atmosphera, o calor indicava chura.

A's $91 / 4$ horas da manhĩ, comecei a observação marcando entito o thermometro. il sombra, $28^{\circ}$ cent. ou $22^{\text {: Reaum. para }}$ a temperatura do ambiente.

1) Iixc. 1., pay. 32, (ab. 1X, V. pay. 16, tals. V. 
Quinze minutos depois, posto se conservasse o calor atmospherico a $28^{\circ}$, o das flores se elevou a $30^{\circ}$. Neia hora depois, isto é. ás ro horas, a temperatura das flores attingiu a $31^{\circ}$ e ás 1014 horas a $32^{\circ}$, havendo por conseguinte em uma hora um augmento de temperatura de $4^{\circ}$ acima do da atmosphera. No primeiro quarto subiu rapidamente dois gráos, levando depois meia hora para subir um gráo, para rapidamente tornar a subir outro gráo dentro de um quarto de hora. Esta temperatura le $32^{\circ}$ conservou até ás I 2 horas da tarde, começando então a descer na primeira hora um gráo, depois de meia em meia hora outro, a attingir a temperatura de $2 S^{\circ}$ ás 2 horas da tarie, hora em que tambem o céo rapidamente escureceu, começou a fuzilar e a ribombar o trovão, cahindo momentos depois grossa chuvá.

Esta observação confirma a de que me occupei, no fasciculo citado. N'esta Orbignya a temperatura não se elevou tanto como na Guillielma coccinca. mas attingiu quasi á observada pelo Dr. Martius, nas espathas de outras especies, o qual nunca encontrou mais do que $5^{\circ}$ acima do ambiente.

Este facto confirma que o acto da fecundação eleva extraordinariamente o calor nos orgãos reproductores de maneira que no momento propicio, quando as antheras se abrem e o pollen se ejacula o calor augmenta e o conserva por algumas horas, para depois decrescer por algumas horas, a attingir o do ambiente.

Essa elevação de temperatura torna proficua a fecundação. O contacto do pollen com o estigma, passado esse calor vital ou se elle não se produzir, a fecundação não se faz. A demora do calor é providencial. Caso, no rompimento da anthera o pollen não possa chegar ao estigma, ou este não esteja ainda preparado para recebel-o, conserva não obstante o calor esperando a brisa ou os insectos que sem demora se apresentam para conduzil-o. Com effeito, o effluvio que se derrama logo que a espatha se abre, atrahe immediatamente os insectos que começam a esvoaçar e de flor em flor a depositar a materia 
fecunclante, directamente ou fazendo-a desprender-se e a calir sobre as flores femininas.

Se por um caso qualquer, na anthese, o calor não se desenvolve, as flores abortam e d'ahi presumo o facto de espadices androgynos. cobertos de flores nåo fructificarem como tanto tenbo visto.

Sabemos que a natureza toma muitas pracauções para que com facilidade se opere a fecunclação e esta seja garantida e proveitosa, e entre outras apparece esta.

$\Lambda$ força activa que cleva os estames, os volve, os curva, ou alongra os peclunculos no acto nupcial, que se dá em muitas plantas, aqui apparece na dehiscencia das antheras com o augrmento de calor. Não posso precisar se elle é desenvolvido em toda a flor e se propaga pelos estames ao pollen ou se só os estames e o pollen o adquirem, mas creio que a séde principal é nos estames, que de incurvos, se indireitam ou se patenteiam no momento da abertura das antheras movidos pela energia que adquirem com a maior somma de oxygeno que absorve a flor. Essa força colorifera, pondo em erecção os estames, fórça as petelas a se abrirem e produz a abertura das antheras e a immediata ejaculação do pollen, que sahe gradualmente augmentando seu calor.

Essa força vital concorre para a boa fecundação. Previdente a natureza rodeou a fecundação de precauções que asseguran a proficuidade e por isso conserva nas llores, por algum tempo a temperatura necessaria, se bem que desprendicla dos ramos. Pelo peso proprio, as llores das palmeiras, não são levadas pelos ventos, cahem perpendicularmente do espadice ao solo e, como são aos milhares, ahi se amontoam. Mesmo no solo conservam o calor que, em vez de diminuir, augnenta. Com que fim. se já fóra de seus ramos, como orgãos inuteis. foram recritadas pela arvore mäi ? natureza tudo previne com muita sabedoria, As vezes, ha dichogamia protandrica quer os espadices sejam androgynos ou monoicos. () espadice? masculo abre as suas flores, antes do outro espaclice apresentar 
as flores femininas promptas a serem fecundadas e então a fecundação não se dará porque quando os estignas de umas apparecem, o pollen das outras tem desapparecido. Outras vezes dá-se o facto contrario. ha a dichogamia protogynica. Para remediar esse mal, a natureza conserva e augmenta o calor nas flores desprendidas, porque os insectos se encarregarão da transmissão. Reunidos no solo, colhendo o pollen das flores despegadas passam destas para as dos espadices e nas femininas, colhendo o nectar dos estigmas para sua subsistencia, isto serve tambem para clar um meio de conduzir o pollen operando assim a fecundação.

A demora da temperatura assegura, por meio dos insectos, a fecundação, que, presumo, se não daria se logo depois da abertura dos loculos das antheras esse calor vital desapparecesse. Nas palmeiras, pelo menos, só o pollen excitado pelo calor póde produzir uma fecundação productiva, é o que concluo das minhas observações.

Entretanto, ha exemplos historicos, que nos mostram que não ha regras sem excepções, pois dizem não ser isso preciso, pelo menos, em relação ás Phœnix e aos Chamarops, pois que o pollen d'estas palmeiras conservam o seu poder fecundante por largos tempos. Isso nos assegura Kempfer e Gleditsch. O pollen do Chamcerops humilis, transportado de Leipzig para Berlin, em I75I, fecundou ahi um exemplar; outro da mesma especie, levado de Karlsruhe para S. Petersburgo, em 1767 , foi fecundante, isto nos affirmam os autores acima e Koëlreuter.

Em Santa Helena tambem foram fertilisadas algumas tamareiras com pollen, levado da Africa.

Não influirá o clima? Dar-se ha em todas as palmeiras este poder fecundante? O que é exacto e tenho visto é o aborto de tlôres femeas, cobertas de milhares de masculinas, sem que estas se fecundem, por ter havido a apparição dos estigrmas fóra das petalas, muito posteriormente á anthese das masculinas. Se bem que as masculinas ainda tenham o pó 
fertilisador, comtudo nảo ha fecundação, creio que por ter passado o tempo preciso, isto é, ter appareciclo os estigmas depois do resfriamento, ou ter passado a força vital clos estames.

Outra observação. Uma Pinansa Kühlii, formando uma explendicla soqueira, coberta de numerosos espadices de fructos verdes, no dia 14 de Novembro apresentava seis vigorosos espadices androgynos de flores, cujas espathas se despegaram deixando os ramos nús. No dia 15 ás 6 horas da manhã ainda as flôres masculas estavam fechaclas, mas já as femeas apresentavam os seus estigmas tumefactos, humidos e prompios a receber o pollen fecundante. Havia perfeita dichogamia protosynica. Attrahidas. as abelhas percorriam os ramos, passavan sobre as flôres femeas, não se detinham sobre ellas, não se importavam conı os estigmas, e pelo contrario forçavam a uniz̃o das petalas, introduzindo as anthenas para abrilas, instinctivamente conhecendo, que estaram prestes a desabrochar. Com effeito, ás $6^{1} /$ horas começaram as thôres a se abrir, espalhando immediatamente o pollen que voáva com o elasterio da abertura das petalas, dando-se immediata pollinisação.

Examinando as flôres observi que pouco antes da anthese, já tinha havido a dehiscencia das antheras. Os estames erectos nas flôres fechadas, no momento da fecundaçio, quando o calor vital os anima, procuram tornar-se patentes e essa força obriga as petalas a se abrirem e a espalharem imme diatamente o pollen, que em abundancia se derrama sobre as flòres femeas.

N'essa occasião desprende-se o calor. mas a temperatura não se eleva a mais de: dois gráos, perturando apenas uma hora. Isto foi conscienciosamente observado.

Por que é menor a temperatura e for que pouco esta se conserva? lorcgue senclo a flôr femea protogynica. está apta a ser fecundada immediatamente agós a anthesc dias flôres masculas, foi o que conclui depois de outras oloservasões.

N"esta especie ainda observei que as fores logo após a sua authese s. despecraram todas dos ramos, nos mostrando que a sua funç̧ân estava terminada, a lecunilaçio estava feita. 
Esse desprendimento rapido dispensa o augmento de temperatura. porque não tem de esperar que se tornem aptas as Hôres femeas para o acto da fecundação. Quando ha dichogamia protogynica o calor è menor e dura menos.

Em geral, nas flôres monoicas e protandiricas das palmeiras, as masculinas se demoram muitas horas, sem se despegarem, apezar de abertas, quando a dehiscencia das antheras é posterior á abertura das petalas.

Ainda uma outra observação, que me leva a formar o meu juizo e me contraprova.

Dois espadices, du um magnifico Elacis Guynuensis (Côco de dendê), um masculino e outro feminino, no mesmo exemplar, e proximos, apresentavam dichogamia protandrica.

Eram io horas e 40 minutos da manhã quando desabrocharam as fôres masculinas. A temperatura atmospherica era de $27^{\circ}$ cent. A's 10 horas e 50 minutos a temperatura das flôres elevou-se a $25^{\circ}$, ás I I a $29^{\circ}$, ás i I e $15^{\prime}$ a $30^{\circ}, 5$ e ás s i e $25^{\prime}$ a $31^{\circ}$. N'esta temperatura se conservou até ás 2 horas da tarde, em que começou a declinar, tendo ás 3 horas 29,5 , quando a temperatura do ambiente se conservava a $27^{\circ}$.

A' I hora e 40 minutos da tarle appareceram os estigmas das tlôres do espadice feminino e meia hora depois as flôres tomaram a temperatura atmospherica.

Um ourro exemplar de Elaeis deu um só espadice macho, cujas flôres levaram $4 S$ horas a se abrir. Estas tiveram um augmento de 2 nas primeiras 24 horas, passando depois a ter a temperatura da atmosphera.

Durante todo esse tempo diversas especies de abellas, entre ellas a faly e a Iinnara on iachorro, cobriam as flôres machos, sem se importarem com as femeas.

Fiz outra observação n'um espadice androsyno do Cocos eriospath:t, tambem de tlores protandricas, as quaes duraram quatro horas, com a temperatura elevada, $3^{\circ}$ acima da do ambiente e só depois d'esse tempo começaram vagarosamente 
a calhir, depois do apparecimcnto dos estigmas, entrando $\mathrm{cm}$ decrescimento o calor.

As ultimas observaçōes foram feitas directamente nos spadices, para melhor ubservar quando começava a desenvol. ver-se o calor.

No Cocos como os ramos são divaricados e não perfeitamente embricados, como no Elaeis, uni todos os ramos e na massa compacta appliquei o instrumento. As comparações foram feita sempre com dois thermometros rectificados para acompanhar melhor a marcha da ascensão mercurial e ver a differença entre as duas temperaturas. a do ambiente e a das hlôres.

No Cocos picropliylla Barb. Rod., de spadice androgyno dichogamo-protandrico, em um quarto de hora a temperatura das 11ôres subiu dois gráos, isto é, sendo a da atmosphera de 27 cent. subiu a d'ellas em um quarto de hora a $29^{\circ}$, começando depois de uma hora a descahir, a chegar á da atmosphera. Comecei a observaçåo ás II horas da manhã e ao meio-dia estava terminada. Durante esse tempo desabrocharam as flôres femeas e começaram, com rapidez, a cahirem as machos, com as antheras quasi completamente rasias, por ter - pollen, com o patenteamento dos estames, sido todo expelliclo. levo notar que a quéda das flôres masculinas auxilia o derramamento do pollen pelo choque nos ramos e de encontro a outras.

Outras observações tive occasião de fazer, que tambem contribuem muito para o estudo da fecundação, apresentando factos de importancia.

Una IVallichia caryolöides Roxb. apresentou simultaneamente dois magnificos, fortes e robustos espadices de flôres, sendo um masculino e outro feminino. Dezoito dias depois da abertura das espathas e de expostas as flòres ao ar, estando todas ben descnvolvidas. começaram bruscamente a caluir as flôres masculinas, sem que houvesse a anthese. Estando perfeitamente descnvolvidas e com as antheras engorgitadas, não 
se deu, apezar d'isso, a dehiscencia das petalas; cahiram as flôres completamente fechadas. Coincidio, entretanto, o facto com o apparcimento incompleto dos estigmas das flôres femeas. Diariamente observava a temperatura, que nunca se alterou, foi sempre a do ambiente. Quando começou a quéda das flôres, observei por mais de duas horas e não houve alteração tambem da temperatura. As abelhas, n'essa occasião, cobriam os ramos, mas desesperadas voltejavam por nāo poderem colher o pollen. Algumas roiam o apice das petalas, mas era perdido o trabalho, porque logo as flôres se despegavam e cahiam.

Não houve, pois, fecundação por impotencia, pela falta do calor vivificador que energicamente activa e fortalece os orgãos.

Notei então que apezar do specimen ser vigoroso e bem desenvolvido, nunca fructificou, dando, não obstante, já por quatro annos consecutivos, lindos espadices.

Os mesnos factos tambem observei na Martinezia erosa Mart.

Vê-se por ahi que o calor que as flores adquirem no acto da fecundação é absolutamente necessario para dar vigor e vida aos orgãos que têm de perpetuar a especie. Sem elle tornam-se impotentes, e se bem que em si contenham as molleculas proliferas desenvolvidas, sem serem oxygenadas, tornam.se inuteis.

Observadas escrupulosamente as nupcias da Martynesia caryotcefolia, esta apresentou-me outra contraprova. Durante um dia simultanea e gradualmente desabrochavam as flores masculinas e as femininas, na proporção média de vinte d'aquellas para uma destas. A temperatura entre a atmosphera e a das flores em doze horas não excedeu nunca de um e meio gráo.

Essa pequena elevação de calor, ligada ao facto de no espadice androgyno, gradualmente ambas as flores simultaneamente desabrocharem, nos mostra qne sendo graduada a anthese das flores, e por consequencia as suas nupcias, desnecessario é a grande elevação da temperatura, porque demorado é o acto 
da fecundaçio, e sempre no mesmo spadice ha novas flores que substituem aquellas que pelo tempo percam o calor. O acto nupcial i sempre assim garanticlo.

Na Gioncma Siholliana Mart. observei n'um espadice androgyno, mas de uma verdadeira dichogamia protandrica, que as thores. depois da dehiscencia das antheras, e estas quasi murchas, nảo apresentaram movimento algum de temperatura.

Com effeito, raros são os espadices androgynos das Geonomas que simultaneamente as flores desabrocham; sempre ha dichogamia protandrica demorada pelo que a fecundação é sempre feita pelas flores de outro espadice. Sendo muito demorada a apparição das flores femininas depois das masculinas. ás vezes mais de tres dias, e dando sempre muitos espadices contemporaneos. que desabrocham successivamente, é inutil a duração do calor porque para as flores velhas haverá sempre novas que as fecundem.

Um Bactris caryotafolia Mart. fornecen-me uma boa observação com a sua dichogamia protogynica. Un individuo apresentando dous espiques em cada un dos quaes deu $u$ m espadice androgyno, que se desenvolveram ao mesmo tempo.

No dia 26 de Dezembro, pelas $5^{\mathrm{b}} \mathrm{e} 45^{\prime}$, houve a dehiscencia da espatha de um e só no dia 27 , á I hora da tarde, começou a dehiscencia das flores masculinas, apresentando-se as femininas com os estigmas engorgitados e exhudando nectar clesde o dia 26. uma hora depois da dehiscencia da espatha.

A I hora da tarde, como disse, começaram as abelhas e pequenos dipteros a affluir para os ramos e as flores masculinas a abrirem as suas petalas e os estames a se levantarem. A temperatura do ambiente era então de $27^{\circ}$ cent. Applicado n'esse momento o thermometro, que anteriormente deu nas thores a temperatura do ambiente, começou a elevar-se a columna mercurial. A $1^{\mathrm{h}}: 30^{\prime}$ apresentou já a temperatura de $33^{\circ}$. ás $2^{\text {h }}$ a de 34 que conservou até ás $3^{\text {h }}$. A esta hora os estames recurvaram-se e algumas antheras tocaram os estigmas, despojando-se do pollen. Tinha attingido o maximo da temperatura, 
que começou a declinar, tendo ás $3^{\mathrm{h}}, 30^{\prime}-33^{\mathrm{u}}$. ás $4^{\mathrm{h}},-32^{\mathrm{t}}$, ás $4^{\mathrm{h}}, 30^{\prime}-31^{\circ}, 5$, ás $5^{\mathrm{h}}-30^{\circ}$, e ás $6^{\mathrm{h}}-28^{\circ}$ e ás $7^{\mathrm{h}}$ a temperatura de $26^{\circ}$, que era então a do ar.

Ás $5^{\text {h }}$ quando a temperatura desceu a $30^{\circ}$ conıeçaram as flores masculinas a cahirem dos ramos e o grande movimento dos insectos.

Quando observava a marcha crescente clo calor e o movimento dos estames e das antheras no maximo do calor, isto é, quando ás $3^{\mathrm{h}}$ attingiu a $34^{\circ}$. com um estalido abriu-se a spatha do segundo spadice, apresentando todas as flores fechadas. Querendo fazer outra observação em relação ás flores femininas, esperei que os estigmas rompessem as petalas. Com effeito ás $4^{\text {h }}$ se apresentaram, conservando-se comtudo as flores masculinas completamente fechadas. Tomando as temperaturas appliquei o thermometro, que teve a seguinte marcha, relativa ao crescimento e engorgitamento dos estigmas:

$$
\begin{array}{lcc}
3^{\mathrm{h}} \text { Tarde }-27^{\circ} \text { Cent. } & 6^{\mathrm{h}}-33^{\circ}, 5 \\
4^{\mathrm{h}} & -30^{\circ} & 6^{\mathrm{h}} 15^{\prime}-32^{\circ} \\
5^{\mathrm{h}} & -3^{\circ} & 6^{\mathrm{h}} 20^{\prime}-31^{\circ} \\
5^{\mathrm{h}} 20^{\circ} & -33^{\circ} & 6^{\mathrm{h}} 30^{\prime}-30^{\circ} \\
5^{\mathrm{h}} 30^{\prime} & -34^{\circ}, 5 & 7^{\mathrm{h}}-28^{\circ} \\
& 7^{\mathrm{h}} / 2-26^{\circ}, 5
\end{array}
$$

Durante esta marcha ascencional e descendente a temperatura da atmosphera desceu de $27^{\circ}$ a $26^{\circ}$. Ás 8 horas da noite os estigmas estavam completamente exsertos com os lobulos tumefactos e erectos, exhudavam nectar, porém as flores masculinas se conservavam completamente fechadas.

A temperatura do espadice d'ahi em diante acompanhou a da atmosphera. Ás 10 horas da noite marcava $23{ }^{\circ}$

No dia 28 , pelas 6 horas da manhã, começou a affluencia dos dipteros e as petalas a desabrochar-se. A temperatura, quer das flores, quer da atmosphera, era então de $23^{\circ}$ cent. 
Começando logro a elevar-se a temperatura das flores, tive a seguinte marcha:

$$
\begin{array}{clll}
\Lambda \mathrm{s} 6^{\mathrm{hr}}=\mathrm{m} . & -23^{\circ} \text { Cent. } & 9^{\mathrm{h}} & -30^{\circ} \\
7^{\mathrm{h}} & -31^{\circ} & 10^{\mathrm{h}} & -29^{\circ}, 5 \\
7^{\mathrm{y}} / 2 & -31^{\circ} & 11^{\mathrm{h}} & -29^{\circ} \\
S^{\mathrm{h}} & -31^{\circ}, 5 & 12 \text { tarde }-27^{\circ}
\end{array}
$$

A temperatura de $27^{\circ}$ era tambem a da athmosphera.

Duando, declinando a temperatura, attingiu a $29^{\circ}$, começaram as flores masculinas a se desprenderen dos ramos. Ás 5 horas da tarle só existiam nos ramos as femininas.

N'estas experiencias a temperatura das flores elevou-se a quasi $9^{\circ}$.

Estas duas observações, feitas simultaneamente em espadices de um só individuo, com todo o cuidado e escrupulosamente, confirmaram os factos anteriores e me fizeram ver que na anthese das flores femininas, no seu preparo para receber o osculo masculino, a sua temperatura tambem se eleva. como nas masculinas. D'ahi vem talvez a propriedade de fazer reviver a força fecundante do pollen, depois do seu resfriamento.

As nupcias dos Bactris concinna Mart. e setosa Mart. confirmaram-me depois as do B. cariotafolia que se deram com as mesma solemnidades.

A dichogamia, vulgar nas palmeiras, se demora a polinisaçīo cm um exemplar isolado ou que dá um só espadice, de hôres protandricas ou protogynicas, favorece entretanto a fructificaçăo em um palmar. Se protandrica em um especimen, os insectos levarão o pollen para outro, cuja florescencia é protogynica e assim assegura a fecundaçào, levando o pollen. ainda quente e excitado para o estignsa tumefacto de outra flôr de outro exemplar. A demora e a elevaçâo da temperatura nos srrãos de pollen, contribuem e facilitam a fecunclação, nâo só cm uma planta como em muitas. O pollen das pal. 
meiras, depois da quéda da temperatura, abandonam as antheras e por si cahem seccos e infecundos. Raro é encontrar-se pollen nas antheras das flôres, que abandonaram os ramos. Baixando a temperatura cae o pollen e as antheras murcham e seccam. Frio o pollen, tendo perdido a energia vital, conservará, entretanto, a sua propriedade fertilisante?

Se o calor para a fecundação nāo é necessario, por que para a união sexual, as flôres augmentam a sua temperatura?

Para que nesse momento proprio absorvem então mais oxygeneo?

Não é essa absorpçâo, o desprendimento de carbono, que dá a energia dos orgãos, que os tornam aptos para dar e receber o germen que perpetuará a especie? A natureza inutilmente dar-se-hia ao luxo de ostentar uma funç̧ão calorifera nas tlôres. sem utilidade?

Natura enim non facit saltus, sabiamente nos disse o grande mestre Linneo, e do seu sentire para o vivere apparece aqui uma funcção identica.

Excitados por esse calor que abala toda a flôr, os orgãos se activam, entram em movimento, dão-se as nupcias e caem depois no abatimento, que demonstra a completa fecundação.

As flôres masculinas murchan e cahem e as femininas se fortalecèm e crescem. Terão os estigmas, na sua excitação nupcial, com o oxygeneo que absorve, com o grande calor que adquire o poder de fazer con que o pollen, tempos depois, se reanime e adquira seu poder fecundante? O calor que os estigmas desenvolvem, o liquido glutinoso e nectarifero que o envolverá, produzindo-lhe entumecimento, o chamará á vida? A estada fóra do meio apropriado não the fará perder a faculdade geradora, como a semente perde a germinativa?

Ha factos, como disse, que provam que tempos depois o pollen de algumas palmeiras, de longe, fertilisaram outras, como se dá entre outras plantas; mas, se assin é, fica latente a faculdade fertilisante do pollen, sob o véo da morte, para reapparecer ante uma propriedade ainda mais vital do estigma, 
que suppre com o seil calor o que antes é necessario ao pollen.

Como no reino animal, a natureza, no vegetal, dá um momento propicio á reproducção da especie, que fóra d'elle é impossivel. Esse momento é o do maximo da temperatura. Só o artificio humano o conseguirá. Como o sperma, o pollen só produzirá seus effeitos por intermedio dos artificios do homem, sem a força que motiva a ejaculação. De artificios nåo cuidou a natureza, que tudo faz por leis sabias e inmutaveis, ligadas como élos de uma cadeia infinita.

Quando a evidencia mostrou a sexualidade das plantas, esse facto causou um assombro geral. A prova dos dois sexos nas plantas, foi um dos élos que ligou o animal ao vegetal e o calor que se desprende das flôres, na polinisaçăo, é outro élo que identifica as nupcias animaes ás vegetaes.

As palmeiras, essas rainhas do reino vegetal, foram as primeiras que fizeram ver ao homem, que as plantas não se afastavam da animalidade, na sua funcção geradora. As plantas, como o homem, festejam as suas nupcias; mas, muito mais festivamente, porque para isso, quando a epoclıa se approxima. cobrem os seus orgãos reproductores com roupagens de galas. de côres modestas ou deslumbrantes, que, conı docéis, occultam das vistas profanas o movimento mysterioso, que se dá no leito de seus amores. Das fôres as petalas luxuriantes. protegrendo, velam o thalamo nupcial.

Os Babylonios foram os primeiros. segundo Herodoto, que desconfiaram que as palmeiras tinham dois sexos e que usces representavam especinens differentes, pelo que, artificialmente derramavam o pollen do espadice de uma tamareina solure $\cap$ de outra para determinar a producçáo dos fructos.

Mais tarle Cesalpinio, naturalista italiano, Nehemio Grew, sabion inglez, Ciuncrarius, Sebastiào l'aillant, reconlıecem a divisio clos sexos. até que foi solemmemente provada e proclanada for limneo, estabelecendo o sen admiravel systcma da classificação. 
Não é occasião, nem aqui posso estender-me sobre o assumpto, porque meu fim é apresentar, sómente, o resultado de observações que fiz, mas folgo que fossem ainda as palmeiras, que viessem nos mostrar, que como o homem, na epocha de seus amores, ellas tambem se electrisam, por assim dizer, no acto de suas nupcias.

Das minhas observações, além das que referi, feitas em varios generos no grande palmar deste Jardim, conclúo que nas nupcias das palmeiras ha sempre:

- Grande augmento de temperatura no acto da dehiscencia dos orgĩos reproductivos:

- Que esse augmento é proviclencial e maior ou menor quando ha dichogamia;

- Que se não lıa dichogamia e simultaneamente desabrocham as flores masculinas e femininas, o calor nunca excede dois gráos acima da temperatura do ambiente, porque a pollinisação se faz immediata e naturalmente ou auxiliada pelos insectos :

- Que neste caso o calor que adquirem as flores é apenas o necessario para dar energia e força aos estames $\left({ }^{x}\right)$, para entrarem em erecção e produzirem a dehiscencia das antheras e a immediata ejaculação do pollen;

- Que quando ha dichogamia protandrica a temperatura attinge então una grande elevação, e esta é demorada. Emquanto amadurecem os estigmas, isto é, emquanto se preparam para receber o pollen, não só patenteando-se como adquirindo a força precisa para o acto fecundador, o calor nos orgãos masculinos cresce e se demora, para descahir logo que o orgão feminino tornou-se apto a receber a fovilla;

- Que n'esta dichogamia, quando os espadices são monoicos, em geral, são os insectos ou as brizas os intermediarios

(1) Linneo, na sua Philosophia botanica, 1787 , pag. 92, diz: "Calyx ergo est Thalamus, corolla Aulium, filamenta Fasa espermatica, antherae Testes, pollen Genitura. Stigma Fulva, Stylus ligina, Germen Ovarium. 
da fecundaçio, e quando são androgynos então directamente ella se effectua :

- Que passado o momento proprio, as flores masculinas deixam immediatamente os seus ramos;

- Que a demora das tlores masculinas nos ramos depois da dehiscencia, que póde ser de mais de 24 horas, é relativa ao tempo cla anthese das femininas;

- Que quando as nupcias clão-se logo depois da abertura das espathas, isto é. quando a dehiscencia é simultanea, momentos depois as flores se despegam e cahem;

- Que quando ha dichogamia protogynica o calor que adquirem as flores tambem é apenas o necessario, porque logo que se dá a dehiscencia das flores masculinas faz-se a fecundação e as flores cahem;

- Que na dichogamia protandrica, quando é muito demorada, as flores masculinas se despegam, ás vezes, mas acarretam comsigo a temperatura obtida nos ramos, e. em vez de diminuil-a. a conservam e a augmentam para que dê lugar á fecundação feita, então, só por meio dos insectos;

- Que a demora do calor e o seu augmento, n'este caso, nos prova que esse augmento de temperatura é necessario para que se dê uma verdadeira, completa e proveitosa fecundação;

- Que sem esse calor vital os ovulos mal fecundados produzem fructos que abortarão, ou se desenvolverão atrophiados, não sendo reproductores;

- Que quanto mais promptas sĩo as nupcias tanto menor é o calor e quanto mais demoradas, pela dichogamia protosyuica, mais elevada e mais demorada é a temperatura:

- Que na dichogamia protogynica as llores femininas adquirem tambem grande calor que perdem depois da sua anthese, e de ficarem aptas para serem fecundadas;

- Que a excitação e o augmento de temperatura que se dá no animal ua epoca de seus amores dá-se no mesmo caso nas flores das palmeiras; 
- Que para ser proficua, como no acto da fecundação animal, o augmento de calor é necessario nos orgãos reproductores dos vegetaes;

- Que sem o excitamento provocado e desenvolvido pelo calor, as flores não adquirem a energia e a força vital precisa, para movimentar os orgãos que tornam-se verdadeiramente impotentes.

Natura enim non facit saltus! 



\section{EXPLICAÇÃO NECESSARIA}

Só hoje me foi proporcionada a dita de ler o n. 3 do 2. volume do "Boletim do Museu Paraense ".

Não tendo até então conhecimento official ou particular da existencia de tal Museu nem por uma simples communicação, que a mais rudimentar delicadeza impõe e a pratica estabeleceu entre estabelecimentos congeneres, não foi possivel ha mais tempo chamar a contas o autor de um artigo, publicado no alludido Boletim, sobre um topico a mim referente, o qual em nada abona a probidade scientifica do seu autor - o Snr. Huber.

Antes, porém, de começar o ajuste de contas com Sr. Huber, permittam os leitores um pequeno cavaco.

E' para admirar que um Boletim que é tão facil e profusamente distribuido e tal é a procura ( ${ }^{\mathrm{T}}$ ) que foi obrigado a elevar a 1500 exemplares a sua tiragem não se lembraram de remetter um só numero que fosse á Bibliotheca do Jardim Botanico, estabelecimento que bem conhecem, tanto que se occupam com o seu Director e suas obras.

Lendo o Relatorio citado fiquei sabendo que não só os taes Boletins säo muito procurados, como tambem que errarix aliás, quem pensasse que o "Boletim" representa o tolal da actividade litteraria do pessoal do Musen (²). Esse orgäo, diz o Relatorio do Director do mesmo Museu, é o meszos da publicasáa e não comporta senáo approximadamente am terso da somma de

(1) Rel. do Director, do anno de I897, pag. 53 .

$\left.{ }^{2}\right)$ O pessoal é todo estrangeiro, julgo que suisso-aliemio. 
trabalho da latra do correr scientrices. Ha uma superpronucçã hommosa cujo cxecsso é logicamente leardo para os paizes ont he snandes rezistas c periodicos para estu on aquella especialudatic $\left(^{3}\right)$.

One thes parece?! O governo do Pará distraindlo o suor de sens filhos, para payar a estrangeiros afim de figurarem na Europa, em detrimento do nome brasileiro! O Pará paga para nåo saber o que sobre as suas riquezas se diz, porque creio, que, como no resto do Brasil. os brasileiros não estão tào versados em allemão, $\mathrm{em}$ ingrez etc., lingua en que é escripta a tal superpruiucio homrosa de trabalhos, porque, diz o mesmo Relatorio, que é enviada para Inglaterra, pura Allcmanha. para Austria, para a Franga c para a Suissa nas respecticas linguas. Nào sei se hoje. a populaçåo que paga para sustentar os estrangeiros do Museu do l'ará, está muito versada n'essas lingruas para ler essas revistas, que natural e forçosamente serão tambem distribuidas no nosso paiz, porque para isso paga. Infelizmente não me chegou nenhuma ás mãos. quando até da Russia, de Hong Kong. e da Nova Hollanda recebo revistas.

Mas infelizmente a tal superproducção creio que nảo passa, do q'ie ahi se chama, uma pomada; pelo menos såo os pro. prios boletins que isso nos provam, se não ha una in liynidade, de enviar traballa s. feitos por individues paros pelo Brasil, fara serem publicalos em revistas estrangeiras quando os deviam imprimir na que o governo paga para si.

Viis quero que digam que ha má vontale da minha parte, por isso vou provar, com "s Buletins, que niw ha a tal super.

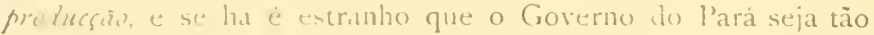
condescendente ou tio filtu de patriotismo que concela serem olviblos nomes hrasieresus de verdadeiro mérito, do passo qu contribue para a exhbição d'essess sabios vindos for encomm nela do estrange iro os quaes mais tarte lhe clarion a paga.

Tinho em mãos e manuscio um Relitorio e sete numeros 
dos Boletins que correspondem a quasi dois annos, e como n'esse Relatorio, para mostrar a grande importancia do mesmo, os avalie pelo numero de paginas $\left(^{+}\right)$, vou tambem d'elles me occupar pelo numero de paginas, afim de mostrar que não ha superproducção e sim falta de material, a não se praticar a exploraçào de publicar no estrangeiro trabalhos sobre o Brazil, feitos no paiz e por conta do Governo do Estado.

Os quatro primeiros fasciculos que fazem o volume de 1897 contém ao tıdo 440 paginas, sendo 72 de relatorios, discursos, cartas etc., que não aproveitam ao paiz, 182 dos trabalhos proprios do Museu, havendo 186, (note-se bem) de trabalhos de individuos que não pertencem ao corpo do Museu.

O que quer dizer que havendo falta de material se aproveitou materia al heia para encher espaço.

Por que não encheram essas paginas com a superproducção?

Do 2. volume tenho tres fasciculos com 392 paginas, sendo de relatorios etc. 68 paginas, de trabalhos do Museu, I 70 , e cheias de trabalhos de pessoas estranhas 154. Donde resulta que. nos dois volumes, foram perdidas 340 paginas com trabalhos que deviam ser preenchidos com a superprodução honrosa, e não distrahidas com outros trabalhos, aliás importantes, como os de Hart, Derby etc., que podiam ser publicados com a mesma utilidade em revistas paraenses ou volumes separados, mesmo porque isto se deprehende do art. I 4. do Regulamento, que não havia de criar uma revista para trabalhos estranhos. Poder-se-ha objectar que essa remessa para o estrangeiro está determinado no art. 22, mas isso foi uma illaqueação á boa fé do legislador, foi um meio de apresentar muito saber e trabalhos feitos por especialistas europeus, quando deviam ser feitos pelo pessoal do Museu, se bem que tambem estrangeiro. Remettam-se collecções estudadas e determinadas; remettam-se publicações, mas as do Museu, as dos estudos feitos e publicados no paiz.

$$
\text { (4) Pas. } 53
$$


E' mais honroso mandar um trabalho feito, quero mesmo que mal, do que pedir um attestado de ignorante confessando que remette as colleç̧oes, porque não ha quem as determine. Se lá ha especialistas aqui ha as obras dos mesmos e guiem-se por ellas.

Dado este cavaco, a que fui provocado, passo ao ajuste com o Sr. Huber, o que farei em poucas palavras:

A pags. 382 , do referido Boletim, deparei com o artigo:

$O$ "Muricy" da Scrra dos Orgãos (Vochisia Goeldii nov. spcc.) - que não me mereceria reparo algum se não viesse, sem necessidade alguma. com o titulo "Observaçåo o seguinte:

" Na litteratura não me consta senão um caso, onde se fala d'um Muricy que nåo seja uma Byrsonima. E' no Hortus Fluminensis de Barbosa Rodrigues. na passagem seguinte (pag. 62) :

a Byrsonima dispar Gr. (B. differente). Patr. Brasil, Rio de Janeiro. Nome vulgar, Muruchy. E' uma bonita arvore de folhas illiptico-oblongas, adelgaçando-se para o peciolo, corn flôres amarello-claro em racimos terminaes. Grisebach descrevendo esta especie deu-lhe o nome de dispar. porque com effeito differe das outras congcneres pelos fructos. Os Muruchrs. nome vulgar das espccies d'este genero, todos têm por fructo uma bag'a arredondada e carnosa, entretanto que os finctos a'esta sīo uma especie de samara trialada, lenhosa e secca. - Ulterior estudo fará levar esta especic para ontro genero $).$

A parte sublinhada o foi, por mim, aqui, propositalmente, para que o leitor se capacite da má vontade e da força do Sr. Dr. J. Huber, que, segundo o mesmo Relatorio citado, è chefe da secção botanica.

Depois da citação acima diz o que me leva a escrever estas linhas, que è o seguinte:

"Para quem conhece a trxinomia (s) das Malpigltiaceas,

1) sempre peneel que cua palavia se derivava de faxis, arranjo e lemes lei, e que se cerevia tatum mil, aprendi mais isto!. 
uma planta com fructos em fórma de " uma especie de samaras trialadas, lenhosas e seccas", com effeito nunca póde ser collocada no genero Byrsonima, e seria muito estranhavel que un sabio do valor de Grisebach tivesse commettido tal disparate.

" Mas a planta do "Hortus Fluminensis" não tem certamente nada a fazer com a Byrsonima dispar de Grisebach. Este sabio deu á sua planta o nome de dispar, não por causa dos fructos, que elle nem conheceu quando publicou a sua nova especie na "Flora Brasiliensis", mas sim por causa da inflorescencia.

"A identificação da planta do "Hortus Fluminensis " com a Byrsonima dispar parece, portanto, baseada sobre supposisões sem fundamento. Se o "Nuruchy " em questão é realmente uma Malpighiacea on talvez a Vochysia Goeldii ou uma especie apparentada, isto não póde se dizer com certeza, visto as indicações pouco precisas do "Hortus Fluminensis ».

Antes de tudo chamo a attenção para a perfida adulteração que foi usada, fazendo-se-me dizer e escrever o que não disse, não escrevi, nem publiquei.

Cita o Sr. Huber o que já vimos: "Byrsonima dispar gr. (B. difterente) Patr. Brasil, Rio de Janeiro. Nom. vulg. Muruchyn.

Onde, no Hortus Fluminensis, ha isso? Na pag. 62? Esta resa simplesmente isto:-Nom. vulg. -

O resto está em branco, por não conhecer o nome indigena. O Sr. Huber, que disso precisava, encheu o espaço em branco e escreveu Muruchy!... para fazer suppor que eu isso havia dito.

Que probidade scientifica !...

Diz o Sr. Huber que não ha senão um caso de falar-se em Muricy que não seja uma Byrsonima e esse é no Hortus Fluminensis.

Quem, não conhecendo o Hortus Fluminensis, ler a "observação» do Sr. Huber, que transcrevi, sabendo que entre scientistas é do mais rigoroso dever ser escrupulosamente exacto 
nas citaçôes, julgarà que eu escrevi tratualmente o que repetiu - Sr. lluber.

Pois bem. I citação está alulteracia : falseatla torpemente.

O Sr. Huber mentiu quanko affirmou que eu dera á Byranima dispar, de Gristbach, o nome vul rar de Murachy e, portanto, commetteu a mais feio dos crimes que po the praticar um sabio (mesmo de encommenia) o de impr bitade scientifica.

Nem o póde desculpar a carencia de conhecimento da lingua do paiz. pois alii năs ha má comprehensảı ou má interpretaçao. ha accrescimo da palavra - Mumihy-depois da abreviatura - ruls.

Ora, no Ilortus Fluminensis deixei em branco um espaço depois da abreviatura a'ulg. citada, o que quer dizer que nào conhecia eu o nome vulsar da planta descripta; portantn. se sou severo, sou justo com o Sr. Huber classificando, como fiz, o seu incorrectissimo procedimento, accrescentando na minha obra um rocabulo que lá nåo existe, com o intuito criminoso de prejudicar minha reputação scientifica.

Muito favor the farei si resolver-me a limitar sua punição a este artigo.

Ainda mais: pela leitura do trecho do Hortus Fuminensis se vi que eu, apresentando uma planta classificada por Grisebach, na sua "Monographia da Flora de Martius, não quiz mudar o nome daclo pelo mesmo sabio, mas ao mesmo tempo se nota que respeitava sua opiniảo, mas não concorclava com ella e. por isso, alem de deixar em branco o nome vuliar,

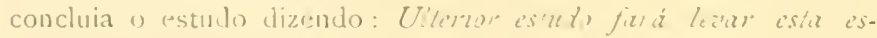
pecie para melro sencro.

Assim, pois, parit quem conbersa medianamente a lingua

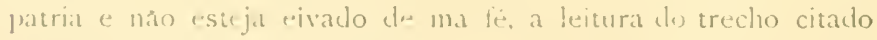
levala forçosamente as seguintes comblusōes: - 1. q que eu năo comlieria o mene vulgar da planta descripta por Grisebach c por iuso náo o escreri: 2.". "que nầ concordava com a

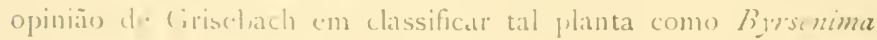


dispar, mas que, cortez e leal, aguardava "ulterior estudo" para dar motivos justificados de minha divergencia com o illustre sabio.

Por minha vez tambem digo: o unico caso onde se fala d'um Muricy que nảo seja uma Byrsonima é no Boletim do Museu Paraense, vol. II, n. 3. pags. 382 !...

Quem daria esse nome vulgar ao Sr. Dr. Goeldi? Algum estrangeiro, com certeza, porque nenhum natural do paiz, indio, caipira, sertanejo ou roceiro daria a uma Vochysia o nome de muricy: São mais intelligentes do que se suppōe. Elles não confundiriam um fructinho pulposo, arredondado e que se come, muito conhecido, com o fructo secco, trigono, trivalve e trilocuar de uma Vochysia, como o Sr. Huber quando diz: "Se o muruchy em questão é realmente uma malpighiacea, ou talvez a Yochysia Goeldi, ou uma especie sua aparentada ».

Para o Sr. Huber facilmente se confunde uma Vochysiacea com uma Malpighiacea.

Com que aplomb e autoridade diz o Sr. Huber "a planta do Hortus Fluminensis não tem certamente nada a fazer com a Byrsonima »!...

Examinou a planta? Pois garanto-lhe que a especie do Jardim Botanico é a verdadeira especie, mal classificada por Grisebach, e que denominou $B$. dispar.

Agora, se a tal Vochysia Goeldi é uma Byrsonima é que eu não sei, porque nunca a vi. Affirma tambem categoricamente que Grisebach deu o nome de dispar, nâo por causa dos fructos que elie nem conheceu, mas sim por causa da inflorescencia; quem the disse isso? tanto foi pelas flores como pelos fructos. Grisebach, que podia dizer, em parte alguma o disse e como sabe o Sr. Huber? Porque pelas flores ? São differentes (dispar) em que? de que? de qual? Parece mais natural que seja pelos fructos, que elle viu, mas, entrando em duvida que pertencesse á especie, não os descreveu. Nem eu nem o Sr. Huber o póde affirmar, porquanto o autor não deu explicação alguma. Para o Sr. Huber é por causa das flores; eu sustentarei, por causa 
dos fructos que năo såo de uma Byrsonima e muito menos de uma Vochysia.

O Sr. Huber, sem offensas minhas, sómente para por gosto ferir-me sem razão, porque nem de nome o conhecia, occupou-se da Byrsonima dispar, noticiada por mim.

$\mathrm{O}$ que tem esta planta com a tal Vochysia que o mesmo senhor descreveu? Dei-lhe por acaso o nome que falsamente citou? Nåo. Nåo fui eu quem disse que essa Byrsonima, por não sel-o devia passar a outro genero? Onde está a base para affirmar que mal classifiquei e determinei a planta? Não me poderá responder, mas eu o explico. O Sr. Huber nåo sabe ler portuguez, não entendeu o que leu, e por isso vem que. rendo mostrar saber, onde espichou-se redondamente.

Vejo ser preciso que o Pará gaste mais dinheiro, accrescentando ao grande pessoal do Museu mais um empregado, um interprete, para traduzir o que fôr escripto em portuguez.

Penso que assás disse para explicar a sem razão do ataque do chefe da secção botanica do Museu Paraense, pelo que aqui faço ponto, garantindo que não disse que a Byrsonima dispar era um Muruchy, que isso o fiz ver e a especie do Jardim está perfeitamente determinada, como a podem examinar os entendidos, sendo até a occasião propria, porque está em flor, o que ainda confirma a exactidåo da minha classificação, porque Grisebach diz que a especie floresce em Janeiro e Fevereiro,

Jardim Botanico, em 20 de Janeiro de 1899. 


\section{EXPLICAÇ̃̃O DAS ESTAMIPAS}

EsT. I. - Trithrinax biflabellata Barb. Rod.

$A$. - Aculeos da parte anterior das vaginas, de tamanho natural.

$B$. - Base dos foliolos para mostrar a divisão da folla, apresentando os dois foliolos internos. Ibidem.

C. - Base dos foliolos, de uma folha inteira, pelo dorso, com um foliolo inteiro, apresentando a sua abertura. Ibidem

D. - Espatha interior, de frente. Ibidem.

E. - Spadice, mostrando as espathas interiores. De um quarto do natural.

r. Flôr femea. 'Tamanho natural.

2. Dita, quatro vezes maior.

3. Calyce, ibidem.

4. Petala, ibidem.

5. Estame, ibidem.

6. Anthera, ibidem.

7. Ovario e utylo, ibidem.

Est. II. - Cocos Paraguayensis Barb. Rod.

1. Porção do peciolo, de tamanho natural.

2. Porção média do rachis, com um foliolo, ibidem.

3. Parte terminal da folha, com foliolos, ibidem.

4. Flôr masculina, aberta, ibiden.

5. A mesma, fechada, ibidem.

6. A mesma, duas vezes augmentada.

7. Calyce, ibidem.

8. Petala, tres vezes augmentada.

9 a. b. c. Estames e antheras, vistos pelo dorso, de lado e de trente, ibidem.

10. Flôr femea, de tamanho natural.

11. Sepala de lado, duas vezes augmentada.

12. Terceira sepala, ibidem.

13. Petala, de lado, ibidem. 
14. Androcen e ovario, ibidem.

15. Ramo, com fructo e enduvia, de tamanho natural.

16. P'etala da induvia, vista pela parte interna, mostrando o androceo, ibidem.

17. Fructo cortado verticalmente, ibidem.

18. O mesmo, cortado transversalmente.

Est. 111. - Cocos safida Barb. Rod

A. - Purçăo média do rachis da folha, com um foliolo, de tamanho natural.

B. - Parte terminal da mesma, ibidem.

C. - Córtes transversaes do peciolo e do rachis, ibidem.

D. - Ramo com uma foôr femea, ibidem.

1. Flôr macho, de tamanho natural.

2. A mesma, duas vezes augmentada.

3. Calyce, tres vezes augmentado.

4. Petala, ibidem.

5 a. b. c. Estames e anthera, de frente, pelo dorso e de lado, ibiden.

6. Fyncecio abortivo, ibidem.

7. Flôr femea, de tamanlıo natural.

8. A mesiua, duas vezes augmentada.

9. Sepala, de lado, ibidem.

ro. Petala, ibidem.

31. Androceo abortivo e ovario, ibidem.

12. Androceo abortivo, tres vezes augnentado.

13. Fructo inteiro, de tamanho natural.

14. O mesmo, cortado verticalmente, ibidem.

15. O mesmo, cortado transversalmente.

E. - Cocos Romanzoffiana Chamisso.

1. Ramo, com flôres machos e femeas, de tamanho natural.

2. Ovario, com o androceo abortivo, tres vezes augmentado.

3. O mesmo, pela parte interna, ibidem.

3a. Córtes transversaes dos dentes do androceo, ibidem.

4. Androceo alortivo, pelo lado externo, ibidem.

5. ()vario, mostrando as depressues causadas pelas compressóes dos dentes do androceo, ibidem.

i. Córte transversal do mesmo, ibidem.

Es]. IV. - 1. - Diflothemium . Inisitsil Barb. Rod.

a. Spatha unterior fechada, de tamanho natural.

1. Androceo ibortuvo da induvia, ilsidem.

2. Fructo inteiro, com a induvia, ibudem. 
3. O mesmo, cortado verticalmente, ibidem.

4. O mesmo, cortado transversalmente, mostrando as tres faixas, ibidem.

B. - Diplothemium leucocalyx Drude.

1. Androceo abortivo da induvia, de tamanho natural.

2. Fructo inteiro, com a induvia, ibidem.

3. O mesmo, cortado verticalmente, ibidem.

4. O mesmo, cortado transversalmente, ibidem.

C. - Diplothemium maritimum Mart.

Androceo abortivo da induvia, de tamanho natural.

I. Fructo inteiro, com a induvia, ibidem.

2. O mesmo, cortado verticalmente, ibidem.

3. O mesmo, cortado transversalmente, ibidem.

D. - Attalea Guaranitica Barb. Rod.

Apice do espadice macho, de tamanho natural e espadice inteiro, reduzido a um terço.

1. Fructo inteiro, cortado verticalmente, de tamanho natural.

2. O mesmo, cortado transversalmente, ibidem.

3. Fructo bispermo, cortado transversalmente, ibidem.

a. Flôr macho, ibidem.

b. A mesma, duas vezes augmentada.

c. Calyce, tres vezes augmentado.

d. Estames e antheras de frente e pelo dorso, quatro vezes augmentados.

EsT. V. - Bactris Anizitzii Barb. Rod.

1. Porção do peciolo, de tamanho natural.

2. Porção média do rachis da folha, ibidem.

3. Parte terminal da folha, com os dois ultimos foliolos, ibidem.

4. Espatha e espadice, reduzidos a um quarto do natural.

5. Flôr femea, de tamanho natural.

6. A mesma, cinco vezes augmentada.

7. Calyce, ibidem.

8. Corclla e ovario, ibidem.

9. Corolla, ibidem.

10. Ovario, ibidem.

II. Fructo ainda novo, tres vezes augmentado.

Est. VI. - Scheelea quadrisperma Barb. Rod.

I. Córte transversal do peciolo, de tamanho natural.

2. Dito do rachis, ibidem.

3. Porção do rachis da folha, ibidem.

4. Parte terminal de um foliolo médio, ibidem.

4a. Parte média do mesmo foliolo. 
46. Parte média de um foliolo inferior, ibtden.

5. Parte terminal da espatha macho, ibidem.

5a. Córte transversal de uma parte do mesmo espatia, para mostrar a disposição das fendas.

6. Parte terminal do espatha femea, ibidem.

7. Flór macho, de tamanho natural.

7a. A mesma, duas vezes augmentada.

8. Estames e antheras, quatro vezes augmentados

9. Flôr femea, de tamanho natural.

10. Sepala externa, ibidem.

11. Sepala interna, ibidem.

12. Petala externa, ibidem.

13. Petala interna, ibidem.

14. Ovario e androceo esteril, ibidem,

15. O mesmo, sem androceo, ibidem.

16. Fructo inteiro, com induvia, ibidem.

17. O mesmo, cortado verticalmente, ibidem.

18. O mesmo, cortado transrersalmente, ibidem. 
Indice das Palmeiras contidas n'este volume

\begin{tabular}{|c|c|c|}
\hline & & \\
\hline crocomia, Mart...................... & PAG. & 18 \\
\hline nibocayayba, Barb. Rod.......................................... & $n$ & 18 \\
\hline Tctaĩ, Mart............. & $"$ & 18 \\
\hline 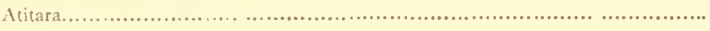 & " & 22 \\
\hline 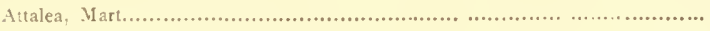 & " & 27 \\
\hline 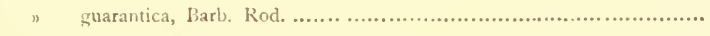 & " & 27 \\
\hline 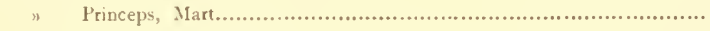 & $n$ & 25 \\
\hline Dactris Jacq & " & 19 \\
\hline 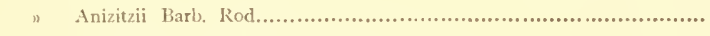 & $"$ & 19 \\
\hline 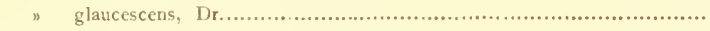 & $n$ & 19 \\
\hline " piscatorum, Wedd ............. & $"$ & I9 \\
\hline Caranda................................ & " & 20,21 \\
\hline 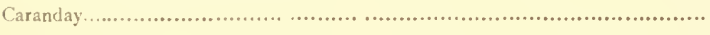 & D & 1 \\
\hline n $\quad$ hu $. . . \ldots \ldots \ldots \ldots \ldots \ldots . . . . . . . . .$. & 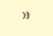 & I, 3 \\
\hline Coco de la Cordillera................ & " & 27 \\
\hline 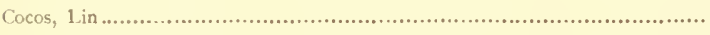 & $"$ & 7 \\
\hline 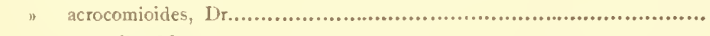 & $"$ & 8 \\
\hline 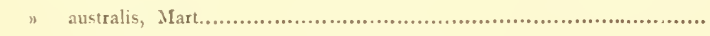 & 1) & 7,13 \\
\hline 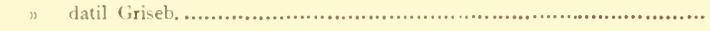 & $n$ & 7 \\
\hline 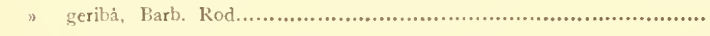 & $"$ & 7 \\
\hline 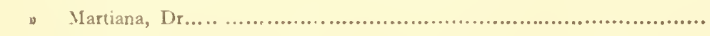 & $"$ & 8 \\
\hline 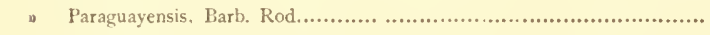 & $"$ & 9 \\
\hline 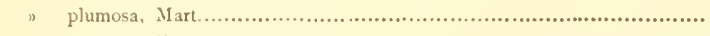 & * & 7 \\
\hline 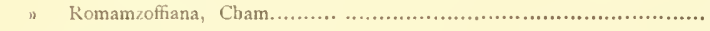 & $"$ & 7 \\
\hline 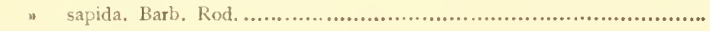 & " & 12 \\
\hline 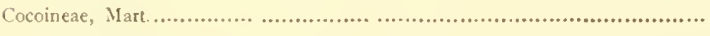 & " & 7 \\
\hline 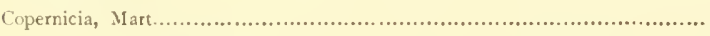 & $"$ & I \\
\hline 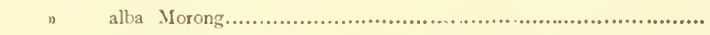 & $"$ & I \\
\hline 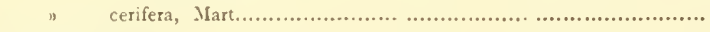 & $"$ & $\mathbf{I}$ \\
\hline 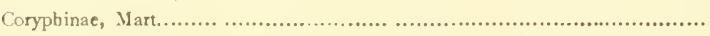 & $n$ & 1 \\
\hline 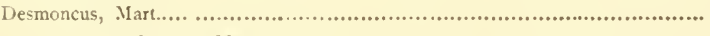 & " & 23 \\
\hline 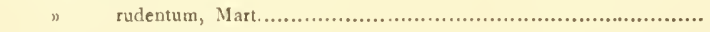 & $n$ & 22 \\
\hline 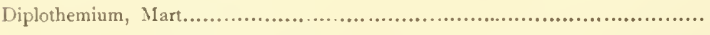 & $n$ & 14 \\
\hline Anizitzi, Barb. Rod & n & $\mathbf{1} 6$ \\
\hline campestre, Mart................................................... & $"$ & 14,15 \\
\hline 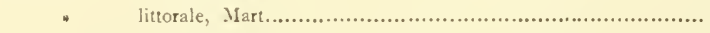 & $n$ & 14 \\
\hline maritimun, Mart.................................................... & $n$ & 14,15 \\
\hline 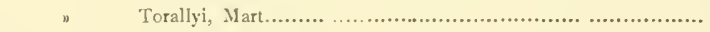 & $n$ & 19 \\
\hline
\end{tabular}




\section{6}

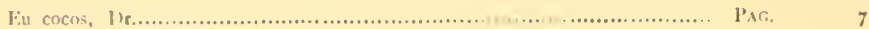

(iuacury..................................................................... " 26

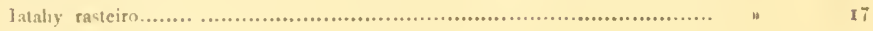

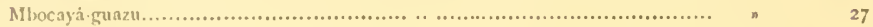

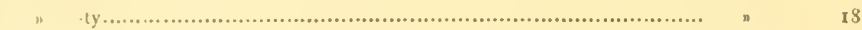

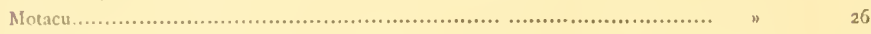

P'aln

P'indo........................................................................... " 8

Scheclea, Karst......................................................... " $\quad 23$

" Anizitziana, Barb. Kod................................................. " $\quad 25$

" Corumbaensis, Barb. Kod.............................................. . 24,26

"I'rinceps, Karst................................................ " "

" quadrisperma, Barb. Rod........................................ n 23

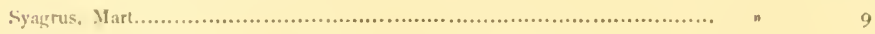

Trithrinax, $M$ art............................................................. n $n_{n}$

" acanthocoma, I) r....................................................... n n

" Jrasiliensis, Mart................................................ " $3,4,2$ I

" campestris Girizeb.................................................. "

n flahellata, Barb. Rod................................................. " $\quad 2,4$

n schizophisla, I)r.................................................... " 3,4

Tucum-mirim de fructa azeda................................................. n 19

" " $\quad$ " doce ....................................................... n

Ushury ...................................................................... " 24

l'rubamba ......................................................................... " 22

Vacytara....................................................................... n $\quad 22$

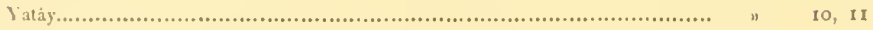

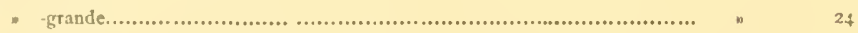

- guazu ............................................................................... " 24

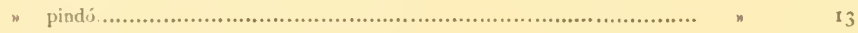

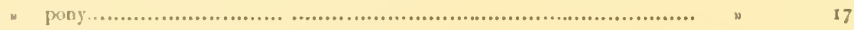


Tab. I.

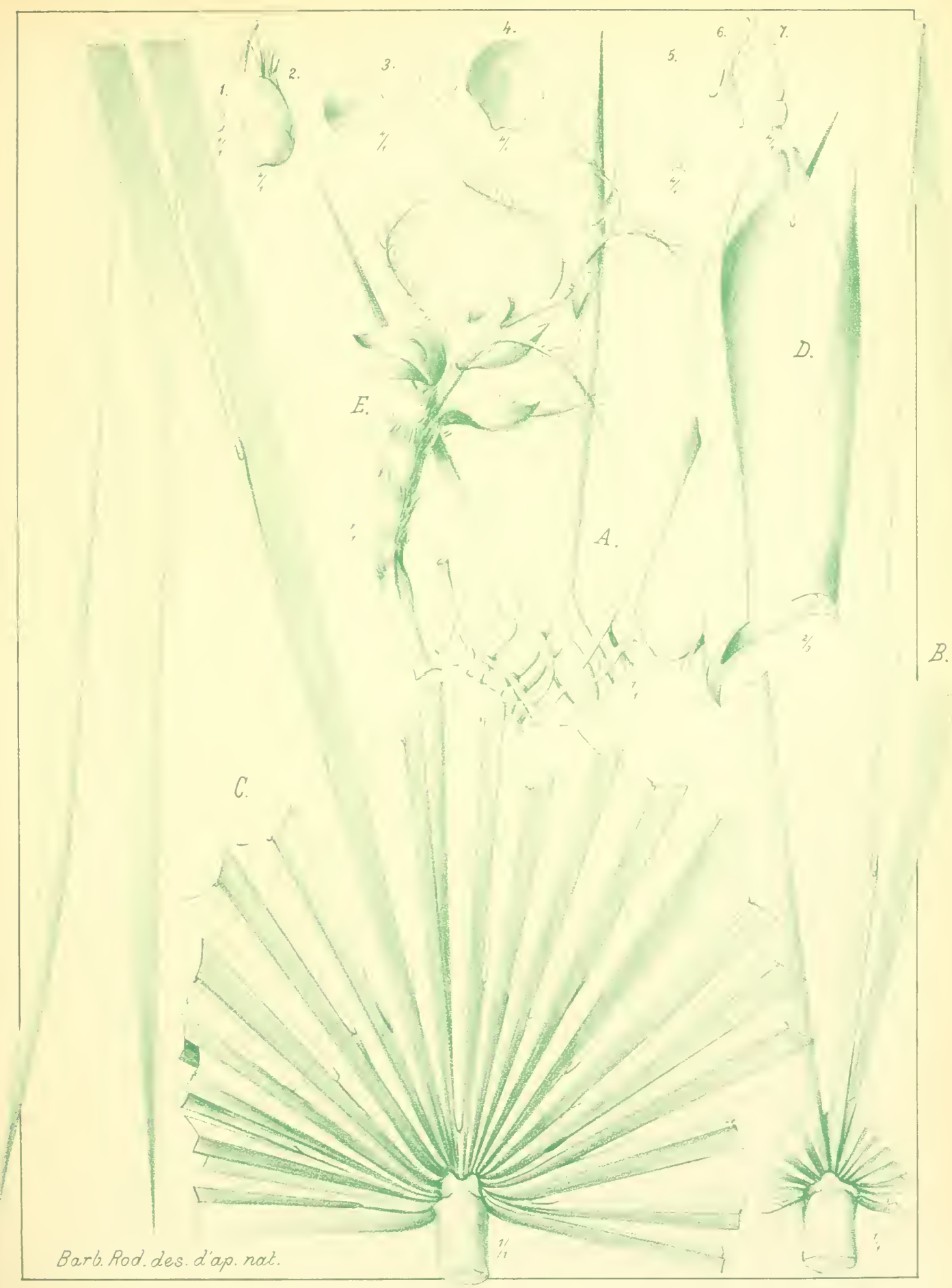

TRITHRINAX BIFLABELLATA Barb. Rod. 

Tab. II.

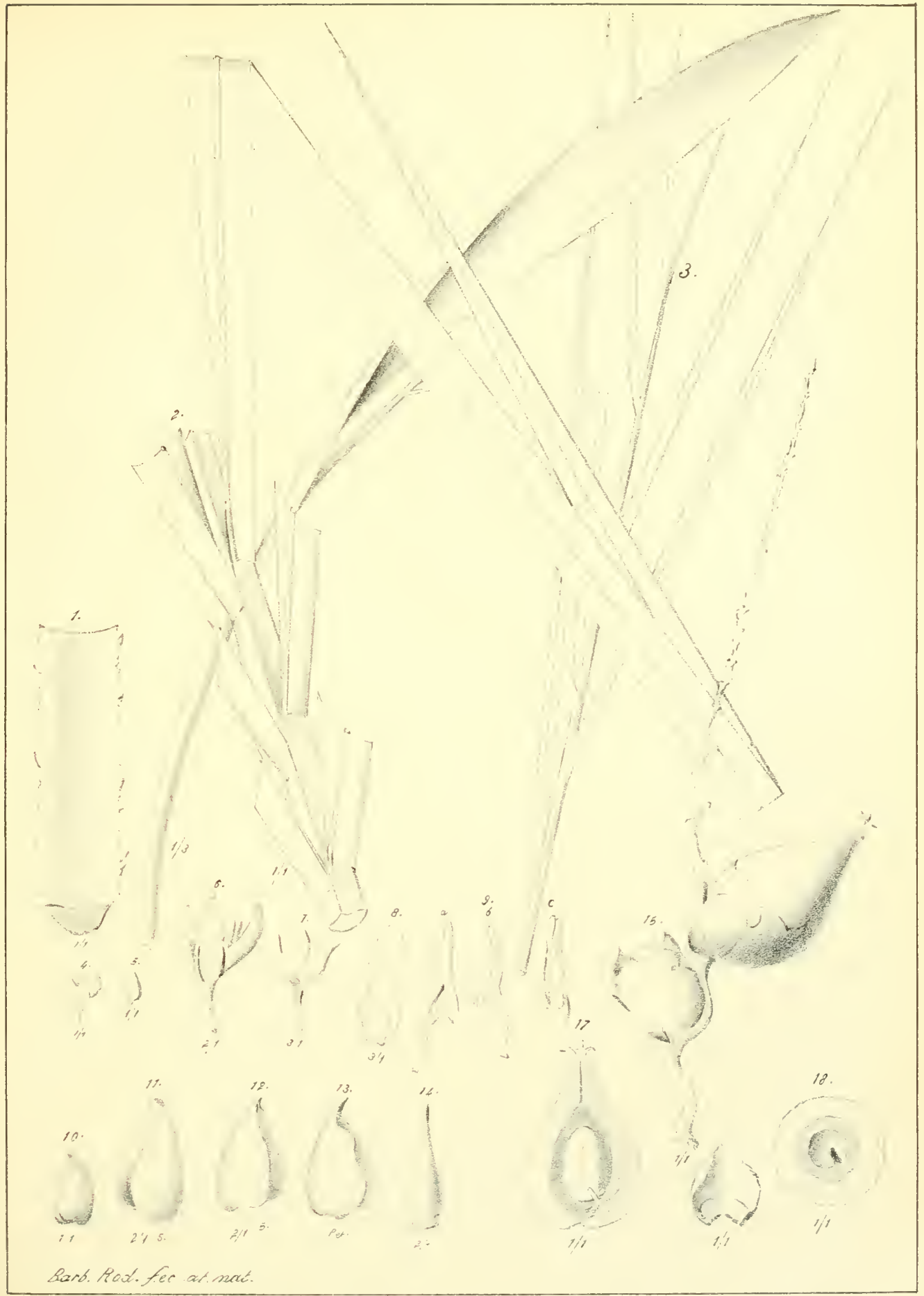

COCOS PARAGUAYENSIS Barb. Rod. 



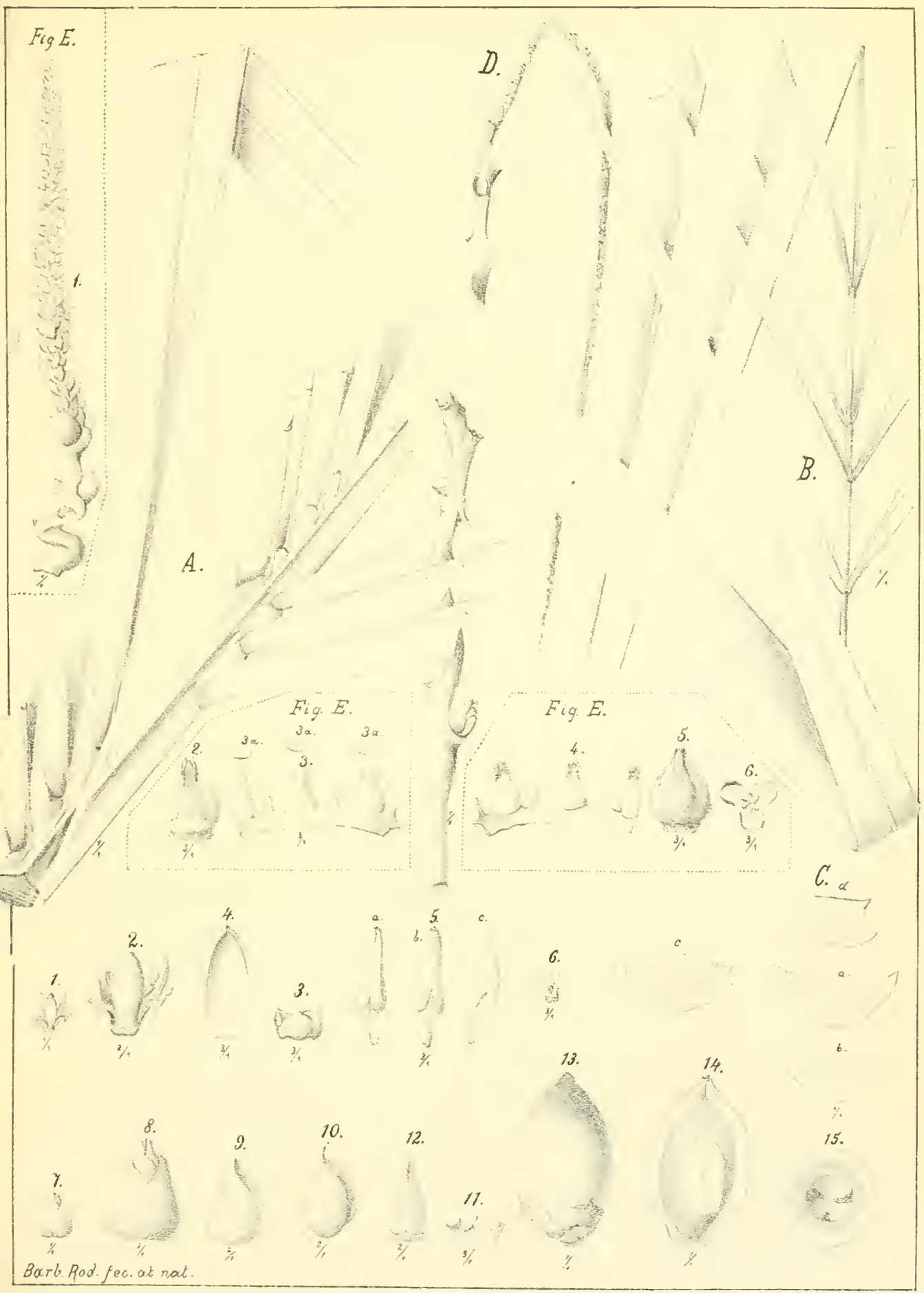



Tab. IV.

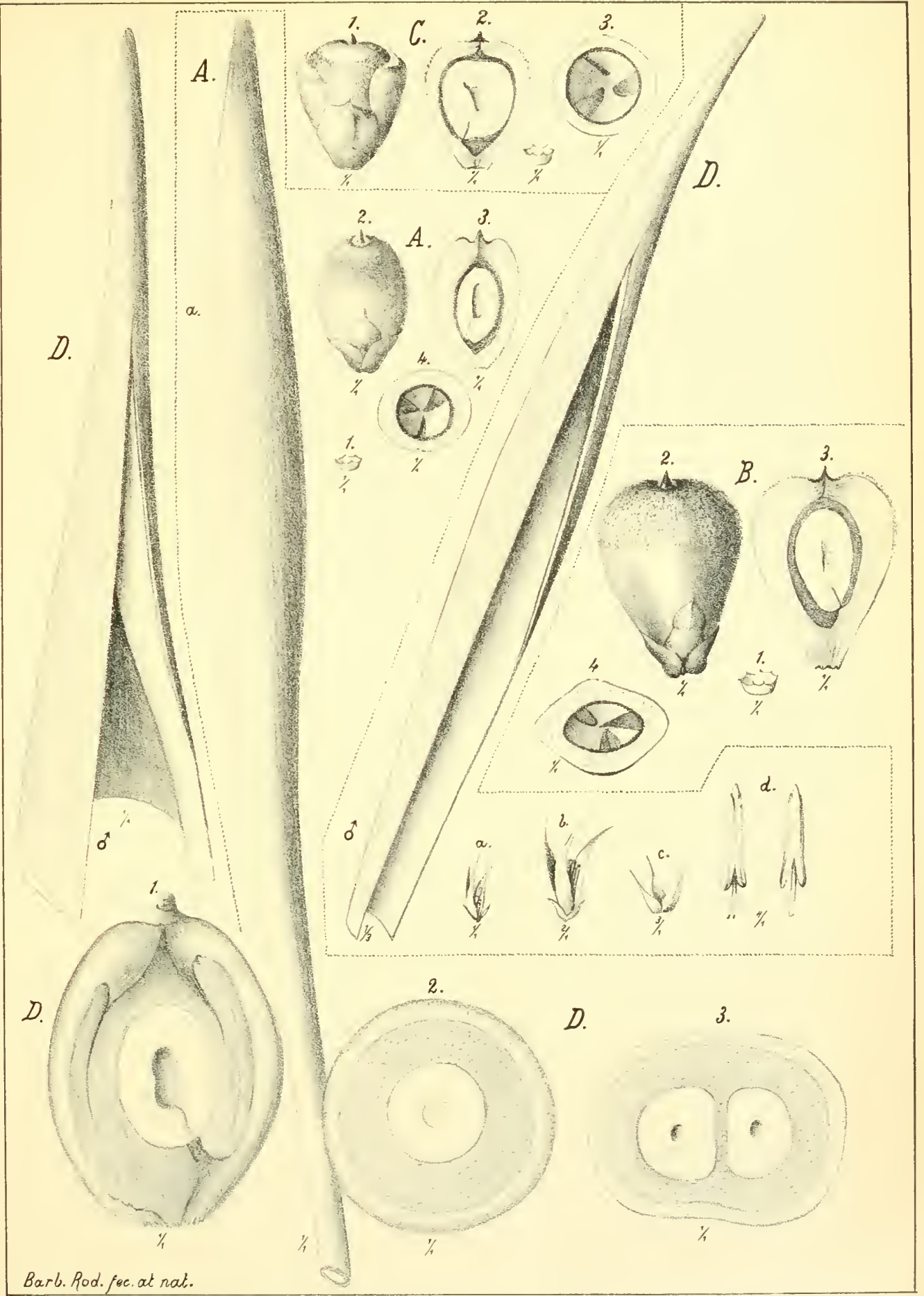

A. DIPLOTHEMIUM ANIZITZII Barb. Rod.

B. DIPLOTHEMIUM LEUCOCALYX Dr C.D. MARITIMUM Mart.

D. ATTALEA GUARANITICA Barb.Rod. 

Tab. V.

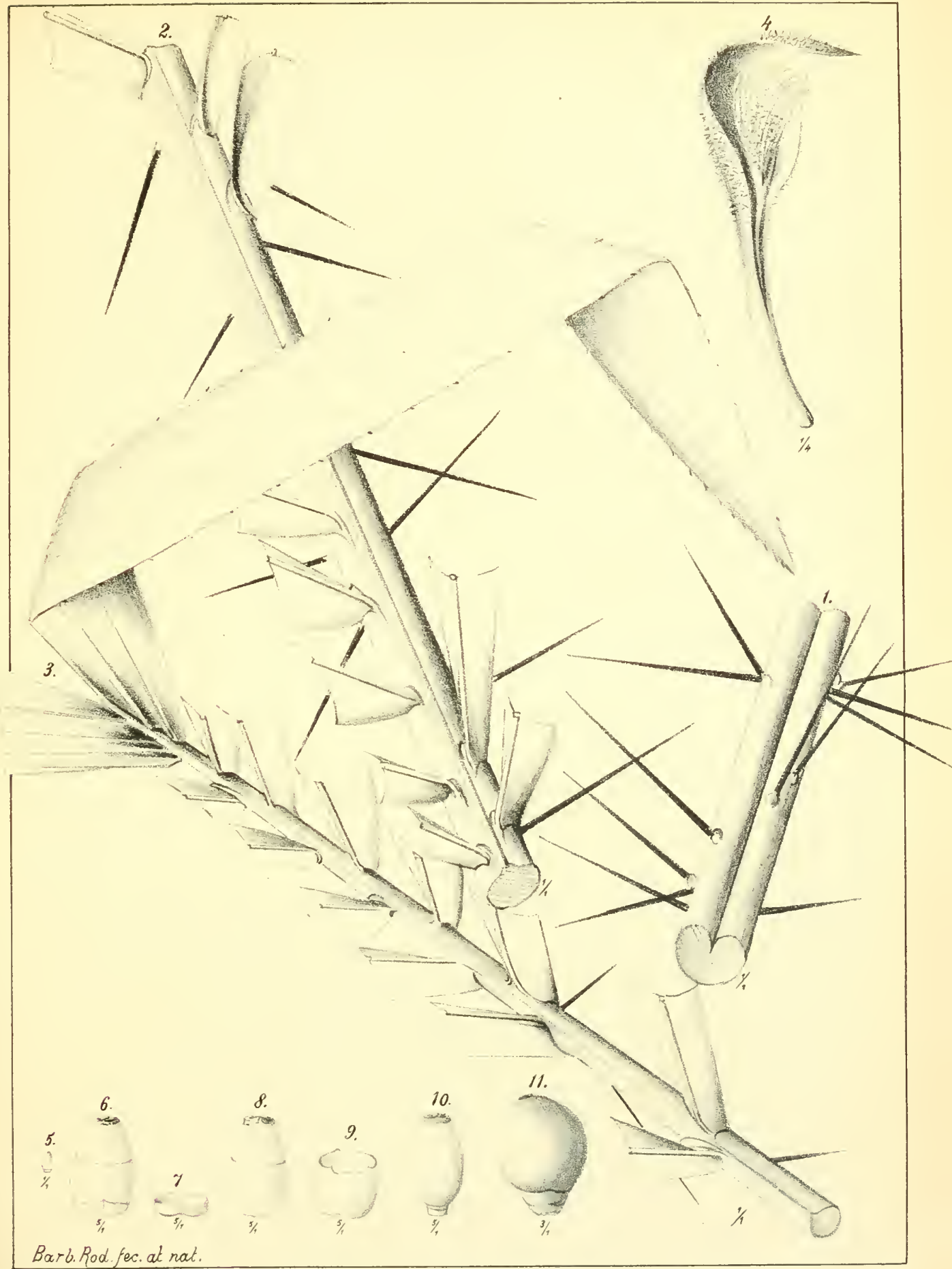

Barb. Rod fec. at nat.

BACTRIS ANIZITZII Barb. Rod. 



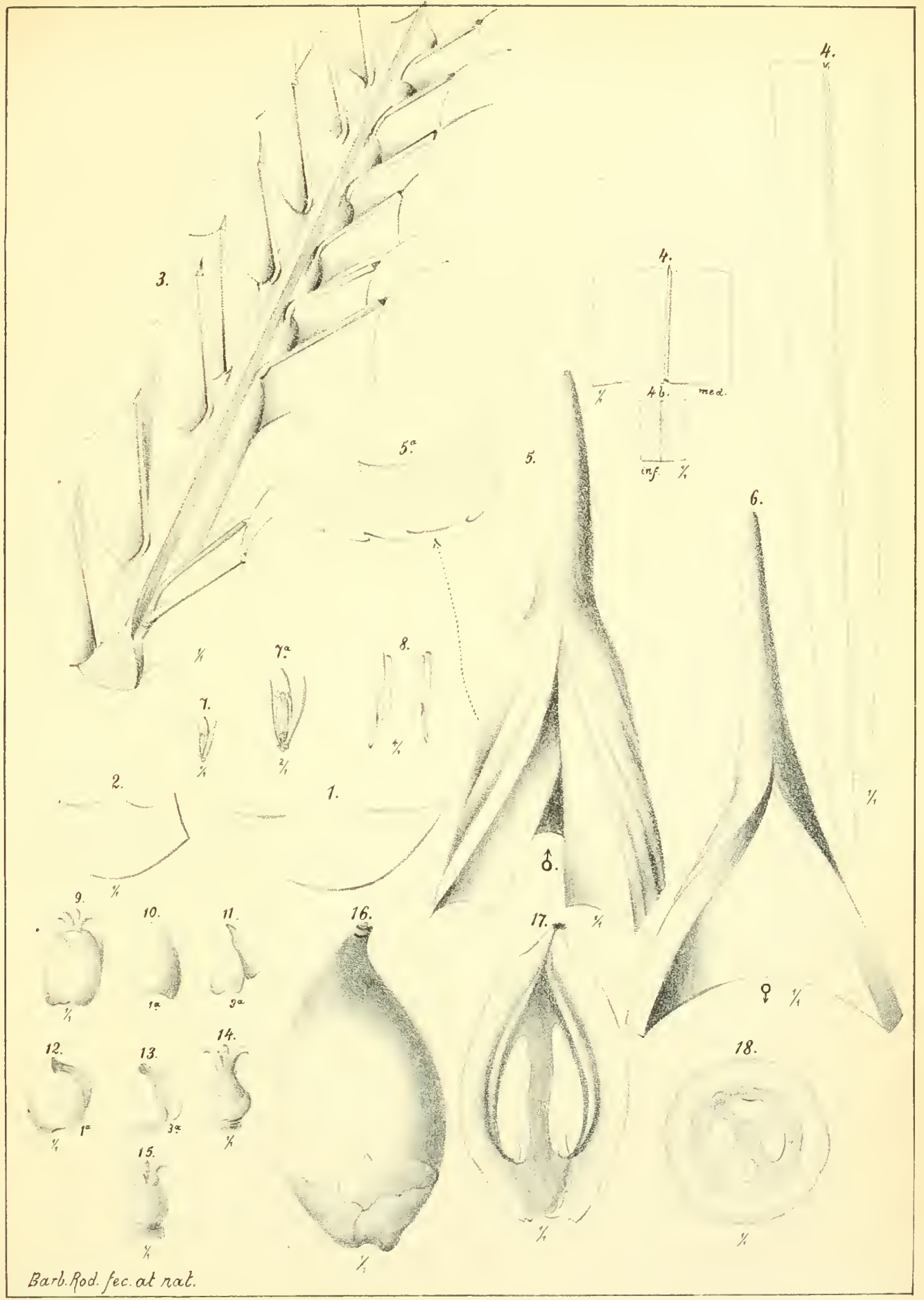

SCHEELEA QUADRISPERMA Barb.Rod. 



\section{PALIMAE HASSLERIANAE NOVAE}

ul

Relação das palmeiras encontradas no Paraguay

PELO

Pr. Enillio Ibassler

DE

$1898-1899$

DETERMINADAS E DESENHADAS

POR

J. BARBOSA RODRIGUES

Director do Jardim Botanico do Rio de Janeiro

RIO DE JANEIRO

'TYPOGRAPHIA IEUZINGEK

1900 

PALMAE HASSLERIANAE NOVAE 



\section{PALMARE HASSLERIANAE NOVAE}

() $\mathrm{L}^{\circ}$

Relação das palmeiras encontradas no Paraguay

PELO

\section{Dr. Entrilio Ibassler}

DE

$1898-1899$

DETERMINADAS E DESENHADAS

POK

\section{J. BARBOSA RODRIGUES}

Director do Jardim Botanico do Rio de Janeiro

RIO DE JANEIRO

TIPOGRAPIHA IFUZINGFR

1900 



\section{FRRATA}

\begin{tabular}{|c|c|}
\hline $\begin{array}{l}\text { I'ags. } \\
1\end{array}$ & $\begin{array}{l}\text { L.mha- } \\
\text { fo }\end{array}$ \\
\hline :3 & $\dot{B}$ \\
\hline$"$ & $"$ \\
\hline$"$ & 14 \\
\hline$n$ & 1.5 \\
\hline$n$ & $11 ;$ \\
\hline$n$ & 34 \\
\hline 5 & $2: 2$ \\
\hline$"$ & $2: 2$ \\
\hline$"$ & 23 \\
\hline$n$ & 31 \\
\hline ti & $2: 3$ \\
\hline$n$ & $29 !$ \\
\hline$"$ & $29 !$ \\
\hline 7 & i) \\
\hline N & 7 \\
\hline$n$ & 30 \\
\hline " & 30 \\
\hline$s$ & 8 \\
\hline$\star$ & 10 \\
\hline$n$ & 10 \\
\hline 9 & 14 \\
\hline ॥ & 17 \\
\hline v & $1 \mathrm{~s}$ \\
\hline$n$ & 1s \\
\hline 10 & 3 \\
\hline 11 & $S$ \\
\hline $1: 3$ & $\overline{3}$ \\
\hline$n$ & 12 \\
\hline 14 & 20 \\
\hline$"$ & 29 \\
\hline 15 & 23 \\
\hline$"$ & 23 \\
\hline$n$ & 25 \\
\hline
\end{tabular}

Onde se lê:
monoici
connatis
dentatis
angulosi
ramosis
divisi
dentati
trianguları
tomentosi
marginam
fluvium
tridentati
acuti
convexi
lanceolata
sulcata
cylundracei
sulcati
cylindraceo
bifaciali
convexi
brevem
bifacili
convexi
adspersi
excedentes
steriii
exserente
bifaciali
inermi
inermi
angulosi
aculeati
distantes

Leia-se

monoecei

connato

dentato

angulosi

ramosam

divisus

dentato

triangularis

tomentosa

marginem

fluvil

tridentato

acuta

convexa

lanceolatis

sulcatis

cylindracea

sulcata

cylindraceum

bifacialia

convexa

breve

bifarialis

convexa

adspersa

excedentibus

steriles

exserentes

bifacialis

inermis

inermis

angulosa

aculeata

distantibus

Outros erros encontrará, ainda, o leitor e que serão pela sua benevo lencia corrigidos. 



\section{AO LEITOR}

Em fins de Maio, do corrente anno, recebi do correspondente do Jardim Botanico do Rio de Janeiro, no Paraguay, o Professor J. Daniel Anisitis, uma carta acompanhada de pequeno herbario, só de palmeiras, colhidas pelo Dr. Emilio Hassler, e que graciosamente este me remettia a fim de que eu as determinasse.

O Dr. Hassler já referido, por mim. nas Palmae Paragzayenses, occupa, desde 1985 , o tempo que the sobra de suas occupações particulares em colleccionar, pelas terras Paraguayas, plantas com que tem euriquecido a sciencia, remettendo-as para a Suissa, sua terra natal, para Paris, Londres e Nova York, as quaes têm sido determinadas pelos Professores De Candolle, Chodat, Micheli, Hallier, Lindau, Clarcke e outros.

As suas excursões têm sido feitas, de preferencia, nas cordilheiras dos Altos, de Atirá, Piribebuy, Acahé, e pelos serros de S. Thomaz e Paraguary, não longe de Assumpção.

D'ellas tem resultado o encontrar muitas especies novas, algumas das quaes, já perpetıam o seu nome, homenagem que lhe tem sido prestada por sabios europeus.

Emprehendendo, ultimamente, de 1898 a 1899 , outra excursão aos longinquos serros desconhecidos, de Amambay, e Maracayú, nas raias de Natto Grosso, voltou " traendo, segundo me diz o Professor Anisitis, una collecion tan hermosa y numerosa que al admirale quedé atolondrado. Son plantas que aqui y en los lugares que ha visto son completamente differentes $n$.

Essa messe foi toda remettida para Europa, e, segundo o mesmo Professor, "solo me ha dejado las Palmeras para 
remetir y regalar á Ud. con el pedido que se sirva examinar y determinar."

Com effeito. se bem que pequena a colleç̧ão que recebi, e. comtudo. rica em novidades, sendo para lastimar que nåo fossem os especimens acompanhados de explicações e com. pletos.

Entretanto facil me foi a determinação cujo resultado aqui apresento. o qual completarei mais tarde, com os dados que solicitei. sendo esta publicação, apenas, um motivo para garantia da prioridade da minlıa classificaçăo.

1) evo observar que d'esta collecção alguns especimens, como os de n. "S96, (Cocos Paraguayensis Barb. Rodr.) 1257 e 1733, foram remettidos ao l'rofessor Chodat, de Genebra, porém, até 5 de Maio, do corrente, não haviam sido classificados e muito menos publicados, "pero non estan classificados, lo menos no estan publicados», como me assegura o meu amigo Anisitis.

As palmeiras aqui descriptas, de lugares que se não elevam a mais de 400 metros acima do mar, se bem que de territorio Paraguayo, comtudo, pode se dizer que são brazileiras, porque foram encontradas em uma zona que confina com o Sul de Matto Grosso, por onde forçosamente se estende a sua área greographica, como por ella entra o Diplothemium lencocaly. Dr., que encontrej no planalto de Mlatto Grosso e que vae até o Rio Grande do Sul, onde tambem, Burchell o encontrou.

Poder-se-ha pôr em duvida que as especies que aqui apresento como novas, nåo o sejam. Mas, se considerarmos que ५ã̃) de uma regiảo inexplorada, como já o fiz ver, nas minlıs J'ylmate l'uraguapenses, e são de una familia de difficil colheita c. conservaço cm herbario, pelo que foi sempre, mais ou menos menosprezala pelos botanistas, motivo não ha para duvidar, mesno porque as especies já descriptas eu as conheço de éisn c vivas me tem passialo pclas mãos. Se assim não fôra, nåo teria o numero de: 152 especies descriptas por min, jil muito 
superior ás classificadas pelo sabio mestre, o Dr. Von Martius, cujo numero é de 128.

Vem esta contribuição, emfim, augmentar a 434 o numero dos membros d'esta a ristocratica familia brazileira, que não inveja o fausto ou a belleza das congeneres do velho mundo.

$$
\text { O intor. }
$$

Jardim Botanico, em 11 de Junho de 1900. 



\title{
PALVAE HASSLERIANAE NOVAE
}

\author{
Ord. PALMAE Mart.
}

Fam. Cocoinede Mart.

Gen. nob. Acanthococos Barb. Rodr.

Flores in eodem spadice interfoliaceo simpliciter ramoso monoici, masc. in parte superiore numerosi solitarii v. $2 \mathrm{mi}$ conferti; fem. in parte inferiore conferti sessiles solitarii. Flores masc., sepala parva, lanceolata, acuminata, dorso subcarinata, erecta, ad basin connata. Petala oblique ob. longa, cucullata, acuta erecta. Stamina 6 inclusa, filamentis subulatis; antherae lineares, obtusae, basi bifidae, in medio affixae, erectae. Germinodium parvum, elongatum, trifidum . Flores fem. masculis sub aequilongis, ovoidei, perianthio post anthesin aucto. Sepala minuta subreniformia, acuta, coriacea, erecta. Petala sepalis multo majora, coriacea, reniformia, convoluto-imbricata, acuta. Androeceum abortivum annularis irregulariter dentatum. Ovarium ovoideum v. globosum, velutinum, in stylum brevem attenuatum, stigmatibus erectis demum recurvis. Drupa subglobosa, monosperma, vertice rostrata, epicarpio fibro-pulposo, endocarpio osseo basin versus triporoso. Albumine crasso, cavo, embryo poro uni oppositus.

Palmae acaules, aculeatissimae. Folia terminalia, inter fibris densis antiquas vaginaram erupentes, pinnatisecta, foliolis conduplicatis, linearibus, acquidistantibus, uninerviis, apice oblique 
"1 watis, mu \&mbus sub lacabus, lachi suburgena superna auma pami auliala, petiolo antice concavo, dorso fusco tomentoso, conivero. Icmiter aculeatissime, vagina fibrosa, persistente, tomnentosa, dinsć horrido-aculcata, aculeis pungentibus. Spallice parri. eredi, simplaciter ramosi, at apicem cermui, ranis atis dommm commis; spatha exterior elongala. lanciolata. apici fissa, interior lato oblonga, lignosa. dorso densé cotonnso-ítulima, sub acula, Irupa sicca brannea, áchulino. aculiala, parara.

Distincta como é. esta especie apresenta, todavia, affinidades que poleriam leval-a para o gencro Cocos, se nio fosse a sua armadura de pungentes aculeos, ou para o bactris se as suas Hores e as suas follus não a affastassem completamente desse genero. Fistabelece, comtudo. mma passagem. uma especie de transiçào, de um para outro genero que se ligam como que por uıı élo.

I'lanta dos terrenos altos e seccos, como são as das especies do Cocos, apresenta pelos aculeos, e pela forma do espadice caracteres do bactris, dosterrenos baixos lumidos e alagados.

A simples leitura dos caracteres e o exame das figuras que apresento bastam para se ver que, a planta em questão. nĩo se filia a nenhum dos dous velhos generos.

Attendendo á affinidacle que apresenta com os dous generos citados, impuz á este novo genero e nome cle fcanthococos, do rixcrthe, espinho e cocos, o nome scientifico tirado do vulgar. dado á fructos l'outras palmeiras, por aparentar uma carcla.

ArMTH Rocos IlAssizk Barb. Rodr.

Acaulis foliis racilibus brcribus recurvis inter fibris aculeatis

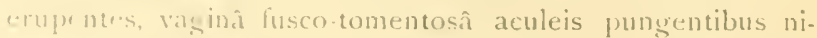
$\mathrm{g}^{\mathrm{r}}$ 's horrida. petiolis tomentosis aculeis pallidolorunneis mollilus uctis, rachi brunneo-tomentosi acule is nigris sparse amati, foliolis lineari conduplicatis regulariter dispo. sis aquilongis recurvo-explanatis apicem ateuto-bidentatis. 
Spadix inter foliis et fibris erupentes petiolum brevior longe pedunculatus, pedunculum fusco-lanosum, rachi in ramos brevis 4-divisâ densé scrobiculatâ, spathâ exteriora lanceolata pedunculum majorâ, brunneo-tomentosâ, interiora lato oblongâ incurvâ extus densé lanâ molli fulva vellutino tecta; floribus fem. sepalis reniformibus minimis acutis, petalis multo majoribus lato-oblongis mucronatis, androeceo sterili ad basin petalorum connatis irregulariter dentatis; drupa parva tomentosa tuntiiter aculeata.

Palma acaulis, caudice brevi terrae immerso, solitaria. Folia 4-5 contemporanea, $0,{ }^{\mathrm{m}} 5-0,{ }^{\mathrm{m}} 8 \mathrm{lg}$., vagina dorso aculeatissima, $0,{ }^{\mathrm{m}} 9-0,{ }^{\mathrm{m}} 10 \mathrm{lg}$., petiolo tomentoso, aculeis brunneis mollibus tecto et magnis esparsé armato, 0, ${ }^{10-0,}{ }^{m}{ }^{1} 5 \mathrm{lg}$., rachi $0,{ }^{\mathrm{m}} 15 \mathrm{lg} ., 4$-angulosi, supra aculeis nigris esparsé armato, foliolis lineari-conduplicatis, $0,{ }^{\mathrm{m}} 30-0,{ }^{\mathrm{m}} 36 \times 0,{ }^{\mathrm{m}}{ }^{3} 00_{4}-$ — o, ${ }^{\mathrm{m} 005} \mathrm{lg}$., subaequilongis. Spadix $0,{ }^{\mathrm{m}} 16-0,{ }^{\mathrm{m}} 20 \mathrm{lg}$., pedunculus $0,{ }^{\mathrm{m} 12}-0,{ }^{\mathrm{m}} 13 \mathrm{lg}$. gracilis, fulvo densé lanatus, arcuatus in rachin 4 -ramosis divisi, ramis $0,{ }^{m} 04 \mathrm{lg}$., densé scrobiculatis. Spatha exteriora $0,{ }^{\mathrm{m}} 16 \times 0,{ }^{\mathrm{m}} \mathrm{O} 12 \mathrm{lg}$., lanceolata, obtusa, interiora $0,{ }^{\mathrm{m}} \mathrm{O} S-0,{ }^{\mathrm{m}} 12 \mathrm{lgs}$., extus lanâ molli brunneo $\checkmark$. fulva velutino densé tecta. brevi mucronata, concava, incurva. Flores masc. 0, ${ }^{\mathrm{m}} 006 \mathrm{lg}$., calyce $0,{ }^{\mathrm{m}} \mathrm{OO} \mathrm{l} \lg$., sepalis ad basin paulo connatis, lanceolatis, acuminatis, dorso subcarinatis, petalis irregulariter lanceolatis, interdum cucculatis, acutis, ad basin attenuatis; staminibus 6 , inclusis ${ }^{2}{ }_{3}$ petala aequantibus, filamentis erectis, ad apicem attenuatis antherae subaequalibus; untherae lineari-oblongae, utrinque emarginatae, lateraliter fissae, medifixae; germinodium minimum, tripartitum. FLOR fem. 3-5 ad basin ramorum, conicis, sepalis minimis, reniformibus, acutis, convexis, disjuntis, $0,{ }^{\mathrm{m}} \mathrm{OO} 2 \mathrm{lg}$., petalis sepalis multo majora, $0,{ }^{\mathrm{m}} 005 \times 0,{ }^{\mathrm{m}} 007 \mathrm{lg}$., acuto-mucronatis, reniformis, concavis, dorsaliter subcarinatis, androeceo sterili urceolari, irregulariter dentati, ad basin petalis connatis ova- 
rium basi cingente. Ovarium conicum, relutinum, stylo brevi. Drupa subrotunda, o, ${ }^{\mathrm{m} O \mathrm{O}} 2$ in diam.. velutino-cotonosa, arguté aculeata.

HAB. in alto planitic Apéthú. in Paraguay. Flor. Oct.. Herb. Hassler $11 .+95 \pi$ et 522.7 .

Entre as especies que me foram remettidas pelo Dr. Hassler, encontrei dous exemplares, com os numeros acima, que, se bem sejam de porte differente comtudo pertencem a uma só especie, en idades diversas: um adulto e outro ainda novo. Aqui represento o adulto. E' um interessantissimo individuo que cresce nas altas campinas dos cerros do Paraguay, e que deve se estender, tambem, pelos campos do Sul de MattoGrosso. Forma um genero bem distincto para o qual, em homenagem ao seu descobridor, o Sr. Dr. Emilio Hassler, proponho o nome especifico de Massleri. 
Gen. Cocos I,in.

Sect. Sragrus Mart.

1. Cocos lilliputiana Barb. Rodr.

Acaulis foliis patentibus gracilis brevibus, aequaliter pinnatisecta, vagina tomento cinnamomeo tecta. foliolis linearibus acutis oblique bidentatis explanatis; Spadix brevis tri-ramosus sub arcuatus; spatha interior lanceolata acuta striata tomento cinnamomeo tecta; glomeruli androgyni racheos dimidio inferiori inserti, superne masculi, floribus masc. femineis sub aequilongis, flor. masc. petalis lineari-lanceolatis sub concavis acutis staminibus inclusis, antherae ad basin subsagittatae ad apicem oblique emarginatae, flor. fem. sub conicis, $2-3$ ad basin ramorum sepalis lato lanceolatis cucculatis, petalis sub cordiformibus acutissimis. Androeceo sterili ovarium cingente annuliformi, ovarium depressum in stylum brevem stigmatibus minimis angustatum. Drupa ignota.

Palma acaulis, O." I alta. Folia 3-5 contemporanea, $0,{ }^{\mathrm{m}} 3-0,{ }^{\mathrm{m}} 4$ lg., vagina tubulosa tomento cinnamomeo tecta ad apicem fibrosa $0,{ }^{\mathrm{m}} \mathrm{O} 6-0,{ }^{\mathrm{m}} \mathrm{O} 7 \mathrm{lg}$., pedunculus recurvus, antice planus extus convexus, cinnamomeo tomentosus, $0,{ }^{\mathrm{m}} \mathrm{O} 5-\mathrm{O},{ }^{\mathrm{m}} \mathrm{O} 6$ $\lg$., rachis triangulari, dorso cinnamomeo tomentosi, foliolis subalternis, linearibus, oblique acutis, ad marginam crassioribus, inferiore minoribus, $0,{ }^{\mathrm{m}} \mathrm{O} 8 \mathrm{O}-\mathrm{O},{ }^{\mathrm{m}}{ }^{2} 3 \mathrm{X} \times 0,{ }^{\mathrm{m}} 005 \times 0,{ }^{\mathrm{m}} \mathrm{00} 7$ Ig., viridi-glaucis; Spatha exteriora non vidi. Interiora $0,{ }^{\mathrm{m}} 12-0,{ }^{\mathrm{m}} 1+\mathrm{lg}$. Spaiix pedunculus compressus laevis, $\mathrm{O},{ }^{\mathrm{m}} \mathrm{IO}$ lg., cylindraceus, uni bracteatus, ramis $0,{ }^{\mathrm{m}} \mathrm{O} 3 \mathrm{lg}$.. sub re. curvis. Flores masc. $0,{ }^{\mathrm{m}} \mathrm{OO} 7 \mathrm{lg}$., caljece $0,{ }^{\mathrm{m}} \mathrm{OO} 9-\mathrm{O},{ }^{\mathrm{m}} \mathrm{OO} 2 \mathrm{lg}$., petala $0,{ }^{\mathrm{m}} \mathrm{O} 06 \times \mathrm{X0},{ }^{\mathrm{m}} \mathrm{O} 02 \mathrm{lg}$. Flores fem. $0,{ }^{\mathrm{m}} \mathrm{00} 6 \mathrm{lg}$. Drupa ignota.

$\mathrm{H}_{\mathrm{AB}}$ in campis ad ripum fludum Capibary, ad Paraguay. Flor. Sept. Herb. Hassler n. $+15 S$. 
Sir o. IRth. Cocos petraca, é a mais humilde das palmeiras no Pirasil. ainla appareceu esta no Paraguay, que disputa a primasia na pequenez do porte. Muito semelhante a esta conmenerc, e entretanto menor e affasta-se por caracteres que a distinguem. Como a primeira vive entre as gramineas dos campos. que sĩo assoladas annualmente pelas queimadas e por isso nunca se pode desenvolver, porque aquellas cujas folhas escapan ilos dentes dos animaes não resistem ás linguas do logo. Sem usses dous elementos destruidores é natural que se desenvolvessem e tomassem mesmo outro aspecto. que não denunciasse rachitismo.

2. Cocos campicola Barb. Rod.

Acaulis foliis regulariter pinnatisecta gracilis patentibus $v$. arcuatis, foliolis linearibus acuminatissimis obliqué insertis (re 10") alternis uninervis. Spadix longissime pedunculatus erectus simpliciter ramosus. Spatha inferiore lanceolata interiora quadruplo minora acuta ancipitata, interiora lanccolata acuta extus nitida pedunculum etiam anthesi involvente. Flores masc. quam fem. ovoideo acuti duplo breviores calyce ${ }^{1}$ " corollae aequante sepalis lanceolatis acutis. stamina basi sagittata. sepalis fem. "sorolae minore lato-oblongis $\mathrm{I}-3$ dentatis, petalis lato-oblongis acuminato-mucronatis, androeceo sterili cupulari tridentati brevi. ovarium lineari-oblongum in stylo brevem stigrmatibus elongatis angustatum. Irupa mili ignota.

tcaulis. Folu 5-o contemporanea, (vagina persistente fibrosodissolutal, gracilia arcuata $0,{ }^{n} 5-0, " S$ lg.. pedunculus supra planus subtus convexus, $0,{ }^{\mathrm{m}} 20$ lg., rachis supra wcuti subtus convexi, o," $3+\mathrm{lg}$., foliolis alternis, linearilus, acuminatissimis, inferiore $0,{ }^{1 "}+0-50 \times 0,{ }^{m} 005$. superiore

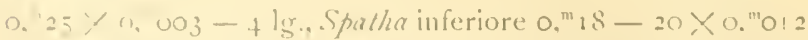

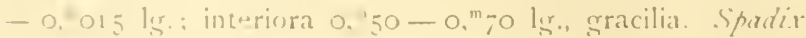
simpliciter ramosus, pedunculus o." $50-0,60$ lị., sub com- 
pressus, laeviș, flexuosus, rachis o, "10 10 $0{ }^{\mathrm{tm}} \mathrm{I}_{3} \mathrm{lg}$., Flores masc. densé imbricati, $0,{ }^{\mathrm{m}} \mathrm{OOg} \mathrm{lg}$. superiore minori $\mathrm{O},{ }^{\mathrm{m}} \mathrm{OO} 4$ - $0,{ }^{\mathrm{m}} \mathrm{OO}_{5} \mathrm{ls}$., calyce saepe pedunculatus, sepala lineari-lanceolata, obiusa, incurva, dorsaliter carinata, ad marginem membranacea, petulis irregulariter lanceolata, acuta intus concaro-sulcata, flamentis antherae minoribus; antherce medifixae, ad basin sagittatae. ad apicem obliqué emargiginatae. Flor. fem. 0, ${ }^{\mathrm{m}} \mathrm{O} 10-0,{ }^{\mathrm{m}} \mathrm{O} 12 \mathrm{lg}$, ovoideo-acuta, sepalis $1 / 3$ corollae minoribus, lato ovatis, :-3-dentatis, ad basin sub cordiformis, convoluto-embricatis, petalis majoribus lato-oblongis, acuminato-mucronatis; androecei sterili brevi. tridentati, cupulliformi. Ovarim oblongo-elongatum. Drupa milhi ignota.

Hab In campis. Ipé hú ad Paraguay. Flor. Oct.. Herb. Has. sler $n .505 \%$.

Ainda uma outra especie que se não póde confundir nem com o Cocos petraea nem com o acaulis de Martius, tendo apenas affinidade pelas espadices com o C. sraminifolia var. nana Dr., affastando-se deste en serem ramosos e não simples, em ter as flores e a disposição dos foliolos differentes. Alem d'isso a espatha na especie de Drude é estriada e n'esta lisa. E' uma bella planta ornamental.

\section{Cocos anadelina Barb. Rod.}

Acaulis foliis gracilibus arcuatis crispatis aequaliter pinnatisectis. foliolis angustissime linearibus conduplicatis ad apicem oblique bidentatis suboppositis erecto-flexuosis. Spadix foliis brevior multiramosus, spatha interiore laevi cinerea laeviter pulverulenta, lanceolata paulo mucronata, pedunculo cylindraceo cinereo pulverulento elongato, rachi cylindracei, laevi sulcati quam pedunculus breviore in $\mathrm{mi}$ nimis interstitiis ramos paucus exerente denique apice florifero caudatâ; flores masc. quam fem. paulo breviores, 
s.palis linearilus, dorso carinatis ad marginam membraraceis acuminatissimis, petalis lineari-lanceolatis acutis, staminibus inclusis. filamentis antherae paulo majore, antherae sub medifixae utrinque emarginatae; flor. fem. conicis. serpalis lato-oblongis arguté mucronatis convolutis, petalis minoribus lato oblongis convolutis longe mucronatis ad maryinem denticulatis, androecei sterili minini annuliformi hasi ovarium cingente; ovarium subcylindraceo in stylum breve attenuatum, tomentosum. Drupa non vidi.

Acanlis. Foliu arcuata, rachis antice bifaciali postice convexi, $0 . " 40-0, " 45 \lg$. foliolis angustissime linearibus, oblique hidentatis, suboppositis, erecto-nutantibus, conduplicatis, inferiore $0, " 150-0,{ }^{m} 55 \times 0,{ }^{m}{ }^{m} 005 \mathrm{lg}$., superiore minoribus $0,25-0 .{ }^{\prime \prime \prime} 30 \times 0 .{ }^{\prime \prime} 002-0,{ }^{m} 004$ lg. Spadix $0,{ }^{\mathrm{m}} 30-0,{ }^{\mathrm{m}} 40$ Iy.s spatha interior lanceolata, involuta, $0,{ }^{\mathrm{n}} 40 \times 0,{ }^{\mathrm{m}} 006 \mathrm{lg}$., extus cinereo tomentosa, paulo mucronata, laevis. pedunculo cylindraceo, tomento cinereo adsperso: "achis $0,{ }^{\mathrm{m}} \mathbf{1} 3$ lg., glabri ramos $15^{-1} \delta$ excerens, patentibus $v$. suberectis O."'10-0,"'14 lg., et ipsa in caudam floriferam ramos superantem excurrens. Flores masc. $0,{ }^{\mathrm{m}} \mathrm{I} \mathrm{lg}$., petalis coriaceis. 0 . 002 lat., germinodium tripartitum fem. in scrobiculis anchrogynis' imis $1-2$ supra ramorum basi et plures in racheos caudâ florifera inserti $0,{ }^{\mathrm{m}} \mathrm{O} 14-0,{ }^{\mathrm{m}} \mathrm{O} 15 \mathrm{lg}$.. sepalis lato-oblongris, petalis lato-oblongis in rostrum acuminatis, ad marginem denticulatis. Androcei sterili annuliformi, o. "OOF alt. Oitrinm tomentosum, subcylindraceum in stigmata *longata angustatum. Drupa ignota.

Hu. in campo Capibary ad Paraguay. Herb. Hassler n. $\cos _{3}$.

Fintre as viute e cinco especies. do Brasil. que já conta o zenere cous, excluindo as synonimias, só duas eram conhecidas como arables. o putraca e o acaulis de Martius: estas. porém. ecm os esparlices simples e não ramificaclos. Entretanto, hoje k. alf re ntam mais alsumas, com espadices ramificados, como 
a presente, e que cresce, mais ou menos, em sociedade nos campos de Capibary.

E' especie robusta e distincta.

4. Cocos campylospatila Barb. Rodr.

Acaulis foliis gracilis interrupte-pinnatis, foliolis binis aggregatis apicem versus solitariis linearibus acuminato-mucronatis pungentibus glaucis. Spadix rachi in ramos $12-16$ fastigiatos divisâ laxe scrobiculatâ et ipsa in caudaın floriferam excurrens: spatha interiore recurvato subconduplicatâ striata acuta tomento albo-cinnamomeo adspersa; flores masc. sepalis lanceolatis acutis staminibus inclusis; flor. fem. calyce quam corolla minore. sepalis lato-oblongis acuto mucronatis, petalis acuminato-mucronatis convolutis ovarium longe ovatum in stylum brevem stigmatibus recurvis angustatum involventibus. Drupa ignota:

Acaulis foliis interrupte pinnatis per acervos longe distantes bijugatis, rachis $0,{ }^{\mathrm{m}} 60-0,{ }^{\mathrm{m}} 70 \mathrm{lg}$. supra bifaciali, subtus convexi, tomento albo adspersi, foliolis per acervos bijugatis, $0,{ }^{\mathrm{m}} \mathrm{O} 3-0,{ }^{\mathrm{m}} \mathrm{O} 6$ distantes, linearibus, oblique acutis, mucronatopungentibus, tomento pulverulento albo adspersis, inferiore $0,{ }^{\mathrm{m}} 13 \times 0,{ }^{\mathrm{m}} \mathrm{OO} 2 \mathrm{lg}$., medio $0,25 \times 0,010 \mathrm{lg}$., superiore decrescentibus $0,17 \times 0,{ }^{\mathrm{m}} \mathrm{OO} 3 \mathrm{lg}$.. Spadix $0,30-0,40 \mathrm{lg}$., spatha interiore $0,45-0,50 \times 0$, 10 $\mathrm{lg}$, recurvata, profunde striata, tomento cinnamomeo tecta, pedunculo 0,20-0,25 lg. subcompresso, ad basin, tomento cinnamomeo tecto, rachis $0,{ }^{\mathrm{m}} \mathrm{I} 4-0,{ }^{\mathrm{m}} \mathrm{I} 5 \mathrm{lg}$, in caudam excurrens; ramis $0,15 \mathrm{lg}$., decrescentibus $1^{-15}$ contemporaneis, inferiore majoribus. Ftor. masc. ad apicem ramorum, o,oog lg., sepalıs ad basin connatis lanceolatis, acutis, dorso carinatis, minimis, petalis lanceolatis, acutis, concavis; antherae filamentis majorae, ad basin oblique emarginatae, sub medifixae; germinodium minimum sub globosum; flor fem. $0,{ }^{\mathrm{m}} \mathrm{O} 0 \mathrm{0} 8-0,{ }^{\mathrm{m}} \mathrm{O} 1 \mathrm{O} \mathrm{lg}$., sepalis 
petalisque minoribus. lato-oblongis, mucronatis, ad apicem carinatis, pulalis angustioribus longe mucronatis stigmatibus recurvis excedentes. Drupa ignota.

IIA3. in campis prope Cordillera de Altos, ad Paraguay. Flor. Dec.. Herb. Ilassler 12 . 1733. N'om anlg. Yatí M!. OU Vatáj-pequeno.

A descripção desta especie não pode ser completa porquanto falham elementos dos especimens que estudei. sendo comtudo sufficientes para bem caracterisal a. E' mais uma especie de espadice ramoso entre os Cocos acaules, e mui distincta da especie antecedente. Presumo ser, tambem dos campos, dos altos serros, batidos pelos ventos e raios solares.

E' notavel pela fórma da espatha interior, que se aproxima da do Cocos acaulis Mart., sendo recurvada como as cimitarras. Só este caracter é sufficiente para distinguil-a de todos os congeneres.

\section{Gen. Diplothemium Mart.}

D) plotiemila Hasslerianum Barb. Rodr.

Acaulis folia gracilia subarcuata regulariter pinnatisecta. foliolis proxime oblique insertis linearibus obliqué acuminatis utrinque glaucis. Spadix minor spathâ striati fusiformi longe rostrati. racheos parte inferiore androgyna quam cauda masc. longiore, florum masc. sepalis lanceolato-acuminatis dorso carinatis quam petala duplo brevioribus, petalis lanceolatis, concavis acutis, staminibus 6 inclusis, filamentis antheran minoribus. antherae ad basin sagittatae, drupa ignota.

Aculis. Foliu 1, $-1 . " 8$ lir. Foliohs regulariter decrescentibus. malio o, 30-0,32X0, $013 \mathrm{lg}$. superior $0,{ }^{\mathrm{m}} 16 \times 0,{ }^{\mathrm{m}} 005$. binis apucalibus $0.00 \times 0, " 002 \lg$.. spadir $0,{ }^{m} 60 \times 0,{ }^{m} 70 \lg .$. pedun(ulo lonsismo sub rachi dilatato. ad basin tomento fusco aci jerso: mehis o, on ly., dense florifera, spatha interiora. 
longe rostrata, arguté striata nitentia extus viridia intus Havescens, deinde extus fusca intus castanea, pedunculum longe vaginantia illic tomento cinnamoneo tecta; Flores masc. (et fem. longiores) $0,{ }^{\text {n'oo}} \mathrm{S} \mathrm{lg}$., dense ad rachin supra pedumculi apicem angustatum inserti; germinodium minimum cylindraceum, trifidum; flor. fem. ante anthesin conici, separla ovata obtusa sub cucullata, petala ad apicem tridentata, androccei sterili minimi, osarium ovoideum in stigmata elongata angustatum. Drupa non vidi.

HAB. in campo Apépu a.t Paraguay. I'lor. Aug.. Herb. Hassler n." 4352 .

No meu recente trabalho sobre as Palmeiras do Paraguay, tratancio de uma nova especie que descrevi, o Diplothemium Anisitsii, me occupei das tres fachas luzentes que internamente, tem o endocarpo. dos fructos deste genero como as que caracterisam os Syagrus, assim como tratei, tambem do androceo esteril, por não terem sidos esses caracteres observados, e a proposito mencionei todas as especies conhecidas até então, em numero de cinco.

Este numero é hoje augmentado con mais esta especie, pelo que já oito representam o genero, sendo que duas já foram por mim anteriormente descriptas, o Anisitsii e o pecinatum.

A especie de que agora me occupo, não ten os fructos conhecidos; entretanto, pelas folhas e pelas Hores affasta-se de todas as outras, pelo que á elle ligo o nome do seu descobridor o Dr. Hassler, perpetuando assim a minha homenagem e gratidão.

Observação. O herbario que me foi remettido continha I 3 numeros indicando outros tantos especimens que ficaram assim reduzidos: 10 especies, sendo 6 novas, aqui descriptas, 3 duplicatas (os ns. 5057, 5224, 5299, 6082) e 3 especies já conhecidas, que são as seguintes: 
Coros l'Mkigliyexis Barb. Rodr.

In I'almae Paraguayenses, pay. 9, tab., II. I'rope Cordillera de Altos. nom, vern. İalay guasu. I Herb. Hassler n. 896 : Aus.

\section{Dirluthemua Laveocalix Dr.}

In Mart. Iilor. I3ras. III, part. II, pag. 43r, tab. XCVIII, Fig. I. Barb. Rodr., Palm. Mattogrossenses, pas. 2S, tab. IX. llerb. Hassler n." 1257 et 6082.

1)iplothemium Jangadense Moore. Trans. Linn. Soc. of. London, 2. vol. IV', 499, tab. n." 36.

Geonoma Schotrian. Mart. Palın. Bras. suppl. p. 143. tab. Il A; I)rude in Mart. Flor. Bras. III. part. II, pag. 492, tab. CXIII, Herb. Hassler n." 4715. Sept.

Jardim Botanico do Rio de Janeiro, em i i de Junho de I 900.

ADIENDA

1) eixei de incluir. propositalmente, a especie que abaixo descrevo. entre as do Paraguay, para se năo confundir com as Hasslerianas.

Listil representarla n'este Jardim por dous magnificos exemplares. cuja origem me é desconbecida. Un foi plantado ha mais de 20 annos e o outro, obtive por sementes lo primitivo exemplar, os quaes plantei em 1890 .

Ambos floresceram anora em Abril, e vigorosamente se desenvolvem.

Tendo completado o sen estado de perfeito desen:olvimento, determinei. a especie porque, agora, nào se dará mais, do que o crescimento do espicjue. 
Cocos quinquefakin Barb. Rodr.

Caudex procerus foliis regulariter dextrosis in spiram pentasticham dispositis erecto-recurvatis, foliolis per acervos .3-4orum aggregatis divaricatis. Spadix longe pedunculatus ramos plurimos dense exserente, spathâ interiore longé lanceolatâ mucronatâ extus argutẻ striatâ fusco-tomentosâ; flores fem. quam masc. minores ad basin ramorum $20-30$ contemporanei; drupa viridi-tlava ellipsoidea endocarpio univittato.

Caudex $3-5^{\mathrm{m}} \times 0,20 \mathrm{lg}$. Folia 25 contemporanea, $4 .^{\mathrm{th}} 50 \mathrm{lg}$., erecto-arcuata, vagina sub-triangularia in fibras dissoluta, petiolus $1,{ }^{\mathrm{m}} 50 \mathrm{lg}$, ad marginam dentatus, intus ad basin concavus, rachis $3 .{ }^{\mathrm{m}} \lg$., bifaciali, foliolis per acervos, erectis, patentibus, pendulis, inferiore $0,{ }^{\mathrm{m}} 60-0,{ }^{\mathrm{m}} 65 \times 0,{ }^{\mathrm{m}} \mathrm{OI} \mathrm{lg}$., médio $0,{ }^{\mathrm{m}} 60 \times 0,{ }^{\mathrm{m}} 65 \times 0,{ }^{\mathrm{m}} \mathrm{O}+\mathrm{lg}$. superiore $0,{ }^{\mathrm{m}} \mathrm{I} 5 \times 0,{ }^{\mathrm{m}} \mathrm{O} 006$ lg., acutis, supra nitentibus, subtus pallidioribus. Spadix recurvatus, longe pedunculatus; pedunculus $\mathrm{I},{ }^{\mathrm{m}} 50 \times 0,{ }^{\mathrm{m}} \mathrm{O} 25$ lg., rachus o, ${ }^{\mathrm{m}} 40-\mathrm{o},{ }^{\mathrm{m}} 50 \mathrm{lg}$.. ramis dense insertis, $0,{ }^{\mathrm{m}} 45 \mathrm{lg}$.; spatha exteriora lanceolata ad apicem bipartita, $0,{ }^{\mathrm{m}} 50 \times 0,{ }^{\mathrm{m}} \mathrm{I}$ lg., interiora lineari-lanceolata, extus arguté lineata. brunneotomentosa, longe mucronata. Fiores, masc. O, ${ }^{\mathrm{m}} \mathrm{O}{ }_{5}-\mathrm{O},{ }^{\mathrm{m}} \mathrm{O} 20$ lg., pallide ochroleuci, calyce corollae ${ }_{i}$ is aequante, petalis irregulariter lanceolatis, acutis. concavis, filamentis corollae minoribus, antherac ad basin sagittatae, ad apicem acutae, germinodium minimum, tripartitum; fem. subconici, sepalis petalisque majoribus, convolutis lato ovatis, acutis, petalis paulo minoribus, lato-subcordatis, acuminatis, androecei sterili annulari, sexdentati. ad basin ovarium cingente; ovarium subglobosum ad apicem attenuatum stigmatibus stylo brevi insidentibus acuminatum. Drupir oblonga v. ellipsoidea, viridi-flava, ad apicem brunneo-lepidota, $0,{ }^{\mathrm{m}} 35-0,{ }^{\mathrm{m}} 28 \mathrm{lg}$., mezocarpio fibroso, pulposo-mucilaginoso, ochroleuco, cndocarpio atro-ferrugineo. osseo, intus monovittato; albumine cavo. 
Ils: "he an Jardim Botanicu do Rio de Janeiro. Flor. et fruct. juli. ad Alus.

Esta especie tem alguma affinidade com o Cocos coronala Mart lela disposição das folhas em espiral, com as vaginas e ns puciolos como que dentados, pela queda dos fibras dos bordos, e pelo fructo, affastando-se, todavia, no aspecto geral. no porte, no espadice e nas folhas. O espique approxima-se do Cocos Romanzeffiana de Chamisso.

Apesar de apresentar grandes espadices de numerosissimas Hores, ponco iructifica e os fructos, quando mesmo muito maduros munca se tornam amarellos, e nelles sempre predomina a corr verde como nos do $C$. corchata.

As folhas dispostas em cinco series, n'uma espiral, perfeitamente pronunciada, da esquerda para a direita, o caracterisa bem e d'ahi o nome especifico que lhe impuz.

\section{BACTRIS UnAENSIS Barb. Rodr.}

Caudex inemis brumneo lanatus, longe annulatus. Foliis longe mvaginantibus, vagina lanato tomentosa, aculeis nigris hirtis obtecta, petiolus brevis longe aculeatus, rachis inermi, foliolis linearibus longissime acuminatis ad marginam ciliatis subtus sotosis, apicalibus multo latioribus bifurcatis, nervis supra minute aculeatis.

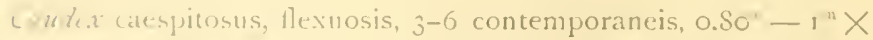
$x$ or oon -0.010 lg.. annulatis. annulis $0^{\prime \prime}: 08-0^{11} .09$ inter ". Jistantes, brumneo-lanato. Folia $5-7$ contemporanea, ise ly. Iayina $0^{\prime} .20$ lgr.. aculeis nigris ad basin gribbosis $=20-0.030$ iz. blutcta, ad basin lanato tomentosa;

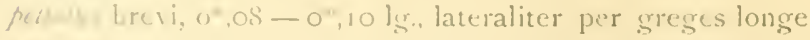
acukeato, malus incrmi, subtriangulari: foliolis $4-5$ utrinque, ariju,atis, sul, oppositis. interrupte insertis, inferiore et 
superiore multo latioribus, inferiore $2-3$-nervatis, linearibus, acutis, $\mathrm{O}^{\mathrm{m}}, 24 \times \mathrm{O}^{\mathrm{m}}, 025 \mathrm{lg}$., medio linearibus, longe acuminatis, $\mathrm{O}^{\mathrm{m}} .26 \times \mathrm{O}^{\mathrm{m}} .018 \mathrm{lg}$. superiore $7-8$-nervatis, lanceolato-falcatis,

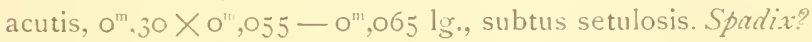
Flores?

Hab. in silvis primaeris ad Rio Una in Pros. Pará.

BaCtR1.5 Nigrispina Barb. Rodr.

Caudex elatus aculeatus aculeis nigris patentibus sparse horriclus. Petiolo cylindraceo aculeis compressis retroflexis nigris per greges magnitudine variae horridus. Foliolis interruptepinnatis linearibus acutis ad marginam longe aculeatis, in facie inferiore albidis. Spadix multiramosus rachi paulo longiores, spathâ magnâ acúleatâ, aculeis parvis $0^{m}, 005-$ - $\mathrm{O}^{\mathrm{m}}, \mathrm{O} 2$ nigris retrollexis per greges sparsim armatâ. Flores fem. calice annulari tridentato, quam corolla cupulari tridentata multo minore.

Candc $x$ 2 $-3 \times 0^{m}, 035-0^{m}, 040 \mathrm{lg}$. Folia $5-7$ contemporanea, longe petiolata, subrecurva $\mathrm{lg}$., vaginct aculeatâ, $0^{m}: 20 \mathrm{lg}$., aculeis nigris compressis horridâ; pedunculo, ramos 20-24 cylindraceo, aculeatissimo, anticé aculeis sparse erectis $\mathrm{O}^{\mathrm{m}}, 005-\mathrm{O}^{\mathrm{m}} .015 \mathrm{lg}$.. posticé per greges retroflexis $\mathrm{O}^{\mathrm{m}}: \mathrm{Ol}-$ - $\mathrm{O}^{\mathrm{m}} .04 \mathrm{lg}$., tomento fulvo tecto, $0,80 \mathrm{lg}$., rachis anticé angulosi, posticé sparse aculeati, aculeis juyatis, nigris, compressis subulatis retrollexis; follolis per greges, 3-5 congregatis, $0,{ }^{\mathrm{m}} \mathrm{O} 5-0,{ }^{\mathrm{m}} 25$ inter se distantes, linearibus, acutis, ad marginam setis $0,{ }^{m} \mathrm{O} 1-0,{ }^{\mathrm{m}} \mathrm{O} / 5 \mathrm{lg}$., armatis, ad basin concavo-reduplicatis, nervo medio subtus prominente, inferiore $30^{\mathrm{m}} .0-\mathrm{O}^{\mathrm{m}} .37 \times 0,01-0^{\mathrm{m}} .023 \mathrm{lg}$, medio $0^{\mathrm{m}}, 43 \times 0^{\mathrm{m}}, 26$ $\mathrm{lg}$. superiore $2-3$ connatis $0^{\mathrm{m}}, 30 \times \mathrm{o}^{\mathrm{m}}, 0,0 \mathrm{lg}$. Spadix $20-25$ ramosus, spathâa exteriore lineariâ, acutâ, lateraliter angu- 
las.ı, albo-roseì tomentosî. raré setosî. interiore lanceolatî, mucronatâ, ad basin pedunculum envolvente. brumneo tomentosî, aculeis nigris $0^{m} .005-0^{t} .015$ lg. ad basin carunculosis sparse lorridâ, perunculo compresso, cinnamomeo tomentoso, incurvo. glabro. 0 ". $.30 \mathrm{lg}$. in rachim. $0^{\mathrm{m}} .06 \mathrm{lg}$. excurrente: ramis tenuis. minuté scrobiculatis, $0^{m} .08-0^{m} \cdot 10$ 1.r. Fils. masc. non vidi. Flor. fom. calyce annulari. tridenticulato, ylabro. corollâ calycem pluriis excedente, tridentatî, Slabra; ararium sub cylindraceum. slabrum. Drupa i.rnota.

11.1. al Muyrátauá supra ripas inundatas, in Rio Amazonas. Flor. fibruar.

Jakdil Botanico do Rio de Janeiko, em i5 de Agosto (le 1900 . 


\section{INDICE}

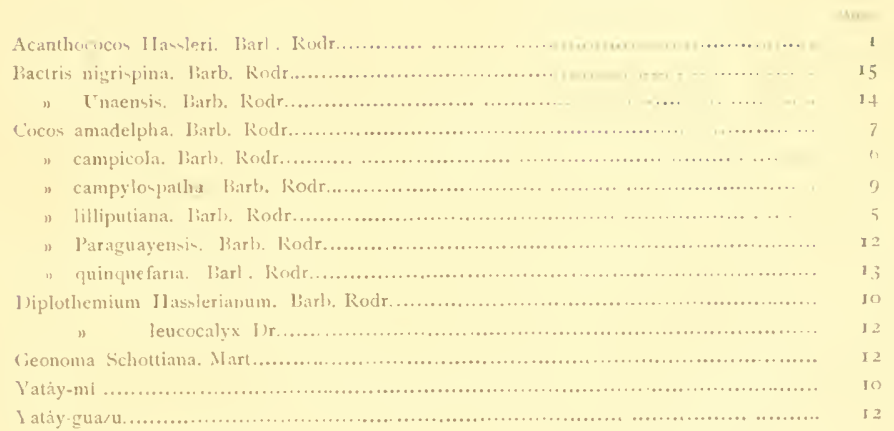






